\title{
Tonalidad sinestésica: Relaciones entre la tonalidad de la música y del color a través de una propuesta personal
}

Francisco Javier González Compeán 


\section{Universitat Politècnica de València}

Facultad de Bellas Artes

Dpto. de Escultura

UNIVERSITAT

POLITĖCNICA

DE VALÈNCIA

TESIS DOCTORAL

\section{Tonalidad Sinestésica:}

Relaciones entre la tonalidad de la música y del color a través de una propuesta personal.

Tesis Doctoral presentada por:

Francisco Javier González Compeán

Dirigida por:

Dr. Miguel Molina Alarcón

Dr. Pedro del Villar Quiñones

Guanajuato-México, octubre de 2011 
Esta editorial es miembro de la UNE, lo que garantiza la difusión y comercialización de sus publicaciones a nivel nacional e internacional.

(c) Francisco J avier González Compeán, 2011

Primera edición, 2011

(c) de la presente edición:

Editorial Universitat Politècnica de València

www.editorial. upv.es

ISBN: 978-84-695-2332-2

Ref. editorial: 5514

Queda prohibida la reproducción, distribución, comercialización, transformación, y en general, cualquier otra forma de explotación, por cualquier procedimiento, de todo o parte de los contenidos de esta obra sin autorización expresa y por escrito de sus autores. 
Al Dr. Miguel Molina Alarcón, sin cuya guía, esta investigación no habría sido posible.

Al Dr. Pedro del Villar, por sus valiosos consejos.

A mi familia, toda.

A Sara, que llena de colores mi vida. 


\section{RESUMEN (Castellano)}

\section{Tonalidad Sinestésica: Relaciones entre la tonalidad de la música y del color a través de una propuesta personal.}

El concepto de "Tonalidad" es un concepto que jerarquiza los tonos y los colores en las disciplinas de la música y el arte visual hasta nuestros días. Esta característica contribuye a establecer la funcionalidad de los elementos presentes en una pieza musical o en un espacio bidimensional o tridimensional, determinado por los colores que le ocupan. Con el concepto de una "Tonalidad Sinestésica", haremos referencia a una relación de correspondencias entre sonidos afinados y colores, determinados por la visión de personas que padecen de la condición clínica conocida como "Sinestesia". Partiendo del establecimiento de los elementos que conforman el concepto de un tono en cada disciplina en lo individual, se unirán los elementos propios de la tonalidad en la música y en el color, a partir de una revisión del fenómeno perceptivo de la sinestesia.

El objetivo de esta tesis es la creación de un nuevo concepto denominado como "Tonalidad Sinestésica", el cual constituya una nueva correspondencia de relaciones entre disciplinas artísticas, además de extraer formas de trabajo interdisciplinar que han trascendido en la historia del arte para con éstas, formular una nueva forma de trabajo en el campo de las traducciones de la música al color, y de la composición musical. Esta investigación se basa 
preferentemente en el método inductivo, a partir de la observación de diferentes formas de trabajo en el campo del arte interdisciplinario, y de los patrones del trabajo creativo personal, que extraeremos de los estudios de la sinestesia (R. E. Cytowic, John Harrison, Paul Hertz, Flournoy, entre otros) y de la teoría de la música y el color (John Gage, E. Goldstein, Scriabine, A. Schoenberg, Kandinsky, Messiaen, Ligeti, etc.), con el fin de crear las bases de un código de relaciones para el establecimiento de un concepto: la "Tonalidad Sinestésica".

Los resultados logrados en esta investigación sobre la correspondencia sinestésica se encuentran especialmente en los experimentos prácticos, tomando en primer lugar la forma de traducciones de música de compositores históricos (J. S. Bach, Claude Debussy y Arnold Schoenberg) y llevados a el color; y en segundo lugar, mediante la composición de música propia ("Miniatura de Colores en Gris-Azul" para piano y un "Trío para marimba y dos vibráfonos") cuyos elementos fueron construidos con criterios de armonía de color en diferentes formatos de instrumentación y duración, así como su presentación pública en concierto multimedial ("Festival Internacional Cervantino 2010"), de forma que estuvieran demostradas las posibilidades creativas de la correspondencia sinestésica. 


\section{ABSTRACT (English) \\ Synesthetic Tone: Relations between the tone of the music and color through a personal proposal.}

The concept of "Tone" is a concept that ranks the tones and colors in the disciplines of music and visual art to the present day. This feature helps to establish the functionality of the elements in a musical piece or a two-dimensional or three-dimensional space, determined by the colors in use. With the concept of a "Synesthetic Tone" we will refer to a relationship of correspondence between tuned sounds and colors, as determined by the vision of people suffering clinical condition called "synaesthesia." From the establishment of the elements that form the concept of tone in each artistic discipline individually, we'll join the elements of tonality in music and painting, from a review of the perceptual phenomenon of synaesthesia.

The objective of this thesis is the creation of a new concept known as "Synesthetic Tone" which constitute a new correspondence between artistic disciplines, in addition to extracting interdisciplinary ways of working that have transcended in the history of art, and with them, formulate a new way of working in the field of translations of music to color, and musical composition. This research is based mainly in the inductive method, on the observation of different ways of working in the field of interdisciplinary art, and personal creative work patterns, extracted from studies of synaesthesia (RE Cytowic, 
John Harrison, Paul Hertz and Flournoy, among others) and the theory of music and color (John Gage, E. Goldstein, Scriabine, A. Schoenberg, Kandinsky, Messiaen, Ligeti...), in order to create the basis of a code of relationships for the establishment of a concept: The "Synesthetic Tone".

The results achieved in this research are to be found particularly in practical experiments, first taking the form of translations of historical music composers (JS Bach, Claude Debussy and Arnold Schoenberg) and taken to painting, and second, by composing new music (a piano miniature and a "Trio for marimba and two vibraphones") whose elements were built using criteria of color harmony in different formats of instrumentation and duration, and its public premiere in a multimedia concert ("International Festival Cervantino 2010"), so the creative possibilities of the "Synesthetic Correspondence" were demonstrated. 


\section{RESUM (Valencià)}

\section{Tonalitat Sinestésica: Relacions entre la tonalitat de la música i del color a través d'una proposta personal.}

El concepte de "Tonalitat" és un concepte que jerarquitza els tons i els colors en les disciplines de la música i l'art visual fins als nostres dies. Aquesta característica contribueix a establir la funcionalitat dels elements presents en una peça musical o en un espai bidimensional o tridimensional, determinat pels colors que li ocupen. Amb el concepte d'una "Tonalitat Sinestésica", farem referència a una relació de correspondències entre sons afinats i colors, determinats per la visió de persones que pateixen de la condició clínica coneguda com “Sinestésia". Partint de l'establiment dels elements que conformen el concepte d'un to en cada disciplina en l'individual, s'uniran els elements propis de la tonalitat en la música i el color, a partir d'una revisió del fenomen perceptiu de la sinestésia.

L'objectiu d'aquesta tesi és la creació d'un nou concepte denominat com "Tonalitat Sinestésica", el qual constitueix una nova correspondència de relacions entre disciplines artístiques, a més d'extraure formes de treball interdisciplinar que han transcendit en la història de l'art per, amb aquestes, formular una nova forma de treball en el camp de les traduccions de la música al color, i de la composició musical. Aquesta investigació es basa preferentment en el mètode inductiu, a partir de l'observació de diferents formes de treball en el 
camp de l'art interdisciplinar, i dels patrons del treball creatiu personal, que extraurem dels estudis de la sinestésia (R. E. Cytowic, John Harrison, Paul Hertz o Flournoy, entre altres) i de la teoria de la música i el color (John Gage, E. Goldstein, Scriabine, A. Schoenberg, Kandinsky, Messiaen, Ligeti...), a fi de crear les bases d'un codi de relacions per a l'establiment d'un concepte: la "Tonalitat Sinestésica".

Els resultats aconseguits en aquesta investigació sobre la correspondència Sinestésica es troben especialment en els experiments pràctics, prenent en primer lloc la forma de traduccions de música de compositors històrics (J. S. Bach, Claude Debussy i Arnold Schoenberg) i portats al color; i en segon lloc, per mitjà de la composició de música pròpia (una miniatura per a piano i un "Trio per a marimba i dos vibràfons") els elements del qual van ser construïts amb criteris d'harmonia de color en diferents formats d'instrumentació i duració, així com la seua presentació pública en concert multimèdia ("Festival Internacional Cervantino 2010"), de forma que estigueren demostrades les possibilitats creatives de la correspondència Sinestésica. 


\section{ÍNDICE}

Introducción 1

1. La tonalidad, un término transdisciplinar $\quad 19$

1.1 La búsqueda del arte total 35

2. La tonalidad en la música 49

2.1 ¿Qué es la tonalidad? 62

2.2 ¿Cómo se define? 70

2.3 Intervalos de repetición en la tonalidad $\quad 73$

$2.4 \mathrm{El}$ sistema temperado de música 81

2.5 Otras afinaciones $\quad 85$

3. La tonalidad en la pintura 99

3.1 ¿Qué son los colores? 106

3.2 Teoría del color $\quad 120$

3.3 Armonía de colores 133

4. Sinestesia 141

4.1 ¿Es objetivable la sinestesia? 144

4.2 Tipos de sinestesia 170

4.3 Arte sinestésico 186

4.4 ¿Qué colores asignan los sinestésicos? 266

5. Propuesta personal y ejemplos 277

5.1 De la música al color $\quad 282$

5.1.1 La creación de una escala cromáticoaudiovisual 284

5.1.2 Series sinestésicas de armónicos 297

5.1.3 Acordes, de la música al color $\quad 313$

5.1.4 Escalas mayores y menores, sus colores $\quad 341$

5.2 Del color a la música 363

5.2.1 La creación de nuevos acordes, del color a la música $\quad 366$

5.2.2 Escalas de color $\quad 414$

5.3 Trabajo creativo personal 421 
$\begin{array}{ll}\text { Conclusiones } & 435\end{array}$

Bibliografía 441

Fuente de las Imágenes $\quad 463$

Anexo: $\quad 475$

I DATA- DVD “Correspondencias sinestésicas”

II VIDEO-DVD “TUMKUL” Concierto 


\section{Introducción.}

Cuando es escuchada la palabra "Tono", y en particular cuando es utilizada con la palabra "Tonalidad" en referencia a una manifestación pictórica o musical, son numerosas las acepciones e ideas a las que queremos hacer mención. Cuando es mencionada la "Tonalidad" de un cuadro o de un espacio tridimensional, se habla de la idea de los "tonos" utilizados por el artista; sin embargo, el creador usualmente ha utilizado más "colores" que a los que nos referimos con la "tonalidad" en la que queremos encasillar su obra, al mismo tiempo, cuando un pintor quiere adquirir alguna tinta o pigmento, el "tono" es sólo una de múltiples características a las que se referirá para adquirir el color específico que desea.

La palabra "Tonalidad” es igualmente empleada en música, así como la palabra "tono", la cual es utilizada usualmente para mencionar una frecuencia sonora en específico; cuando el público conoce de la obra musical, utiliza la palabra "tono" para mencionar la "Tónica" de la obra, la frecuencia sonora particular sobre la que una pieza es construida.

El concepto de "Tonalidad" en la música, es una herramienta que sirve para organizar y jerarquizar los sonidos que son escuchados en un espacio temporal determinado por la duración del fenómeno sonoro. Es un concepto que además ha servido a través de la historia del arte occidental para contribuir a la formación del estilo de la 
música creada, e incluso, al violentar o abandonar el uso "académico" de la tonalidad, se crea un estilo distinto de música por oposición al uso de la herramienta.

De la misma forma, en el ámbito de las artes visuales, el término define o determina los colores que son percibidos en un espacio bidimensional o tridimensional, el cual es visualizado por la audiencia sin un límite temporal preestablecido, en el caso de las artes visuales, la tonalidad es determinada tanto por la frecuencia lumínica preponderante, como por el manejo armónico del color del espacio en cuestión.

Mediante una breve revisión histórica del arte occidental, encontramos numerosas propuestas de formación de un arte global, de una práctica creativa que englobe más de un sentido, que excite no únicamente el oído o la vista, sino que sea capaz de abarcar las sensaciones humanas como una unidad; en este ámbito, han existido varios compositores de música, así como pintores y representantes de diferentes disciplinas artísticas, para quienes es común el anhelo de trascendencia del medio específico en el que se trabaja; anhelo que ha sido expresado por artistas como Kandinsky, Richard Wagner, Arnold Schoenberg, y otros, que en diferentes manifiestos o tratados han expresado el "sentir" de la existencia de reglas universales para el arte, entendido de una manera global; intuición que es posible encontrar desde el mundo antiguo en el arte griego e hindú. 


\section{Introducción}

El hecho de la existencia de reglas universales para el arte como un fenómeno unívoco, podría llevar a pensar el hecho de que siendo que diferentes disciplinas artísticas se ocupan de fenómenos físicos de diferente índole, deberían de existir también patrones de comportamiento iguales o como mínimo, similares de los diferentes fenómenos que atañen a la percepción humana, sin embargo, en particular la óptica y la acústica, han demostrado mediante la observación y experimentación que esto no es así. El comportamiento particular de las frecuencias lumínicas y sonoras es disímbolo, además de que las relaciones entre frecuencias de la misma naturaleza, el fenómeno conocido en ambos ramos como "Armonía", tampoco puede ser regido por las mismas relaciones proporcionales.

La percepción humana es un fenómeno subjetivo, y el arte apela de forma directa al ser humano, el arte es creado mayoritariamente para ser percibido por los semejantes, y es desde este punto de partida que existe la posibilidad de unión entre el concepto de la tonalidad entre las frecuencias lumínicas y sonoras. Apelando a los fenómenos de percepción humana, encontramos el fenómeno neurológico denominado como "Sinestesia".

Con el concepto de una "Tonalidad Sinestésica" denominaremos a una nueva correspondencia de sonidos y colores, que pueda demostrar su utilidad como herramienta para la creación artística en los ámbitos de la pintura y la música. 


\section{Introducción}

Es precisamente este fenómeno el que representa la principal motivación de esta investigación. El deseo de creación de una nueva correspondencia entre fenómenos lumínicos y sonoros, que tengan su fundamento en las investigaciones realizadas en los campos de la Psicología y Neurología sobre la condición clínica denominada como "Sinestesia" y el preguntarse, si es posible extraer patrones creativos de las personas que padecen esta condición.

La sinestesia ha sido definida como la unión de dos o más sentidos ante un solo estímulo, la unión subjetiva de dos respuestas perceptivas ante un solo fenómeno físico. El sinesteta verá colores al escuchar sonidos, escuchará sonidos o percibirá olores al observar un fenómeno lumínico, incluso, en su forma más común. Para el sinesteta, los grafemas tendrán un color implícito a su forma, de manera independiente al color de la tinta en que hayan sido impresos.

$\mathrm{Al}$ aprender sobre esta condición, nos es inevitable el pensar en la posibilidad de extracción de patrones creativos que puedan servir como herramienta para la creación, teniendo como fundamento un fenómeno neurológico, algo implícitamente humano, ¿podríamos crear un nuevo concepto de "Tonalidad"?

El fenómeno de la Sinestesia parece ser altamente individual, las visiones sinestésicas tienen un carácter altamente subjetivo, no podemos estar seguros de la índole de la visión sinestésica de la persona, pero por medio de esta investigación, podremos observar que las personas con sinestesia padecen de un funcionamiento cerebral de 
distinta naturaleza que las personas que no tienen la visión sinestésica, y que es posible determinar -en varios de sus aspectos- que la sinestesia es fisiológica, real y objetivable. Una vez establecida la realidad del fenómeno, realizaremos una revisión de los estudios realizados en el campo de la Psicología y Neurología, los cuales abarcan tiempos anteriores al siglo XIX, y cómo, gracias a la tecnología actual en el campo de la imagenología cerebral, hemos podido tener nuevas certezas, y también dudas sobre la naturaleza del fenómeno.

El planteamiento de esta investigación tendrá sus bases en el análisis de los fenómenos sonoros y visuales, ¿Cómo son percibidos? ¿Cómo han sido utilizados por el hombre? Por la naturaleza de la investigación, en donde buscamos una nueva forma de unificar fenómenos disímbolos bajo un mismo concepto unificador, la “Tonalidad Sinestésica", la investigación de cada fenómeno en lo individual será orientada a la obtención de patrones unificadores del fenómeno mismo, ¿Existen estándares para la afinación musical y para los colores?

A la par, realizaremos una reseña histórica del arte comúnmente denominado como "arte sinestésico". La búsqueda histórica en el arte de establecer correspondencias entre los fenómenos sonoros y pictóricos; el establecimiento de relaciones entre la luz y el sonido que aparece como una constante en el arte occidental, y es virtualmente uno de los puntos de partida para algunas escuelas artísticas no occidentales. 


\section{Hipótesis y objetivos}

Con lo anterior, hemos formulado la siguiente hipótesis: Es posible extraer correspondencias entre colores y sonidos de la información que nos proveen las investigaciones sobre la sinestesia. Estas relaciones entre dos fenómenos distintos pueden crear nuevas formas de traducción música-pintura y pintura-música; estas simbiosis de disciplinas pueden servir como herramienta para la creación; al permitir escribir música, música nueva, tomando como referencia el fenómeno del color y las combinaciones y contrastes que le son propios.

El objetivo de esta investigación es la creación de un nuevo concepto que denominaremos como "Tonalidad Sinestésica", una forma nueva de jerarquización de la música al ser unida de forma intrínseca al color, con bases en la percepción sinestésica, además, extraer formas de trabajo que han trascendido en el manejo de relaciones entre fenómenos pictórico-sonoros, y con esto proponer una nueva forma de trabajo con el color y el sonido, que demuestre su utilidad como una herramienta para la creación.

Para poder observar las características, y posible utilidad de esta "Tonalidad Sinestésica", realizaremos un proyecto práctico que constará de dos partes: 
La primera parte constará de traducciones de la música al color, mediante la creación de imágenes digitales y el recurso de la animación. Ilustraremos la correspondencia de colores en la música de compositores históricos occidentales, hemos elegido tres fuentes: Johan Sebastián Bach (1685-1750), Claude A. Debussy (1862-1918), y Arnold Schoenberg (1874-1951); tres compositores que han sido trascendentes en la historia de la música occidental y representativos de su época y estilo, se han elegido compositores que representen diferentes estilos para poder observar las relaciones de colores correspondientes a diferentes estilos de escritura musical. Al obtener las relaciones de colores correspondientes a las notas musicales, la pregunta es evidente: ¿Es posible obtener además, una herramienta para el análisis musical por medio de los colores? El análisis musical reviste la dificultad que es propia del medio, la intangibilidad y temporalidad del material a ser analizado, por medio de la traducción de un fenómeno temporal e intangible a un medio espacial, existe la posibilidad de una herramienta que nos provea de mayor facilidad para el análisis de la música.

La otra parte práctica de esta investigación, será la composición de escalas musicales, formaciones de acordes y música nueva, todo estos elementos que son propios de la música, tendrán su base en el fenómeno del color, los criterios de combinación que son propios del arte visual y la armonía de colores como concepto, traducido y aplicado de forma directa en la música. 


\section{Introducción}

Las características de la luz y el sonido son diferentes, sin embargo, en la práctica de la creación artística comparten conceptos como: la armonía, la tonalidad y el contraste; al realizar una correspondencia cuyo fin último sea la unificación de ambos fenómenos perceptivos, esperamos observar la interacción resultante para el público, interacción que es un subproducto inevitable de la unión de dos fenómenos disímbolos, ¿Qué ocurre al unirlos?

Aunque la práctica artística en la música y la pintura data desde los principios de la historia, abarcando al periodo histórico denominado como "pre-historia", no es el propósito de esta investigación realizar un recuento de todas las corrientes artísticas que han tenido lugar al paso de los años; razón por la cual, ha sido necesario acotar el objeto de estudio a las manifestaciones que involucren una relación entre el lenguaje musical y la pintura. Son estas corrientes artísticas a las que haremos referencia como "arte sinestésico", entendiendo como sinestésica toda corriente artística que involucre correspondencias entre sonidos musicales y color, sin importar si el representante de la corriente artística es un "sinesteta clínico". De estas manifestaciones artísticas, expondremos aquéllas que encontremos como de mayor trascendencia para nuestros propósitos, para el establecimiento de una herramienta de creación audiovisual. 


\section{Metodología}

La metodología a seguir en la investigación comporta dos aspectos en lo general. Por un lado, una base teórica del objeto de estudio. Esta etapa se ha centrado en los conceptos de "Tonalidad" en la música y en la pintura, y la manera en que han sido utilizados a través de la historia del arte, así como la forma en que se han realizado propuestas para la unión de ambas disciplinas a través de correspondencias de fenómenos sonoros y lumínicos. Se presenta además, una sintesís sobre la manera en que funcionan los fenómenos del sonido y de la luz, y la forma en que son percibidos por los sentidos e interpretados por el cerebro, lo que nos conducirá a establecer la manera en que se trabaja con estos en los diferentes campos artísticos; además de permitirnos vislumbrar la posibilidad de unión de diferentes campos artísticos por medio de correspondencias de valores que podamos calificar como "sinestésicas".

Se realizará una reseña sobre el fenómeno de la sinestesia en el ser humano, realizando una recopilación sobre algunos de los estudios más trascendentales sobre el tema, y los patrones que algunos de los estudios "clásicos" realizados en el siglo XIX aportan al respecto. Además, mediante una revisión de los estudios “contemporáneos" del tema de la sinestesia, observaremos la naturaleza fisiológica del fenómeno, así como algunos de los criterios de diagnóstico que rigen en nuestros días y algunas de las herramientas de la imagenología cerebral, que han sido aplicadas para observar el cerebro "in vivo" para demostrar la realidad física del fenómeno. 
Comenzaremos estableciendo el concepto de tonalidad como un término que es utilizado en diferentes disciplinas, un concepto "transdisciplinar" como punto de partida para el establecimiento de una "Tonalidad Sinestésica", que funcione con elementos de dos disciplinas artísticas: la música y la pintura. Será definida además, una diferencia entre el "arte sinestésico" y el concepto del "arte total", con objeto de acotar nuestro objeto de estudio, y mantener la investigación dentro de los márgenes del arte que se ha propuesto de forma intrínseca a a la presente, así como también, el establecimiento de correspondencias entre diferentes fenómenos físicos.

Posteriormente a la exposición del corpus teórico, se realizará el análisis y selección de la información obtenida para precisar en aquellas fuentes que sean afines al objetivo de la investigación, mediante el establecimiento de estándares para la música y la pintura, y la obtención de patrones posibles extraídos de los estudios realizados en el campo de la sinestesia. Se seleccionarán aquellos elementos que puedan ser considerados como un patrón confiable y útil, para construir un lenguaje artístico basado en las “correspondencias sinestésicas", la extrapolación de los patrones útiles de la visión sinestésica y de la teoría de afinación musical y colorimetría.

Esta investigación será basada en el método inductivo. Será a partir de la observación de diferentes formas de trabajo en el campo del arte interdisciplinario, y de los patrones de trabajo, que extraeremos de la sinestesia y la teoría de la música y la pintura, un 


\section{Introducción}

código de relaciones para el establecimiento de un concepto, la “Tonalidad Sinestésica".

Una vez establecida la correspondencia sinestésica, y los elementos que le serán propios al concepto de "Tonalidad Sinestésica”, por medio de la unión del color y la música, se realizará un ensayo práctico a manera de experimentación, para la comprobación de la hipótesis formulada, a saber: ¿Es posible extraer patrones de trabajo creativos del fenómeno de la Sinestesia? ¿Es posible usarlos como herramienta creativa de manera efectiva? Considerando las aplicaciones esperadas de la herramienta, esta debe ser capaz de permitirnos realizar traducciones de la música a la pintura, extrapolar de una materia temporal la información y plasmarla en un plano espacial. Debe permitirnos realizar además música nueva, que esté basada en el fenómeno del color, y pueda ser compuesta en diferentes formatos temporales y de instrumentación.

\section{Estructura de contenidos}

La presente investigación se ha estructurado en dos partes. La primera parte, teórica, desarrolla una investigación sobre el concepto de la tonalidad y la manera en que ha sido utilizado en las disciplinas de la música y la pintura, y cómo ha sido considerado como un concepto aplicable para ambas; además de una revisión sobre el fenómeno de la percepción humana en los campos de la acústica y la óptica, y la subjetividad que impera en la percepción de los fenómenos 


\section{Introducción}

físicos. En esta primera parte, también se examinarán los estudios realizados sobre el fenómeno conocido como "sinestesia", de manera intrínseca, y haremos una exploración al funcionamiento del cerebro y su anatomía, y la manera en que este conocimiento en conjunto con la tecnología actual de imagenología cerebral, hace posible el diagnóstico certero de un "sinesteta clínico".

En la segunda parte de la investigación, la sección de experimentación práctica, pondremos a prueba la utilidad de la herramienta; el concepto de "Tonalidad Sinestésica", como una manera nueva para la creación de jerarquías funcionales en la música, además de comprobar la utilidad del concepto para la traducción del fenómeno sonoro al visual.

En el primer capítulo, "La tonalidad, un término transdisciplinar", se realizará un acercamiento al concepto del tono y la manera en que este funciona en ambos campos del arte: Las artes visuales y el arte de la composición musical. Conoceremos también, algunas propuestas en el sentido de la unión de ambas disciplinas, y haremos una distinción entre el denominado "arte sinestésico" y el "arte total", en el apartado designado como: "La búsqueda del arte total", en donde buscaremos definir la idea del arte total como fue conceptualizada por la escuela germana del Gesamtkunstwerk, y que puede ser rastreada hasta las festividades del mundo antiguo en Grecia. 


\section{Introducción}

En el segundo capítulo, "La tonalidad en la música", nos concentraremos en el mundo del sonido y la música; la manera en que el sonido se comporta, y cómo funciona el concepto del tono en la música occidental. Se realizará además, una revisión sobre la percepción humana del sonido, y la naturaleza propia de las ondas sonoras y su comportamiento; así como una exploración sobre la afinación occidental, ¿Cuál es el estándar actual de afinación? ¿Cómo se llegó a esto? ¿Cuáles son las consecuencias de la afinación actual?

Serán presentados también los conceptos de interválica y armonía en la música, y las relaciones proporcionales que rigen estos conceptos,y la manera en que han sido estandarizados en occidente. A manera de comparativa, y para la extracción de un concepto necesario para la medición de la interválica musical, realizaremos una revisión al concepto del "cent" como fue establecido a finales del siglo XIX por Alexander Ellis, y cómo lo utilizó para la medición de escalas, que en occidente denominamos como "exóticas".

Presentaremos la manera en que "académicamente" en la música occidental, se reafirma el concepto de un "Tono" como más importante que los demás, y la manera en que esto crea jerarquías, que pueden ser expresadas por medio de relaciones proporcionales entre un tono y otro. A la par, se realizará una revisión al manejo del intervalo de repetición de fenómenos aplicados en la música, y cómo este tiene consecuencias directas en el estilo musical, y la confirmación o no confirmación, de una tonalidad. 


\section{Introducción}

En el tercer capítulo," La tonalidad en la pintura", exploraremos el concepto del tono en la pintura: Cómo se define y cómo contribuye a establecer el estilo de un espacio. Además, estableceremos la terminología que le es específica al manejo de los colores y sus mezclas, así como los esfuerzos por fijar estándares internacionales de colorimetría, haciendo énfasis en la teoría del color de Munsell, teoría y terminología que es considerada por la industria, como un estándar internacional.

Tomando como referencia la percepción humana del color, estableceremos el color como una sensación, diferenciando la sensación del color de la realidad física del espectro electromagnético, y las consecuencias que esto tiene para la teoría del color, con énfasis en la anatomía del ojo humano y la importancia de la interpretación última que hace el cerebro con la información obtenida de la realidad. Se realizará un seguimiento de la teoría del color desde la perspectiva de la óptica, con las nociones del fenómeno desde la escuela griega y el tratado de óptica de Newton, hasta los estándares establecidos por medio de los espacios de color actuales, desde Munsell hasta el "C.I.E.-LAB".

Se presentará una recopilación del concepto de armonía del color y las combinaciones y contrastes que le son propios; así como el establecimiento de un círculo cromático de colores para fines prácticos de la investigación. Se añadirán también algunas de las combinaciones de "triadas" y "cuatriadas" de colores; verdaderos acordes de color, cuyo funcionamiento en cuanto a reforzamiento 
óptico y contraste, puede ser comparable al de los acordes en la música.

En el capítulo cuarto, "Sinestesia", se expondrá una investigación sobre el fenómeno neurológico, haciendo referencia a los ensayos e investigaciones "clásicas", en las que por medio de experimentación conductual y estadística, se establecía la realidad del fenómeno y hasta nuestros días, con los que los avances en imagenología cerebral que permiten establecer diferencias entre el funcionamiento cerebral de un "sinesteta clínico" y alguien con una percepción normal. Se definirá la sinestesia desde su vocablo, hasta las condicionantes consideradas para el diagnóstico de la misma, así como sus posibles causas, para las que existen varias hipótesis actualmente.

Realizaremos una reseña de los tipos de sinestesia clasificados actualmente por investigadores de la Neurología, como Cytowic o Sean Day, y otra reseña de investigaciones clásicas como la de Wheeler, que en 1922 realizó una clasificación de los posibles tipos de sinestesia existentes.

En el mismo capítulo, se expondrá un resumen histórico sobre el "arte sinestésico", y será definido el término y los requisitos considerados para que cierta manifestación o escuela artística sea incluida. Serán observadas también, algunas de las aportaciones que la tecnología ha realizado para el arte sinestésico, y cómo los avances en la misma, traen consigo mejores posibilidades para la unión de 
disciplinas. Asimismo, será presentará un análisis breve de algunas de las manifestaciones que son de trascendencia para el arte, y se tomará como referencia el corpus teórico de algunos compositores y pintores, como Arnold Schoenberg; quienes a pesar de no ser representativos en el arte intermedial, establecieron mediante manifiestos o escritos, ideas y posibilidades sobre la unión de disciplinas artísticas.

Al final del apartado, se expondrá una síntesis de las correspondencias sinestésicas establecidas por algunos de los estudios “clásicos" sobre el tema, considerando también, las correspondencias dictadas por compositores de música de diferentes épocas y culturas, que asignan sus correspondencias a partir de un impulso subjetivo automático, y no de una racionalización de los fenómenos de la luz y el sonido.

En la segunda parte de esta investigación, en el capítulo "Propuesta personal y ejemplos", comenzará la fase de experimentación práctica de la síntesis anteriormente expuesta por los estudios clásicos de sinestesia, en conjunto con la visión de algunos compositores sinestetas. Después será realizada una posterior discriminación de correspondencias, con el fin de obtener una "escala cromática audiovisual” que pueda ser representativa de la visión sinestésica, además de manejable de forma práctica.

Una vez obtenido este primer elemento, se procederá a crear el resto de los elementos de un lenguaje audiovisual, los que serán parte del concepto "Tonalidad Sinestésica". Se realizarán las traducciones 
del lenguaje académico musical, como las series de armónicos, escalas mayores y menores, y los acordes del ámbito musical clásico, con el fin de obtener las herramientas necesarias para poder realizar traducciones de la música al color. Una vez obtenidos los elementos de traducción de música a color, se continuará estableciendo los elementos para la creación de música nueva, que contenga sus criterios de armonía, consonancia y disonancia, desde la perspectiva del color. Será el color el que determine la música y sus elementos de construcción, desde las escalas a los acordes, y de forma intrínseca, la forma musical.

Una vez obtenidos los elementos de traducción y de construcción formal de la tonalidad sinestésica, se experimentará con la herramienta mediante la traducción de algunos autores representativos de la música occidental, algunas piezas seleccionadas del repertorio de autores de música serán traducidas al color, a manera de prueba de la efectividad de la escala cromática audiovisual y sus elementos anteriormente establecidos. Las traducciones serán expuestas en forma de imagen y en los anexos en forma de animaciones, con el propósito de visualizar la construcción de las traducciones de la música al color en su forma primigenia, y constatar la utilidad de la herramienta no solo para la creación artística, sino sus posibles aplicaciones al análisis musical y la didáctica.

Una vez realizada la traducción de música a pintura, se trabajará en el sentido inverso, mediante la composición de "música de colores", que tenga como punto de partida los criterios de 


\section{Introducción}

combinación del color. Se compondrán dos tipos de piezas: Miniaturas para instrumento solista y una pieza de gran formato para música de cámara. Con el propósito de establecer la verdadera utilidad de la "Tonalidad Sinestésica", se considera necesario la composición de música en diferentes formatos y combinaciones instrumentales. Las partituras de las obras compuestas serán presentadas en anexos, así como los videos y animaciones resultantes de la música y sus posibles presentaciones a público.

En el apartado de "Conclusiones” se realizará una síntesis de la información teórica más fundamental utilizada para el establecimiento de la "Tonalidad Sinestésica", además de realizar una evaluación de los resultados de la parte de experimentación práctica de la investigación; de esta manera se determinará la posibilidad de extracción de patrones creativos del fenómeno de la sinestesia, y su posible aplicación en el campo de la creación artística. Y para la visualización y escucha de estos resultados obtenidos, se adjunta un DVD de las experimentaciones realizadas, con las traducciones de la música al color y de la grabación de video del trabajo creativo personal mostrado en concierto multimedial en el "Festival Internacional Cervantino 2010” (Guanajuato, México). 


\section{1.- La tonalidad, un término transdisciplinar ${ }^{1}$.}

El concepto de "Tonalidad" tanto en la música como en las artes visuales, ha sido usualmente utilizado como una herramienta para jerarquizar, para establecer distintos niveles de importancia o funciones entre diferentes notas musicales o colores. El concepto del "Tono" como podemos establecer, es un concepto que depende del contexto en el que es expuesto dentro de la obra, el manejo "tonal" del sonido o del color, depende del resto de los tonos que escuchamos u observamos en un espacio o lapso temporal determinado.

Tanto el color como el sonido son frecuencias, lumínicas o sonoras, que a través de la investigación en los ramos de la física, la neurología y psiquiatría, hemos podido determinar que no son solo un fenómeno físico. La realidad de ambos fenómenos depende en un grado esencial de la percepción humana; el sonido no existe como tal, si no hay alguien que lo escuche, así como el color no puede ser clasificado sin un individuo que lo perciba. Hechos que conforman nuestra realidad como miembros de una sociedad occidental. En este sentido, se ha vuelto famosa en nuestra sociedad, una de las preguntas

\footnotetext{
${ }^{1}$ Recogemos el concepto "transdisciplinar" a partir de la denominación realizada por Nicolescu, donde el prefijo "trans" presupone simultáneamente "entre, a través y más allá" de las fronteras disciplinares. Un enfoque que une y amplia el estudio disciplinar ("desde una sola disciplina"), interdisciplinar ("una disciplina se apropia de otra") y multidisciplinar ("desde varias disciplinas simultáneamente"). Véase: NICOLESCU, Basarab. Manifesto of Transdisciplinarity. Albany-NewYork: State University of New York Press, 2002.
} 


\section{Capítulo l.- La tonalidad, un término transdisciplinar}

para los que inician en la práctica del Budismo Zen: “¿Cuál es el sonido de un árbol que cae en un bosque solitario?”, para un occidental la respuesta es simple (descontextualizando la pregunta de la práctica budista), el árbol que cae no produce sonido si no hay quien lo escuche.

Para efectos prácticos, en la sociedad occidental, tanto el sonido, como la luz, no existen sin la percepción humana; las frecuencias lumínicas o sonoras necesitan de un receptor para poder ser conceptualizadas como luz o sonido. De tal manera que, cuando hablamos de la tonalidad en la música, cuando decimos que determinada pieza se encuentra en tal tono, en realidad estamos haciendo referencia a la nota más grave (el sonido con la frecuencia más baja) con la que esta pieza (o conjunto de frecuencias sonoras) escuchamos que comienza y termina. Con este término, también nos referimos a una determinada organización de las notas o frecuencias sonoras, y a un intervalo de repetición determinado con el que esta frecuencia y/o sus "armónicos" aparecen en un lapso determinado de tiempo.

De la misma forma, cuando nos referimos al "tono" en las artes visuales, estamos hablando de la frecuencia de luz que predomina en un espacio bidimensional o tridimensional, y de la manera en que están organizados los colores en este espacio predeterminado, así como de la "calidad" de los mismos, hablamos de colores "cálidos" o

\footnotetext{
2 Véase capítulo 2. "La tonalidad en la música".
} 
"fríos", colores "contrastantes" o "armónicos", términos con los que hacemos mención a la organización de frecuencias lumínicas que el artista utilizó en su objeto de trabajo.

Desde la antigua Grecia, se ha argumentado que el color, como la afinación (la frecuencia determinada de un sonido), podrían ser consideradas como cualidades físicas de la música ${ }^{3}$, y esto, eventualmente llevó a la idea de que los colores y los sonidos podían ser relacionados mediante reglas matemáticas.

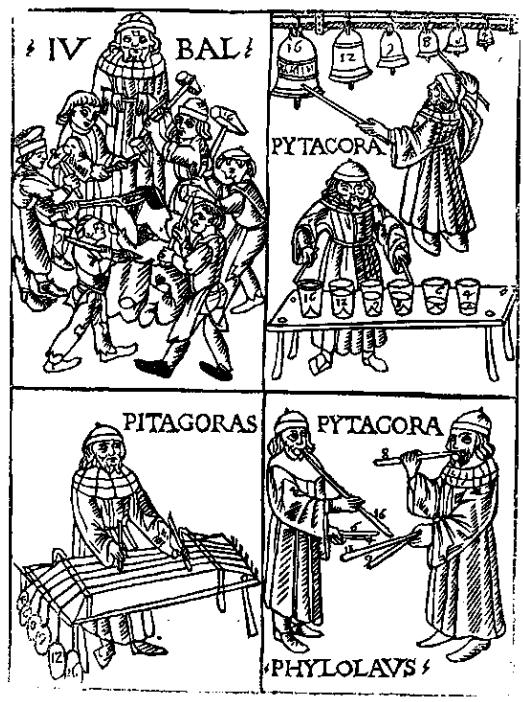

Figura 1. Pitágoras realizando sus experimentos sobre las relaciones interválicas que rigen el sonido. (Matemáticas. Colección Científica de TIME-LIFE).

Pitágoras, filósofo griego, descubrió las relaciones matemáticas que permiten reforzar un sonido mediante su "octava" (la frecuencia sonora que se encuentra al doble de ciclos o hertzios que la original). Mediante experimentos con cuerdas, Pitágoras estableció

\footnotetext{
${ }^{3}$ GAGE, John. Color y Cultura. Madrid: Siruela, 1993, p. 227.
} 


\section{Capítulo l.- La tonalidad, un término transdisciplinar}

que una cuerda de la mitad del tamaño del original producía la octava. Y a través de relatos, nos llega la aseveración del músico francés Jean Phillipe Rameau, en el sentido de que "el sonido de cada cuerda, contiene en sí mismo todos los demás sonidos"4. Descubrimientos e intuiciones que desde el mundo antiguo, nos hacen pensar que la música era regida (y podía ser comprendida) por el lenguaje matemático.

Del mismo modo, Isaac Newton, físico inglés, siglos después, mediante sus experimentos con prismas, plasmados en su libro "Óptica", afirmó que la "luz" contiene todos los colores, y que estos pueden ser separados por medio de prismas, los cuales reflejan en diferentes direcciones las distintas frecuencias que componen lo que conocemos como "luz".

La búsqueda y experimentación realizada a través de los años en los campos de cada disciplina artística en lo individual, han llevado a considerar como viable la posibilidad de la unión de diferentes lenguajes artísticos mediante un mayor conocimiento de las leyes naturales que rigen la materia misma con la que se trabaja. Generalmente, buscando conexiones matemáticas que permitan establecer "correspondencias" entre los fenómenos característicos de cada uno de los lenguajes. Todo esto ha generado a través del tiempo, un deseo que podemos observar que se repite de manera intermitente, de crear un arte que englobe todas las disciplinas artísticas; deseo que

\footnotetext{
${ }^{4}$ RAMEAU, J.P. Démonstration du príncipe de l'Harmonie; París; 1749; Prefacio VIII.
} 


\section{Capítulo l.- La tonalidad, un término transdisciplinar}

ha cristalizado en múltiples productos artísticos, que mediante la unión de diferentes estímulos con diferentes tipos de contenidos conceptuales, han creado las manifestaciones que conocemos como “obra de arte total” (Gesamtkunstwerk) y "arte sinestésico".

Como ejemplos vivos de lo que conocemos como "obra de arte total" podemos citar la ópera, idea defendida en forma particular por el músico alemán Richard Wagner (1813-1883), quien más que establecer correspondencias entre música y color, unía diferentes manifestaciones artísticas como la música, el teatro, la escenografía, el vestuario, etc. en un mismo momento en el foro, creando con esto, una nueva manifestación artística, logrando que no fuera solo música o solo teatro, sino una creación nueva, emanada de la unión de las demás, que contenía fuertes elementos místico-religiosos, políticos y nacionalistas (o comunales), entendiendo que solo lo "comunitario es libre" (frente a lo "solitario"), al unirse entre sí sus capacidades:

"En consecuencia, sólo es libre el arte que corresponde a esa total capacidad del ser humano, no la modalidad artística que proviene únicamente de una sola capacidad humana. El arte de la danza, el del sonido y el de la poesía son limitados si los consideramos individual y separadamente; cuando sus lindes entran en contacto, cada uno siente que no es libre tan pronto como, en el punto fronterizo en que confluyen, no consigue tender la mano, con un amor incondicionalmente pleno de reconocimiento, a la modalidad artística correspondiente. Con que a ese arte le cojan de la mano superará sus límites (...)"

\footnotetext{
${ }^{5}$ WAGNER, Richard. La obra de arte del futuro. Valencia: Univèrsitat de València, 2007, p. 57
} 


\section{Capítulo l.- La tonalidad, un término transdisciplinar}

Trabajando en otro sentido, varios artistas han establecido correspondencias entre los sentidos (música-color, movimiento-trazo pictórico, etc.), en lo que conocemos como "correspondencias sinestésicas"; asignando a cada nota musical un color que le correspondía, han hecho una aproximación diferente a la unión de las disciplinas artísticas.

Podemos afirmar que generalmente esta aproximación no se ha limitado a establecer una "correspondencia sinestésica", sino que también ha venido acompañada de un método de trabajo particular, que nace de la necesidad de crear con esta materia nueva, lo que podría denominarse como "arte sinestésico". Usualmente, estas correspondencias cuando son establecidas entre la música y el color, han estado regidas por las reglas físicas del sonido y de la luz, y en numerosos casos, por una visión subjetiva del artista acerca de los colores que "sentía" correspondían a la música.

En consecuencia, podríamos utilizar el concepto del tono, no solo como una herramienta jerarquizadora de cada uno de los lenguajes a tratar, sino además, como un concepto que nos permita "unir" estas dos visiones (el sonido y el color) ya que en ambos casos hay una relación de "clases" o jerarquías unidas bajo un solo término. Es la idea del tono, de la "tonalidad", la que nos permite decir que tal pieza musical está en "Do" (cuando nos referimos a la función asignada a las frecuencias sonoras), o que es música tonal o atonal (cuando nos referimos al intervalo temporal en el que determinadas 


\section{Capítulo I.- La tonalidad, un término transdisciplinar}

frecuencias se repiten); o que el tono de tal cuarto (espacio tridimensional) o tal cuadro (espacio bidimensional) es azul.

Surgen entonces las preguntas: ¿Cómo podemos hacer para englobar ambas formas de jerarquías en una sola idea del tono?, ¿Cómo crear un sistema de trabajo que nos permita decir que estamos creando una "Sonata" para piano en color azul, o un cuadro a la manera de Beethoven?:

Han existido numerosos intentos de crear la "obra de arte total", un arte que envolviera a todos los sentidos al estimularlos simultáneamente, y vemos ejemplos de esto en la poesía de Mallarmé; en la música desde Wagner hasta Scriabine y Messiaen, y en la pintura, con artistas como Kandinsky.

¿Por qué retomar el tema? Creemos poder observar un renovado interés en el fenómeno conocido como "Sinestesia", condición clínica, que a pesar de haber sido observada como tal desde el siglo VI A.C ${ }^{6}$, fue diagnosticada por primera vez en 1812 por el Dr. G.T.L. Sachs ${ }^{7}$.

El fenómeno conocido como "Sinestesia" consiste en la unión de dos o más sentidos, antónimo de anestesia, sinestesia en su raíz proviene de los vocablos "syn" (junto) y "aesthesis" (percepción),

\footnotetext{
${ }^{6}$ HARRISON, John. El extraño fenómeno de la Sinestesia. México D.F.: Fondo de Cultura Económica, 2004, p. 38.

${ }^{7}$ CAMPEN, C. "Artistic and Psychological Experiments with Synesthesia." Massachusetts: MIT, Leonardo vol.32, 1999, No.1, p. 12.
} 


\section{Capítulo l.- La tonalidad, un término transdisciplinar}

condición que ocurre de forma "rara" (estadísticamente hablando) en la población mundial.

Como hemos podido observar, la idea de la unión de los sentidos, es un deseo que ha rondado el arte desde hace tiempo. Uno de los intentos que consideramos más sólidos, en el sentido de la creación de "correspondencias sinestésicas" que unan el concepto de "tonalidad" de música y colores, es el del músico Alexander Scriabine, que fue quien le asignó un color a cada una de las doce notas de la música "temperada" occidental...Y además, una emoción ( o lo que él llamaba "estados del alma") y sobre esta base, llegó a escribir obras de todo tipo de formato con gran éxito, entre ellas cabe destacar: "Prometeo" (1910), obra orquestal de gran formato, en la que Scriabine se sirvió de un "piano de luces" construido especialmente para la obra y que fue utilizado por primera vez en un concierto en New York (1915).

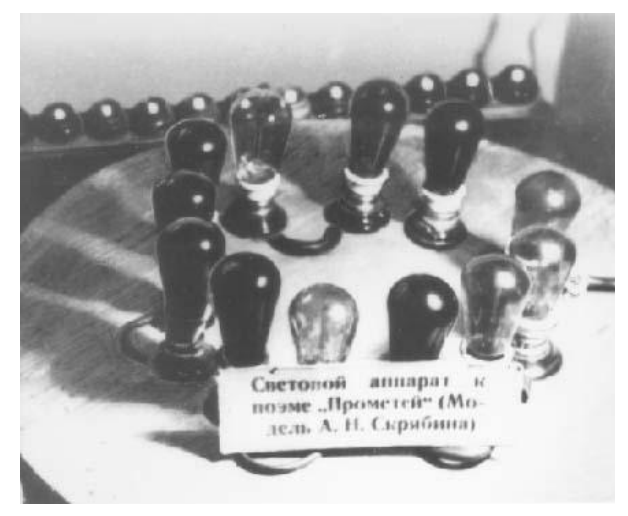

Figura 2. El "Clavier à Lumières" de Scriabine, uno de los diseños, consistente en bulbos de colores para la proyección.

La producción de este artista no solo es bastante amplia, 74 opus, y varias obras no clasificadas, que en su mayoría, siguen siendo 


\section{Capítulo l.- La tonalidad, un término transdisciplinar}

escuchadas por todo el mundo occidental, y han influido en numerosos artistas e intérpretes al grado de que en nuestros días, existe una subcultura (o "subreligión") que lo considera como un iniciador.

Cabe mencionar, que a pesar de que Scriabine asignó un color específico a cada nota musical, su método de trabajo no consistía en la asignación en tiempo real de un color a cada sonido escuchado. Para Scriabine, el color debía de servir para resaltar la "tonalidad" que era escuchada, entendiendo tonalidad como la escala musical en la que la música era construida; como resultado, el público podía escuchar varias notas distintas durante un tiempo más o menos largo (dentro del contexto de la obra musical) sin percibir un cambio en el color que era proyectado.

A pesar de que algunos de los detractores de Scriabine alegan que por esta circunstancia, la correspondencia entre los colores y la música no es perceptible si se realiza una presentación al público, mediante animaciones o sistemas lumínicos (como la idea original con el piano de luces), su obra continua siendo motivo de análisis por numerosos teóricos, y se le sigue considerando como uno de los más originales creadores de música y de fenómenos multimediales.

Creemos que en este caso, el problema puede ser resuelto simplemente asignando los colores de cada una de las notas en tiempo real, y no solo a los campos armónicos, consiguiendo de esta forma, que el movimiento musical pueda ser percibido mediante los colores 


\section{Capítulo l.- La tonalidad, un término transdisciplinar}

proyectados. Vale la pena destacar, que el uso que Scriabine hizo de las correspondencias música-color, asignándolo a campos armónicos, obedecía a la idea de que era precisamente el cambio en la escala musical la que causaba un cambio de "color" (entendido como una percepción auditiva) en la música, y que al asignar un cambio visual a este parámetro, llamado escala musical o campo armónico, se reforzaba la impresión de este cambio en el público.

Otras mejoras que creemos posibles al sistema "músicovisual", es el de procurar parámetros los más común posibles con nuestro público, para buscar una vía de comunicación con los espectadores. En el caso de Scriabine, (como en numerosos casos de manifestaciones del género), la correspondencia música-coloremoción era subjetiva, eran los colores que el artista "sentía" que correspondían, a pesar de que parece haber referencias matemáticas, en particular del círculo cromático de colores establecido por Newton, para los colores de Scriabine.

Siendo el fenómeno de la Sinestesia, un fenómeno intrínsecamente humano, se podría defender, que mediante un ligero estudio que nos lleve a una mejor comprensión sobre el fenómeno y las personas que lo padecen, así como las consecuencias que las teorías más recientes en los ramos de la Neurología y Psiquiatría sobre las causas de este fenómeno; se podrían extraer parámetros comunes para trabajar "correspondencias" en un sistema creativo audiovisual en una forma lo más sólida posible, que nos permita tener una mejor comprensión o interés de parte del espectador. 
Para poder hablar de la extracción de parámetros comunes de la sinestesia (siempre entendida como un fenómeno clínico), tendríamos que comprobar que existen generalidades en la visión de varios sinestetas, cosa que mediante recientes experimentos y las herramientas estadísticas parece posible. Por dar algunos ejemplos, se ha establecido que el 50\% de los sinestésicos "observan" la letra "e" de color verde, así como un porcentaje enorme "observa" el número “2” como rojo, sin importar la tinta en que estén impresos.

Creemos que mediante la extracción de estos parámetros que nos da la sinestesia, es posible obtener patrones creativos de trabajo, los cuales, no solo tengan su base en la física y matemática presente en los fenómenos de la luz y el sonido, cosa que consideramos necesaria también, o en una percepción subjetiva; sino además, dotar a la correspondencia propuesta de una mayor solidez mediante la inclusión de una visión humana que pueda ser considerada como "compartida" por diversos individuos. Al asignar una correspondencia sinestésica a nuestra teoría audiovisual, tenemos la posibilidad de plasmar en una propuesta creativa, una realidad humana, que no está fundada en la subjetividad de un individuo, sino en un fenómeno automático que comparte un porcentaje de la población.

Partiendo de esta información proporcionada por investigaciones de neurólogos como Cytowic, Sean Day, y miembros de "A.S.A." (Asociación Americana de Sinestesia, por sus siglas en inglés) la pregunta nos fue inevitable: ¿Están los colores ahí, solo que no podemos verlos?, ¿sería posible que la visión sinestésica sea en 


\section{Capítulo l.- La tonalidad, un término transdisciplinar}

realidad una visión más completa, y no una visión deformada? Por explicar un poco más el fenómeno, en palabras del Dr. R.E. Cytowic:

"Sinestesia significa sensaciones unidas, en los casos que dos o más sentidos están unidos, como por ejemplo, que una voz, no solo es escuchada, sino también vista o saboreada". ${ }^{\circ}$

A las personas que experimentan estas sensaciones unidas se les llama sinestésicos. De acuerdo a los experimentos realizados a la fecha, el fenómeno es involuntario, automático y persistente, además que parece pasar de generación en generación, como una característica familiar. Cytowic además afirma que “...algún tipo de sinestesia ocurre en 1 de cada 23 individuos" $"$.

Se ha descubierto además, mediante pruebas y experimentos, que van, desde pruebas de monitoreo cerebral hasta experimentos de tipo conductual, que la mayoría de la población infantil es sinesteta, solo que no lo es de forma consciente, cosa que por otro lado, ocurre también en la población sinesteta adulta, al grado que se puede afirmar que muchos de ellos se asombran al comprobar que su sinestesia es una visión "particular", no compartida por el resto de la población ${ }^{10}$. Vale la pena recalcar, que es mayor el porcentaje de indicios de sinestesia en la población infantil que en la adulta, la estadística y

\footnotetext{
${ }^{8}$ CYTOWIC,R.E. “Cytowic-Punset”[enlínea].Disponible en: http://www.rtve.es/tve/b/redes2007/semanal/prg232/entrevista.htm [Consulta: 31/Diciembre/2010].

${ }^{9}$ CYTOWIC, R.E. “Cytowic-Punset” [en línea]. idem

${ }^{10}$ HARRISON, John. El extraño fenómeno de la Sinestesia. México D.F.: Fondo de Cultura Económica, 2004, p. 97.
} 


\section{Capítulo l.- La tonalidad, un término transdisciplinar}

diversos experimentos parecen apuntar al hecho de que, la capacidad sinestésica disminuye conforme uno crece.

Existen, por supuesto, varios detractores de este enfoque, uno de los argumentos es que "las personas, y no las obras de arte, son sinestésicas... en última instancia, no existe el arte sinestésico" ${ }^{11}$. De hecho, el Dr. Cytowic afirma que la fenomenología de la sinestesia puede ser claramente distinguida de la metáfora, del simbolismo del sonido y de sistemas artísticos, los cuales, de una forma deliberada empleen el término "sinestesia" para describir alguna unión de sentidos ${ }^{12}$.

Creemos necesario mencionar que la presente propuesta de la creación de una "Tonalidad Sinestésica", no pretende crear una sensación o experiencia sinestésica en individuos no sinestésicos, sino la inclusión de parámetros nuevos que nos otorga la visión sinestésica, así como los recientes descubrimientos que se han hecho sobre la naturaleza del fenómeno, en una nueva "correspondencia" que podamos utilizar en un sistema creativo audiovisual, y extraer patrones para la creación a partir del fenómeno clínico; sin embargo, hemos podido observar que el uso del simbolismo y la metáfora en el arte (herramientas que algunos detractores parecen olvidar que son usadas desde el mundo antiguo), en muchas ocasiones ha recibido la

\footnotetext{
${ }^{11}$ HERTZ, PAUL. "Synesthetic Art, an Imaginary Number?" [en línea]. Disponible en: http://adrianwinter.co.uk/logbooks/303\%20Logbook/pdf/imagm.pdf [Consulta: 31/Diciembre/2010].

${ }^{12}$ CYTOWIC, R.E. “Cytowic-Punset” [en línea]. Disponible en: http://www.rtve.es/tve/b/redes2007/semanal/prg232/entrevista.htm [Consulta: 31/Diciembre/2010].
} 


\section{Capítulo l.- La tonalidad, un término transdisciplinar}

etiqueta de "sinestésica", no olvidemos que en numerosas ocasiones, el uso de la terminología no es aplicada únicamente a un fenómeno en específico (en este caso, el fenómeno neurológico), sino que en numerosas propuestas artísticas, este término ha sido aplicado, por la etimología de la palabra, para describir objetos de arte que hayan hecho uso de confluencias multisensoriales.

A pesar de lo anteriormente dicho, hemos podido observar en nuestra experiencia, que individuos no sinestésicos alcanzan sensaciones sinestésicas y usan descripciones del género para describir sensaciones obtenidas ante fenómenos artísticos. La sinestesia también puede ser subjetiva ${ }^{13}$, podríamos extendernos en ejemplos, damos uno; numerosos compositores de música contemporánea como Jean-Louis Florentz, Héctor Quintanar, Juan Pablo Muñoz, etc. han descrito ciertas combinaciones de ámbito armónico-orquestal como "un colchón... como estar envuelto en algo suave", descripción que también utilizan numerosos individuos del público general, de manera coloquial, muchas personas también mencionan como se les "enchina la piel" (respuesta neurológica natural que hace que el vello de la piel se extienda ante fenómenos como el frío o el miedo) al estar frente a ciertas obras de arte visual o sonoro, lo cual, es una respuesta sinestésica de unión de estímulos, en este caso, la vista con el tacto o el oído con el tacto.

\footnotetext{
${ }^{13}$ STAFFORD T.; y M. WEBB. "Mente Locale” Milano: Apogeo, 2005, p. 365.
} 
Al entrar al mundo del arte, abunda la metáfora para poder describir los elementos propios de las distintas disciplinas artísticas, como lo mencionábamos anteriormente, para describir colores hablamos de frialdad o calidez; en música, para describir el efecto que nos producen ciertos ámbitos de afinación hablamos de brillantez $\mathrm{u}$ oscuridad, al grado, que incluso en la Edad Media, compositores como Guillaume de Machaut (compositor de la "Messe de Nostre Dame" primera "Misa" vocal polifónica escrita por un solo compositor), trabajaron con una teoría que encasillaba las escalas musicales en términos de luz u oscuridad de acuerdo a la posición geográfica que ocupaban en el llamado "círculo de quintas"14, propuesta, que no podemos dejar de mencionar, une el concepto de tonalidad en la música con la idea de la luminosidad en el arte visual; el concepto de “tonalidad" como un puente de unión entre dos disciplinas.

El fenómeno de la Sinestesia, nos hace cuestionarnos sobre la percepción humana, conforme nos adentramos en las más recientes investigaciones sobre el modo de funcionar del cerebro, no podemos dejar de asombrarnos ante las conclusiones a las que nos llevan los experimentos realizados en los campos de la psicología conductual y la neurología, que gracias a los avances en la tecnología de exploración cerebral, nos permiten "asomarnos" en el interior del tejido vivo, mientras este realiza funciones en tiempo real, funciones que podemos condicionar para realizar experimentos.

\footnotetext{
${ }^{14}$ Véase el capítulo 2. "La tonalidad en la música".
} 
Son múltiples los caminos para la unión de las disciplinas artísticas, y gracias a las herramientas actuales y nuevas tecnologías que existen a la disposición del artista, se ha renovado el interés (interés que recalcamos, no es nuevo) por la creación de nuevas propuestas que buscan la unión de los sentidos. Creemos que mediante la unión del concepto del "tono" tal como es entendido en las artes visuales y la música, con parámetros extraídos de la visión sinestésica, es posible crear una forma de trabajo que nos proporcione un mundo artístico más amplio, y del cual, podamos afirmar, que tiene sus raíces en la percepción humana. 


\subsection{La búsqueda del arte total.}

El término "arte total", tal como lo conocemos ahora, fue empleado por primera vez, por Richard Wagner, músico alemán del siglo XIX, quien se refería con esta etiqueta, a cierto tipo de "Ópera" en la que se unieran varias disciplinas al mismo tiempo en el foro. Existen antecedentes en la música de Berlioz y Franz Liszt:

"Las sinfonías del francés Hector Berlioz tendrán un carácter programático, dando unidad a sus movimientos por medio de un motivo conductor. (...) a diferencia de los verdaderamente románticos, que consideraban a la música autosuficiente en la expresión; Liszt y sobre todo Wagner ya no piensan así, pues buscan apoyarse en el significado de las palabras (historia, etc.) que serán reforzadas por la música (poemas sinfónicos)."15

Para Wagner, no bastaba con el hecho de que distintas manifestaciones creativas nos fueran ofrecidas de manera simultánea, el esfuerzo no era solo de forma, cabe destacar, que le era un requisito el hecho de que todas las disciplinas artísticas debían mantenerse en lo posible, en un mismo plano de importancia, hacer lo necesario para que no estuvieran solamente acompañando a la música, sino unidas de forma intrínseca a ella. Había además, un componente comunitario

\footnotetext{
15 ALCOVER ALCODORI, Francisco y LAFUENTE AVEDILLO, Rafael. La música y los instrumentos desde el Barroco hasta el s. XX. Valencia: UMA Editores, 2011. pp. 341, 343.
} 


\section{Capítulo I.- La tonalidad, un término transdisciplinar}

fundamental para definir una ópera como obra de arte total: la búsqueda de una experiencia trascendente para el público, así como conseguir una transformación de la sociedad por medio del arte, para de esta forma, conseguir el efecto de la creación de un arte nuevo, al que le acuñó el término Gesamtkunstwerk (obra de arte total):

"El verdadero drama sólo es concebible cual brotando del afán común de todas las artes por comunicarse del modo más inmediato a la opinión pública común (...)Ni siquiera una sola capacidad ampliamente desarrollada de las artes individuales permanecerá sin utilizarse en la obra de arte integral (Gesamtkunstwerk) del futuro. (...)Así complementándose en el corro siempre cambiante, las artes hermanas reunidas se manifiestan y se dan a valer, bien sea en conjunto, bien a dúo, bien en solitario, de acuerdo a lo exigido por la acción dramática, que es la única que da la medida y señala un objetivo"16.

Wagner consideraba que no toda ópera podía ser calificada con este término, en su opinión, en no todas las óperas de su época podía decirse que el texto, la dramática, el teatro, iluminación, vestuarios, escenografía, o incluso la disposición de los asientos, cumpliesen con el requisito de estar en un alto nivel de importancia; además, revestía una importancia fundamental la elección del texto o drama a ser representado, y la manera en que este era adecuado en la forma de un guión operístico, todo esto a fin de crear en el espectador una emoción trascendental al momento de la representación, e incluso llegar más

\footnotetext{
16 WAGNER, Richard. La obra de arte del futuro. Valencia: Univèrsitat de València, 2007, p. 57pp. 143-150.
} 


\section{Capítulo l.- La tonalidad, un término transdisciplinar}

lejos, que el espectador llegara a considerarse parte o sentido último del espectáculo.

Wagner utilizaba textos mitológicos que podían ser encasillados como dentro del sentimiento nacional alemán, para de esta forma, conseguir una más profunda interacción con el público, las historias de "Parsifal", "las Walkirias", "Tristán e Isolda", eran bien conocidas por su público. Como una consecuencia de su época, así como de su búsqueda de una experiencia de vida a través del arte, podemos afirmar que algunos de los rasgos más característicos de las óperas de Wagner, pueden considerarse el deterioro de la razón para favorecer la exaltación sensorial, el nacionalismo, y la exaltación de lo instintivo.

Esta exaltación de lo sensitivo, condujo a Wagner a plantear una revolución, no solo en la forma de presentar una ópera, o de concebir la unión de las artes, como mencionábamos anteriormente, sino que la revolución también fue de fondo, ya que existía de forma implícita la consideración del lenguaje musical que tenía que ser utilizado para realizar la obra, esto lo llevó a romper con la idea académica de la "tonalidad", alargando el intervalo de repetición del centro tonal de la obra, hasta que este se volvía imperceptible para el oyente; revolución musical que llevó a su punto más alto en la introducción de su ópera "Tristán e Isolda", considerado como el primer momento de música "atonal" (sin referencia a un centro tonal), abandonando la armonía como era conocida tradicionalmente, para 


\section{Capítulo l.- La tonalidad, un término transdisciplinar}

realizar música compuesta de continuas tensiones acumulativas, que resuelven en momentos aislados con efectos altamente sensoriales.
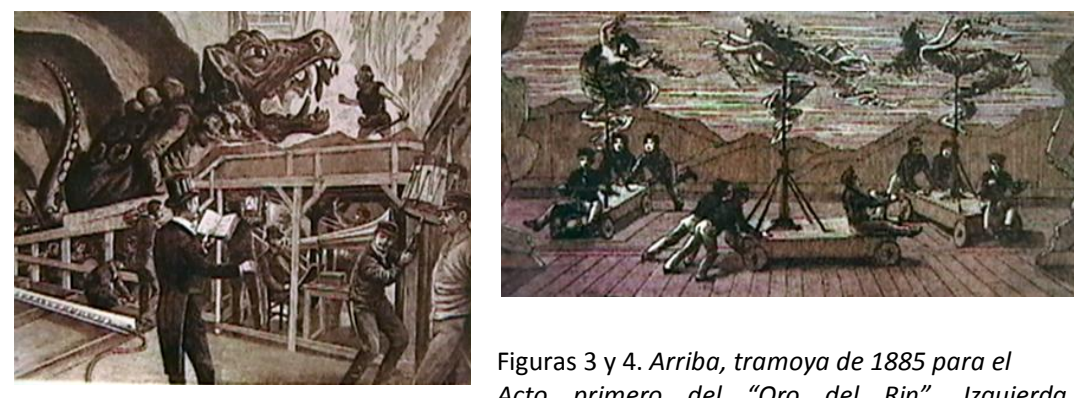

Figuras 3 y 4. Arriba, tramoya de 1885 para el Acto primero del "Oro del Rin". Izquierda, andamiaje y maquinaria de 1902 para el Acto segundo de "Siegfried". Para la Tetralogía, "El anillo de los Nibelungos", de R. Wagner. Enciclopedia Salvat de los Grandes Compositores Tomo 7.

No es casual la elección de textos de índole nacionalista para los guiones de ópera Wagneriana, existía una preocupación grande por conseguir involucrar al espectador dentro de la obra a ser representada; al elegir textos que el público ya conociera, se esperaba conseguir una mayor interacción con el mismo. Una preocupación grande por los contenidos de fondo, y no solo de forma, se consideraba necesaria para la realización de una obra de arte total, elementos que tenían que estar todos supeditados a la mejor transmisión de una idea.

Él consideraba que el drama griego y la manera en que era representado, sí podían considerarse dentro de este rubro, y creía que su idea de arte total, correspondía a una continuación de la escuela 


\section{Capítulo l.- La tonalidad, un término transdisciplinar}

dramática griega. En el drama griego, asistimos a un momento casi único en la historia del arte, toda vez que en la tragedia griega, somos testigos de una fusión de diversas disciplinas artísticas todas supeditadas a una idea. Como componentes de esta manifestación artística podemos considerar a la poesía, que lleva de forma implícita un ritmo que no puede dejar de considerarse como un elemento musical, además de la música en sí misma que, por medio de el elemento del "corifeo", los "recitativos" o los solos de flauta o instrumentos de cuerda que se manifestaban en escena, unía de forma implícita dos o más disciplinas artísticas en una sola manifestación creativa.

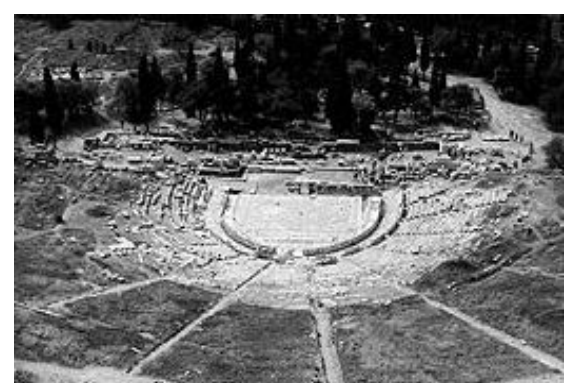

Figura 5. El Teatro de Dionisos, en Atenas.

Además, está el componente del vestuario, el arte visual y arquitectónico; las obras teatrales eran representadas al aire libre, en un espacio enmarcado por un anfiteatro, que por medio de la sencillez escenográfica, permitía que el público ateniense, imaginara de forma eficaz los espacios descritos en el texto. La escenografía griega parece legarnos una búsqueda de la sencillez, no se pretendía trasladar por medio de objetos el espacio descrito, solo se utilizaba el paisaje enmarcado por el foro para encuadrar el drama, y como el guión era 


\section{Capítulo l.- La tonalidad, un término transdisciplinar}

conocido por todo el público, esto permitía que mediante la imaginación el espectador recreara de forma eficaz el entorno dramático de la obra. No olvidemos, que además, había un número limitado de guiones a representar, el drama griego era una manifestación artística de tipo convencional, había numerosas "reglas del arte" que eran respetadas por los creadores.

Hay que mencionar, que los textos utilizados en el drama griego, eran convencionales en el sentido de que eran conocidos por todos. La tragedia de Edipo, los relatos de los dioses, las guerras que eran parte de la historia, todas teñidas por las leyendas que les acompañaban, eran conocidas por la generalidad de los atenienses ${ }^{17}$; herramienta que permitía la participación del público de una manera íntegra en la obra.

Paralelismo que utiliza Wagner en su ciclo de óperas, al incorporar textos que eran familiares al pueblo alemán, Wagner busca la interacción a fondo con su público, esperando el crear una experiencia trascendental, más que de entretenimiento banal en los asistentes a la experiencia artística. Un arte comunal, que a través del conocimiento compartido del drama representado, permita la elevación de los asistentes a ser participantes de la obra:

“¿quién será el artista del futuro? ¿el poeta? ¿el actor? ¿el músico? ¿el artista plástico? - Digámoslo en una palabra: el pueblo. El mismo pueblo, al que hoy en día nosotros mismos

\footnotetext{
${ }^{17}$ NIETZSCHE F. “El drama musical griego.” [en línea]. Disponible en: www.adamar.org/ivepoca/node/1071 [Consulta: 31/Diciembre/2010].
} 
le debemos la única obra de arte verdadera que habita en nuestro recuerdo y que no hemos imitado sino deformándola; el pueblo que es el único que le debemos el arte en general"18.

Esta unión del público con la obra, parece ser una de las metas fundamentales en la búsqueda de la obra de arte total, búsqueda que aún en nuestros días parece continuar. Siguiendo un impulso similar al de Wagner, el pianista y compositor ruso, Alexander Scriabine, en el siglo XIX no solo establece una correspondencia de colores con la música, en lo que podríamos describir como una "correspondencia sinestésica", sino que además, en su obra inacabada "Mysterium" que comenzó a principios del siglo XX, nos recuerda este anhelo por la creación de un arte comunitario, el cual recuerda la participación de los griegos en sus eventos artístico-político-religiosos.

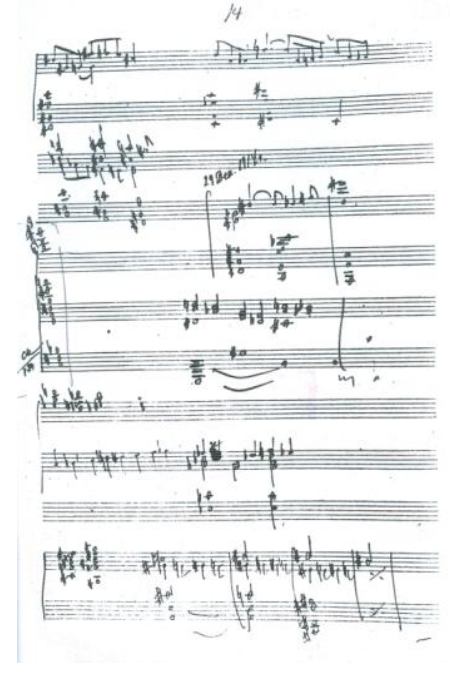

Figura 6. Página manuscrita del "Acte Préalable" de la obra inacabada "Mysterium" (19121915) de A.Scriabine, donde se incluye un acorde de 12 tonos. Museo Scriabine de Moscú

18 WAGNER, Richard. La obra de arte del futuro. Valencia: Univèrsitat de València, 2007, p. 164. 


\section{Capítulo l.- La tonalidad, un término transdisciplinar}

"Mysterium" de Scriabine, obra inacabada, nos llega a través de bocetos que el compositor nos dejó, así como de reconstrucciones de una fracción de la obra que han abordado diferentes artistas. Estaba planeada como una obra monumental, de siete días de duración continua, en un "templo" construido ex profeso para la representación, dotando con esto a la obra de un componente místico-religioso.

Del mismo modo, cuando en la Grecia antigua se realizaba el festival a Apolo, a los Bacantes, o a otra divinidad, interactuaban la arquitectura, la escultura, la danza y la música en una experiencia artística que no solo tenía componentes creativos y religiosos, además contenía una fuerte carga política, que quedaba subrayada por la sensación mística de poder que envolvía a la población asistente al acto. Esta carga política de la obra de arte total, podemos vislumbrarla en la unión de texto y música que se realizó durante el movimiento de Reforma y Contrarreforma religiosa de la sociedad europea en el siglo XVI.

Como una reacción a diversas prácticas de la iglesia católica en Roma, Martín Lutero publica una tesis que provoca una escisión en la religión y política del continente europeo, este movimiento lo conocemos como la Reforma, y a la reacción de la iglesia católica a este suceso la conocemos como Contrarreforma; movimientos que no solo supusieron un cambio en el panorama político, sino reacciones en el arte, que tuvo un contexto político religioso fuerte durante la época. Quisiéramos hacer referencia a dos obras representativas del periodo: La "Misa" en si menor de J.S. Bach y el "Mesías" de Händel, ambas 


\section{Capítulo l.- La tonalidad, un término transdisciplinar}

obras, como representantes artísticos de cada uno de los movimientos: El de Reforma, con la "Misa" en si menor de Bach y el de Contrarreforma, con el "Mesías" de Händel.

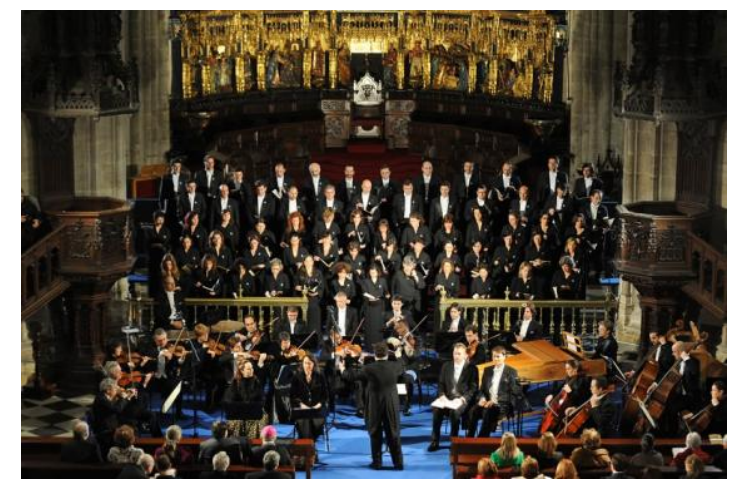

Figura 7. Representación del "Mesías" de Händel en la Catedral de Oviedo.

En ambos casos hay una unión "sine qua non” del texto con la música, como obras diametralmente opuestas en sus resultados, lo eran también en su concepción y en el tipo de experiencia místicoreligiosa que buscaban crear en el oyente.

La "Misa" en si menor de Bach (luterano en su religión), parece apoyar la tesis de Lutero de la búsqueda por la sencillez y la introspección, consideradas por los reformistas como cualidades perdidas por la iglesia vaticana. De un estilo severo y austero, la música escuchada no propone el gozo inmediato, sino una reflexión de fondo sobre la vida, obra y consecuencias para los creyentes.

Por otro lado, con el "Oratorio" del "Mesías" de Händel, somos testigos del fasto y elevación del goce estético del cual 


\section{Capítulo l.- La tonalidad, un término transdisciplinar}

comúnmente ha hecho uso la iglesia católica, para representar el poder divino en la tierra; es una de las obras más extrovertidas en la historia de la música, y refleja una preocupación exitosamente lograda por la fácil comprensión del texto y el manejo tonal de la armonía; todo con el fin propagandístico que la iglesia católica requería para hacer frente al movimiento Reformista al que se enfrentaba.

En ambos casos, el texto tiene una importancia fundamental en la obra musical, la cual, es concebida desde problemas de fondo como el manejo tonal de la armonía y la forma musical, para obtener del oyente una experiencia religiosa con trasfondos políticos. Desde ese punto de vista, podemos encontrar paralelismos con el drama griego y el esfuerzo que de forma posterior realizó Wagner por su búsqueda de un arte comunitario, la búsqueda de la obra de arte total, que solo podía conseguirse al obtener del público una participación activa, que tuviera consecuencias de fondo en la vida de la sociedad. La búsqueda del arte no como un mero entretenimiento, sino además, como una herramienta político-religiosa, la cual llevara a la sociedad hacia un mejor y más alto nivel de vida.

En la actualidad, esta búsqueda del "arte total" es retomada por las posibilidades que la tecnología unida al arte, nos brinda. Cuando en 1895 los hermanos Lumiere comienzan a proyectar diferentes actividades cotidianas por medio de un cinematógrafo, podemos considerar que comienza la historia (polémica) del cine, como una nueva forma de arte total. 


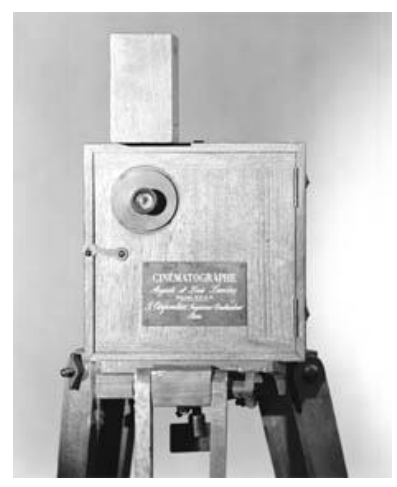

Figura 8. Cinematógrafo Lumiere.

En un comienzo el cinematógrafo permite la inclusión de un concepto nuevo en la historia, la proyección en un espacio fijo de imágenes en movimiento, supone una revolución en el mundo del arte visual; por esta misma vía de la unión tecnología-arte, pronto, lo que conocemos como cine incorpora el sonido y el color a sus proyecciones, y con esto, de inmediato, el texto y el guión se hacen presentes en la obra cinematográfica como una parte integral de la obra.

Esta idea, de utilizar la herramienta tecnológica del cinematógrafo para continuar la búsqueda del arte total, la encontramos en autores como Greenaway, Bergman, e incluso David Lynch; directores de cine que utilizan las posibilidades dadas por la tecnología, para la mejor transmisión de una idea.

Como espectadores podemos darnos cuenta en distintas obras de estos autores, del afán artístico detrás de la obra, que sobrepasa lo que se ha vuelto un común denominador del cine, como una mera forma de entretenimiento cotidiano; nada más alejado del concepto de 


\section{Capítulo l.- La tonalidad, un término transdisciplinar}

"obra de arte total", que a través de la historia, nos da referencia al arte como una herramienta para la búsqueda de la mejora del hombre y de la sociedad.

En algunas de las obras del género, podemos contemplar cómo se les dota además de un trasfondo político (defensa de derechos civiles, denuncia social, etc.) o de contenidos de búsqueda filosófica u onírica (Bergman o Lynch), al dotar a la imagen en movimiento de estos contenidos de fondo, podemos afirmar que el contenido y búsqueda del director de cine, en este caso se vuelve artística, ya que en un paralelismo que viene desde Grecia y el romanticismo alemán, se busca, por medio de la unión de distintas disciplinas artísticas, crear una sensación de vinculación casi mística en el espectador, transformar su mundo y/o mejorar el entorno social en el que vive.

Escuchamos "ecos" de la obra de arte total que conocimos en Grecia y que autores como Bach, Wagner o Scriabine, nos legaron en la búsqueda artística de autores de "cine de arte" de nuestros días; podríamos afirmar que muchas de ellas no pueden ser calificadas mas que como una forma de entretenimiento, y no merecen la misma descripción que los antecesores que trabajaron en la búsqueda del arte total; sin embargo, algunos autores del medio cinematográfico, nos revelan una búsqueda artística auténtica, con un lenguaje y medios propios de expresión que el cine proporciona, a los cuales, en ocasiones, dotan no solo de un sentido político, sino que consiguen una expresión comunal, la cual es transmitida a la audiencia. 
Quedaría por observar si el espectador realmente puede ser calificado como un elemento más de la obra artística en el medio cinematográfico, objetivo que tradicionalmente persigue la obra de arte total. En el cine, observamos la desventaja de la poca o nula participación del espectador en la obra, el público se encuentra "adherido" a la butaca y queda como un mero "vidente" de la pantalla de proyección, desvirtuando así, uno de los propósitos más fundamentales del arte total. 


\section{La tonalidad en la música.}

La idea de la tonalidad en la música es un concepto que sirve para organizar las notas o frecuencias sonoras que el público percibirá durante un lapso de tiempo determinado. Sirve además, para determinar el estilo de la pieza, cuando decimos que tal pieza es de estilo clásico, romántico, o incluso “atonal”, dodecafónica o popular y nos referimos a cierta manera en que el autor utilizó el concepto de la tonalidad. Hay una tercera idea sobre lo que es un tono en la música, y es el sonido por sí mismo cuando este se encuentra "afinado", como occidentales, cuando escuchamos un frecuencia sonora a 440 hertzios, decimos de manera estandarizada que escuchamos la nota o tono "La".

Como podemos ver, la idea de la tonalidad en la música no es unívoca, tenemos al menos tres usos para el término en el lenguaje sonoro: un uso del término como concepto jerarquizador, cuya función es organizar las frecuencias sonoras. Otro uso del concepto, que está íntimamente ligado al anterior, cuya función determina el estilo de la música que escuchamos y que tiene que ver con el intervalo de repetición en que aparece la función tonal o armónica que denominamos como "Tónica"; y un tercer uso del término es con el que denominamos la frecuencia sonora escuchada (el tono de "La") fuera de todo contexto. 
Haciendo referencia al "Tono" como un sonido descontextualizado y afinado, es como a través de la historia se ha construido lo que conocemos ahora, en el mundo occidental, como música; es por medio de las características propias del sonido por sí mismo, que se construyó todo nuestro sistema tonal de música, y la razón del éxito del mismo, es un sistema "emanado" directamente de las características físicas del sonido en nuestro planeta, la manera en que este es percibido, y cómo "viaja" a través de distintos medios.

Como decíamos anteriormente, el sonido son "ondas" o frecuencias sonoras, es movimiento, una vibración de algún objeto que es propagada a través de algún medio físico, impacta nuestro oído (en realidad todo nuestro cuerpo), y a través de señales eléctricas originadas por los órganos de audición humanos, es enviada a nuestro cerebro para su interpretación.

Por lo tanto, podemos hablar de varias condiciones para la existencia de un sonido, tal y como lo entendemos, el sonido existe cuando lo escuchamos, y para esto es necesario una vibración, la propagación de la misma por un medio (aire, agua o un sólido) y la recepción de la vibración por un órgano de escucha; si falta alguno de los tres requisitos anteriormente nombrados, no podemos cabalmente asegurar que el sonido existe.

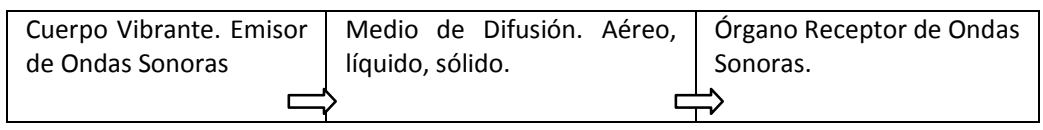

Figura 9. Esquema de la audición. 


\section{Capítulo II.- La tonalidad en la música.}

Todo sonido es producido por alguna "fuente sonora" 19 esto es, un cuerpo que vibre lo suficientemente rápido para que el sonido sea emitido. Para que el sonido se produzca en forma audible para el ser humano se debe cumplir con un mínimo de 16 oscilaciones por segundo; esta oscilación que el cuerpo sonoro produce, afecta a las partículas de aire que se encuentran alrededor, produciendo un efecto en cadena, estas partículas afectadas por la fuente sonora afectan a las siguientes partículas de aire y así sucesivamente hasta llegar a un receptor. La onda sonora es esférica, se transmite en todas las direcciones alrededor de la fuente sonora.

Existe un acuerdo, sobre el considerar el sonido como portador de tres características que le son fundamentales, estas son: La "Amplitud", "Frecuencia" y "Timbre".

La "Amplitud" de un sonido (o llamada también amplitud de presión) hace referencia a la intensidad de cómo lo escuchamos, con que fuerza nos impacta la onda sonora; se le llama amplitud, ya que depende de la altura que alcance un punto en la onda sonora respecto a su posición de equilibrio (cuando no vibra). Es además una sensación subjetiva, que en realidad depende en cierto grado de la salud del oído de cada individuo, pero sí podemos de forma estandarizada asignar valores a la amplitud de presión de un sonido. Fechner y Webber, experimentadores de "Psicofísica" (el estudio de la percepción humana) le llamaban la sensación subjetiva de la intensidad. La

\footnotetext{
${ }^{19}$ CASELLA, A.; y VIRGILIO M. La técnica de la orquesta contemporánea. Buenos Aires: Ricordi Americana, 1950, p.1.
} 


\section{Capítulo II.- La tonalidad en la música.}

amplitud es medida en "Belios" pero por razones prácticas, generalmente usamos la décima parte de la medida, el "Decibelio" y utilizamos diferentes tablas para dar una idea de forma práctica del uso del decibelio para medir la amplitud sonora.

El silencio lo "escuchamos" a cero decibelios ( $0 \mathrm{db})$, es una condición extremadamente rara poder estar en las condiciones necesarias para cumplir la condición de que con un medidor de decibelios en la mano, este no registre nada, puede cumplirse con esa condición, por ejemplo, en un estudio de grabación sonora que se encuentre vacío, y nos encontremos en la cabina insonorizada o a prueba de ruidos. El pasar las hojas de un libro haría que nuestro medidor de decibeles registre diez decibelios, una conversación a una distancia promedio de tres metros la escuchamos a $45 \mathrm{db}$, una orquesta sinfónica en el teatro marcaría alrededor de $70 \mathrm{db}$, una calle con mucho ruido de tráfico alcanza los 90 db. El "umbral del dolor" auditivo se encuentra a los $120 \mathrm{db}$, cuando escuchamos un sonido a esta medida de decibeles es cuando afirmamos que nos duele, nos sobresalta y tendemos a llevar nuestras manos a los oídos. Vale la pena mencionar, que una exposición continuada a sonidos desde 85 decibeles en adelante causa un daño irreversible en nuestra audición, como efecto, el individuo que esté continuamente expuesto a una calle ruidosa (90 db según el estándar) verá su audición disminuida con el paso del tiempo.

La "Frecuencia" del sonido, la determinamos por el número de oscilaciones por segundo que produce una fuente sonora, es necesario 


\section{Capítulo II.- La tonalidad en la música.}

un mínimo de 16 hertzios (16 oscilaciones por segundo) para que como humanos registremos un sonido, la frecuencia de un sonido determina la "altura" o el "tono" que estamos escuchando, a mayor número de hertzios escuchamos el sonido como más "agudo" y a menor número de hertzios lo escucharemos como más grave. Los umbrales de la percepción humana de la frecuencia sonora también son subjetivos, sin embargo, existe un estándar al respecto, considerando que los umbrales de audición humana se encuentran entre 20 Hertz (como el sonido más grave que podemos escuchar) a 20,000 Hertz (el sonido más agudo que escuchamos). Estos umbrales varían entre los individuos, además que están en relación proporcional con la amplitud de presión sonora, algunos tonos normalmente audibles no podemos escucharlos si no están en cierta relación con el número de decibeles escuchados, así como algunos sonidos que por su frecuencia no escucharíamos, al variar el numero de decibeles podríamos percibirlos.

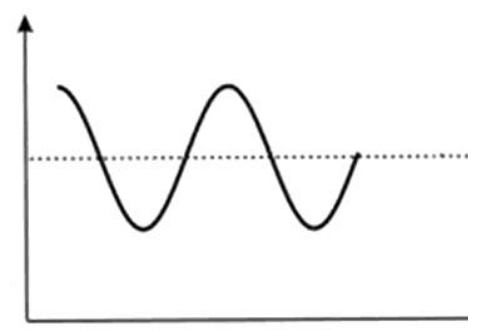

Figura 10. Amplitud y Frecuencia, La línea punteada indica la posición de equilibrio (silencio). La Flecha vertical la Amplitud sonora y la flecha horizontal la frecuencia, las líneas curvas representan una onda sonora. (Imagen realizada por Fco. Javier González Compeán.)

El "Timbre" de un sonido, es comúnmente definido como la característica del sonido que hace que dos sonidos que están en la misma frecuencia y amplitud, se escuchen diferentes, usualmente lo 


\section{Capítulo II.- La tonalidad en la música.}

consideramos como el "color" propio de un instrumento musical, o de una voz. El timbre de un sonido es determinado por los "armónicos" que le acompañan, como veremos más adelante, en realidad en la naturaleza, ninguna frecuencia sonora es escuchada "sola" de forma "pura" si no que va acompañada por una serie de frecuencias secundarias (armónicos) las cuales determinan la forma de la onda sonora, así como múltiples características de la misma.

No todos los armónicos de los distintos instrumentos y/o voces, se "comportan" de la misma manera, cada armónico puede tener una distinta amplitud sonora, lo cual establecerá el timbre que escuchamos, por ejemplo, cuando escuchamos una frecuencia de 440 hertzios emitida por una flauta (lo que los músicos conocen como "La") sus armónicos tienen una amplitud menor al sonido fundamental (el emitido de forma consciente por el flautista), si lo comparamos con una trompeta, la cual emita la misma frecuencia de 440 hertzios al mismo número de decibeles, los armónicos emitidos por el trompetista poseen una amplitud mayor en comparación a los emitidos por el flautista, esto provoca que el sonido de la trompeta sea comúnmente descrito como más "estridente" que el de una flauta.
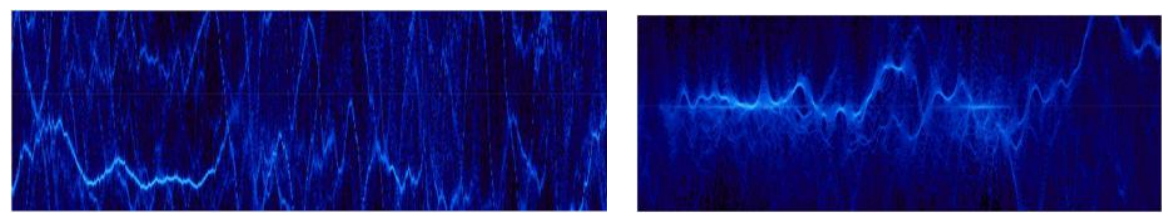

Figuras 11 y 12. Izquierda, panorámica espectral de un trombón. Derecha, panorámica espectral de un violín. Ambos instrumentos ejecutando una sola nota.

(Imágenes creadas con el software "Adobe Audition" por Fco. Javier González Compeán.) 


\section{Capítulo II.- La tonalidad en la música.}

Hay más factores en juego cuando hablamos del timbre en el sonido, los cuales se encuentran en relación unos con otros (llamada “envolvente"), de manera muy somera podríamos mencionar cuatro:

1. Ataque: Tiempo que tarda una onda sonora desde el momento en que es iniciada la vibración de la misma, al momento en el que alcanza su mayor amplitud sonora.

2. Caída: Tiempo que tarda la onda sonora para volver al estado de equilibrio $(0 \mathrm{db})$ después del punto máximo de amplitud sonora.

3. Sostenimiento: Tiempo que la onda sonora permanece estacionaria en la misma amplitud.

4. Liberación: Tiempo que tarda la onda sonora para ir del sostenimiento al estado de equilibrio (0 db).

Esto cambia de emisor en emisor de ondas sonoras, y es más fácilmente ejemplificar con los instrumentos musicales, de esta manera, un piano tiene un "ataque" más rápido que un violín, ya que el "ataque" de un piano es realizado por el golpe casi instantáneo que produce el martillo con la cuerda, mientras que el roce de un violín, producido por un arco frotado contra una cuerda produce un ataque más lento.

De la misma manera, es más rápida la "caída" de un oboe que de un piano, que se ve favorecido por el tamaño de su caja de resonancia. Por otro lado, el "sostenimiento" que un piano puede realizar es mínimo, más aún si se le compara con una flauta, que podrá 
permanecer estacionaria en la misma amplitud todo el tiempo que se lo permita la capacidad pulmonar del ejecutante, mientras el flautista pueda mantener la columna de aire con la misma intensidad, podrá aumentar el tiempo del "sostenimiento". La "liberación" también podrá ser más larga en instrumentos cuya caja de resonancia sea mayor en tamaño.

Todos estos factores afectan a la percepción global que como humanos tenemos del sonido, del "color" que de forma subjetiva nos produce el timbre de una onda sonora, y todos interactúan además en cada sonido que escuchamos. Al escuchar un sonido fuera de todo contexto, este es portador de todos estos conceptos que son altamente dinámicos, están en constante evolución.

El sonido "viaja", recorre distancias sobre diferentes medios para poder pasar del emisor al receptor y continuar con lo que podemos considerar como el ciclo de la audición. Es requisito para la audición la existencia de un medio para la transmisión del sonido, ya sea un medio sólido, líquido o gaseoso, sin la existencia de un medio de transmisión el sonido no podrá ser percibido. En el siglo XIX, Jean-Jacques Matrás realizó un experimento sobre la conducción del sonido y que es muy popular actualmente, colocó un timbre bajo una campana de vidrio, que estaba unida a una máquina neumática con el propósito de crear un vacío de aire alrededor del timbre, para beneplácito de los “oyentes”, en cuanto se alcanzó un nivel aceptable 


\section{Capítulo II. - La tonalidad en la música.}

de vacío, pudieron observar que el timbre funcionaba, pero ya no se escuchaba $^{20}$.

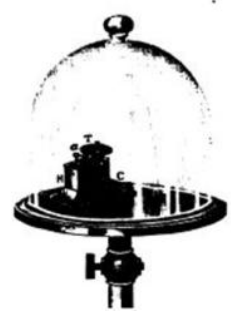

Figura 13. El experimento de Matrás. Una alarma sonora consistente en un martillo golpeando una campana, no producirá sonido cuando se encuentra en un ambiente "al vacio" (ZAHM, J.A.: Sound and Music. Chicago: Ed. McClurg and Company, 1892).

El primer medio, antes de nacer, a través del cual escuchamos es el líquido amniótico, después durante nuestra vida adulta, la mayor parte de nuestra audición es "aérea" por decir, que es a través del aire que percibimos las ondas sonoras. Gracias a experimentos realizados hace cerca de dos siglos, se pudo determinar que la velocidad del sonido en el aire es de 340 metros por segundo, cuando la temperatura ambiental es de 20 grados centígrados, esto de forma estandarizada, ya que la velocidad del sonido varía en relación al medio en que es transmitida, y las condiciones de este. La velocidad del sonido en el aire, varía por factores como: La presión atmosférica y la temperatura, curiosamente, el sonido viaja mejor en el agua o en algunos medios sólidos.

Para completar el fenómeno de la audición humana, es necesario que podamos captar las frecuencias sonoras emitidas y transmitidas anteriormente, y poderlas interpretar. Como seres

${ }^{20}$ MATRAS, J. El Sonido. Buenos Aires: El Ateneo, 1979 , p. 8. 


\section{Capítulo II.- La tonalidad en la música.}

humanos poseemos órganos de recepción sonora propios, lo que conocemos como el oído. Cuando una onda sonora nos impacta, el oído comienza a ejercer sus funciones, en realidad, el oído nunca descansa, aun mientras dormimos el oído y nuestro cerebro permanecen en funciones. Podríamos ejemplificar esto, recordando cómo, aun mientras estamos dormidos, cuando nos impacta algún sonido inesperado, este nos despierta o nos sobresalta, muchas veces, sin importar realmente la amplitud del sonido escuchado, aun en estas circunstancias, el oído, junto con nuestro cerebro, discriminan las ondas sonoras percibidas, y cuando este sonido escuchado durante nuestro sueño es algo que podríamos calificar como realmente inesperado, este activa nuestro "consciente" y nos hace reaccionar.

Tradicionalmente, nuestros órganos de percepción sonora se agrupan en lo que denominamos como nuestro "oído", y este, lo dividimos en tres secciones: El oído externo, oído medio y el oído interno.

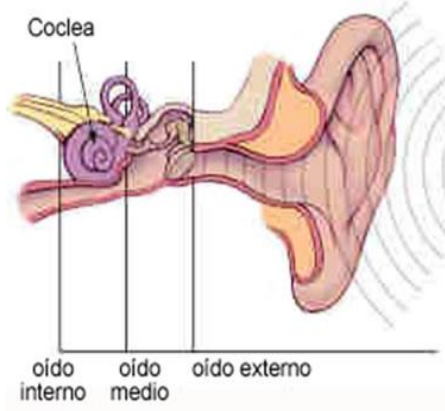

Figura 14. Esquema de las tres secciones del oído humano. 


\section{Capítulo Il.- La tonalidad en la música.}

Podríamos resumir el fenómeno de la percepción sonora, en la sección de captación, como un mecanismo de escucha que pasa por los tres medios posibles de transmisión del sonido. Cuando una onda sonora impacta nuestro oído externo, este conduce de forma aérea la onda sonora hacia el oído medio, el pabellón del oído (lo que comúnmente conocemos como la "oreja") por su forma, ayuda a amplificar y discriminar las ondas sonoras escuchadas. El oído medio está compuesto de pequeños huesos y una membrana, comúnmente la membrana es denominada como el "tímpano" y los huesos como "martillo", "yunque" y "estribo", estos órganos forman una cadena, y sirven para transformar la onda sonora "aérea" en vibraciones de cuerpos sólidos $^{21}$, lo cual, contribuye a amplificarlos, así como para realizar una segunda discriminación del sonido escuchado, además de dirigir la onda sonora (ahora por medios sólidos) al oído interno.

El oído interno está formado por la "cóclea", además de otros órganos que nos sirven para el equilibrio y otras funciones, la cóclea, o caracol (denominado comúnmente), es en realidad un tubo enrollado, que crea su forma de caracol, y se encuentra lleno de líquido y de "pelillos" en toda la superficie interna de su estructura, que son conocidos como "cilios", y estos, en sus raíces forman las "células ciliadas" que a su vez están conectadas con el nervio auditivo; estas células ciliadas son el puente al cerebro.

\footnotetext{
${ }^{21}$ CHION, M. El Sonido. Barcelona: Paidos, 1999, p. 47.
} 
Cuando las vibraciones transmitidas por medios sólidos, gracias al oído medio, llegan a la cóclea, estas son transmitidas a través del líquido que se encuentra en el interior de la misma, y excitan o mueven los cilios, parece ser, que determinados cilios se mueven en respuesta a frecuencias sonoras determinadas, que contribuiría a realizar una discriminación más del sonido escuchado; al excitarse los cilios, activan las células ciliadas correspondientes y a través de medios electroquímicos, envían su mensaje al cerebro. $\mathrm{Al}$ recibir nuestro cerebro los estímulos electroquímicos enviados por el oído interno, podemos entonces decir que "escuchamos", es en ese instante cuando podemos afirmar que hemos escuchado un tono, o un sonido; todo sonido posee una frecuencia particular, y cuando poseemos el suficiente entrenamiento auditivo (que en realidad consiste en memoria auditiva), podemos con la información previamente recopilada a través de nuestra experiencia, afirmar que hemos escuchado un tono determinado.

Existen músicos, con una memoria auditiva lo suficientemente entrenada, que son capaces de determinar el tono de virtualmente todo sonido escuchado, y traducirlo al lenguaje musical, como ejemplo podemos mencionar al músico Olivier Messiaen (Aviñón 1908 - Clichy 1992) quien dedicó parte de su vida a realizar traducciones de los cantos de los pájaros tal como eran escuchados en la naturaleza, por supuesto, las aves no realizan su canto en lo que conocemos como las escalas occidentales, o en afinaciones que un piano pueda ejecutar, cuando ocurría el caso, Messiaen "redondeaba", 


\section{Capítulo II.- La tonalidad en la música.}

asignaba el sonido a la nota más cercana de nuestro sistema musical. Existen sinnúmero de ejemplos, algunos no pasan de ser anecdóticos, como cuando un músico decía que cuando escuchaba el agua hirviendo, era capaz de escribir una línea para un instrumento musical determinado, que nos permitiera reconocer el fenómeno anteriormente mencionado.

Esto nos permite afirmar a-priori que la última discriminación del sonido se da en el cerebro, es gracias a la memoria auditiva que el sonido termina de transmitirnos todas sus características tales como el timbre, amplitud, frecuencia, etc. Podríamos afirmar, que mediante un entrenamiento, o el habituarse a realizar una escucha de forma consciente, el sonido nos transmite mayor información, la percepción sonora, depende en un grado fundamental de lo que poseemos en nuestra memoria, y somos capaces de discernir. 


\section{1 ¿Qué es la tonalidad?}

"La tonalidad es una fuerza natural
como la gravedad".
Paul Hindemith
El arte de la composición musical,
$1937^{22}$

Como mencionábamos anteriormente, la idea de la tonalidad en la música es un concepto, una herramienta que sirve para jerarquizar y organizar el sonido producido en un lapso determinado de tiempo. Lo que define el tono de una pieza, a grandes rasgos, es la nota (o frecuencia) que más se repite, si nos referimos a la música que conocemos como clásica, tendremos como característica fundamental, que la nota que conocemos como tónica será la primera y última nota con la frecuencia más grave que aparezca en la pieza musical.

Cuando hablamos de la construcción de una pieza musical, y el estilo en que está realizada, nos referimos también al manejo de la armonía en la misma, así como de la manera en que se crearon jerarquías entre los acordes (frecuencias simultáneas), y al intervalo de repetición del acorde al cual le fue adjudicada la función de tónica o tonalidad.

\footnotetext{
${ }^{22}$ Citado por Javier Darias para su poema-tarjeta "Homenaje a Paul Hindemith" en RUVIRA, Josep: Javier Darias. Obra de composición e investigación musical. Valencia: Generalitat Valenciana, 1990, p. 210.
} 
Un acorde, es la emisión simultánea de dos o más notas o frecuencias sonoras, en realidad, escuchamos acordes todo el tiempo, cuando estamos envueltos en una conversación con varias personas que hablen simultáneamente, cuando escuchamos cualquier pieza musical, incluso, cuando escuchamos música para un solo ejecutante (el concepto conocido como "armonía implícita") o cuando nos encontramos inmersos en el ruido del tráfico de la ciudad, estamos escuchando acordes o frecuencias sonoras simultáneas.

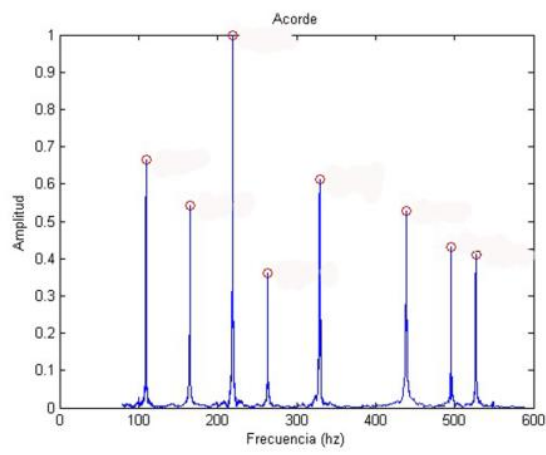

Figura 15. Sonograma de un acorde, varias frecuencias simultáneas.

En la música occidental, las frecuencias sonoras simultáneas están organizadas por "terceras", buscando la sensación de "refuerzo" acústico, al hacer que una frecuencia sonora determinada posea una mayor amplitud gracias a las frecuencias que le acompañan, podríamos decir, que el manejo de la armonía, conceptualizada como la manera de formar acordes de forma independiente $y$ descontextualizada, está dedicada a estructurar formaciones de acordes destinadas a reforzar las frecuencias deseadas.

Esto nos lleva al concepto de la "consonancia" y la "disonancia" en la armonía, considerando como la consonancia la 


\section{Capítulo II.- La tonalidad en la música.}

relación de notas que nos proporciona esta sensación de refuerzo acústico, y la disonancia como la relación de frecuencias que nos dan la sensación de contraste.

Cuando realizamos una breve revisión histórica sobre los conceptos de consonancia y disonancia, podemos ver cómo la definición cambia en cuanto a las causas de los mismos, sin embargo, las observaciones que desde la antigüedad se han realizado, siguen siendo tan válidas hoy como en aquellos días. J.N. Forkel, primer biógrafo de Johann Sebastián Bach, y contemporáneo al mismo, nos define la consonancia como una relación matemática de frecuencias:

"La consonancia de dos sonidos entre sí es un hecho que, como se sabe, ocurre acústicamente cuando las vibraciones respectivas de ambos sonidos están en una relación sencilla (...) La relación matemática más simple es la de un número con su doble o con su mitad y se expresa $2 / 1$ o $1 / 2,23$.

Esta relación matemática del doble o mitad, es conocida en música como la "octava" cuando la nota se "repite" (nota "La" a 440 Hz. y nota "La" a 880 Hz.), y nos proporciona la sensación de mayor refuerzo, lo escuchamos casi como una sola nota, siendo la frecuencia más aguda reforzada por la grave, se considera a los tonos separados por octavas (relaciones de dobles o mitades) como poseedores del

${ }^{23}$ FORKEL, J.N. Juan Sebastián Bach. México D.F.: Fondo de Cultura Económica.. 1998, p.172. 


\section{Capítulo II.- La tonalidad en la música.}

mismo "color tonal"24. Cuando esta relación matemática entre dos frecuencias sonoras "se complica" (en palabras de Forkel):

"Camina hacia la disonancia (...) en un orden de mayor sencillez a mayor complicación en las relaciones respecto al sonido fundamental (la longitud entera de la cuerda o del tubo vibrante) es la de relaciones 3:2 que produce una "quinta", 4:3 que produce una "cuarta"; 5:4, que produce una "tercera mayor", etc. $" 25$

Los acordes en la música occidental, están formados a partir de la nota generadora por una relación de 5:4 (tercera mayor) y 3:2 (una quinta), creando de esta manera lo que conocemos como el "acorde perfecto mayor", se menciona que los acordes están construidos por terceras ya que, la relación entre cada una de las notas (la generadora y la segunda nota, la segunda nota y la tercera) es de "terceras" (relación de 5:4 y de 6:5, tercera mayor y menor). Sin embargo, la estructura de los acordes se define como los intervalos que lo conforman a partir de la nota generadora, por esto el acorde mayor se considera una relación de 5:4 y de 3:2.

Esta manera de crear los acordes está hecha en imitación a la naturaleza, y es parte del éxito que la música occidental ha tenido imponiéndose al resto de las construcciones musicales del mundo, por dar algunos ejemplos, gran parte de la música asiática tradicional estaba construida a partir de un concepto abstracto: Un número, el 5; y

\footnotetext{
${ }^{24}$ GOLDSTEIN, E. B. Sensación y Percepción. Madrid: Debate,1993, p. 343.

25 FORKEL, J.N. Juan Sebastián Bach. México D.F.: Fondo de Cultura Económica.. 1998, pp. 172-173.
} 
gran parte de la música africana era construida en base a repeticiones rítmicas con contenido simbólico-religioso. En el caso de la música occidental, hubo una exploración histórica del sonido, de sus características intrínsecas y forma de "comportamiento" que las frecuencias sonoras poseen.

El hecho, es que todo sonido emitido es un conjunto de frecuencias y no una sola, a este conjunto de frecuencias le llamamos “Armónicos", fenómeno natural del que ya teóricos de la música desde hace siglos nos hablan, es importante la cita de Jean Phillipe Rameau (1683-1764), el cual, confirmando los experimentos que realizó Pitágoras en cuerdas y piedras, en su tratado de armonía "Traité de l'harmonie réduite à ses principes naturels" publicado en 1723, nos dice: “Toda cuerda posee en sí misma a todas las cuerdas", refiriéndose a cómo es posible escuchar que "Todo sonido posee en sí mismo todos los sonidos"; estos sonidos que acompañan a todo sonido, son los armónicos.

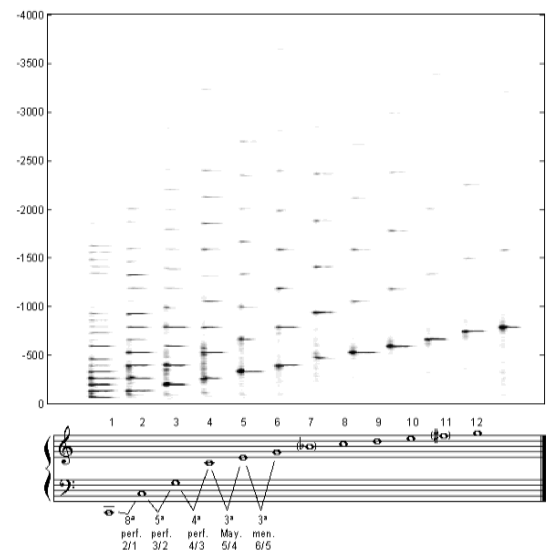

Figura 16. Sonograma de los armónicos, frecuencias secundarias producidas por el ataque a una sola nota. (Imagen realizada por Fco Javier González Compeán) 
Todo sonido va acompañado de la misma relación de frecuencias sonoras, y le corresponden de acuerdo a su frecuencia generadora o fundamental. Estos armónicos pueden verse reducidos o ampliados de acuerdo a la longitud de la cuerda o tubo vibrante, y pueden poseer diferencias en los parámetros que le son propios al sonido como la amplitud, el ataque, etc., pero la relación de frecuencias siempre será la misma.

Por ejemplo, si consideramos como nuestro sonido generador el "Do" índice 4 a $131 \mathrm{~Hz}$., este produce primero un armónico a la “octava" ("Do" índice 5, relación 2:1) a $262 \mathrm{~Hz}$., luego la "quinta" ("Sol” índice 5, relación 3:2) a 392 Hz., y en sucesión de sonidos cada vez más agudos o de frecuencias más altas: "Do" índice 6 a $523 \mathrm{~Hz}$., “Mi" índice 6 a 659 Hz. (relación de 5:4), "Sol” índice 6 a 784 Hz., "Si bemol” índice 6 a 934 Hz., "Do" índice 7 a 1047 Hz., "Mi” índice 7 a 1319 Hz., "Sol” índice 7 a 1568 Hz., y así sucesivamente, en distancias cada vez menores, o en palabras de Forkel: "Relaciones cada vez más complicadas", hasta pasar el umbral de audición del hombre.

A partir de este hecho de la naturaleza, el hombre occidental (en particular músicos, filósofos y físicos con oídos extremadamente finos) sintetizó esta "serie de armónicos" en un acorde que llamó “acorde de dominante", y en una escala, la "escala mayor". 


\section{Capítulo II.- La tonalidad en la música.}

Podemos considerar el "acorde dominante" como la síntesis del fenómeno sonoro natural proporcionado por los armónicos, tal como fue conceptualizado al momento de realizar la síntesis anteriormente descrita, la realidad física de los sonidos armónicos, no contiene de forma exacta estas afinaciones; es con esta serie de sonidos con los que se ha trabajado durante siglos de tradición de música occidental de concierto, y es esta síntesis, la que ha permitido el desarrollo de la música occidental tal y como la conocemos.

Si tomamos el mismo generador que en el ejemplo anterior, el "acorde dominante" resultante está formado por los armónicos que más se repiten en la serie: El sonido generador, la "quinta", la "tercera", y la "séptima menor", que aparece en dos ocasiones, cuando avanzamos hacia los armónicos más alejados de la nota generadora, es decir: siendo nuestro generador el "Do" índice 4 a $131 \mathrm{~Hz}$., de forma sintetizada, formando el acorde por "terceras", las siguientes notas del acorde dominante sería el "Mi" índice 4 a 165 Hz., "Sol" índice 4 a 196 Hz., y el "Si bemol" índice 4 a 222 Hz., las relaciones entre las notas a partir de la generadora en el acorde dominante son: 5:4 (tercera mayor), 3:2 (quinta), 9:5 (séptima menor).

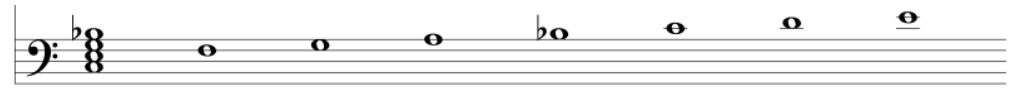

Figura 17. Acorde "Dominante" teniendo como nota generadora el "Do" indice 4 a $131 \mathrm{~Hz}$. con su escala "mayor" resultante. (Imagen realizada por Fco. Javier González Compeán). 


\section{Capítulo II.- La tonalidad en la música.}

Después de sintetizar la serie de armónicos en sonidos simultáneos, fue creada la "escala mayor" como una serie de sonidos sucesivos; el "molde" de la escala mayor es el siguiente: Considerando el mismo sonido "Do" como nuestra "Tónica" (el Tono de la escala), el siguiente sonido es el conocido como "Re" y su relación con la "Tónica" es de 9:8, seguido del "Mi" en relación de $5: 4$, "Fa" en relación de 4:3, "Sol" en relación de 3:2,"La" en relación de 5:3, "Si" en relación de 15:8; si seguimos adelante, la siguiente nota es la repetición de la Tónica, en relación de 2:1.

Como podemos observar, la tonalidad está compuesta de una serie de relaciones de las frecuencias sonoras que giran en torno a una nota generadora, estas relaciones han sido establecidas siguiendo el parámetro del fenómeno natural de los armónicos, y esta relación matemática se "complica" cuanto más se aleja de la nota generadora. 


\section{Capítulo II.- La tonalidad en la música.}

\section{2 ¿Cómo se define?}

La música es por su propia naturaleza un elemento inmaterial; no puede ser retenida. Existen al menos dos maneras de fijar la importancia de un tono determinado en una construcción musical, las cuales contribuyen a formar nuestra idea o "imagen" 26 del fragmento musical o pieza que escuchamos.

La primera de las herramientas que existen para fijar un tono establecido en la música, es mediante la asignación de jerarquías o "funciones tonales" en la pieza musical, existe un acuerdo, impuesto por la tradición musical, sobre la importancia de la relación entre el acorde de dominante y el acorde de tónica en la música. Hemos podido observar la formación del acorde de dominante a partir del fenómeno natural proporcionado por los armónicos que acompañan a todo sonido, y cómo, se dedujo a partir del mismo fenómeno la posibilidad de creación de una "escala" o sucesión de sonidos. Adjudicando a cualquier nota dada la función de "Tónica" la nota que tendrá la función de "Dominante" de la misma se encuentra en relación de 3:2 (una "quinta"), y los acordes construidos a partir de las mismas son los que consideraremos como el acorde de "Tónica" y el acorde de "Dominante".

\footnotetext{
${ }^{26}$ DORFLES, G. El devenir de las artes. México D.F.: Fondo de Cultura Económica. 1993, p.139.
} 


\title{
Capítulo II.- La tonalidad en la música.
}

Un acorde presentado de forma aislada y descontextualizada de cualquier otro acorde no puede representar una función tonal ${ }^{27}$, es necesario el "enlace" de varios acordes sucesivos para poder determinar las funciones tonales, las cuales contribuirán tanto a la construcción de la pieza musical, como a la sensación acústica de mayor importancia de cierta nota o acorde. La relación de notas generadoras de acordes utilizada para crear esta sensación de refuerzo es la de 3:2, la "resolución" o continuada sucesión del acorde de dominante al de tónica, es lo que en música se conoce como una "cadencia", 28 .

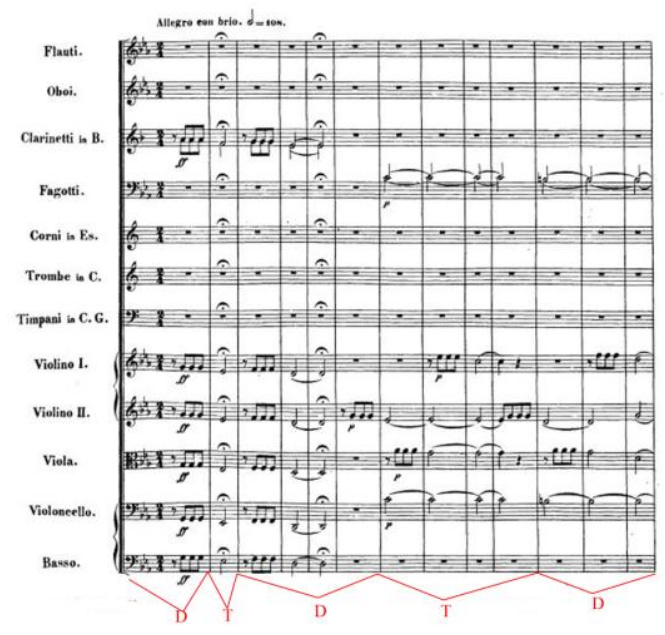

\author{
Figura 18. Cadencias, el \\ acorde "Dominante" \\ indicado con la letra " $D$ " $y$ \\ el acorde "Tónica" con la \\ letra " $T$ " en el inicio de la \\ Quinta Sinfonía de L.V. \\ Beethoven. (Leipzig: Ed. \\ Breitkopf \& Härtel. Ludwig \\ van Beethoven's Werke, \\ Serie I, Symphonien no. 5, \\ 1862).
}

Este fenómeno conocido como "cadencia", desde el punto de vista armónico, crea en el público la sensación de un final, y/o de un reposo; dependiendo de los recursos utilizados antes o después por el

27 SCHOENBERG, A. Funciones estructurales de la armonía. Barcelona: Idea Books, 1999, p. 23.

28 Diferente al concepto utilizado en la música popular para denominar ciertos ritmos (N. del A.). 
compositor, este "final" marcará una frase, un periodo, sección o el final definitivo de la pieza, esta sucesión específica de acordes tiene la función de establecer un tono, y podemos asegurar, que mientras más sea escuchada esta relación en una pieza de música, mayor será la sensación de refuerzo tonal para el escucha.

La tonalidad en la música, a partir del manejo de los diferentes acordes que componen la escala mayor, ocurre cuando las diferentes frecuencias que suceden en la pieza musical están relacionadas con la nota denominada como tónica ${ }^{29}$, y reforzadas por la relación cadencial de $3: 2$.

${ }^{29}$ ALDWELL, E.; y C. SCHACHTER. Harmony \& Voice Leading. New York: Schirmer, 2004, p.4. 


\section{Capítulo II.- La tonalidad en la música.}

\subsection{Intervalos de repetición en la tonalidad.}

La segunda herramienta a considerar para el establecimiento de un tono en una estructura de frecuencias sonoras es la "repetición". La memoria auditiva del hombre precisa de constantes repeticiones para poder aprehender una melodía, aún más, si quiere retener un tono determinado de forma independiente a cualquier otro tono.

Hay una relación directa entre la sensación de "Tonalidad" de una pieza musical y el número de veces que se repite la función tonal de tónica, la nota o acorde que deseamos definir como nuestro "centro tonal"; por decirlo de otra manera, mientras el intervalo de repetición de la tónica sea más corto, mayor será la sensación de importancia de esa nota determinada para el oyente.

Mientras más se repita un fenómeno acústico, este queda fijado con mayor firmeza en la memoria; por otro lado, mientras más tiempo pase en la obra sin que escuchemos una repetición, se debilita la sensación de existencia de un centro tonal, hasta que eventualmente este llega a desaparecer. Este fenómeno de la repetición en la música, contribuye de sobremanera a definir el estilo de la pieza musical a tratar, junto con las funciones tonales asignadas (y repetidas), definen la impresión que el público tendrá del fenómeno sonoro escuchado. Además, este suceso de la repetición para fijar en la memoria un centro tonal, y el refuerzo o agresión que el compositor 


\section{Capítulo II.- La tonalidad en la música.}

realice en contra o a favor del mismo, son los que han determinado en gran parte la evolución del lenguaje musical en nuestra sociedad.

En la siguiente partitura de la sonatina op. 36 no. 1 de Muzio Clementi (1752-1832), podemos observar como el intervalo de repetición de la tonalidad es corto, a una velocidad promedio de dos segundo por compás (la línea vertical que durante la partitura divide los grupos de notas), no pasan más de dos segundos en el inicio de la obra sin que se repita la nota asignada como tónica (en este caso el "Do"), además de ser también la nota que inicia y finaliza el movimiento o parte de la obra que nos ocupa. Observamos también, que siguiendo el procedimiento clásico, aproximadamente a la mitad de la obra, el centro tonal se desplaza a la región de la dominante (la nota "Sol") y la relación cadencial de 3:2 refuerza a este nuevo centro tonal, para posteriormente volver a reforzar el centro tonal original.

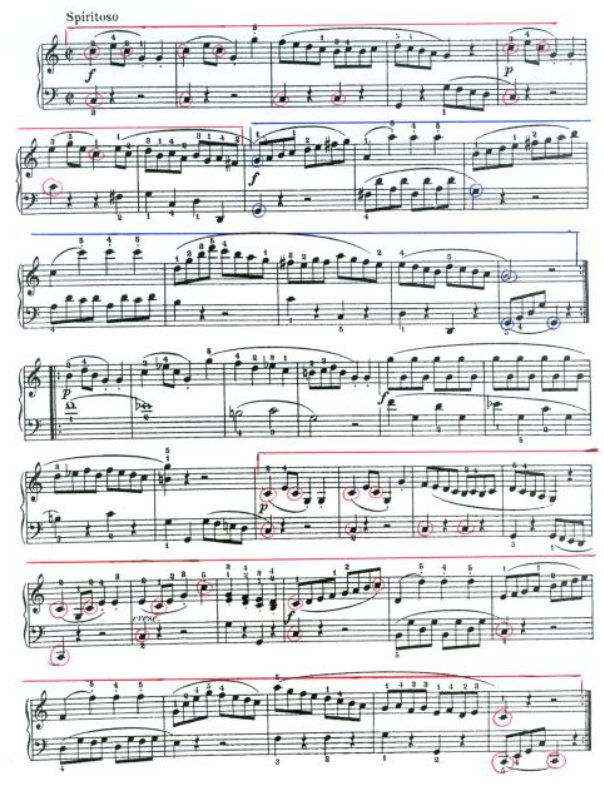

Figura 19. Primer movimiento de la "Sonatina en Do mayor" de Clementi. En círculos rojos las notas con función de "Tónica", enmarcados en rojo los pasajes cuya función tonal "gira" en torno a la tonalidad original; enmarcado en azul, el pasaje central cuya función "gira" en torno a la función de dominante. (New York: Ed. Schirmer, Inc. 1904). 


\section{Capítulo II.- La tonalidad en la música.}

Conforme fue evolucionando la música, encontramos que las fuerzas centrípetas $^{30}$ o el ataque al centro tonal establecido, se vuelven cada vez más preponderantes. En el periodo denominado como "música romántica" encontramos que la relación cadencial se vuelve cada vez menos recurrente, así como la repetición del centro tonal establecido. El siguiente ejemplo, "Papillons" de Schumann (18101856), observamos cómo el centro tonal es la primera nota en aparecer, pero la relación cadencial en la armonía, no ocurre sino hasta el final de la danza designada como "1.", lo cual es un intervalo que, tomando en cuenta los antecedentes, podemos considerar como largo para poder escuchar otra vez tanto el centro tonal, como la relación armónica de 3:2 entre generadores de la dominante y la tónica.

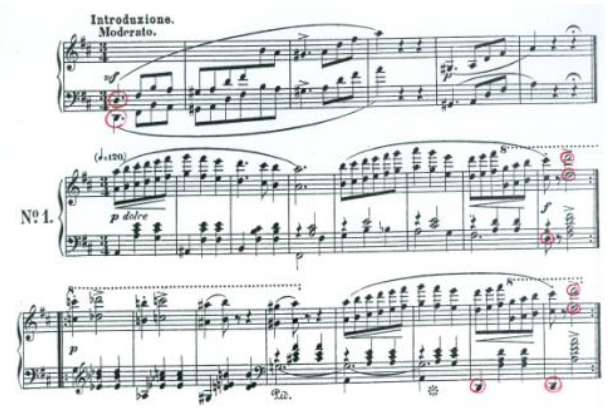

Figura 20. Inicio de "Papillons op.2" De Robert Schumann. En círculos rojos las notas con función de "Tónica", nótese que son las primeras notas escuchadas en la obra, pero no vuelven a aparecer con una función cadencial sino hasta el final de la primera frase de la primera danza, y al final de la misma. (Leipzig: Ed. Breitkopf \& Härtel. Robert Schumanns Werke, 1912).

\footnotetext{
${ }^{30}$ SCHOENBERG, A. Funciones estructurales de la armonía. Barcelona: Idea Books, 1999, p. 24.
} 
Este intervalo de repetición, continuó haciéndose más largo conforme continuaba la evolución del lenguaje musical en occidente, hasta llegar a desparecer la sensación de un centro tonal establecido, como un hito histórico en este aspecto, se considera el preludio a “Tristán e Isolda” ópera de Richard Wagner (1813-1883); preludio durante el cual, se considera como abandonado todo centro tonal, los primeros acordes no son los que representan la tónica, no existe una función cadencial hasta aproximadamente después de más de dos minutos de música, además, esta función cadencial no es realizada a la nota que podríamos, de una manera u otra, denominar como la tónica de la obra; razones por las que históricamente, se considera a este instante como la primera música "atonal” (carente de un centro tonal) escrita.
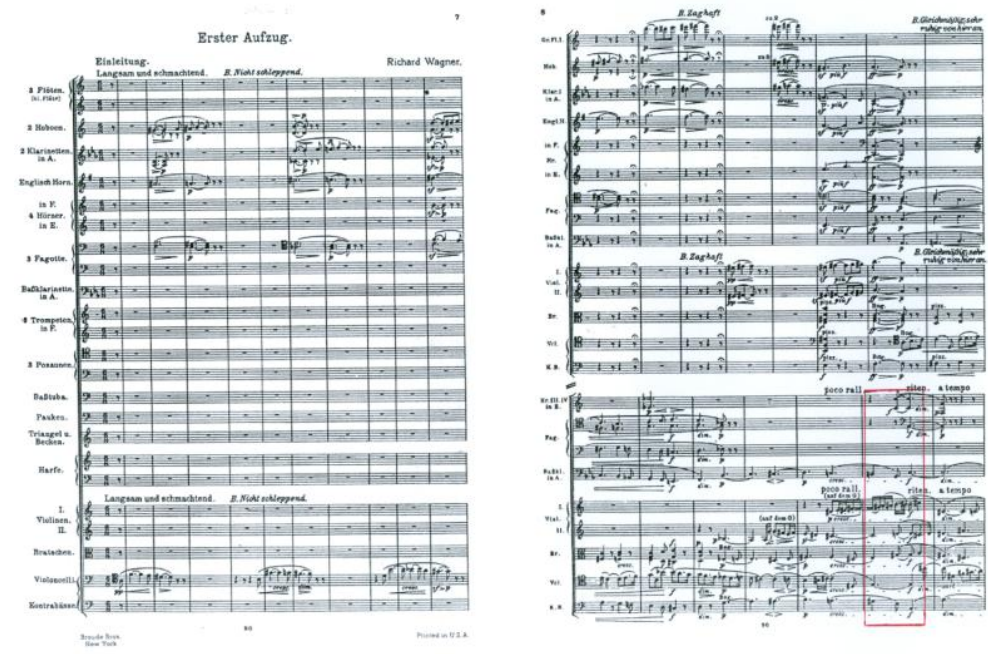

Figura 21. Inicio de la opera "Tristan und Isolde" de R. Wagner. Enmarcado en rojo, el pasaje con la primera cadencia de la obra, aproximadamente a los dos minutos con cuarenta segundos de la obra (Leipzig: Ed. Breitkopf \& Härtel. Tristan und Isolde, 1911). 


\section{Capítulo II.- La tonalidad en la música.}

Partiendo del principio de "atentar" contra el centro tonal establecido, múltiples compositores como Mahler, Strauss, o el mismo Schoenberg, escribieron música que a-posteriori fue denominada como "tonalidad ampliada" por lo largo del intervalo de repetición de la tonalidad establecida, partiendo de la idea de que, se estaba escribiendo música tonal, cuyas relaciones fueran cada vez más "complicadas".

Schoenberg (1874-1951) compositor austriaco, después de haber escrito múltiples obras por la vía de la tonalidad ampliada, o incluso lo que fue denominado como "atonalismo libre", propone una nueva forma de organización de las relaciones entre las frecuencias sonoras en una pieza musical, el "dodecafonismo".

En principio, el dodecafonismo parte de la idea del abandono de la tonalidad, mediante la no jerarquización de los sonidos escuchados, al dejar de un lado las jerarquías o funciones tonales en la música, cada nota tendría la misma importancia para el oyente, abriendo así, la posibilidad de creación de música nueva, que no esté supeditada a la idea de un centro tonal. Para conseguir esto, Schoenberg comprendía que era necesario tomar en cuenta la no repetición de un tono determinado, ya que la repetición de una nota sobre las demás, crea la sensación de un centro tonal, aun si las funciones tonales o las relaciones de cadencia no están presentes, por esto, como principio básico para la construcción de música dodecafónica, es necesario el no repetir un tono hasta que los otros doce tonos de la música occidental, hayan sido escuchados. 


\section{Capítulo II.- La tonalidad en la música.}

Con esto, se pretende no jerarquizar ninguna frecuencia sonora, no darle ninguna importancia especial a alguna nota sobre las demás, podemos hablar de un afán democratizador en la música al crear series dodecafónicas, y ciertamente, para el público, la sensación es de una pérdida total del centro tonal. Incluso algunos investigadores han interpretado una visión ideológica de la tonalidad, según la cual "la armonía tonal de toda la vida reproducía el esquema de la monarquía absoluta, con la tónica representando al rey y la subdominante al príncipe preparado para reemplazarlo" 31 , y que escuchar esta música influía subliminalmente al público a "aceptar este tipo de orden jerarquizado en la sociedad"; encontrándose por el contrario, que en el dodecafonismo, eliminando este centro tonal, creaba "un espíritu más igualitario". Esta asociación queda paradójicamente reflejada cuando Arnold Schoenberg recordó que el compositor Paul von Klenau quiso convencer a Hitler de que "el sistema de doce notas reflejaba fielmente la estructura del nacionalsocialismo y, por tanto, constituía el vehículo perfecto para expresar sus ideas" ${ }^{32}$. La historia posterior demostró que no pudo convencerlo, quizá porque Hitler esperaba mejores resultados de un centro tonal, para su influencia emocional en las masas.

Se considera el "Walzer" op.23 no. 5 como la primera pieza dodecafónica escrita, y podemos observar, cómo el compositor ha utilizado dos series dodecafónicas de manera simultánea al inicio de la

\footnotetext{
${ }^{31}$ Véase "Compositores: Arnold Schoenberg" en http://ambargris.blogspot.com/2008_11_01_archive.html [consulta 3-09-2011]. ${ }^{32}$ Ídem.
} 


\section{Capítulo II.- La tonalidad en la música.}

pieza, en una especie de exposición del material a ser trabajado, y posteriormente, trabajar con una $\mathrm{u}$ otra serie haciendo múltiples variaciones de las mismas, pero sin repetir ni jerarquizar ninguna nota, hasta que haya transcurrido la serie dodecafónica completa.

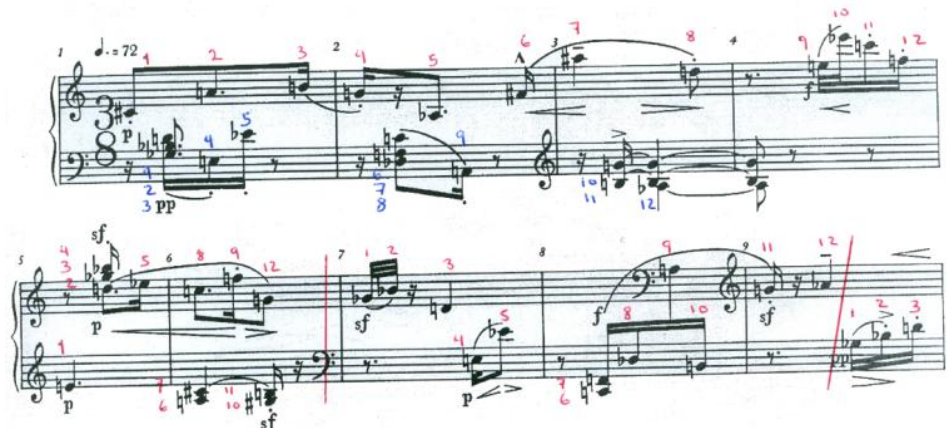

Figura 22. Inicio del "Walzer" op. 23 de A. Schoenberg. Al inicio en rojo y azul, numeradas las dos series dodecafónicas simultaneas; posteriormente, numeradas en rojo y separadas por líneas del mismo color, las notas presentadas en series de doce sonidos; nótese la ausencia de repetición de un centro tonal hasta no haber transcurrido todas las notas del sistema temperado occidental (Copenhagen: Ed. Wilhelm Hansen, Fünf Klavierstücke op.23, 1923).

El manifiesto dodecafonista planteó una revolución en la manera de conceptualizar la música, y su influencia en la música posteriormente realizada se siente aún en nuestros días con manifestaciones como la música "serialista" o incluso en reacciones en contra, como con la música "espectral” francesa de finales del siglo $\mathrm{XX}$.

En la música dodecafónica, no solo se han abandonado las funciones que le son propias a la música tonal (3:2) sino que, además se alargó de forma sistemática, el intervalo de repetición de la 
Capítulo II.- La tonalidad en la música.

tonalidad, creando una total igualdad entre las notas o frecuencias sonoras presentadas en una pieza musical. 


\section{Capítulo II. - La tonalidad en la música.}

\subsection{El sistema temperado de música.}

El "temperamento" en la música occidental, hace referencia a una forma de afinación específica en los instrumentos, para llegar a esta forma de afinación, usada actualmente de forma universal, se pasó primero por sinnúmero de afinaciones y relaciones tonales distintas, siendo un punto importante en la adquisición de esta afinación, los experimentos realizados en Grecia por Pitágoras (582 A.C.-507 A.C. aprox.) y su alumno Phylolaus. Mediante experimentos con cuerdas, tubos, campanas, agua y piedras, Pitágoras descubrió el hecho de las matemáticas que subyacen en la música, estableciendo las relaciones entre un sonido y el tamaño del cuerpo vibrante y su “octava” que estará en relación de 1:2.

Mediante el uso de esta afinación "natural" o denominada posteriormente como "pitagórica", ocurrían ciertos problemas para la ejecución práctica de música cuando esta transcurría en diferentes centros tonales, cuya relación de uno con otro fuera "enarmónica". El término "enarmonía" sirve para denominar dos notas de diferente escritura, pero igual afinación (por ejemplo "Do sostenido" y "Re bemol”), y que cuando las ejecutamos en un piano, el músico tocará exactamente la misma tecla a pesar de tener plasmada en la partitura dos notas diferentes.

El piano es un "instrumento temperado", por decir que su afinación no corresponde exactamente a las relaciones dictadas por los 


\section{Capítulo II.- La tonalidad en la música.}

experimentos pitagóricos, tiene pequeñas "desafinaciones", que sirven a un fin práctico. Una de las obras cumbre de la sociedad occidental por el aporte que realiza al concepto de la afinación en la música, es la serie de dos libros "Das Wohltemperirtes Clavier" de Johann Sebastián Bach (primer libro recopilado en 1722, el segundo en 1744).

Es en esta colección de piezas que queda definida la afinación "temperada" o "igual" que ha permitido el desarrollo de la música occidental, así como los posteriores avances en la construcción de instrumentos.

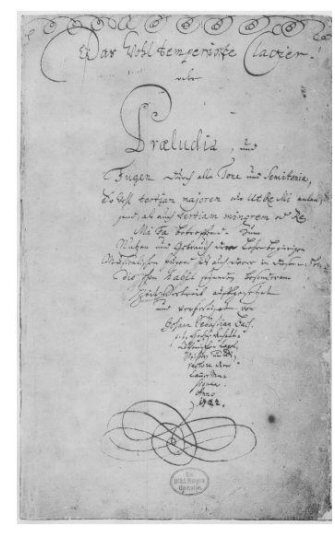

Figura 23. Portada manuscrita de la primera recopilación de preludios y fugas realizada por Johann Sebastian Bach

El temperamento en la música, consiste en un abandono pragmático de la teoría de afinación pitagórica, que es después de todo, una afinación natural de los sonidos y que corresponde a la serie de armónicos dados por la naturaleza.

Cuando avanzamos hacia los armónicos más alejados que un sonido produce, notamos una diferencia entre las notas enarmónicas, 


\section{Capítulo II.- La tonalidad en la música.}

el "Do sostenido" es diferente al "Re bemol" en una relación de 80:81, la diferencia es realmente mínima, pero tenía cierta importancia al momento de realizar formaciones acórdicas en piezas que involucraran a dos o más ejecutantes. Bach "fue el último de los inconformes y quien se resolvió a adoptar, en contra del dogma de la afinación "exacta", otro sistema, netamente empírico, que igualaba para un oído exigente, pero práctico, las entonaciones de las dos notas enarmónicas, haciendo iguales, por lo tanto, el "Do sostenido" y el "Re bemol", etc." ${ }^{33}$. Para estos propósitos, para igualar las notas enarmónicas, fue necesario igualar asimismo, los intervalos que componen la escala musical.

Como medida para igualar los intervalos que conforman la "octava" (relación 1/2) se estableció el semitono como el intervalo "igual", y se dividió la octava musical en doce semitonos, que son los que actualmente conforman la llamada "escala cromática" en la música occidental. El semitono se encuentra en una relación de 16/15 en la mayoría de los sistemas del llamado "temperamento" musical, en particular del "buen temperamento" (Wohltemperirtes) y si tomamos como referencia un "La" a $440 \mathrm{~Hz}$., el semitono superior tiene como medida estándar $466.16 \mathrm{~Hz}$. y es conocido como "La sostenido" o "Si bemol".

No podemos recalcar lo suficiente la importancia de estos hechos, en apariencia sencillos, en la evolución histórica de la música.

\footnotetext{
${ }^{33}$ FORKEL, J.N. Juan Sebastián Bach. México D.F.: Fondo de Cultura Económica, 1998, pp. 166-167.
} 
Al hacer uso de la afinación temperada, se ha vuelto más práctico el trabajo para un compositor occidental ${ }^{34}$, al combinar estos hechos dados por la naturaleza y la lógica con la música, no solo amplió su mundo y sus posibilidades, además se convirtió en un elemento casi biológico, qué tiene la capacidad de conmover y mover a la gente de cualquier cultura, ya que hace uso de la serie de armónicos proporcionados por la naturaleza, y que corresponden en proporciones de forma matemática y casi exacta con la cóclea o caracol del oído interno del hombre. Además, mediante la adopción del sistema "igual" o temperado de afinación, como una medida práctica dictada por la lógica, se puede hacer uso de relaciones tonales cada vez más elaboradas, sin tener que recurrir a la necesidad de cambiar de manera constante la afinación de las cuerdas de los instrumentos.

\footnotetext{
${ }^{34}$ DORFLES, G. El devenir de las artes. México D.F.: Fondo de Cultura Económica, 1993, p.58.
} 


\section{Capítulo II. - La tonalidad en la música.}

\subsection{Otras afinaciones.}

Por la tradición histórica musical en nuestra sociedad, estamos acostumbrados a afinar y escuchar los instrumentos en la escala "temperada", la cual hemos podido observar que fue construida a través de experimentos con cuerdas y los sonidos que eran conceptualizados como los armónicos o frecuencias secundarias que acompañan a toda nota.

Sin embargo, la afinación de los armónicos no es temperada, gracias a tecnologías de medición de frecuencias, obtenidas ya anteriormente al siglo XX, somos capaces de determinar con mayor precisión las frecuencias exactas de los sonidos armónicos, y podemos darnos cuenta, que la realidad "física" de los frecuencias secundarias de toda nota, no son exactamente como fueron dictadas en la antigüedad.

Esto nos ha llevado a la necesidad de establecer diferentes medidas para estandarizar la afinación de los sonidos, y de manera práctica, ha ganado fuerza el uso del "Cent" como estándar para la medición de los intervalos que forman las diferentes frecuencias sonoras, sobre todo, en afinaciones no temperadas y/o fenómenos acústicos cuya medición no es práctica mediante el sistema temperado.

El "cent" como medida para la medición de intervalos entre frecuencias sonoras, fue propuesto por Alexander J. Ellis (1814-1890); 


\section{Capítulo II.- La tonalidad en la música.}

el cent comparándolo con el "semitono" de la escala temperada (relación de 84:89) es la centésima parte de este intervalo:

"Supongamos que en un piano (...) podamos intercalar 99 teclas entre cualquier tecla contigua, y que pudiéramos afinar estas en intervalos exactamente iguales, llamados cents, para que de esta forma 100 cents formen un semitono temperado"35.

Esta medida, propuesta por Ellis, se ha convertido en un "estándar" internacional, y utilizado para la medición de cualquier fenómeno acústico "no temperado", además de haber sido utilizado frecuentemente por compositores del siglo XX para la construcción de escalas propias.

Con el cent como herramienta, podemos ahora establecer de una forma un cuanto más práctica la afinación de las frecuencias secundarias o armónicas que acompañan a todo sonido. Los armónicos 1 (sonido generador o fundamental), 2, 4, 8 y 16 (relación de $1: 2 \mathrm{u}$ octava musical) no tienen variación con respecto al sistema de afinación temperada; los armónicos 3, 6, 12 (relación de 3:2 o quinta) tienen una variación de aprox. $+.45 \mathrm{~Hz}$. en comparación a la afinación temperada; los armónicos 5, 10 (relación de 5:4 o tercera mayor) varían -2.62 Hz., los armónicos 7 y 14 (séptima menor, relación 4:7) varían -7.61 Hz. de la afinación temperada, el armónico 11 (relación de $3: 4$ o cuarta justa) tiene una variación de aprox. $+22 \mathrm{~Hz}$. y el

35 ELLIS, J.A. "On the Musical Scales of Various Nations". The Garland Library of Readings in Ethnomusicology: A Core Collection of Important Ethnomusicological Articles, Vol. 7, London, 2006, p.3. 


\section{Capítulo II.- La tonalidad en la música.}

armónico 13 (sexta mayor, relación de 5:8 ${ }^{36}$ ) tiene una diferencia de aproximadamente $-23.5 \mathrm{~Hz}$. con respecto al sistema temperado. ${ }^{37}$

De la misma manera que la afinación temperada, la medición del sonido por cents obedece a una necesidad práctica, no resulta en una realidad física de la misma manera que la afinación temperada, no es un reflejo verdadero del comportamiento del sonido, ya que la afinación del mismo varía de acuerdo a múltiples circunstancias que pueden ir desde la temperatura, hasta el hecho de estar acompañado de otro instrumento y si este otro instrumento es de afinación fija o no. En mediciones cuidadosamente realizadas por Ellis, él mismo pudo observar cómo, en la práctica, la afinación que los cents predecían (por ejemplo, 1200 cents para una octava) no era real al momento de realizar las mediciones correspondientes en un instrumento musical; por dar un ejemplo que el mismo Ellis mide, y publicó en su tratado sobre afinaciones "On the Musical Scales of Various Nations".

Si tenemos la medida Cent como la centésima parte de un semitono, y la escala temperada occidental consiste en doce semitonos antes de llegar a la relación interválica de 1/2 (la octava musical, el mismo color tonal), entonces, en la teoría, nuestra escala temperada debería de resultar de la siguiente manera:

\footnotetext{
36 CONTI, L. "La entonación justa en la acústica de Helmholtz." Perspectiva Interdisciplinaria de Música, Vol.1 2006, No.1, México D.F., p.11.

${ }^{37}$ HELMHOLTZ, H. On the Sensations of Tone as a physiological basis for the Theory of Music. 3a ed. London: Longmans, Green and Co., 1895, p.22.
} 
1. Do

2. Do sostenido

3. $\mathrm{Re}$

4. Re sostenido

5. $\mathrm{Mi}$

6. $\mathrm{Fa}$

7. Fa sostenido

8. Sol

9. Sol sostenido

10. La

11. La sostenido

12. $\mathrm{Si}$

13. Do
0 cents

+100 cents

+200 cents

+300 cents

+400 cents

+500 cents

+600 cents

+700 cents

+800 cents

+900 cents

+1000 cents

+1100 cents

+1200 cents

Siendo la afinación de un instrumento algo relativo a las circunstancias que le acompañan, cuando Ellis comparó esta teoría con la práctica con diferentes ejemplos, en realidad en ninguno se cumplía con la predicción anteriormente descrita. En uno de los ejemplos de afinación más cercanos a la teoría, con una afinación de un piano de concierto, realizada por un afinador de la compañía "Broadwood", afinación realizada de forma expresa para el experimento, se obtuvieron las siguientes afinaciones en cents:

1. Do

2. Do sostenido

3. $\operatorname{Re}$

4. Re sostenido

5. $\mathrm{Mi}$

6. $\mathrm{Fa}$

7. Fa sostenido

8. Sol

9. Sol sostenido

10. La

11. La sostenido

12. $\mathrm{Si}$
0 cents

+100 cents

+200 cents

+300 cents

+395 cents

+502 cents

+599 cents

+702 cents

+800 cents

+897 cents

+999 cents

+1100 cents 


\section{Capítulo Il.- La tonalidad en la música.}

13. Do

+1200 cents

Creemos necesario remarcar, que la afinación fue realizada justo antes del experimento, y por la información brindada por Ellis en esta tabla, fue de forma excepcional; aún así existen discrepancias, sin embargo, en un piano afinado de esta forma, de manera pragmática, puede afirmarse que está bien afinado, y estas diferencias en afinación por cents son imperceptibles.

En una comparativa realizada en el mismo experimento, en un piano afinado en un lapso temporal corto, anterior al experimento, y no tocado hasta el momento de la medición, el resultado fue el siguiente:

1. Do

2. Do sostenido

3. $\operatorname{Re}$

4. Re sostenido

5. $\mathrm{Mi}$

6. $\mathrm{Fa}$

7. Fa sostenido

8. Sol

9. Sol sostenido

10. La

11. La sostenido

12. $\mathrm{Si}$

13. Do
0 cents

+96 cents

+197 cents

+297 cents

+392 cents

+498 cents

+590 cents

+700 cents

+797 cents

+894 cents

+990 cents

+1089 cents

+1201 cents

Obteniendo una diferencia aún mayor a la predicción dada por la teoría del "cent", estas afinaciones fueron realizadas en un instrumento considerado como de afinación temperada y fija, es posible afirmar a-priori que en un instrumento no temperado y de 


\section{Capítulo II.- La tonalidad en la música.}

afinación no fija, como sería un violín o la voz humana, las frecuencias exactas de cada nota son aún más relativas. El ejecutante de un instrumento, en la práctica musical, buscará la sensación de refuerzo tonal en cada frase musical, comparando esta sensación con la acústica de su propio instrumento, o de los instrumentos que suenan a su alrededor.

La concepción del tono, como fue establecido, es una sensación subjetiva, y a pesar de que la música, como materia artística, tiende a la imitación de la naturaleza, la misma es variable:

"El tono y la sensación del tono existen por sí mismos, y producen sus efectos de forma independiente al contexto". 38

Sin embargo, teniendo como herramienta el cent, es posible obtener una visión panorámica sobre diferentes tipos de afinaciones utilizadas tanto de forma tradicional por diferentes culturas no occidentales, como obtenidas de manera matemática y/o subjetiva por compositores de música occidental.

Un caso que ejemplifica una medida diferente de divisiones entre una octava es en la India, en la escala conocida por los occidentales como la "Hindú-Shruti", en la que nos encontramos con divisiones entre la "octava" musical que no coinciden con la escala temperada. La escala shruti, recibe su nombre por la división

\footnotetext{
${ }^{38}$ HELMHOLTZ, H. On the Sensations of Tone as a physiological basis for the Theory of Music. 3a ed. London: Longmans, Green and Co.,1895, p.3.
} 
interválica de lo que es considerado en la cultura hindú como la “octava", la cual no está en una relación exacta de 2:1 ${ }^{39}$. El shruti en términos prácticos, en la música hindú sería el equivalente al semitono en la música occidental, el intervalo más chico en la escala, que divide a la "octava" en 22 shrutis, de la siguiente manera:

1. diferencia de cero cents como el unísono.

2. diferencia de 90.226 cents.

3. 111.732 cents a partir de la tónica.

4. 182.4038 cents a partir de la tónica.

5. 203.9100 cents a partir de la tónica.

6. 294.1351 cents a partir de la tónica.

7. 315.6414 cents a partir de la tónica.

8. 386.3139 cents a partir de la tónica.

9. 407.8201 cents a partir de la tónica.

10. 498.0452 cents a partir de la tónica.

11. 519.5515 cents a partir de la tónica.

12. 590.2239 cents a partir de la tónica.

13. 611.7302 cents a partir de la tónica.

14. 701.9553 cents a partir de la tónica.

15. 792.1803 cents a partir de la tónica.

16. 813.6866 cents a partir de la tónica.

17. 884.3591 cents a partir de la tónica.

18. 905.8654 cents a partir de la tónica.

19. 996.0905 cents a partir de la tónica.

20. 1017.596 cents a partir de la tónica.

21. 1088.269 cents a partir de la tónica.

22. 1109.775 cents a partir de la tónica. ${ }^{40}$

\footnotetext{
${ }^{39}$ En el caso de la música occidental, recordemos que en términos prácticos esta condición dada por la teoría de que la octava o repetición del color tonal esté en la relación exacta del doble en medición de frecuencia, no se cumple cabalmente en la práctica. (N. del A.)

40 LAFUENTE, H. "Microtonalismo y afinaciones alternativas" [en línea]. Disponible en: http://www.apocatastasis.com/microtonalismo-afinacionesalternativas.php\#axzz0kdwIsEat [Consulta: 31 Diciembre 2010].
} 


\section{Capítulo II.- La tonalidad en la música.}

Lo anterior nos da una diferencia de afinaciones importante comparándolo con la escala occidental, por ejemplo, en la escala bien temperada, si tomamos como referencia la nota "La" afinada a 440 Hz. (estándar actual de afinación para la orquesta), su próximo semitono se encontrará en 466.16 Hz., sin embargo, si construyéramos la escala a base de shrutis, a partir del mismo tono (440 Hz.) su próximo intervalo (el shruti) se encontrará a 463.54 Hz., una medida más chica.

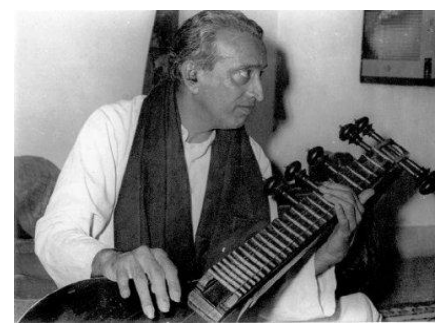

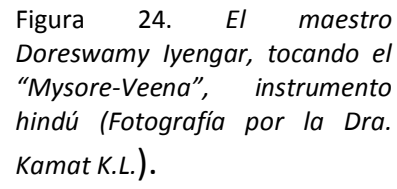

Además, hipotéticamente, el siguiente semitono en la escala temperada, tomando como referencia la misma nota, se ubicará en la frecuencia de $493.88 \mathrm{~Hz}$., manteniendo un temperamento igual, o una diferencia de 100 cents entre cada semitono, sin embargo, el siguiente shruti no estará en la misma proporción que el anterior, y se ubicará en la frecuencia $469.33 \mathrm{~Hz}$., ampliando la diferencia con los semitonos occidentales.

En el caso de la música Javanesa, la división de la octava fue conceptualizada por compositores occidentales como de seis tonos, una división de la relación $1 / 2$ en seis divisiones considerablemente amplias. La influencia de la escala musical javanesa en la música occidental ha sido considerable, uno de los primeros compositores 
occidentales de trascendencia en utilizar una conceptualización de la misma, fue el compositor francés Claude Debussy (1862-1918), quien tuvo la oportunidad de escuchar una agrupación de música javanesa en 1889 durante la exposición internacional en París. Debussy tradujo las divisiones no temperadas javanesas y las conceptualizó como divisiones de un tono (dos semitonos, 200 cents) de la escala bien temperada, utilizando esta escala en su obra para piano "Voiles" (publicada en su primer libro de "Preludios" en $1909^{41}$ ), así como en varias de sus obras para diferentes instrumentaciones.

La escala Javanesa, ejecutada por los instrumentos tradicionales de Java, funciona de la siguiente manera: Tomando el unísono como una diferencia de 0 cents, el siguiente intervalo se encuentra a +240 cents, más alto que la correspondencia con el intervalo de la escala temperada por una diferencia de aproximadamente $10.28 \mathrm{~Hz}$., el siguiente intervalo está a 484 cents de la tónica, luego a 728 cents, a 960 cents y a 1200 cents (la repetición del color tonal).

Esta escala es una de las muchas escalas ejecutadas por los músicos javaneses, y es la más cercana a la adoptada por Debussy y múltiples compositores occidentales, realizando un temperamento de la misma para poder ser ejecutada en instrumentos occidentales. La manera más común de ejecutarse esta escala en la música occidental es dividiendo la octava musical en seis tonos sucesivos, diferencias

${ }^{41}$ DEBUSSY, C. Complete Preludes. New York: Dover, 1989, p. 3. 


\section{Capítulo II.- La tonalidad en la música.}

iguales de 200 cents o aproximadamente $94 \mathrm{~Hz}$. entre cada tono escuchado, y se le ha llamado como la escala "Hexáfona".

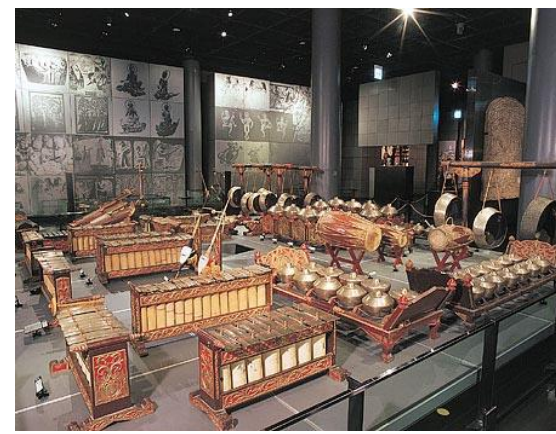

Figura 25. Instrumentos de música javanesa para un ensamble "Gamelan" (metalófonos percutidos) instrumentos construidos para poder ser ejecutados juntos, con la misma afinación. Museo Nacional de Etnologia "Minpaku" en Osaka.

Realizando una comparativa entre la escala como es ejecutada de forma tradicional en instrumentos nativos de Java, y como se acostumbra a ejecutar en instrumentos occidentales, tendríamos las siguientes diferencias:

Ejecutada en instrumentos tradicionales de Java, como nos remarca Alexander Ellis, cuando pudo escuchar las agrupaciones javanesas en Londres en 1882, es una escala de cinco sonidos, o Pentáfona:

1. 0 cents

2. +240 cents

3. +484 cents

4. +728 cents

5. +960 cents

6. +1200 cents

Ejecutada en instrumentos temperados occidentales, imitando el efecto javanés, con una resultante de seis sonidos:

1. 0 cents 
2. +200 cents

3. +400 cents

4. +600 cents

5. +800 cents

6. +1000 cents

7. +1200 cents

En China es de común uso la escala denominada como Pentáfona, (diferente a la pentafonía tradicional javanesa) por el uso tradicional de cinco notas. Aún en nuestros días, como occidentales, es amplia la creencia que estas cinco notas podían coincidir con intervalos del temperamento occidental, tocando en un piano, las notas "Fa sostenido", "Sol sostenido", "La sostenido", "Do sostenido" y "Re Sostenido" y a continuación la repetición del color tonal con el "Fa sostenido" al doble de Hertzios del original.

Sin embargo, al realizar mediciones en cents, de la ejecución de músicos tradicionales de China en instrumentos autóctonos, nos encontramos con diferencias importantes, ya que usan intervalos que no coinciden con los intervalos dictados por el sistema temperado de afinación, ni sus proporciones como son dictadas.

Alexander Ellis realizó mediciones en diferentes instrumentos autóctonos de la China, midió los intervalos de la flauta Ti-tsu, una flauta traversa de siete agujeros, que era utilizada de forma orquestal, y los instrumentos de cuerda se afinaban a ella, con la posibilidad de ejecutar siete intervalos diferentes, el resultado era el siguiente:

1. 0 cents

2. +178 cents 


\section{Capítulo II. - La tonalidad en la música.}

3. +339 cents

4. +448 cents

5. +662 cents

6. +888 cents

7. +1103 cents

8. +1196 cents

Resultado que, aunque se aproxima a nuestra escala temperada, contiene importantes diferencias.

En Japón, existe sinnúmero de escalas tradicionales con diferentes afinaciones no temperadas, siendo algunas, incluso específicas de ciertos instrumentos y/o regiones del país. Se han realizado algunas mediciones del Koto, especie de arpa tradicional japonesa, considerada como el instrumento nacional del Japón, que se ejecuta con uñas, y el modelo tradicional consta de 13 cuerdas, de la misma longitud, tensión y diámetro, a los que se les colocan diferentes “capos" movibles (especie de puentes de madera para cambiar la tensión de las cuerdas), para poder realizar diferentes escalas.

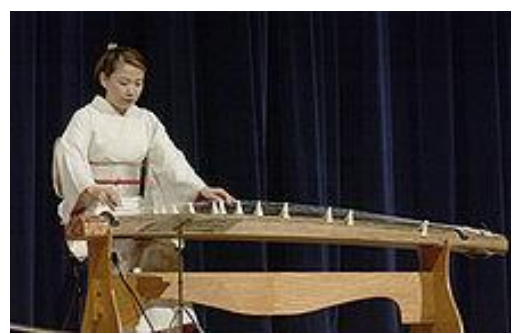

Figura 26. Ejecutante de Koto.

En el Koto, solo cinco cuerdas dan diferentes notas, siendo las restantes unísonos (diferencia de $0 \mathrm{~Hz}$.) u octavas (diferencias de $\mathrm{x}$ Hz. por dos, o $1 / 2$ en la proporción), si consideramos solo las 
primeras siete cuerdas del Koto, nos encontramos con que la quinta cuerda es una repetición de las frecuencias de la primera, dando a esta la sensación del mayor refuerzo tonal, y utilizada frecuentemente de manera cadencial con la segunda cuerda. En una de las muchas afinaciones del Koto, nos encontramos la siguiente:

1. Primera cuerda: +683 cents de la segunda cuerda.

2. Segunda cuerda: como centro tonal, cero cents de diferencia consigo misma.

3. Tercera cuerda: +185 cents de la segunda cuerda.

4. Cuarta cuerda: +337 cents de la segunda cuerda.

5. Quinta cuerda: +683 cents de la segunda cuerda.

6. Sexta cuerda: +790 cents de la segunda cuerda.

7. Séptima cuerda: +1200 cents de la segunda cuerda.

Esto en realidad es una mera aproximación al mundo enorme de las diferentes afinaciones tradicionales. Como podemos ver, en realidad, la afinación es un fenómeno artificial y muchas veces caprichoso además de adaptable, como en el caso de las escalas conocidas como Hexáfona y Pentáfona, que son imitadas en instrumentos temperados occidentales. Parece haber coincidencias, en la mayoría de las escalas, aun en las tradicionales no temperadas, encontramos la aproximación a la octava o repetición del color tonal al doble aproximado de vibraciones por segundo o Hertz, se puede conjeturar que en todas las culturas existe el conocimiento empírico del fenómeno de los armónicos o frecuencias secundarias de todo sonido, y como, la frecuencia más repetida en los armónicos es la relación del doble de la frecuencia original, (siendo esta, además, la 
Capítulo II.- La tonalidad en la música.

que provee la sensación de mayor refuerzo tonal), encontramos la imitación del fenómeno natural, también en todas las culturas. 


\section{La tonalidad en la pintura.}

El concepto de la tonalidad en las artes visuales, hace referencia a la idea del color que predomina sobre los demás en un cuadro (un espacio bidimensional determinado) o en un espacio tridimensional. Además, de manera similar al concepto del tono en la música, la tonalidad contribuye a definir el estilo de un pintor, o de un cuadro en particular. La tonalidad de un espacio puede ser definida por su "temperatura" por colores fríos o cálidos; por los colores que predominan: tonalidades doradas o verdosas, rojizas o azuladas; por variaciones de los grises, tonalidades brillantes u oscuras; y todo este conjunto de características no solo nos sirven al público para poder definir lo que vemos, sirven primordialmente al creador para proponernos mundos de combinaciones lumínicas que funcionan como portadoras de sensaciones e ideas.

De una forma más precisa, el "tono" en la pintura, también hace referencia a una cualidad específica del pigmento utilizado, Cuando se colorea un cuadro o un espacio, se utilizan "materias muertas" para poder crear la sensación del color, para conseguir estos fines, el creador utiliza tierra, arcilla, tintas, químicos y diversos materiales para capturar parte del espectro lumínico y reflejar solo la parte que le interesa que el espectador "vea".

Como una cualidad o característica del pigmento específico a utilizar, el artista visual hace referencia al "tono" que necesita de cada 


\section{Capítulo III.- La tonalidad en la pintura.}

pigmento o color, desde este punto de vista, el tono del pigmento hace referencia a la "luminosidad" del color utilizado. Mediante experimentos realizados con la luz, se llegó a la comprensión de que la luz contiene en sí misma todos los colores, y cuando trabajamos con pigmentos en las artes visuales, la unión de todos los colores es representada por el blanco; de la misma manera, la falta de luz, lo que conocemos como oscuridad, es la ausencia de color, ya que no podemos percibir color alguno cuando no hay una fuente lumínica que permita que los objetos a nuestro alrededor reflejen parte del espectro de colores. En el arte visual, la ausencia de color es representada por el negro, de esta forma, el tono en la pintura representa la cantidad de luz (blanco) u oscuridad (negro) presente en cada color utilizado; podemos hablar de varios tonos de rojo o de azul, y con esto estamos mencionando la cantidad de blanco ò de negro presente en el pigmento utilizado.

De esta manera, tenemos como otro uso del concepto del tono el "color" específico a utilizar, hay diferentes "tonos" de azul, y para determinar de forma más o menos exacta el pigmento o tinta a utilizar se han realizado diferentes sistemas de notación de colores en el mundo, los cuales parten de diferentes parámetros para su notación. Estos sistemas de colores, conforman lo que hoy en día conocemos como la teoría del color, y la combinación de los diferentes colores, utilizados en forma específica de acuerdo a los estándares existentes que se han establecido para determinar los diferentes parámetros que 


\section{Capítulo III.- La tonalidad en la pintura.}

aplican al color, y conforman lo que conocemos como la Armonía en el color.

Uno de los primeros y más trascendentes intentos de crear un estándar en cuanto a "tonometría" fue realizado por Chevreul ${ }^{42}$ (17861889) químico francés, que estableció 22 tonos, desde el blanco al negro, realizando lo que conocemos ahora como la "escala de grises". Actualmente, la división de la escala de grises en 22 tonos diferentes, no es utilizada comúnmente, ya que al obtener una escala de forma tan detallada, el contraste entre cada uno de los tonos es apenas perceptible para el hombre; para los fines usualmente perseguidos por las artes visuales, se utiliza una escala de aproximadamente diez tonos diferentes entre el blanco y el negro, obteniendo de esta manera un contraste más fácilmente perceptible para la vista, y cuando se vuelve necesario, se utilizan los denominados "semitonos" o los colores grises que se encuentran entre los establecidos por el "tonómetro" utilizado.

Albert Henry Munsell (1858-1918) alumno y posteriormente profesor del "Colegio de Arte de Massachusetts" en Boston, creó un sistema de denominaciones para el color, que ha ganado enorme aceptación hasta nuestros días. Mediante "árboles" tridimensionales de colores, creó una nomenclatura mucho más exacta para determinar el tono, así como las diferentes cualidades de un color. Munsell distingue tres términos como fundamentales en su clasificación:

${ }^{42}$ SALA, E. Gramática del color. Valencia: Instituciò Alfons el Magnànim, 1999 , p. 27. 


\section{Capítulo III.- La tonalidad en la pintura.}

1. Chroma: Del griego "color", y utilizado actualmente como “intensidad". Munsell lo define como: "El grado de partida de una sensación de color desde la intensidad del blanco o el gris, la intensidad de un tono distintivo".

2. Hue: Tono o Matiz, "Específica y técnicamente, el aspecto en que el rojo, verde, amarillo, etc. difieren uno de otro, a pesar de poseer la misma luminosidad y Chroma".

3. Value: Valor "En la pintura y las artes afines, la relación de un objeto, parte o plano de una imagen en la atmósfera, con las demás en referencia a la luz y sombra" ${ }^{43}$.

Esto nos remite a mencionar la definición de "luminosidad" dada por el mismo autor: "Luminosidad, en concreto, la intensidad de la luz en un color",44.

Munsell define esta intensidad de la luz en un color como la diferencia entre una luz estandarizada, medida fotométricamente hasta que es igualada con la luz del color en cuestión. Estas medidas las plasmó en planos tridimensionales que nombró “Atlas de color", y siguen siendo el estándar en varios países. En estos "Atlas" el "Valor" o lo que el pintor valenciano Emilio Sala nos describe como "tono" 45 está representado por el eje de este "árbol" de colores, y estandarizado en valores del 0 (como el negro) al 10 (como el blanco).

\footnotetext{
${ }^{43}$ MUNSELL, A.H. A color notation. Boston: H. Ellis co.,1905, pp 75-80. ${ }^{44}$ Ídem.

${ }^{45}$ SALA, E. Gramática del color. Valencia: Instituciò Alfons el Magnànim, 1999 , p. 26.
} 


\section{Capítulo III.- La tonalidad en la pintura.}

Alrededor de este eje, tenemos 20 "aspas" de matices (lo que comúnmente interpretamos como el color), cada una de las cuales representa su "Chroma" o intensidad por el grado en el que se aleja del eje, el grado en que es más intenso el color, más puro. De forma estandarizada, el "Atlas" de Munsell, contiene alrededor de 427 muestras diferentes de colores, una pequeña muestra de las posibilidades de pigmentación que el hombre ha conseguido para poder realizar una imitación de la sensación del color que crea la naturaleza. Actualmente, gracias a las posibilidades de notación del “espacio de color Munsell” se han podido determinar con exactitud, no solo los colores posibles de ser elaborados en la industria del color, además, podemos conocer los posibles colores ideales, que conforme la técnica de elaboración de colores en la industria avance, podremos conseguir; por dar un ejemplo, a pesar que el espacio de color de Munsell parte de un eje de grises con valores del 0 al 10 en este momento, la industria de colores Munsell oferta un abanico de 31 grises con valores desde el 0.5 (casi negro) al 9.5 (casi blanco) pasando por valores de cuarto de tono entre cada paso, de forma estandarizada, ya que, gracias al establecimiento de un sistema de notación colorística, es posible obtener de forma física incluso los octavos de tono de grises que sean requeridos.

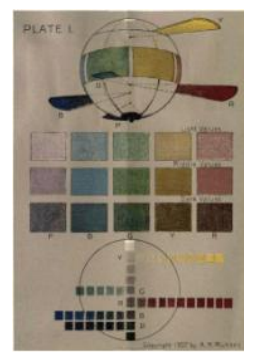

Figura 27. "Atlas" de color de Munsell. MUNSELL, Albert Henry: Color Balance Illustrated (Boston: Ed. H. Ellis Co., 1913, s.p.). 


\section{Capítulo III.- La tonalidad en la pintura.}

La notación del color de acuerdo a Munsell, parte de los tres parámetros definidos anteriormente, el "Croma", "Valor", y "Matiz"46, de esta manera, para ordenar un color de ciertas características empleamos la siguiente nomenclatura: $\mathrm{Hv} / \mathrm{C}, \mathrm{H}$ por "Hue" o Matiz, V por el valor, C por el Croma, si queremos un rojo como el presente de forma oficial en las franjas rojas de la bandera estadounidense, realizamos el pedido en clave Munsell como 5r3/14; 5r es el matiz, el color rojo; 3 el valor o luminosidad, ligeramente oscuro; y 14 la saturación del color, en este caso, un rojo muy saturado, bastante alejado del eje de grises ${ }^{47}$.

El espacio de color tridimensional de Munsell, representa hasta nuestros días uno de los intentos más valiosos en el establecimiento de un estándar para la definición del tono en el color, y ha sido el punto de partida para numerosos sistemas de notación del color posteriores, como: El sistema de notación NCS (Sistema de Color Natural, por sus siglas en inglés) desarrollado por laboratorios escandinavos, el sistema Pantone, o el sistema CIELAB; sistemas de color que se han convertido en fundamentos de la teoría del color que rige en nuestros días. El tono por la forma en que es utilizado en las diferentes disciplinas visuales, es en realidad una cuestión de cómo manejó el artista la luz, el fenómeno visual y la percepción humana del mismo, así como las combinaciones que la descomposición de la luz le

\footnotetext{
${ }^{46}$ MUNSELL, A.H. Color Balance Illustrated. Boston: H. Ellis co., 1913, p 5.

${ }^{47}$ MUNSELL, A.H. A color notation. Boston: H. Ellis co., 1905, p. 21.
} 
Capítulo III.- La tonalidad en la pintura.

permiten; es además, la manera en que un "color" es definido en forma específica y los parámetros utilizados para su definición. 


\section{1 ¿Qué son los colores?}

Los colores son sensaciones, no poseen una realidad objetiva, ni son una característica de la materia ${ }^{48}$, al igual que el sonido, dependen de varios factores, como el emisor de luz y el receptor de la misma; en particular, el color depende en grado fundamental del órgano receptor de luz, el ojo humano. Para fines prácticos, si nuestro ojo estuviera conformado de otra manera, como alguna de las especies marinas, o como los de otros mamíferos terrestres como los caninos, la sensación de color sería radicalmente diferente o incluso inexistente.

Esto nos obliga a abordar el problema de definición del color desde dos diferentes ángulos, a saber: La emisión de luz y la percepción humana de la misma; de manera similar al sonido, si no existen estos requisitos, no podemos aseverar que la "sensación del color" existe.

El color es una respuesta del cerebro, aun más que el puro fenómeno del color, "el fenómeno visual no ocurre en los ojos, sino en el cerebro del hombre" 49 ,mediante un proceso en el que se ven involucrados el espectro lumínico, el órgano de la vista y la interpretación a nivel neurológico de lo que es observado. Además, el

\footnotetext{
${ }^{48}$ TAYLOR, E.J. Colour-sense training and color using. London: Blackie \&Son, 1908 , pp. 15 y 16 .

${ }^{49}$ VV.AA. Luz y visión. México D.F.: Time Life, 1976, p. 75.
} 


\section{Capítulo III.- La tonalidad en la pintura.}

color se ha utilizado a través de la historia como un símbolo ${ }^{50}$, y el contexto psicológico del mismo, afecta también la percepción del color y las connotaciones que este tiene de acuerdo al contexto en el que es presentado.

Al hablar sobre la manera en que la sensación del color es producida, veremos que el primer requisito necesario para producir el color es la luz, en un principio, las ondas de energía irradiadas por el sol.

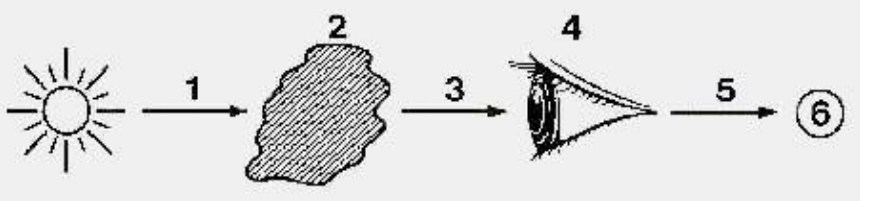

Figura 28. Esquema de producción de la "sensación del color". (1) La luz cae sobre un objeto (2) Parte de la luz es absorbida por el objeto causando que su temperatura aumente, (3) la parte no absorbida de la luz es reflejada (4) El órgano receptor, el ojo humano, es impactado por la luz reflejada (5) y transmitida por medio de impulsos eléctricos a los nervios y de estos al cerebro; (6) Los datos proporcionados por medio de impulsos eléctricos son traducidos en imagen tridimensional y multicolor.

Las ondas de energía lumínica son medidas en "Nanómetros", un nanómetro es una milmillonésima parte de un metro, aquellas que se encuentran en una distancia de 380 a 780 nanómetros son las que llamamos "Luz", ya que son estas las que podemos percibir por medio de nuestro órgano de visión, son las que nos producen la sensación de "ver". Esta medida no es la totalidad de la irradiación de la luz solar, es únicamente la que puede ser captada por el ojo humano, es lo que

\footnotetext{
${ }^{50}$ CALERO P.G. La música del color y el color del sonido. Málaga: Maestro, 2006, p.43
} 


\section{Capítulo III.- La tonalidad en la pintura.}

conocemos como el "espectro visible", en realidad la radiación solar, abarca desde frecuencias altísimas, que conocemos como "microondas", hasta las ondas "ultravioleta" y "rayos gamma", todo este conjunto de frecuencias es lo que conocemos como "espectro electromagnético", y lo que conocemos como luz, se encuentra entre las ondas "infrarrojas" y las "ultravioleta". En los límites de nuestro espectro visible, se encuentra el rojo como las ondas de luz que terminan en 780 nanómetros, y las ondas de luz más cortas del espectro visible las conforman las que conocemos como violeta, que terminan en 380 nanómetros.

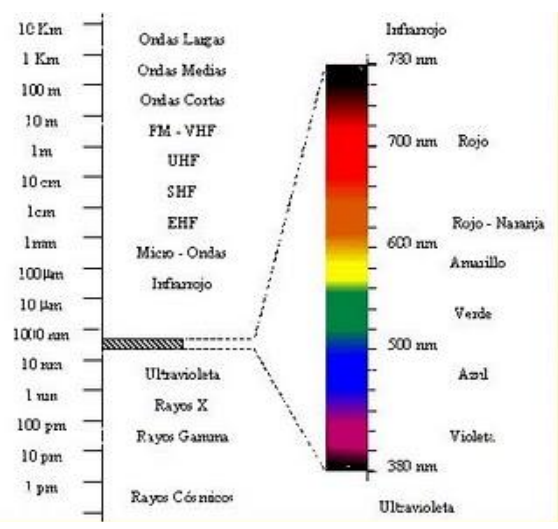

Figura 29. El espectro electromagnético.

El espectro electromagnético ha podido ser mesurado gracias a la capacidad de absorción del mismo que presenta la materia, el espectro electromagnético es energía, y la materia tiene la capacidad de absorberla, es gracias a este fenómeno que podemos medir la radiación solar mas allá de lo que nuestro sentido de la vista permite y podemos percibir o medir los efectos del espectro electromagnético. A una frecuencia más alta que las ondas infrarrojas, se encuentran las 


\section{Capítulo III.- La tonalidad en la pintura.}

"microondas", con las que se han encontrado múltiples aplicaciones en la industria de electrodomésticos y la investigación científica. Sabemos que tenemos que cuidarnos de exposiciones prolongadas a los rayos del sol ya que, el absorber las ondas ultravioleta puede ser perjudicial para nuestra salud.

Tengamos en cuenta que la energía es incolora, es radiación, nuestro concepto del color es el que está relacionado con el espectro visible, en concreto, el que la materia refleja y el ojo humano puede ver, es parte de la misma energía que nos calienta y nos previene de morir congelados, pero no absorbemos toda la energía que recibimos, y tampoco lo hace ningún material sobre la tierra, de ser así, no podríamos verla, probablemente veríamos una especie de inquietante forma negra. Las consecuencias de este fenómeno son grandes, sabemos que la luz no solo son ondas, también son partículas, lo que los físicos han expresado en la teoría cuántica que establece la dualidad onda/partícula para la luz, y esto, junto con el descubrimiento de que la luz viaja a una velocidad finita $(299,792$ kilómetros por segundo, mucho más rápido que el sonido), ha permitido establecer que la luz también es sometida por la fuerza de la gravedad. Cuando los astrónomos y físicos descubren un punto, que absorbe toda la luz que recibe sin reflejar nada, le llaman "agujero negro",51, pudiendo asegurar que no existe sobre la superficie terrestre.

${ }^{51}$ HAWKING S.W. Historia del tiempo. Barcelona: Planeta-Agostini, 1992, p. 121. 


\section{Capítulo III.- La tonalidad en la pintura.}

La luz reflejada por la materia y absorbida por nuestro ojo, es llamada "resto de luz",52, es este fenómeno el que impacta nuestra vista, el que posee la información que a-posteriori podremos llamar color; sin embargo, este "resto de luz" no es el color, a pesar de que el espectro visible contiene la información en frecuencias que nos permite asignar "colores" a cierto número de frecuencias, esto no significa que de manera fija esto cree los colores, esto queda demostrado por múltiples efectos ópticos, entre ellos el llamado "contraste simultáneo", en el que un color que se encuentre rodeado por otro color, nos crea la sensación de un cambio en su tono, ya que se "funde" punto de color, de exactamente el mismo tono, y cada uno de estos puntos lo rodeamos por colores diferentes, esto nos creará la ilusión de que los dos puntos de color que han sido rodeados, poseen tonos distintos.
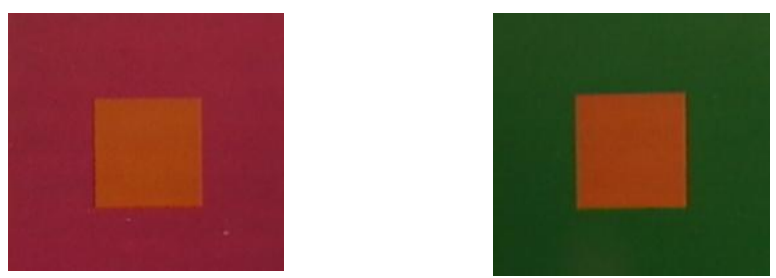

Figura 30. Contrastes Simultáneos. (WONG, Wucius: Principios del diseño en color, Ed. Gustavo Gili, Barcelona 1988, p. 53).

Lo mismo ocurre con la luz en un espacio tridimensional, la sensación que la luz produce se encuentra con un sinnúmero de

\footnotetext{
${ }^{52}$ KÜPPERS H. Fundamentos de la teoría de los colores. Barcelona: Gustavo Gili, 1980 , p. 103.

${ }^{53}$ WONG W. Principios del diseño en color. Barcelona: Gustavo Gili, 1988, p. 53.
} 


\section{Capítulo III.- La tonalidad en la pintura.}

"peculiaridades", como el adagio popular de que "el negro adelgaza", cuando usamos prendas de color negro para vestirnos, ya que el contraste del negro que nos viste, con la luz que nos rodea, tendrá el efecto de crear la sensación de que nuestra figura es recortada por la luz.

Todas estas peculiaridades de la luz, respaldan la idea de que la sensación del color, tiene como base la interpretación que el cerebro realice sobre el resto de luz que impacta nuestra retina.

Las frecuencias del espectro visible que poseen la información que traduciremos a la sensación de color, medidas en nanómetros (nm.), son:

1. Azul: a $450 \mathrm{~nm}$.

2. Verde: a $520 \mathrm{~nm}$.

3. Rojo: a $629 \mathrm{~nm}$.

En medidas aproximadas, entre el azul y el verde, a $490 \mathrm{~nm}$. aprox. se encuentra el cyan, y entre el verde y el rojo, a $580 \mathrm{~nm}$. aprox. el amarillo; a una frecuencia menor que el azul y aprox. a 380 nm. encontramos el violeta.

Además de esto, el cerebro humano, produce la sensación de percibir más colores de los que recibe, cuando se mezclan diferentes partes del espectro visible, y percibimos los colores que conocemos como secundarios o terciarios, que son los que resultan de la combinación de los tres colores antes establecidos como "principales" 


\section{Capítulo III.- La tonalidad en la pintura.}

en el espectro visible y que comúnmente conocemos como primarios cuando hablamos de la luz: el azul, el verde y el rojo. Cuando combinamos diferentes espectros de la luz, "obtenemos" sumas de frecuencias, casi a la manera de los armónicos en el sonido, y es por esto que a la obtención de colores "nuevos" por combinar diferentes haces de luz, se le conoce como síntesis "aditiva", el equivalente a sumar; por otro lado, cuando combinamos pigmentos, en realidad estamos añadiendo "sustractores" a la mezcla, quitando partes del espectro visible para solamente obtener el resto de luz que nos dará el tono deseado, por esto se le conoce a la combinación de pigmentos, tintas, tierras, etc. como síntesis "sustractiva".

Durante la síntesis sustractiva de color, ocurren también peculiaridades, la primera que impacta a nuestra retina, es que si intentamos obtener el amarillo al combinar el azul y el verde, no obtenemos amarillo, como ocurre con la síntesis aditiva; el amarillo no lo obtenemos por sustracción combinando ninguno de los colores "primarios" de la síntesis aditiva, por lo cual, se le considera como parte de los colores "primarios" de la síntesis sustractiva, obteniendo de esta forma diferentes colores "primarios" en cada uno de los tipos de síntesis o procesos de combinación de color.

Esto ilustra brevemente algunos de los fenómenos conocidos del comportamiento de la luz, lo que podríamos considerar como el primer factor necesario para crear la sensación de color en el hombre, el segundo factor necesario es el ojo humano. El órgano de la vista en el hombre es realmente único en las especies animales, compartimos 


\section{Capítulo III.- La tonalidad en la pintura.}

un sinnúmero de características del órgano de visión con otras especies, en particular de los mamíferos, pero no podemos dejar de tomar en cuenta que por ejemplo, los canes, que son parte de los mamíferos, son ciegos al color. Nuestra percepción posible, por nuestro órgano de la vista, va más allá de la conformación del ojo en específico, abarca también la forma de nuestro cráneo y la situación geográfica de los globos oculares en el mismo.

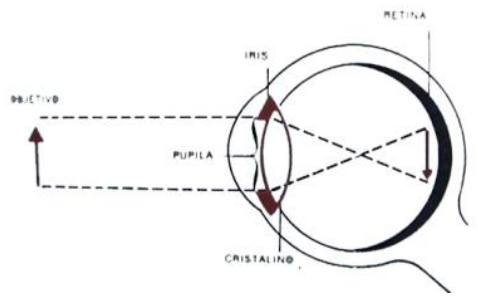

Figura 31. Esquema generalizado de la anatomía del ojo humano.

(V.V.A.A.: Luz y Visión. Ciudad de México:

Colección Científica de TIME-LIFE, Ed.

Offset Larios, 1976.p. 54).

El ojo humano, en un esquema generalizado, se compone de numerosas partes, que funcionan de forma mecánica como una cámara fotográfica.

El primer componente del ojo en ser impactado por la luz es la "Córnea", que consiste en una membrana transparente que cubre el ojo por delante hacia fuera, por supuesto, es una superficie curva (en un ojo sano), gracias a esto, la Córnea actúa como un lente convexo desviando los rayos de luz a un solo punto. Justo después de la Córnea encontramos el "Iris", un círculo de color que se dilata y contrae, casi a la manera de un diafragma de cámara fotográfica, estas dilataciones y contracciones sirven para regular la cantidad de luz que atravesará la 


\section{Capítulo III.- La tonalidad en la pintura.}

"Pupila", agujero que se encuentra en el centro del Iris, usualmente lo percibimos como el círculo negro que se encuentra en medio del ojo, su función es dejar pasar la luz al "Cristalino".

El Cristalino es una esfera transparente cuya forma puede ser cambiada por el "músculo ciliar", estos cambios de forma que sufre el Cristalino, sirven para enfocar la luz de forma exacta en la Retina.

La "Retina" es una especie de red cuya función es similar a la del rollo fotográfico de una cámara análoga, esta "red" cubre totalmente la superficie interna del ojo, exceptuando el frente, en donde se encuentran el Cristalino, el Iris y la Pupila, que son el espacio que tiene que dejar pasar la luz. En la Retina, se encuentran los fotorreceptores del hombre, que semejan "líneas" o "bastoncitos" y los "conos", en el caso de la visión humana, se hace necesario de estos dos tipos de fotorreceptores por las diferentes condiciones de luz que nos afectan, los “conos” son más bulbosos, y sirven para ver en el día, los "bastoncitos", (de los cuales tenemos 18 veces más que "conos") sirven para la visión nocturna.

Estos fotorreceptores se encuentran distribuidos a través de toda la Retina, pero ocurre un fenómeno, que incide de forma directa en el mecanismo del ojo: la Retina tiene un "agujero" en la parte posterior, a este agujero se le llama "Fóvea" y concentra en sí, el mayor número de fotorreceptores en forma de "cono", la Fóvea es el punto de mayor agudeza visual, y su alcance es muy limitado, en promedio de unos quince centímetros cuadrados a dos metros de 


\section{Capítulo III.- La tonalidad en la pintura.}

distancia, y por eso, cuando queremos ver algo con atención, buscamos que este objeto se encuentre en el centro de nuestra visión. Ocurre otra peculiaridad, que atañe a los fotorreceptores y a la Fóvea: los fotorreceptores son en realidad el vínculo casi directo de la luz recibida por el ojo hacia el cerebro; en toda la periferia de la Fóvea, y distribuidos en la Retina, los fotorreceptores de forma de "bastoncito", se combinan con los de forma de "cono", y estos se conectan a las denominadas "Células Bipolares" y estas a las "Células Ganglionares" que son los siguientes eslabones hacia el "nervio óptico" que transmite la información al cerebro; en la periferia de la Fóvea, la combinación de los dos tipos de fotorreceptores no está conectada de forma directa a las Células Bipolares, varios fotorreceptores pueden estar conectados a una sola Célula Bipolar, y varias de éstas, a una sola Célula Ganglionar, a causa de esto, la información visual es menos precisa que en la Fóvea, en la cual, no solo se encuentran fotorreceptores de "cono" sino que, cada uno de ellos está conectado a una sola Célula Bipolar y a una sola Célula Ganglionar.

Los fotorreceptores con sus diferentes formas, también contribuyen a realizar una primera discriminación del color, los de forma de "cono" reaccionan mejor a las frecuencias de 520 a $700 \mathrm{~nm}$, en particular a las frecuencias de $629 \mathrm{~nm}$, la sección que va del verde al rojo del espectro visible de luz; en cambio, los fotorreceptores de forma de "bastoncito" a pesar de darnos una visión básicamente en 


\section{Capítulo III.- La tonalidad en la pintura.}

blanco y negro (pero más sensible a la oscuridad), reaccionan mejor a las frecuencias de 520 a $380 \mathrm{~nm}$. (Del verde al violeta) ${ }^{54}$.

Esta capacidad diferente de reacción de los fotorreceptores de acuerdo a su forma, afecta ya, como un primer filtro, la sensación del color que resultará después de ser interpretada por el cerebro, un ejemplo de esto lo encontramos al observar un color rojo y uno azul de la misma intensidad durante el día, y después observarlos en la noche, como los fotorreceptores de "cono" no funcionan durante las situaciones de luz nocturna, veremos como más brillante el mismo color azul que durante el día veíamos con la misma intensidad que el rojo, esto es porque los fotorreceptores de "bastoncito" reaccionan mejor a las frecuencias menores a $520 \mathrm{~nm}$. que es donde se encuentra el azul, en el espectro visible de luz.

Los fotorreceptores además, contienen "pigmento", tanto los "conos" como los "bastoncitos" del ojo humano, contienen lo que hoy conocemos como "Rodopsina" que es el pigmento visual de los fotorreceptores, y cosa curiosa, hay tres clases de pigmento en los fotorreceptores, uno que es más sensible al rojo, otro al verde y otro al azul.

Como hemos podido observar, la luz no solo es onda, también es partícula, estas partículas de luz son llamadas "Fotones", y esto reviste una gran importancia en el siguiente paso de creación de la sensación de color. En los fotorreceptores, se encuentra este

\footnotetext{
${ }^{54}$ VV.AA. Luz y visión. México D.F.: TIME LIFE, 1976, p.76.
} 


\section{Capítulo III.- La tonalidad en la pintura.}

"conjunto" de pigmentos de diferentes capacidades de sensibilidad a diferentes colores, cuando los Fotones de luz saturan alguno de los pigmentos encontrados en los fotorreceptores de la Retina o la Fóvea, se activa el paso de sustancias químicas, y mediante por un proceso electroquímico similar a la fotosíntesis de las plantas, dan energía a los fotorreceptores, que en ese momento, envían señales eléctricas a las células nerviosas y a través del nervio óptico, que constituye la unión de las Células Bipolares y Ganglionares, que llevan la información proporcionada al cerebro.

En el cerebro, podemos afirmar que ocurre la última discriminación e interpretación sobre el color, a pesar de que los fotorreceptores y el ojo humano en su conjunto, ya realizan algunos pasos en la interpretación de la sensación del color, podemos mediante sencillas demostraciones afirmar que la sensación de color es subjetiva, y depende en parte fundamental del cerebro humano y los procesos de memoria del mismo. Por ejemplo, si proyectamos sobre una pantalla naranja un cuadrado azul, una persona con vista normal dirá que el cuadrado es gris, ya que al mezclar estos dos colores "complementarios" se anulan mutuamente produciendo un color neutro; sin embargo, si primero proyectamos este cuadrado azul en una pantalla blanca, el espectador normal lo verá azul, y si inmediatamente lo cambiamos a una pantalla naranja para el mismo espectador, este lo seguirá viendo azul.

El color tiene constancia, y es provocada por la memoria del hombre, tendiendo a ver los objetos que le son familiares del mismo 


\section{Capítulo III.- La tonalidad en la pintura.}

color sin importar el contexto en que le es presentado. A este fenómeno se le conoce como "memoria cromática", la cual funciona en ocasiones, pero no siempre, si vemos objetos familiares como ciertos alimentos bajo una luz azul, lo más probable es que no podamos reconocerlos como son realmente.

Investigadores desde el siglo XIX, como Helmholtz y Ewald Hering, han trabajado en teorías sobre la manera en que ocurre la interpretación del color a nivel nervioso-cerebral, a pesar de trabajar desde teorías que en ocasiones resultan opuestas, es posible armonizarlas en una sola. Thomas Young, físico inglés (1773-1829) trabajó a partir de una teoría "tricromática" de la visión, y consideraba la imposibilidad de que en la retina existieran tantos tipos diferentes de fotorreceptores como colores existen en el mundo, y por tanto, de manera similar a como ocurre en un aparato de televisión, la retina realizaba la mezcla de colores $^{55}$. Helmholtz reescribió la teoría de Young tiempo después, incluyendo la idea de que los fotorreceptores son estimulados (de entre todos), como de forma más importante por un solo color, y de manera secundaria por los otros, lo cual produciría la sensación de una mezcla en la retina.

Ewald Hering, fisiólogo alemán (1834-1918) formuló una teoría que contradice en aspectos fundamentales la idea propuesta por Young y rescatada por Helmholtz. Hering subrayó la subjetividad psicológica de la sensación de color; como punto de partida, Hering

\footnotetext{
55 YOUNG T. Ouvres Ophtalmologiques. Copenhague: Andr.Fred. Höst \& Son, 1894, pp. 222- 224.
} 


\section{Capítulo III.- La tonalidad en la pintura.}

no solo parte de cuatro colores elementales, sino del hecho que el sistema visual del hombre parece actuar de acuerdo a términos de pares de colores y su semejanza u oposición.

Actualmente, hay una "armonización" de ambas teorías, se considera que la visión cromática, la sensación de color, ocurre en dos etapas, se concuerda con la teoría Young-Helmholtz en cuanto los fotorreceptores y lo que ocurre en la retina, de alguna manera, es en esta que se elabora la visión "tricromática", y esta es traducida en señales bicolores (Hering) por cada una de las células Ganglionares que se transmiten al área ocupada de los estímulos visuales en el cerebro. 


\section{Capítulo III.- La tonalidad en la pintura.}

\subsection{Teoría del color}

En el ramo de la óptica, en particular, entendemos que no fue sino hasta después de los experimentos y descubrimientos que Isaac Newton (1643-1727) realizó sobre la descomposición del espectro visible con prismas, así como en la anatomía humana, y la percepción de la luz en el hombre, que comenzó a esbozarse una teoría del color con bases científicas comprobables. La teoría del color, como la búsqueda de fundamentos que expliquen la sensación del color y las mezclas resultantes de la luz y los pigmentos. Encontrando que esta puede ser rastreada hasta el mundo antiguo, en especial, con los filósofos griegos, que por medio de recursos derivados de la observación y deducción del fenómeno natural, iniciaron los cimientos de lo que conocemos ahora como las leyes que rigen la mezcla de la luz y los pigmentos y/o tintas.

Algunas de ellas realmente valen la pena de ser mencionadas, no solo por la "visión intuitiva" que poseen, sino porque reflejan además, la inquietud, el "sentir" de una relación de estímulos entre la luz y el sonido, y cómo ambos fenómenos dependían en un grado fundamental, de la percepción e interpretación que se realizaba de ellos.

Aristóteles (384 A.C.-322 A.C.) filósofo griego, de trascendencia en los campos de la lógica formal, y cuyos intereses 


\section{Capítulo III.- La tonalidad en la pintura.}

abarcaron múltiples campos del pensamiento, como la percepción y la anatomía, en su libro "De Sensu et de Sensiti” afirma:

“(...) lo mismo que en el aire hay unas veces luz y otras veces oscuridad, de la misma manera en los cuerpos se hallan el blanco y el negro (...)".

Concepción errónea sobre el color, como quedó demostrado por el fenómeno de los contrastes simultáneos, el color no es, una propiedad de los cuerpos; sin embargo, son valiosas sus observaciones sobre la mezcla de los colores y la definición de un tono observable, de la misma fuente, nos dice:

“(...) en cuanto a los demás colores, vamos a pasarles revista a los modos según los cuales se forman. En primer lugar, puede hacerse que el blanco y el negro se yuxtapongan paralelamente de suerte que cada uno de ellos en particular se torne invisible a causa de su débil extensión y de que ya no se ve sino el resultado de esta yuxtaposición; ya no habrá ni el blanco ni el negro; ahora bien, puesto que es necesario que esto sea un color, y que no sea ninguno de los precedentes, será un color mezclado y que presente un aspecto de un género nuevo. Puede así comprenderse que haya otros colores además del blanco y del negro, que haya muchos de ellos. En efecto, sus relaciones proporcionales de yuxtaposición, (...) los colores engendrados de las relaciones más perfectas, como esto sucede también para los sonidos, parecen ser los más agradables" $" 56$.

Descrito lo anterior, nos lleva a la definición de un tono a través de la resultante de la mezcla, dicho en otras palabras, la frecuencia resultante o preponderante de la luz en un espacio determinado. De "Timeo" de Platón, nos llega una concepción que se

${ }^{56}$ DÈRIBÈRÈ, M. El color. México D.F.: Diana, 1967, p.22 


\section{Capítulo III.- La tonalidad en la pintura.}

acerca de manera asombrosa a la concepción actual del color como una sensación:

“(...) un cuarto género de impresiones, el cual comprende un gran número de variedades que hemos designado con el nombre general de colores, especie de llama que se escapa de los cuerpos y cuyas partes, al unirse simétricamente con la vista (que es una flama ella misma) producen la sensación"57.

Podemos comenzar a encontrar esbozos del concepto actual de los colores, como una sensación que resulta de la percepción del espectro visible que escapa de los cuerpos.

En nuestros días, la tonalidad de un espacio es definida como la frecuencia dominante del espectro visible percibido por el ojo humano, y el color como una sensación que depende en grado fundamental de la percepción y el contexto en el que es presentado. En el experimento en el que Newton pudo visualizar los componentes del espectro visible, por medio de la refracción de la luz a través de un prisma, se realizó un hito para la colorimetría o la medición del color; sin embargo, no olvidemos que el espectro visible realmente es energía, no colores, y que estos continúan siendo solo una sensación.

Para establecer una teoría del color, es fundamental la comprensión de la teoría de la percepción visual, así como del comportamiento de la luz y la interacción entre ambos fenómenos para

${ }^{57}$ DÈRIBÈRÈ, M. El color. México D.F.: Diana, 1967, pp. 23-24 


\section{Capítulo III.- La tonalidad en la pintura.}

la creación de la sensación del color, como dice Küppers: "La ley de la visión es la ley fundamental de la teoría de los colores" ${ }^{\text {} 58}$.

En el arte visual, la teoría del color representa las leyes para realizar la mezcla de luces o pigmentos que comúnmente conocemos como "primarios". Partiendo de la teoría del color de Newton, como la primera realizada a partir de una experimentación de carácter comprobable, conocemos que el espectro visible, en combinación con los pigmentos presentes en los fotorreceptores de la retina del ojo humano, contienen la información necesaria para realizar el proceso de creación de la sensación de color; en el espectro visible encontramos a diferentes frecuencias los colores rojo, naranja, amarillo, verde, azul y violeta; teniendo mayor intensidad el rojo, verde y azul. Y en los fotorreceptores del ojo humano, encontramos "pigmentos" rojo, verde y azul; los colores de la teoría tricromática de Young-Helmholtz.

Sólo los colores rojo, verde y azul, pueden combinarse en efectos lumínicos para obtener cualquier color, mas no los pigmentos, considerados como colores primarios por ser los que permiten obtener cualquier color a través de sus mezclas, y son: el rojo, azul y amarillo. Tenemos entonces que en la luz, al combinar el verde y el azul, obtenemos el color amarillo, sensación de color que no podemos obtener al mezclar los pigmentos anteriormente mencionados.

\footnotetext{
${ }^{58}$ KÜPPERS H. Fundamentos de la teoría de los colores. Barcelona: Gustavo Gili, 1980, p.22
} 


\section{Capítulo III.- La tonalidad en la pintura.}

Unida a la teoría tricromática de Young-Helmholtz, resulta importante la interacción con la teoría de Hering, que establece que el cerebro interpreta las señales de sensación de color, en términos de comparación de pares de colores. Estos pares de colores serían el rojoverde, azul-amarillo, y negro-blanco.

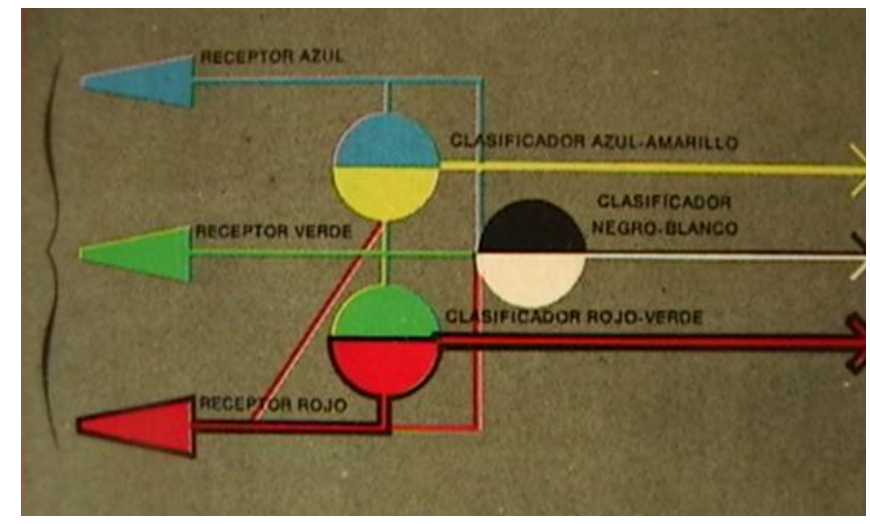

Figura 32. Esquema de la teoría Young-Helmholtz y Hering. Un receptor sensible al color capta una luz (a la izquierda) y envía un impulso a uno de los tres clasificadores de pares de colores que la absorben y descifran antes de transmitir la señal al centro visual del cerebro (V.V.A.A.: Luz y Visión. Ciudad de México: Colección Científica de TIME-LIFE, Ed. Offset Larios, 1976.p. 133).

Estos "pares de colores" pueden ser explicados por las zonas “compartidas" por las frecuencias correspondientes a los mismos colores en el espectro visible. El rojo y el verde tienen una zona compartida de frecuencias entre 560 y 600 nm., (comparten una zona aún mayor, pero este sería el punto de mayor intensidad en la mezcla), así como el azul y el amarillo entre 480 y $520 \mathrm{~nm}^{59}$.

\footnotetext{
${ }^{59}$ KÜPPERS H. Fundamentos de la teoría de los colores. Barcelona: Gustavo Gili, 1980, p.106
} 


\section{Capítulo III.- La tonalidad en la pintura.}

Basándose en las características propias de la sensación del color y los conocimientos de su época en anatomía y percepción, así como de las posibilidades de las mezclas de pigmentos, fue que Munsell propuso los tres parámetros que ya conocemos para determinar un tono en específico en el color, a saber: Matiz, Valor e Intensidad, escalonando el Valor del 0 (como el negro), al 10 (como el blanco), y la Intensidad, de forma variable en cada Matiz, de acuerdo a las posibilidades dadas por los pigmentos en cada color.

Curiosamente, los Matices (o coloquialmente, los "colores"), pueden ser determinados por las mezclas obtenidas ya sea por medio de sustracción (pigmentos) o adición (luz), de las teorías de la percepción humana del color, en concreto, las teorías YoungHelmholtz, y la de Hering. De la mezcla de los colores considerados como primarios, y los encontrados por Newton en el espectro visible, a través de su experimento con prismas, puede deducirse la propuesta de Matices existentes dictada por Munsell: Rojo, Amarillo, Verde, Azul y Morado $^{60}$ (que en el espectro visible es Violeta).

La propuesta de elegir los tres parámetros como Intensidad, Matiz y Valor, para los tonos de color, sigue vigente e implementada en posteriores teorías de color.

Un ejemplo de un espacio de color, realizado a partir de lo anteriormente descrito, es el conocido como "Sistema de Color Natural" (N.C.S. por sus siglas en inglés). que parte del "Atlas"o

\footnotetext{
${ }^{60}$ MUNSELL, A.H. A color notation. Boston: H. Ellis co., 1905, p. 85.
} 


\section{Capítulo III.- La tonalidad en la pintura.}

“Árbol” de colores de Munsell, y de la teoría de pares de colores de Hering, también designada como de colores opuestos, y funciona como un espacio determinado por dos pirámides cuyas bases están unidas formando un "rombo tridimensional”,y sus ángulos se colocan los colores primarios dictados por Leonardo da Vinci, Blanco, Negro, Azul, Amarillo, Verde Y Rojo ${ }^{61}$; el Blanco y el Negro funcionando como "Valores" a la manera de Munsell, formando un eje.

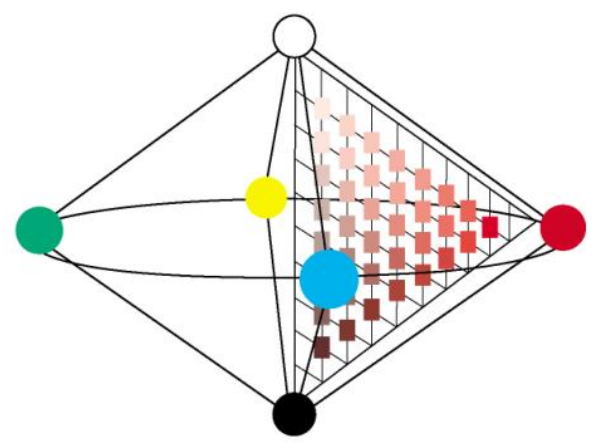

Figura 33. El "Espacio de color
NCS". En los puntos
cardinales los colores
primarios de da Vinci, con un
eje compuesto por los colores
blanco y negro, también
considerados como primarios,
sistema de similitudes y
diferencias entre colores
primarios.

El funcionamiento de este espacio puede considerarse como "relativista" a diferencia del "Atlas" de Munsell, el cual da valores absolutos basados en la colorimetría. El sistema NCS, funciona en términos de semejanza entre los colores, y su notación es designada por las letras siguientes: Blanco $=\mathrm{W}$, Negro $=\mathrm{S}$ (el eje de valores, del 0 al 10), Amarillo = Y, Rojo = R, Azul = B, Verde $=\mathrm{G}$.

Como una muestra del espacio tridimensional NCS, su círculo cromático de colores ("El circulo de colores NCS"), toma una muestra

61 DA VINCI, Leonardo. Trattato della pittura. Milano: Società Tipografica de'Classici Italiani, 1804, p. 76-II. 


\section{Capítulo III.- La tonalidad en la pintura.}

de la mitad del eje de valores, el valor 5 de "luminosidad", y divide cada cuadrante o espacio entre dos colores equidistantes en 100 partes iguales, la paleta de colores formada cada 10 pasos es la mostrada en el círculo de colores NCS. ${ }^{62}$

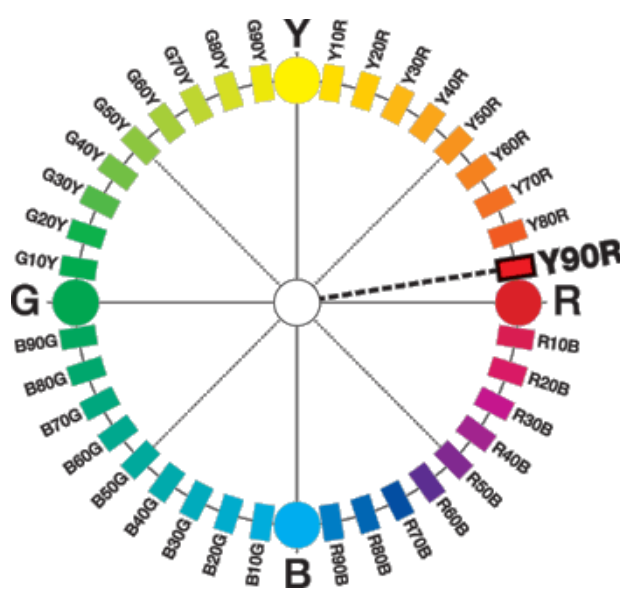

Figura 34. Circulo cromático de colores resultante del espacio de color NCS.

Para la exacta localización de un tono de color mediante este sistema, se elige la "paleta" o "Triángulo de Color NCS", colocando primero la letra que designa el color de partida ( $\mathrm{R}$ para rojo, B para azul, etc.) y el símbolo de sustracción para designar qué tan alejado está el "Triángulo de color" de la semejanza con el siguiente color equidistante, como en el siguiente ejemplo, cuyo triángulo de colores es el designado como “-Y90R”, partiendo del amarillo, diez pasos hacia el rojo.

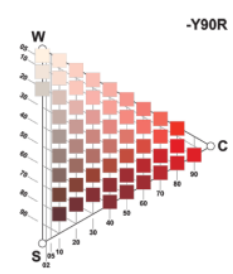

Figura 35. Uno de los "Triángulos de Color" del sistema NCS. EI

"Triangulo de Color -Y9OR"

\footnotetext{
${ }^{62}$ Scandinavian Colour Institute. "The NCS System.” [en línea]. http://www.ncscolour.com [Consulta: 31 Diciembre 2010].
} 


\section{Capítulo III.- La tonalidad en la pintura.}

Este sistema nos reporta las ventajas de poder designar a los colores de una manera parecida a la percepción humana, sin necesidad (aparente) de la utilización de herramientas de colorimetría o muestrarios de color, además de designar de una manera "cómoda" las mezclas resultantes de colores entre cada uno de los colores considerados como "primarios".

La "Comisión Internacional de Iluminación” (C.I.E., por sus siglas en francés), fundada en 1913, es considerada en numerosos países como la máxima autoridad en los diferentes campos de la óptica y colorimetría, y entre sus funciones están las de proponer estándares de normalización de medidas de combinación de colores, posee también sus propios "espacios de color", tanto para pigmentos como para la luz.

Para identificar estímulos de color, C.I.E., creó el espacio tridimensional C.I.E.LAB, que recuerda al "Atlas" de Munsell, como espacio de colores.

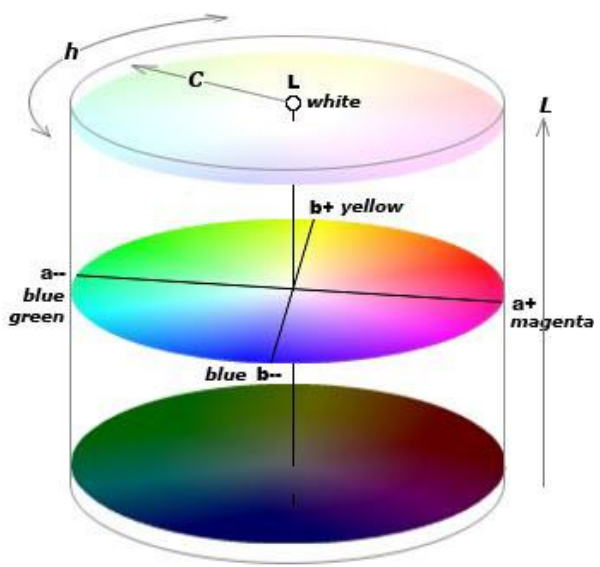

Figura 36. Espacio C.I.E.L.A.B. 1976.

Establecido por la Comisión Internacional de lluminación. 
El eje "L" es la medida de tonos de grises, del 0 (como el negro) al 100 (como el blanco), tomando sus fundamentos en la teoría de Hering, sobre la percepción del color, divide sus coordenadas en "A positivo" (A+) y "A negativo" (A-) como el plano rojo (A+) y verde (A-), y el plano azul-amarillo; siendo el azul el eje (B-) y el amarillo $(\mathrm{B}+)$.

De manera similar al "Atlas" de Munsell, mientras más "saturado" esté el color o la mezcla resultante entre colores equidistantes, mientras más puro sea el color, más alejado se encontrará del eje "L".

Realizando investigaciones constantes en el campo de colorimetría, C.I.E., también ha realizado un espacio de color para la luz y la cromaticidad, que abarca la totalidad del espectro visible, plasmando en este espacio la intensidad de frecuencias de cada color, a este espacio de color se le conoce como: "C.I.E. 1976", ya que en este año fue que se realizaron las correcciones necesarias al espacio de colores del espectro visible realizado en 1931.

El espacio "C.I.E. 1976" se encuentra insertado en un plano de coordenadas $\mathrm{X} / \mathrm{Y}$, en un espacio de localización cartesiano; el eje X es designado como eje "U" y el eje Y como eje "V", y manteniendo en el centro el punto "E" para el punto acromático del espectro visible, la unión de los colores en el punto blanco, como la medida de luminosidad. 


\section{Capítulo III.- La tonalidad en la pintura.}

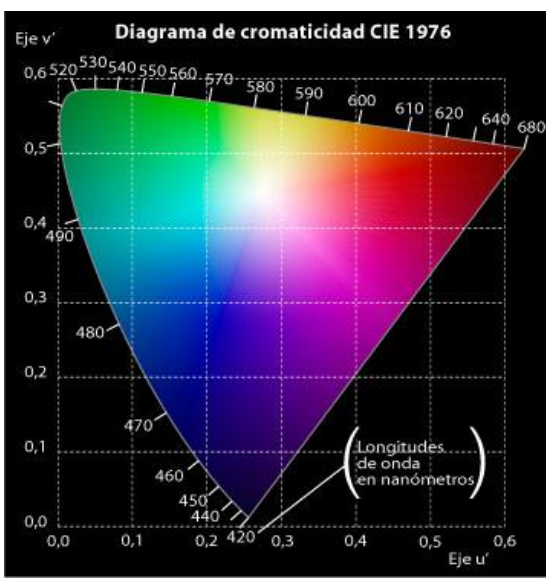

Figura 37. Diagrama de cromaticidad C.I.E. 1976.

Insertado en ejes

bidimensionales.

Podemos observar las ventajas del espacio "C.I.E. 1976" por la curva trazada, la cual nos delimita la totalidad del espectro visible, tomando como inicio de la curva delimitadora del espacio de color a $380 \mathrm{~nm}$. con el violeta, hasta $700 \mathrm{~nm}$. aprox. para los rojos de mayor saturación, así como la intensidad y las mezclas resultantes entre los colores.

La teoría del color en su forma básica, como podemos ver, tiene su reflejo inmediato en los "espacios de color", que tienen sus fundamentos en las teorías de percepción de la luz y los colores del espectro visible,y la unión de ambos fenómenos; así como la toma de criterios para la medición de un tono de color, que son los que dan la forma final a los diferentes espacios de color existentes.

En la práctica, también implica las leyes de la mezcla de colores por síntesis aditiva y sustractiva, con las que se puede obtener toda la gama de colores utilizados de forma práctica en el arte visual, ya sea en la luz, con base en las mezclas realizadas por medio del sistema RGB (rojo, verde y azul por sus siglas en inglés) en el arte 


\section{Capítulo III.- La tonalidad en la pintura.}

digital; y la síntesis sustractiva, que no es más que la mezcla de pigmentos, tintas, o cualquier "materia muerta".

El sistema RGB, que es el comúnmente utilizado en el manejo del color por medios digitales, parte de las mezclas posibles entre los colores primarios rojo, azul y verde; tomando como un parámetro aparte, el factor de luminosidad, en medidas que están en relación directa con el espacio CIELAB, de esta forma, las medidas de cada color en coordenadas RGB van del 0 al 255, siendo el 0 la ausencia del color y el 255 su punto de mayor saturación, la luminosidad es medida del 0 al 100.

En la síntesis sustractiva de colores, se utilizan por convención como colores "primarios" el rojo, azul y amarillo, los que permiten en sus diferentes mezclas, la creación de toda la gama de colores. Al combinar por medios sustractivos los colores primarios anteriormente citados, obtenemos los conocidos de manera coloquial como "secundarios": el violeta, de mezclar el rojo con el azul; el naranja, del rojo y amarillo; el verde, del amarillo y azul. Al mezclar los colores secundarios con los primarios, obtenemos los conocidos como "terciarios": rojo-violeta o rojo violáceo, amarillo-naranja u ocre, azul-verde o cyan, azul-violeta o añil, amarillo-verde o verde limón y rojo-naranja o rojo anaranjado.

Al mezclar por métodos sustractivos cualquiera de los colores obtenidos anteriormente, con diferentes cantidades de negro o blanco, 
Capítulo III.- La tonalidad en la pintura.

obtenemos diferentes tonos, los cuales complementan nuestra gama de colores. 


\subsection{Armonía de colores.}

El concepto de "Armonía" es un término transdisciplinar que también es compartido por la pintura y la música, conceptualizando el término como la manera de trabajar con dos o más frecuencias simultáneas, lumínicas o sonoras. En el arte visual, se hace referencia a las combinaciones de colores que son "agradables" a la vista, y aquellos que excitan o crean contrastes; es además, un concepto necesario para poder comprender la creación de ciertos colores, como los conocidos coloquialmente como "pardos" o la gama de colores del “café". En la armonía de colores, hablamos fundamentalmente de dos ideas o parámetros para la combinación de colores: Analogía y Contraste. $^{63}$

Como herramienta fundamental para el uso de la armonía de colores, se utiliza el denominado "círculo de colores", del que existen diversas presentaciones de acuerdo a los criterios o necesidades de distintos autores. Johannes Itten, (1888-1967), miembro de la escuela Bauhaus, proponía un círculo de colores compuesto de 12 colores puros (Hue), en el que se ilustraban en el centro con un triángulo, los tres colores primarios de las mezclas substractivas, y junto a este triángulo, otros tres colores que representaban los colores secundarios "puros" ( in mezclas de blanco o negro), y en un círculo rodeando esta

\footnotetext{
${ }^{63}$ WONG W. Principios del diseño en color. Barcelona: Gustavo Gili, 1988, p. 5.
} 


\title{
Capítulo III.- La tonalidad en la pintura.
}

figura, los colores primarios, secundarios, y los terciarios; la unión de estos colores, formaba su círculo de colores.

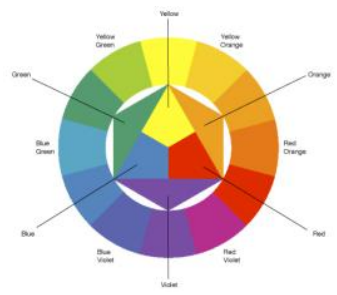

Figura 38. El círculo de Itten.

Para ilustrar un círculo de colores, que contenga los tres parámetros del color de acuerdo a la teoría de Munsell, presentamos el siguiente:

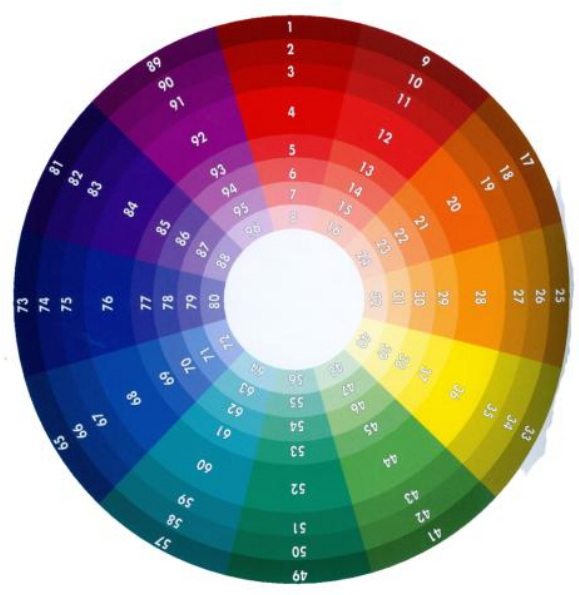

\author{
Figura 39. Un \\ círculo de colores \\ con mayor \\ luminosidad al \\ centro. \\ (V.V.A.A.: Color \\ Harmony. \\ Massachusetts: Ed. \\ Rockport, 2007).
}

En esta figura podemos observar los tres parámetros de medición de un tono de color presentados de forma práctica, representados por los números 4, 36, y 68, encontramos los colores "primarios" como color "puro" en su mayor intensidad, los colores 


\section{Capítulo III.- La tonalidad en la pintura.}

que no pueden ser obtenidos por la combinación de otros en una mezcla substractiva.
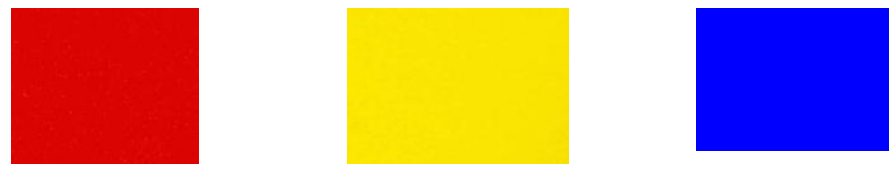

Figura 40. Colores primarios.

Los colores secundarios: verde, naranja y violeta, los encontramos en los ángulos de un triángulo de este mismo círculo en los números 28,52 , y 84 ; y los colores terciarios los encontramos en los números 12, 20, 44, 60, 76, y 92; siendo estos últimos, la combinación de un color secundario con uno primarios.

Conocemos como colores complementarios a aquellos que crean contraste, o los que al combinarlos nos dan un tono neutro, prácticamente acromático, para visualizarlos no hace falta más que trazar un diámetro en el círculo, y los colores diametralmente opuestos son los que formarán una paleta de colores complementarios. Como podemos observar, en este círculo en particular, encontramos también representado el parámetro del "Valor" o luminosidad, la cantidad de blanco o negro en el color, en este caso, nos encontramos con mayor luminosidad al centro, partiendo del color de mayor intensidad, (por ejemplo, el rojo de mayor intensidad es el numero 4, mayor luminosidad del 5 al 8) y por el contrario, al acercarnos a la circunferencia, nos acercamos a los colores más oscuros (valores que estarían más cercanos al 0 de acuerdo al "Atlas" de Munsell). De 


\section{Capítulo III.- La tonalidad en la pintura.}

forma práctica, denominaremos como "tinte" cuando a un color "puro" se le añaden blancos para darle un mayor valor de luminosidad, y "sombras" cuando añadimos negros para hacerlo más oscuro. Estos parámetros nos llevan a la posibilidad de realizar no solo mezclas de colores para obtener diferentes tonos, sino que además, nos permiten la creación de "acordes" o paletas de colores.

Una paleta "monocromática" está representada por un solo "Chroma" o Matiz, (un solo color), presentado con sus diferentes tintes o sombras.
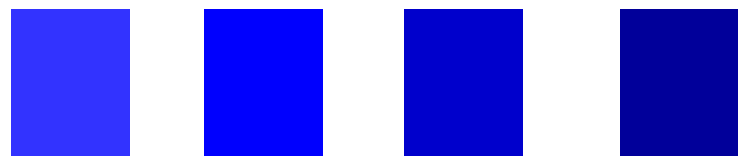

Figura 41. Paleta monocromática.

Por otro lado, cuando presentamos los valores (escala de tonos del negro al blanco) se le considera como una paleta "acromática".
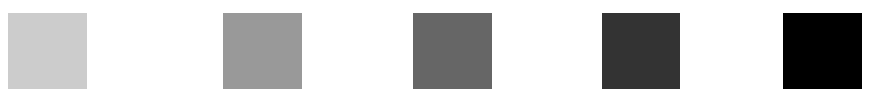

Figura 42. Paleta acromática.

La paleta de colores primarios, es un "acorde" o "triada" compuesta de los colores: rojo, verde y azul; de manera similar, podemos realizar las "triadas" de colores secundarios, compuestas de los colores: verde, violeta y naranja. 


\section{Capítulo III.- La tonalidad en la pintura.}

Podemos obtener también las "triadas" terciarias mediante un simple manejo del círculo de colores, y estas consisten en tres colores terciarios formados de los que se encuentran en los ángulos equidistantes de un triángulo equilátero inserto en el círculo de colores, de esta manera, obtenemos dos triadas: rojo-violeta, amarillonaranja y azul-verde; y la segunda triada de colores terciarios está compuesta por los colores rojo-naranja, amarillo-verde y azul-violeta.
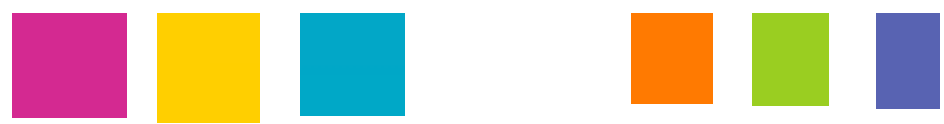

Figura 43. Triadas terciarias.

La armonía de colores también contempla las llamadas paletas de colores análogos, que se obtienen de los colores adyacentes en el círculos de colores, incluyendo sus tintes y sombras, podemos encontrar numerosos ejemplos de la paleta de colores análogos en la naturaleza, algunas de las triadas que obtenemos mediante este proceso son compuestas por el Verde, Verde-azul, Azul; Rojo-naranja, Naranja y Amarillo, y producen la sensación de una consonancia, una ausencia casi total de contraste.

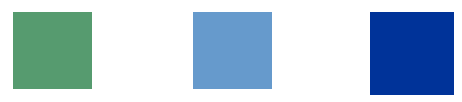

Figura 44. Paleta de análogos. Verde, Verde-azul, Azul. 


\section{Capítulo III.- La tonalidad en la pintura.}

Otras de las muchas posibilidades que nos ofrece la armonía de colores, es lo que conocemos como la triada de "complementarios divididos", partiendo del uso de los colores complementarios (los que se encuentran diametralmente opuestos en el círculo de colores), tomamos cualquier color como base, y utilizamos los colores que se encuentran a los lados del color complementario que le corresponde, por ejemplo, siendo colores complementarios el rojo y el verde, para obtener la triada de complementarios divididos, utilizaríamos el Rojo con el verde-amarillo y el verde-azul; o viceversa, el Verde con el rojo-naranja y el violeta.

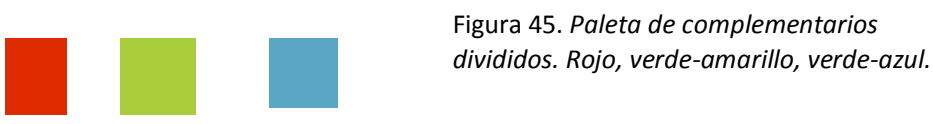

Para obtener los colores "neutros", realizamos una mezcla de colores complementarios y de la misma obtenernos las posibilidades de los colores neutros o coloquialmente conocidos como "pardos", la gama de los colores "café", y al añadirles diferentes valores, o cantidades de blanco o negro, extienden su paleta, obteniendo así los colores que conocemos como "marrón”, “canela”, el mismo "café”, el "beige" y la gama de colores neutros.

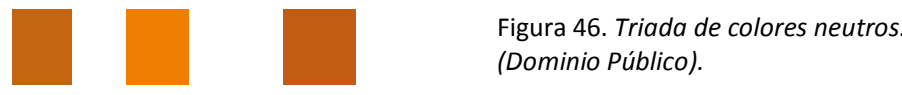




\section{Capítulo III.- La tonalidad en la pintura.}

Las posibilidades del uso del círculo de colores como herramienta para crear esquemas o acordes de colores se expanden en base al uso y función deseado, tanto en el arte como en la industria, y contribuyen a determinar el estilo del espacio de color presentado. El color posee al igual que el sonido, una carga simbólica y subjetiva, que depende del contexto en el que es presentado; así un color aislado, puede no poseer un simbolismo unívoco, al ser combinado y presentado en diferentes esquemas, y la función de cada color queda evidenciada por los tonos que le rodean, con lo cual, cada tono en particular, se convierte en portador de ideas, simbolismos o sensaciones, que tendrán la posibilidad de conformar el lenguaje del artista. 


\section{Sinestesia}

Las recientes investigaciones en el campo de la Neurología y Psicología sobre la condición clínica conocida como "Sinestesia" son uno de nuestros principales motivos para la propuesta de una nueva “correspondencia" o "tonalidad audiovisual". La extracción de posibles patrones creativos otorgados por la "visión sinestésica", puede ser vislumbrada a partir del conocimiento que los avances en la exploración funcional de la imagen cerebral nos brindan; así como la posible visión común de dos o más sinestetas sobre un mismo fenómeno, que nos permitiría establecer una "correspondencia sinestésica" entre distintos fenómenos sensoriales que pueda tener como base un fenómeno de percepción humana.

Entendiendo la Sinestesia como la unión de dos o más sentidos, encontramos que es un fenómeno que, entendido a un nivel subjetivo y metafórico, es bastante común para la población mundial En la literatura, la crítica de arte, o incluso, en la conversación diaria, abunda la metáfora comparativa para describir fenómenos sensoriales, probablemente, debido a la dificultad intrínseca de realizar una descripción "hablada" de un fenómeno sensorial con el cual se ha vivido desde el nacimiento, y que resulta una parte fundamental de la manera de percibir el mundo; dificultad que, se nos presenta de la misma manera para entender la "visión sinestésica" de una persona que haya nacido con esta condición, y no, que la haya adquirido tras 


\section{Capítulo IV.- Sinestesia.}

una modificación accidental del córtex cerebral, u otras causas, lo que usualmente permite una introspección más detallada de una condición adquirida.

La sinestesia ha creado un gran interés en diversas ramas del pensamiento como la pintura, la música, y la literatura en diferentes épocas; ${ }^{64}$ interés que gracias a los avances en la tecnología parece haber renacido en los inicios del siglo XXI La tecnología ha realizado avances que implican un paralelismo en las diferentes ramas del conocimiento humano, como lo es en la medicina y las disciplinas artísticas. Sin embargo, la Sinestesia, entendida como un fenómeno clínico, una condición fisiológica, está lejos de ser "metafórica" unión de dos o más sentidos, al nivel de la percepción humana en el cerebro, al recibir los órganos sensoriales un solo estímulo, de manera inconsciente y automática, es un fenómeno raro, pero, documentado por la ciencia desde el siglo XVIII ${ }^{66}$; e incluso, con referencias anteriores, que nos llevan al estudio clásico de la Grecia antigua. Por ejemplo, cuando un "sinesteta clínico" percibe una onda sonora, activará en su cerebro (de forma inconsciente, automática y constante), la zona de estímulos visuales, "verá" colores al mismo tiempo que escuche los sonidos percibidos de forma real, a pesar de no tener luz alguna alrededor. Hay diferentes manifestaciones del fenómeno de la sinestesia, correspondencias de sonido afinado con

\footnotetext{
${ }^{64}$ ROCLAW S. Sinestesia arte e tecnología: fundamentos da cromossomía. Sao Paulo: Annablume, 2002, p.3

${ }^{65}$ SACKS O. Musicofilia. Relatos de la música y el cerebro. Barcelona: Anagrama, 2009 , p. 202.

${ }^{66}$ GOLDSTEIN E.B. Sensación y Percepción. Madrid: Debate, 1993, p. 343.
} 


\section{Capítulo IV.- Sinestesia.}

colores, formas geométricas con sabores, olores con sonidos, y un amplio catálogo de combinaciones de los sentidos.

La sinestesia, es una cuestión clínica, que depende de forma intrínseca de la percepción humana y de las condiciones anatómicas del cerebro humano; no es vivido como una metáfora para un segmento considerable de la población humana, sino una realidad constante e involuntaria. Como es una experiencia que en ciertos niveles, no parece afectar la vida social de los individuos, un individuo sinestésico usualmente cree que su percepción es compartida por el resto de la población, y el fenómeno ha permanecido hasta cierto punto, "oculto", casi como un "recurso creativo", más que como una realidad mesurable. Es gracias a los avances en la tecnología de exploración cerebral, que podemos comenzar a vislumbrar la realidad neurológica, no solo del fenómeno de la sinestesia, sino de la percepción humana. Comenzamos a aprender mediante experimentos en el ramo de la medicina, la función fundamental que el cerebro realiza al interpretar la realidad "capturada" por los distintos sentidos, y cómo, esta interpretación realizada a nivel cerebral, determina la realidad que nos rodea. 


\section{Capítulo IV.- Sinestesia.}

\section{1 ¿Es objetivable la Sinestesia?}

El vocablo "sinestesia" significa "sensaciones unidas" en una traducción libre de la raíz griega syn que significa "unión”, y aesthesis traducido como "percepción". Es un término que ha sido utilizado para describir a personas que tienen la "condición" o "característica" de tener dos o más sentidos "unidos".

Cuando una persona "a-sinestésica",67 (término acuñado por el profesor Boring E.G., para describir una persona no sinestésica) percibe una onda sonora, visual, o cualquier otro estímulo externo, su respuesta "normal" a este estímulo, es lo que podríamos considerar como una respuesta "especializada". El individuo a-sinestésico, tendrá únicamente la sensación de "escuchar" al percibir una onda sonora, únicamente la sensación de "ver" al percibir luz, o la sensación de "sabor" al degustar un alimento. En un individuo sinestésico las cosas ocurren de forma diferente, su respuesta a los estímulos externos no es tan "especializada" como en un individuo asinestésico, al percibir un estímulo de una sola clase (auditivo, visual, táctil, etc.) responderá "sintiendo" que este estímulo denota más de una respuesta, es decir: Cuando una persona que posee sinestesia

\footnotetext{
${ }^{67}$ WHELLER R.H.; y T.D. CUTSFOTH. The Synaesthesia of a blind subject with comparative data from an Asynaesthetic blind subject. Oregon: University of Oregon P., 1922, p. 3.
} 


\section{Capítulo IV.- Sinestesia.}

escucha un tono o nota musical, "verá" un color, que le aparece asociado de forma permanente, al tono específico escuchado.

Existen numerosos tipos de sinestesia, siendo una de las más comunes la que conocemos como: "sinestesia grafema-color" en la cual, el individuo sinestésico al observar una letra o un número, lo "ve" de cierto color, de manera independiente a la tinta en que este grafema fue impreso. En un experimento realizado por Sean Day, catedrático de la Universidad de Taiwán, siendo él mismo sinestésico, le pidió a diferentes individuos que asignaran los colores que ellos percibían de forma "interna", a los números del uno al nueve, la mayoría observaban el número 1 de "color negro", el número 3 con color "amarillo-mostaza", y así sucesivamente, hasta que asignaron la paleta completa de números con los colores que en palabras de los sujetos de experimentación, eran "intrínsecos a las formas".

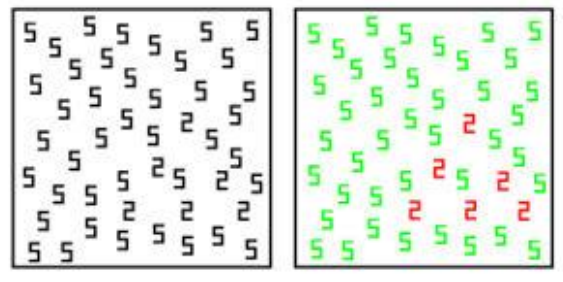

\author{
Figura 47. Visión sinestésica. Ejemplo \\ de un "test" para diagnosticar \\ sinestesia. A la izquierda, visión \\ normal, a la derecha visión \\ sinestésica. \\ The journal of Consciousness Studies \\ http://www.bbc.co.uk
}

Otro ejemplo para ilustrar más ampliamente el fenómeno de la sinestesia, se nos ilustra con el siguiente testimonio de un individuo, con amplias razones para creer que posee esta condición. Cuando esta persona fue presentada con un sonido aislado de $2000 \mathrm{~Hz}$, él lo describió de la siguiente manera: "Parecen fuegos artificiales teñidos de un matiz entre rosa y rojo...", que implica una asociación visual 


\section{Capítulo IV.- Sinestesia.}

con el sonido, pero continuando con la descripción: "La franja de color se siente áspera y desagradable..." otra asociación, que es táctil, y de forma extraordinaria, lo que en numerosos estudios clásicos sobre la sinestesia, es descrito como una asociación simbólica o de carácter "psicológico"68. Al mencionar el individuo que la sensación le era “desagradable", la descripción de un solo sonido aislado, no se detiene aquí... "Tiene un sabor feo, como el de verdura en conserva"69, que todavía comprende una asociación más, en este caso, con el sentido del gusto.

No siempre hay un común acuerdo entre la gente con condición de sinesteta, sobre el carácter de las asociaciones y las sensaciones secundarias que corresponden a cierto fenómeno auditivo o de otra índole. Las asociaciones parecen revestir un carácter altamente individual y son además, bastante específicas; aunque, al valerse de un número mayor de individuos de muestra para la extracción de posibles patrones de la visión sinestésica, comienzan a vislumbrarse algunos puntos en común sobre algunas de las "visiones sinestésicas", de esta forma, podemos obtener que un alto porcentaje de sinestésicos, "ven" la letra "o" como blanca con un borde negro, o las frecuencias sonoras correspondientes al sonido temperado "Do" como blanco.

Parece que la mayor parte de las asociaciones sinestésicas tienen que ver con el color y esta es la sinestesia conocida como:

\footnotetext{
${ }^{68}$ LAURES, H. Les Synésthesies. Paris: Librairie Bloud et C., 1908, p.14.

${ }^{69}$ GOLDSTEIN E.B. Sensación y Percepción. Madrid: Debate, 1993, p.368.
} 


\section{Capítulo IV.- Sinestesia.}

“audición coloreada", es así que el sonido (en diferentes modalidades) produce colores, el gusto asociado al color, el dolor asociado al color, como lo táctil con el color; sin embargo, las asociaciones sinestésicas parecen ir mucho más allá que la mera asociación de sentidos, a una percepción secundaria visual.

Existen testimonios de sinestetas sobre asociaciones espaciotemporales, un lapso determinado de tiempo se encuentra asociado a una distancia o posición geográfica con respecto al individuo; un sinesteta podría experimentar que los días de la semana o los años se encuentran a cierta distancia geográfica a partir de él mismo, no metafóricamente, sino como una sensación real, la sensación de un lapso temporal como algo "palpable geográficamente".

Una revisión sobre los diferentes tratados realizados sobre el tema de la Sinestesia, permite generalizar la manera en que el fenómeno ha tratado de ser explicado y comprobado a través de las distintas épocas en que ha existido un interés científico por el mismo. La sinestesia ha suscitado el interés de diversos investigadores por el carácter mismo del fenómeno, “¿Es algo real?, ¿qué lo causa?”; y parece ser que estamos más cerca de comprobar la realidad fisiológica del fenómeno, que de determinar sus causas. 


\section{Capítulo IV.- Sinestesia.}

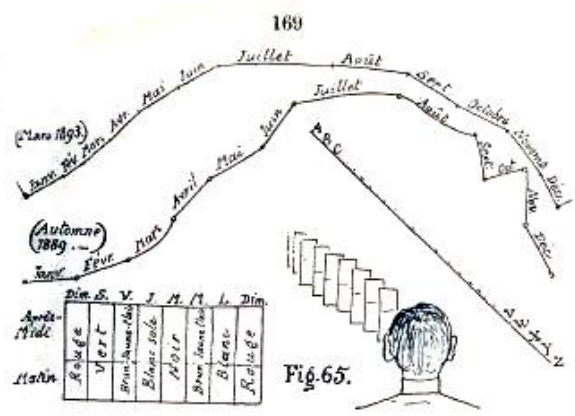

Figura 48. Ejemplos de sinestésica espaciotemporal, "Diagramas" realizados por el sujeto ejemplificando la espacialidad de lapsos temporales. FLOURNOY, T.H.: Des phénomènes de synopsie (audition colorée). París: Ed. Félix Alcan, 1893, p. 169.

Podemos describir el primer método de carácter científico para la comprobación del fenómeno como: "Experimentación no invasiva", experimentos de índole conductual y comparativa. En estos experimentos usualmente se le pide a un grupo de sujetos sinestésicos que "padezcan" del mismo tipo de sinestesia, como una manera de estandarizar el grupo a estudiar, que describan y asignen las sensaciones secundarias que argumentan "ver" o "sentir" al fenómeno primario o "físicamente real", y sus resultados son comparados con un grupo de control, o individuos a-sinestésicos; usualmente, los datos obtenidos de este tipo de experimentación son de carácter introspectivo, y se necesita (como en casi toda experimentación científica) que las pruebas y resultados sean obtenidos en condiciones fijas, o estandarizadas, que sean iguales tanto para el grupo de control, como para el grupo de sinestésicos.

A partir de relatos de estudios clásicos, fueron fijadas algunas de las condiciones estandarizadas para la experimentación y/o muestreo estadístico para la obtención de datos de este fenómeno, por 


\section{Capítulo IV.- Sinestesia.}

ejemplo, Francis Galton nos describe el fenómeno y sus características a partir del relato de varios sinestetas,y a través de los investigadores que obtenían los datos y características de la condición, extrayéndolos del promedio obtenido de las introspecciones realizadas en un número significativo de sinestetas; de esta forma, Galton hace énfasis en las siguientes características de la sinestesia:

1. "La persistencia de la asociación del color con el sonido". La asociación siempre es la misma, un sinesteta nunca asigna diferentes colores a la misma nota, y ocurre de la misma forma con asociaciones de otra índole.

2. "Los sonidos de las vocales evocan la asociación". Al describir la sinestesia como: "sonido de vocal-color", Galton hace énfasis en el hecho de que lo específico de la sinestesia, es el sonido, no el grafema lo que en este caso, detonaba la sinestesia; y en cuanto a la sinestesia "grafemacolor", es la figura impresa la que detona la correspondencia sinestésica y no, el sonido.

3. "El sujeto es escrupuloso en la descripción exacta del tinte y matiz del color asociado", nunca están satisfechos en decir simplemente azul, sino que se toman grandes trabajos para expresar el azul en particular al que se refieren. Lo detallista que un sinesteta puede llegar a ser sobre la descripción del color asociado, puede llegar al extremo de 


\section{Capítulo IV.- Sinestesia.}

que el color asociado sea de un tinte y matiz, que nunca haya visto de forma "real" en su vida. ${ }^{70}$

4. "La tendencia de la sisnestecia es bastante hereditaria". Incluso estudios recientes parecen comprobar la tendencia de que el fenómeno se vuelve recurrente en las familias; parece que si se tiene un pariente sinestésico, es probable que más personas en la familia, también padezcan esta condición. $^{71}$

Galton remarca la condición hereditaria de la sinestesia con observaciones sobre sujetos que él conocía, es de particular interés las observaciones que realiza sobre asociaciones de los sonidos de las vocales con colores, que nos describe una persona a la que Galton se refiere como "Mis $\mathrm{H}$ ". después de describir las asociaciones que existían de manera intrínseca para ella, nos relata: “(...) de mis dos hijas, una observa los colores relacionados a las vocales, de "diferente" color a esta correspondencia: (A es azul, E es blanco, I es negro, $\mathrm{O}$ es café claro, $\mathrm{U}$ es café oscuro). Mi otra (hija) es simplemente heterodoxa en la A y la $\mathrm{O}(. .$.$) y mi hermana y yo, nunca$ hemos concordado con estos colores (...), ${ }^{\text {,72 }}$.

Al observar en diferentes grupos de experimentación este tipo de características, se generaliza el hecho de que parece haber una

\footnotetext{
${ }^{70}$ SACKS O. Musicofilia. Relatos de la música y el cerebro. Barcelona: Anagrama, 2009, p. 207.

71 GALTON F. Inquiries into Human Faculty and its Development. London: McMillan and Co., 1883, p.148.

72 GALTON F. Inquiries into Human Faculty and its Development. London: McMillan and Co., 1883, p. 151
} 


\section{Capítulo IV.- Sinestesia.}

tendencia hereditaria en la condición sinestésica; y de la misma forma, se extraían patrones que permitieran formular características de la condición. Una vez que los investigadores de diferentes ramos, tenían conocimiento previo sobre la sinestesia y sus manifestaciones, que en esos momentos eran aparentes, comenzó un interés grande por realizar experimentos para comprobar la veracidad de la condición y sus características.

A finales del siglo XIX y principios del XX, comenzó lo que algunos autores han descrito como: Una "avalancha" de experimentos sobre la sinestesia. La mayoría de los mismos, eran experimentos de tipo conductual, experimentos clásicos con un grupo estandarizado de sinestésicos comparados con un grupo de control. A partir de algunas de las generalizaciones que existían previamente, las condiciones más usuales de los experimentos eran las siguientes: Los sujetos de experimentación debían de estar aislados y en un ambiente controlado, en un estado mental relajado, y cuando se quería comprobar la realidad de un tipo específico de sinestesia, todos los individuos del grupo de sinestetas, deberían padecer del mismo tipo de sinestesia, y ninguna otra.

Como además, la sinestesia parecía ser una respuesta inconsciente y automática a un estímulo externo, el tiempo de respuesta resultó importante, así como la periodicidad en las pruebas. Un filtro que ha resultado de lo más útil para distinguir a un "sinesteta fisiológico" de un "sinesteta subjetivo", es que las asociaciones de un sinesteta fisiológico jamás cambian; esta característica ha llevado a 


\section{Capítulo IV.- Sinestesia.}

que la mayoría de los experimentadores no solo realicen diferentes pruebas en lapsos temporales largos, de más de seis meses, sino que además las apliquen sin previo aviso, para que los sujetos de experimentación, no preparen de manera previa sus asociaciones.

Es de remarcar este último filtro, la diferencia que la periodicidad en las pruebas ocasionan entre el grupo de sinestetas y el grupo de control a-sinestésico es notoria, los "sinestetas fisiológicos" mantienen exactamente las mismas asociaciones entre fenómenos durante toda su vida, y sus respuestas son automáticas, ambas cosas marcan esta gran diferencia con el grupo de control y los "sinestetas subjetivos", cuyas asociaciones cambian de prueba en prueba, y aún más, cuando el lapso temporal entre dos pruebas es largo.

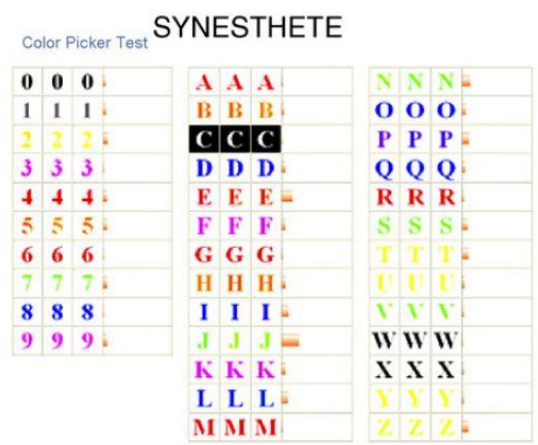

Score: 0.27
CONTROL

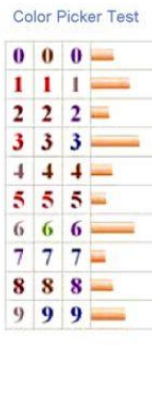

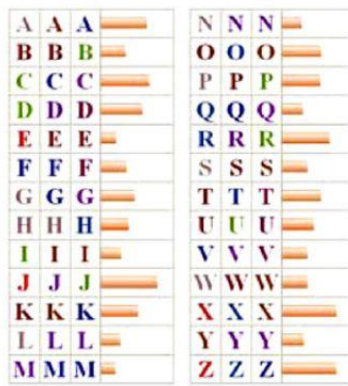

Score: 2.11

Figura 49. Comparativa de resultados entre un sujeto sinestésico (izquierda) y un no sinestésico (derecha) de control, al cual se le pidió que imitara una condición sinestésica. La barra a la derecha del grafema indica la diferencia en asociaciones, mientras la barra es más grande mayor es la diferencia en la correspondencia. 


\section{Capítulo IV.- Sinestesia.}

Estos experimentos en su mayoría, han sido de índole “conductual", partiendo de un análisis de la información que el comportamiento del sujeto de experimentación realiza, y vale la pena mencionar que estos mismos experimentos, tienden a remarcar la realidad del fenómeno y sus características, comprobando el comportamiento de los grupos de sinestetas, y comparándolo con el comportamiento del grupo de control.Y así, la mayor parte de los investigadores han llegado a conclusiones similares que afirman la existencia "real" de las asociaciones sinestésicas, encontrando interesante que algunos de ellos han clasificado a la sinestesia como un "reflejo",73, una reacción involuntaria, automática y constante a un estímulo.

Esta serie de experimentos de tipo conductual sobre la sinestesia nos da razones para creer en la realidad del fenómeno como una condición clínica, inevitable y objetiva; sin embargo, no nos dicen nada sobre las causas de la condición, o la realidad anatómica de la misma.

A partir de los avances tecnológicos del siglo $\mathrm{XX}$, en materia de microscopía y exploración del cuerpo humano, es que ha sido posible determinar la realidad fisiológica del fenómeno, como una condición física, más que como un reflejo condicionado por factores educativos o familiares.

\footnotetext{
${ }^{73}$ WHELLER R.H.; y T.D. CUTSFOTH. The Synaesthesia of a blind subject with comparative data from an Asynaesthetic blind subject. Oregon: University of Oregon P., 1922, p. 102.
} 


\section{Capítulo IV.- Sinestesia.}

El conocimiento del cuerpo humano, sus funciones y estructura, ha estado ligado intrínsecamente al estudio de la microscopía, la elaboración de herramientas necesarias para permitir al ojo humano analizar la flora y la fauna, que sin estas no sería posible ver; asimismo, el conocimiento del cuerpo humano ha sido dependiente del estudio de la anatomía humana. Durante siglos, el hecho de abrir el cuerpo humano y extirpar tejido, o el examinarlo cuando este está a la vista, ha sido el método por excelencia para la comprensión de la mecánica subyacente de los sistemas fisiológicos del humano.

El método anatómico conocido como "extirpación”, que consiste en la extracción o cauterización de una parte de un órgano, como el cerebro, ha sido la clave para el inicio de la comprensión de fenómenos como el uso específico de un órgano, o las funciones específicas de diferentes áreas del cerebro; es mediante este recurso, que en la actualidad conocemos con los términos de "biopsia" y "autopsia", que ha sido posible determinar que el cerebro posee áreas especializadas con funciones específicas que atañen no solo al funcionamiento automático de órganos como el corazón, el hígado, etc., sino que las diferentes áreas del cerebro, también están involucradas en el fenómeno de la percepción humana.

La "biopsia", consiste en la extirpación de tejido de un ser vivo, la idea en una biopsia es que el sujeto de investigación permanezca con sus funciones vitales; la "autopsia" por otro lado, es realizada en sujetos sin funciones vitales, lo que permite la extracción 


\section{Capítulo IV.- Sinestesia.}

completa de diferentes órganos y su exploración detallada. Los métodos de extirpación, a pesar de haber sido la causa de avances dramáticos en el ramo de la medicina, neurología, filosofía y demás ramas del conocimiento; poseen la desventaja de que al momento de analizar el tejido extirpado, este se encuentra muerto, y descontextualizado de la función que realizaba en el cuerpo humano.

Mediante el análisis obtenido por el estudio anatómico del cerebro, se han podido diferenciar varias áreas en la estructura del cerebro humano, si observamos un cerebro humano, lo primero que salta a la vista son los "hemisferios cerebrales", que constituyen el mayor porcentaje de masa del cerebro, dos grandes objetos constituidos de tejido nervioso que ocupan casi todo el cráneo; los hemisferios se encuentran unidos por un "puente" de células nerviosas que permiten a los dos hemisferios trabajar de manera conjunta, y la superficie de los mismos, se encuentra llena de pliegues llamados "circunvoluciones" y que conforman lo que conocemos como el "córtex".

Son estas circunvoluciones y el córtex, lo que creemos tiene que ver con la inteligencia y la mayor parte de las funciones típicamente asociadas con la percepción humana. Debajo de una "protuberancia" en la parte posterior de los hemisferios cerebrales, se encuentra el "cerebelo", también dividido en dos hemisferios; justo arriba del cerebelo y entre este mismo y los hemisferios cerebrales, se encuentra el "tálamo" y el "sistema límbico". El sistema límbico, parece afectar a las emociones e intervenir (al igual que los 


\section{Capítulo IV.- Sinestesia.}

hemisferios cerebrales) en la conciencia del individuo; al tálamo, se le ha encontrado la función de integración y dirección de los nervios sensitivos dirigidos al córtex, y por debajo del cerebelo encontramos el "tronco cerebral" que conecta la médula espinal con el cerebro.

Desde el descubrimiento, alrededor de $1870^{74}$, de que el “córtex" cerebral responde a estímulos eléctricos, y que es mediante impulsos eléctricos que la comunicación entre neuronas toma lugar, se han realizado experimentos no solo en animales, sino en seres humanos, en que ha sido posible comenzar a vislumbrar las funciones específicas de distintas áreas cerebrales, así como la injerencia en diferentes fenómenos de percepción de las diferentes áreas de la corteza cerebral.
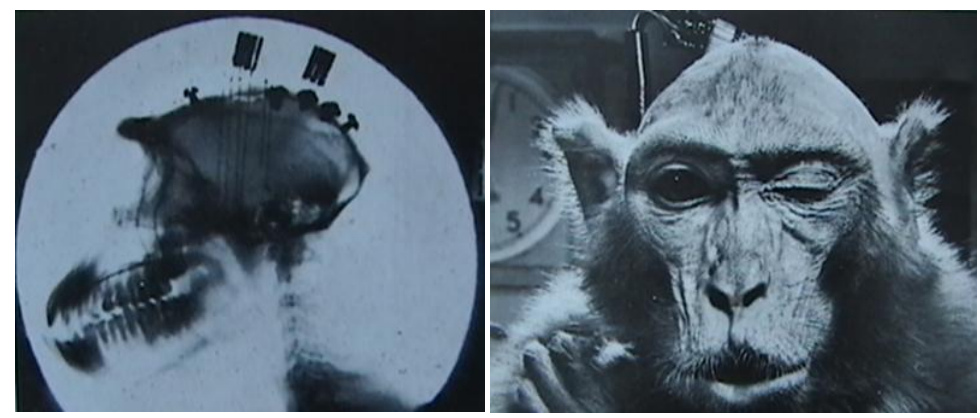

Figura 50. A la izquierda, radiografía mostrando la implantación de electrodos superficiales y profundos en el cráneo de un mono. A la derecha "Cuando por el electrodo pasa una corriente eléctrica al cerebro, el mono reacciona con un guiño".

(V.V.A.A.: La Mente. Ciudad de México: Colección Científica de TIME-LIFE, Ed. Offset Larios, 1976.p. 185).

El método de estimulación eléctrica del córtex, y otras áreas del cerebro, se realiza por medio de la inserción de electrodos, los

${ }^{74}$ FRANZ I. Localization of brain function. New York: Macmillan Co., 1901, p. 420 


\section{Capítulo IV.- Sinestesia.}

cuales, pueden estar sujetos al exterior del cráneo, y llevar la corriente eléctrica producida por el cerebro a mecanismos de medición de energía eléctrica, que sirve para registrar zonas de actividad cerebral, en momentos determinados, y en respuesta a estímulos externos controlados; aún más notorio, es cuando el electrodo es implantado (insertado) en el cerebro, y conectado a una fuente de energía eléctrica, la ciencia ha utilizado este método para determinar qué respuesta causa la estimulación eléctrica de un área específica del cerebro, encontrando que, la estimulación de determinadas secciones causa no solo acciones musculares individualizadas, sino que pueden causar emociones, recuerdos (los cuales permanecen vívidos mientras el estímulo eléctrico permanece, para desparecer en cuanto este cesa), y sensaciones. El impulso eléctrico cerebral tiene la función de liberar "paquetes" químicos de una neurona a otra, lo que constituye el método de comunicación del cerebro, de una manera muy similar a la fotosíntesis de las plantas.

Este método de medición de la actividad eléctrica del cerebro, fue pionero en la investigación del cerebro "vivo", en funciones, y permitió comenzar a vislumbrar la idea de que diferentes áreas del cerebro realizan diferentes funciones. Podemos dividir el cerebro en varias áreas, además de los hemisferios izquierdo y derecho, encontramos en el área posterior los "lóbulos occipitales" en donde encontramos el centro de percepción visual. Arriba de los lóbulos occipitales encontramos los "lóbulos parietales" los cuales se encargan de la información sensorial, tanto a nivel interno como externo de 


\section{Capítulo IV.- Sinestesia.}

nuestro cuerpo, son los que indican que debe de actuar y nos indican que lo hace, la información sobre músculos, tendones, posición de la mano, etc., y se le atribuyen funciones asociativas $\mathrm{y} d e$ reconocimiento del espacio.

Los "lóbulos frontales" situados al frente del cráneo, contienen una amplia gama de funciones, entre las que cabe destacar funciones verbales, motoras y de memoria; los lóbulos frontales además tienen que ver con la toma de decisiones, la sensación de peligro y la reacción al mismo, que se efectúa en asociación con el sistema límbico.

Al costado del cerebro, debajo de los lóbulos parietales se encuentran los "lóbulos temporales" en el área que se considera como la corteza auditiva primaria; los lóbulos temporales se encargan de la sensación auditiva, y los daños en esta área, no solo ocasionan daños en la percepción auditiva, sino también la percepción visual.

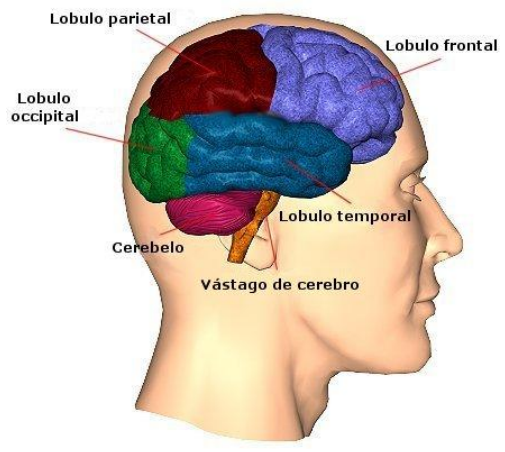

Figura 51. "Mapa" de la división de los lóbulos en el cerebro.Centre for Neuro Skills.

En estas grandes divisiones del cerebro, se encuentran también, en áreas aún más determinadas, las que conocemos como "funciones cerebrales inferiores", y estas se encargan de estímulos y reacciones 


\section{Capítulo IV.- Sinestesia.}

más específicas, como lo son: los estímulos visuales, auditivos, motores, el habla, etc.; podemos encontrar a grandes rasgos, el área de estímulos visuales en los lóbulos occipitales y el área auditiva en los lóbulos temporales, así como el área que se encarga del gusto (el sabor) en los lóbulos parietales.

El conocimiento sobre estas áreas y sus funciones, ha sido posible, en parte, gracias a la estimulación eléctrica del cerebro, la patología derivada de lesiones producidas en distintas zonas del mismo, y recientemente, a las nuevas técnicas de imagenología cerebral.

El conocimiento sobre la Sinestesia como un fenómeno fisiológico, se ha conseguido gracias al monitoreo de la actividad eléctrica y de otro tipo de actividades del cerebro, vislumbrando cómo en un individuo sinestésico, la respuesta cerebral a un determinado estímulo, es diferente a la de un individuo a-sinestésico. Como primer paso para poder explorar las funciones cerebrales, mediante la imagenología funcional cerebral, se trabaja con la idea de que una zona del cerebro consume más oxígeno si trabaja más ${ }^{75}$, siendo el flujo sanguíneo el portador de oxígeno al cerebro, la variable a medir es conocida como "flujo sanguíneo cerebral regional"76.

\footnotetext{
${ }^{75}$ HARRISON, J. El extraño fenómeno de la sinestesia. México D.F.: Fondo de Cultura Económica, 2004, p. 127

${ }^{76}$ HARRISON, J. El extraño fenómeno de la sinestesia. México D.F.: Fondo de Cultura Económica, 2004, p. 127
} 


\section{Capítulo IV.- Sinestesia.}

Una de las primeras técnicas funcionales para medir el flujo sanguíneo cerebral es la "tomografía computarizada por emisión de fotón único" (SPECT por sus siglas en inglés). La técnica consiste en la introducción al sistema circulatorio humano, de una sustancia radioactiva que pueda ser inyectada o inhalada, y se colocan dispositivos de detección para medir los niveles de radiación emitida en el cerebro del paciente, al detectar los fotones producidos por la descomposición de la sustancia radioactiva en cuestión.

Un experimento realizado por medio de esta técnica, por el neurólogo Cytowic, consistió en pedirle a un paciente con tipo de sinestesia "sabor-figuras geométricas" (asociaciones del gusto y visuales) , que inhalara gas Xenón 133, una sustancia que no sufre ninguna transformación química durante su paso por el cuerpo humano, y el paciente no se ve afectado por el proceso, y monitorear la emisión de fotones del gas Xenón, que se encontraba en la sangre del paciente, en su recorrido por el cerebro, mientras el sujeto de experimentación pasaba por distintas condiciones de estímulo y/o descanso.

El experimento consistió en tres sesiones con diferentes condiciones de estímulo, la primera de las sesiones se realizó para establecer la condición de "descanso" y las mediciones obtenidas del paciente cuando este estaba únicamente acostado, con los ojos cerrados y en lo posible, sin ruido alguno alrededor (únicamente el sonido de la máquina de medición); el resultado de la medición de la 


\section{Capitulo IV.- Sinestesia.}

condición de "descanso" fue el esperado, un flujo sanguíneo homogéneo por todo el cerebro.

En la segunda sesión, la primera de activación, se le suministraron aromas al sujeto de experimentación, y en la tercera sesión, se "potenció" la sinestesia del individuo con nitrato de amyl, sustancia que el paciente había dicho anteriormente que exaltaba su estado de sinestesia. Usualmente se espera que el flujo sanguíneo se incremente en el área de estudio alrededor de un 10\%, y mediciones de un incremento de $20 \%$ a $50 \%$, son normales ${ }^{77}$. Por otro lado, el nitrato de Amyl, es una sustancia cuyo efecto es la reducción del flujo sanguíneo cerebral, sin embargo, fue administrada como un factor que permitiría una más clara "lectura de la sinestesia".

Los resultados obtenidos del experimento de Cytowic fueron excepcionales, en más de un sentido, las mediciones del cerebro del paciente fueron completamente distintas de las mediciones obtenidas de pacientes a-sinestésicos sometidos a estímulos similares, además, como un fenómeno completamente inesperado, el flujo sanguíneo del paciente se redujo dramáticamente, obteniendo que el flujo sanguíneo del córtex cerebral era tan bajo, que resultaba en mediciones que señalaban zonas neurológicamente muertas; en el caso del hemisferio izquierdo del paciente, el flujo sanguíneo bajó hasta un 18\%, a pesar de que se estaba tratando con un paciente neurológicamente sano, y que lo usual ante un estímulo, es que el flujo sanguíneo se incremente;

${ }^{77}$ CYTOWIC, R.E. The man who tasted shapes. New York: MIT P., 2003, p. 148 


\section{Capítulo IV.- Sinestesia.}

en palabras de Cytowic, el paciente con mediciones semejantes debería haber estado paralizado o ciego. Este estudio llevó a Cytowic a considerar que el fenómeno de la sinestesia, se encuentra en el sistema límbico del cerebro, a niveles más profundos que lo medible por la tomografía computarizada de fotón único ${ }^{78}$.

La conclusión de Cytowic no puede ser comprobada como tal, ya que no hay una posibilidad de medición de estructuras tan profundas del cerebro, esto es en parte debido a la composición del gas Xenón 133, ya que las emisiones del mismo son muy tenues.

El siguiente avance en técnicas de imagenología cerebral es conocido como la "Tomografía de emisión de positrones" (PET por sus siglas en inglés) la cual, permite una exploración de sustratos más profundos de la actividad cerebral, así como, un mayor número de mediciones de la función cerebral en un mismo paciente. El método de la tomografía de emisión de positrones es bastante parecido al de la SPECT, consiste en la inyección de una sustancia radioactiva en el torrente sanguíneo, usualmente se utiliza agua radioactiva $(15 \mathrm{H} 2 \mathrm{O})$, la cual puede ser inyectada un mayor número de veces que el gas Xenón 133 en una misma sesión, sin afectar al sujeto de experimentación.

${ }^{78}$ CYTOWIC, R.E. The man who tasted shapes. New York: MIT P., p. 151 


\section{Capítulo IV.- Sinestesia.}

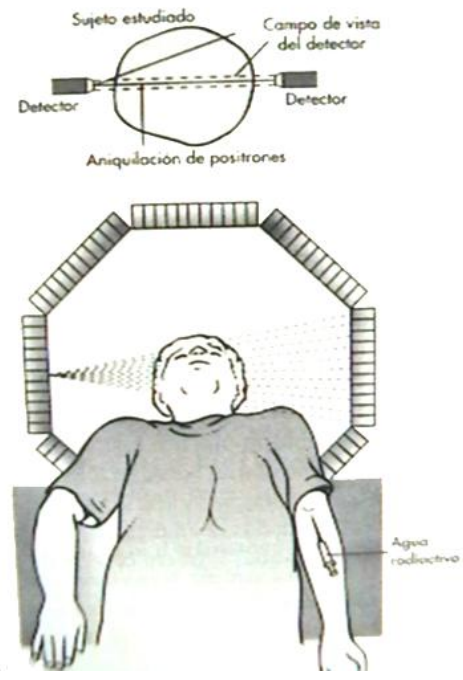

Figura 52. Esquema de una tomografía por emisión de positrones (TEP). "El compuesto radiactivo se administra por vía intravenosa. Aproximadamente treinta segundos después llega al cerebro. Los positrones en descomposición se encuentran con los electrones del tejido cerebral y se aniquilan mutuamente en un choque del cual se desprenden rayos gamma... Estos rayos son detectados por las cámaras colocadas en círculo alrededor de la cabeza del sujeto... De esta manera se obtiene un mapa de los cambios en el flujo sanguíneo". (HARRISON, John: EI Extraño Fenómeno de la Sinestesia. Ciudad de México: Ed. Fondo de Cultura Económica, 2004, p. 136.)

Los investigadores Baron-Cohen y John Harrison efectuaron una serie de experimentos en los cuales trabajaron bajo la misma hipótesis de que la actividad cerebral de un sinesteta, debería de ser distinta a la de un a-sinestésico bajo las mismas condiciones y estímulos. Se eligió un grupo de sinestetas que reaccionaran como tales, al sonido de palabras, pero no a algún otro tipo de sonido, lo que les permitiría introducir como variable de control, el sonido de tonos puros, y comparar estos resultados con el grupo de control asinestésico; como un factor añadido de control, se les vendaron los ojos a los participantes, y se experimentó con seis individuos sinestésicos y seis individuos no sinestésicos.

Como conclusiones de este experimento, John Harrison marca haber encontrado diferencias en el flujo sanguíneo entre los individuos sinestésicos y a-sinestésicos, y tal vez más sorprendente, se encontró 


\section{Capítulo IV.- Sinestesia.}

que las zonas involucradas en el procesamiento del color se activaron en los pacientes sinestésicos, a pesar de tener los ojos vendados ${ }^{79}$.

Los resultados arrojados por los experimentos que han usado las técnicas de imagenología cerebral funcional, la exploración de las funciones cerebrales, han sido poco consistentes unos con otros, excepto en un hecho, el cerebro sinestésico funciona de una manera diferente al cerebro de un a-sinestésico ante los mismos estímulos; sin embargo, no coinciden sobre las causas o las zonas de activación cerebral, es de esta forma que mientras el experimento realizado por Cytowic sobre un solo individuo, el cual poseía sinestesia del sentido del gusto con el color y formas geométricas, llevó al investigador a concluir que el fenómeno de la asociación sinestésica se encontraba en el sistema límbico, conclusión a la que llegó por los bajos niveles de irrigación sanguínea en los extractos superiores del cerebro. El experimento realizado por Baron-Cohen y John Harrison, en un grupo de sinestetas que poseían asociaciones de sonido-color, muestra zonas de activación no en el sistema límbico, sino en zonas del córtex cerebral, asociadas a la percepción del color.

Se han realizado también experimentos con la "resonancia magnética funcional" (MFR por sus siglas en inglés), implicando procedimientos menos invasivos y comprobaciones de resultados más rápidas, la MFR al igual que las otras técnicas de imagenología cerebral, mide el flujo sanguíneo regional del cerebro, y el cambio en

\footnotetext{
${ }^{79}$ HARRISON, J. El extraño fenómeno de la sinestesia. México D.F.: Fondo de Cultura Económica, 2004, p. 144
} 


\section{Capítulo IV.- Sinestesia.}

los niveles de oxígeno en la sangre. Los experimentos realizados parten de la misma idea de que una sección del cerebro que se active bajo un estímulo determinado, mostrará un incremento en el área cerebral, que tiene una función determinada. En experimentos realizados con esta técnica en pacientes con "audición colorida", mostraron una claro incremento en el flujo sanguíneo regional, en zonas involucradas en el procesamiento del color.

Son resultados opuestos los obtenidos por diferentes investigadores, en particular, los obtenidos por medio de la tomografía de emisión de fotón único (SPECT) y la tomografía de emisión de positrones con respecto la resonancia magnética (las cuales arrojan resultados similares), $\mathrm{y}$ esto ha llevado a los investigadores a considerar que no existe "un tipo de sinestesia", sino que tal vez, sería más adecuado hablar de "Sinestesias de diferentes tipos", que pueden ser diferentes incluso en las razones que las causan, y que las diferencias que arrojan los estudios de la exploración cerebral funcional, sobre la manera de comportarse del cerebro de sujetos que padecen de diferentes tipos de asociaciones sinestésicas, son un indicativo de diferentes causas y realidades, para diferentes tipos de asociaciones sensoriales.

En los estudios clásicos, el fenómeno de la sinestesia era definida como "la aparición de ciertas imágenes estereotipadas 


\section{Capítulo IV.- Sinestesia.}

producidas por una experiencia sensorial" ${ }^{\prime 80}$, pero los investigadores actuales han abandonado la idea de lo "estereotipado" de la imagen producida, por las "experiencias sensoriales primarias" (o físicamente reales). Incluso Galton, en uno de los primeros textos de carácter no artístico, sobre la sinestesia, resalta la marcada individualidad de la percepción sinestésica; en la actualidad se considera la sinestesia como algo diferente a una imaginación vivida, o poesía, o metáfora subjetiva $^{81}$. La sinestesia es una realidad en la percepción de los individuos; estableciendo que la realidad del color y del sonido dependen de manera intrínseca de la interpretación final que el cerebro de una persona realiza del fenómeno físico, hemos hablado de la sensación del color y del sonido, podemos afirmar que la percepción sinestésica es una manera de percibir el mundo, que a pesar de no ser compartida por la mayoría de la población humana, es una percepción real, no metafórica, la cual puede ser comprobada no únicamente por experimentos de orden conductual, sino mediante el monitoreo de la actividad cerebral y las diferencias que estos experimentos arrojan entre un cerebro sinestésico y uno a-sinestésico.

Aún hay mucho que investigar sobre las causas que ocasionan los diferentes tipos de sinestesias, el hecho de que un individuo padezca de dos o más percepciones ante un solo estimulo físico; una

\footnotetext{
${ }^{80}$ WHELLER R.H.; y T.D. CUTSFOTH. The Synaesthesia of a blind subject with comparative data from an Asynaesthetic blind subject. Oregon: University of Oregon P., 1922, p. 3.

${ }^{81}$ CYTOWIC R.E. \& EAGLEMAN D.M. Wednesday is indigo blue, discovering the brain of synesthesia. Cambridge: MIT P., 2009, p. 14.
} 


\section{Capítulo IV.- Sinestesia.}

teoría reciente sugiere que el fenómeno podría ser causado por una inusual "poda neuronal" alrededor de los tres años de edad.

En investigaciones sobre la red neuronal del hombre en diferentes estadíos de su vida, (algunas de ellas obtenidas desde el siglo XIX, gracias a los avances en materia de microscopía y estudios realizados por métodos de extirpación), se ha podido observar que el desarrollo del cerebro humano comienza desde que este se encuentra en el vientre materno, y que el mismo, crea una "sobrepoblación" de neuronas y de conexiones entre ellas conocidas como "sinapsis", proceso de interconexión neuronal, el cual 'continúa hasta aproximadamente los tres años de edad. El cerebro humano es extremadamente moldeable y flexible, al grado de que las experiencias y el entorno que nos rodea influye en la conformación fisiológica final del cerebro; mientras un estímulo se repite, este causa que ciertas conexiones neuronales se refuercen, y aquellas conexiones que no son reforzadas terminan por ser destruidas.

Aproximadamente entre los dos y tres años de edad, ocurre un fenómeno conocido como "poda neuronal" en el cual, de forma natural y espontánea, se destruyen un sinnúmero de conexiones intraneuronales en el cerebro; se cree que el fenómeno es realizado para dar mayor efectividad al mismo, mediante una mayor especialización de funciones y comunicación cerebral. Una hipótesis obtenida como resultado de experimentos de orden conductual en niños menores de tres años, es que todos somos sinestésicos hasta antes de esta "poda neuronal", y que cuando este fenómeno ocurre, la 


\section{Capítulo IV.- Sinestesia.}

percepción sinestésica se pierde para la mayoría de nosotros, al ocurrir una mayor especialización en las conexiones neuronales utilizadas para la percepción, aún más, desde los estudios clásicos sobre la sinestesia, se ha reportado que la mayoría de los sinestésicos recuerdan padecer de esta condición desde la infancia temprana, antes de los siete $a_{n ̃ o s}{ }^{82}$, y de la misma manera, testimonios recientes indican el recuerdo de asociaciones ligadas a un solo estímulo desde edades tempranas ${ }^{83}$; parece que mientras el individuo se desarrolla, la capacidad sinestésica se reduce. Este fenómeno ha llevado a pensar que en individuos cuya percepción sinestésica se mantiene a lo largo de su vida, esta poda neuronal fue inusual, obteniendo como resultado, que las conexiones que posiblemente unían dos o más percepciones de diferente tipo en el cerebro, y que en la mayoría de la población son desechadas para obtener una percepción más especializada, no fueron destruidas en los individuos que padecen de sinestesia hasta el final de sus días, idea que ha sido reforzada por resultados de experimentos de orden conductual en niños.

Esto es llamado como la "hipótesis neo-natal" 84 , sobre las posibles causas de la sinestesia, la cual establece que mientras somos niños, todos padecemos de la condición sinestésica, ya que muchas de las funciones especializadas en los cerebros de los niños funcionan de

\footnotetext{
${ }^{82}$ FLOURNOY T.H. Des phénomènes de synopsie (audition colorée). Paris: Félix Alcan, 1893, p. 231

${ }^{83}$ CYTOWIC, R.E. The man who tasted shapes. New York: MIT P., p. 9.

${ }^{84}$ Ibidem, p. 245.
} 


\section{Capítulo IV.- Sinestesia.}

manera muy pobre, mientras que las funciones "transmodales" del cerebro infantil funcionan correctamente; y que, probablemente a causa de una mutación genética en el cromosoma "X", la poda neuronal que debería de destruir algunas de las conexiones transmodales entre fenómenos de la percepción no es realizada, ocasionando que el estado de la sinestesia se mantenga durante toda la vida.

En la mayoría de nosotros, estas conexiones "transmodales" nunca llegan a ser conscientes, por lo cual, no percibimos nunca de manera sinestésica; sin embargo, existen evidencias de que se puede llegar a adquirir la percepción sinestésica mediante el uso de alucinógenos, (que de acuerdo a las investigaciones neuronales y el testimonio de sinestetas, no ocasionan una percepción sinestésica idéntica a la "natural"), o por efecto de diferentes patologías ocurridas en zonas específicas del cerebro, o la destrucción de zonas del cerebro, que ocasionarían un cambio irreversible en la percepción del individuo. 


\section{Capítulo IV.- Sinestesia.}

\subsection{Tipos de Sinestesia.}

Tradicionalmente, la sinestesia ha sido vinculada a fenómenos de asociación de diferentes estímulos que detonan la sensación del color; sin embargo, se han encontrado casos de sinestesia completamente distintos, y abarcando tantas variables como fenómenos de percepción son posibles en el hombre. La sinestesia parece abarcar no únicamente las funciones cerebrales primarias, como lo sería: la vista, el oído, el tacto y el gusto, o lo que podemos considerar como las funciones de percepción aisladas; toda vez que encontramos que la sinestesia parece abarcar también fenómenos que pertenecen a funciones cerebrales superiores, como: las asociadas al lenguaje, (en el caso de la sinestesia grafema-color, o número-color), así como las relacionadas con la memoria afectiva, (las respuestas a diferentes personalidades), y las asociaciones relacionadas con el tiempo y la ubicación geográfica.

Cuando se realiza un estudio sobre la posible clasificación de tipos de sinestesia, se encuentra como primer obstáculo la "rareza" del fenómeno. Actualmente existe el acuerdo que marca que un solo individuo de cada 2,000 en la población mundial, padecerá sinestesia ${ }^{85}$; estadística relativamente reciente. La incidencia marcada

${ }^{85}$ ROBERTSON, L.C.; y N. SAGIV. Synesthesia: Perspectives from cognitive neuroscience. New York: Oxford University P., 2005, p.43. 


\section{Capítulo IV.- Sinestesia.}

por los investigadores sobre sinestesia ha bajado con el lapso del tiempo, algunos investigadores marcaban la incidencia de sinestetas en la población mundial, como de un $8 \%$ a un $10 \%$ de la población, y figura que a principios de siglo, fue reducida a "no más de un 5\% , un número un poco mayor al fenómeno de la ceguera al color" ${ }^{» 86}$.

La dificultad se plantea en los mismos términos, para poder presentar un listado completo de los tipos de sinestesia. Como la sinestesia no es un fenómeno que dificulte la vida de los individuos, no existe un registro de posibles sinestetas se hayan acercado a un médico o una institución para resolver su "problema" de percepción.

Es posible determinar que una de las sinestesias aparentemente más comunes, es la conocida como "audición coloreada" de la cual existen testimonios y reportes sólidos desde el siglo XIX, sin mencionar relatos no comprobables que datan del mundo antiguo, existe una clasificación "temprana" de la sinestesia que divide los fenómenos de asociación visual en tres diferentes tipos de asociaciones de acuerdo a la sensación visual producida por un fenómeno físico: Cuando un fenómeno físico denota colores, a estos se les llamaba "fotismos", cuando desencadena figuras, se les conocía como "esquemas visuales", que eran divididos en "símbolos" o "diagramas", y por último, cuando el fenómeno físico denota una idea más compleja de asociación, como por ejemplo, cuando un sonido

\footnotetext{
${ }^{86}$ WHELLER R.H.; y T.D. CUTSFOTH. The Synaesthesia of a blind subject with comparative data from an Asynaesthetic blind subject. Oregon: University of Oregon P., 1922, p. 5 ..
} 


\section{Capítulo IV.- Sinestesia.}

denota la idea del "cemento", con las características de dureza, tacto, color, etc. que le son propias a la idea completa del concreto, o de cualquier otro "personaje" que pueda ser asociado a un fenómeno de percepción física ${ }^{87}$.

En el lapso comprendido entre finales del siglo XIX y principios del XX, tuvo lugar un inusitado interés en la investigación sobre el fenómeno de la sinestesia, que parece ir aunado a los avances técnicos de la época, en una manera similar a la que ocurre en nuestros días; y curiosamente, es notoria la preponderancia que los tratados "clásicos" sobre la sinestesia dictan como el tipo de sinestesia más usual, la "audición coloreada", o sinestesia sonido-color; de esta manera, las primeras clasificaciones de los tipos de sinestesia partían usualmente de este fenómeno particular.

Una de las primeras clasificaciones de este tipo plantea la idea de una gran división entre la "audición coloreada simple" y sinestesias del mismo tipo, como la sinestesia grafema-color, número-color, y las diferentes asociaciones entre un solo fenómeno físico de carácter no visual, el cual denota un "fotismo" o color de forma simple, sin otro tipo de asociación simultánea; y la segunda división es conocida como las "sinestesias con carácter emocional", cuando la correspondencia iba acompañada de sensaciones que ahora podríamos relacionar con

87 FLOURNOY T.H. Des phénomènes de synopsie (audition colorée). Paris: Félix Alcan, 1893, p. 8. 


\section{Capítulo IV.- Sinestesia.}

las funciones cerebrales superiores, como juicios y sentimientos, todo acompañado de más correspondencias simultaneas. ${ }^{88}$

Conforme fueron avanzando las herramientas de estadística y experimentación conductual, las clasificaciones de tipos de sinestesia, a pesar de siempre mantener un vínculo con clasificaciones anteriores, fueron obteniendo la posibilidad de convertirse en más específicas. En una clasificación clásica realizada por el Dr. Raymond H. Wheeler, en 1922, toma como punto de partida el fenómeno físico que denota la sensación sinestésica, criterio que ha sido conservado parcialmente hasta nuestros días; actualmente nos referimos al fenómeno físico comprobable y percibido por un humano como la "sensación primaria", la cual en un sinesteta detona la "sensación secundaria" o clasificada por muchos investigadores como "sensación subjetiva secundaria”, la cual es percibida únicamente por el sujeto sinestésico.

La clasificación de las "variedades conocidas de sinestesia" en 1922, por el Dr. Wheeler es la siguiente:

A. De origen acústico. En en las que comprendía las siguientes subdivisiones: "Audición colorida" de tonos, sonidos, acordes, melodías, sonidos de vocales, consonantes, palabras, y similares. "Audición gustativa", en la que el sonido escuchado es asociado a un sabor. "Audición figurada", cuando el sonido es asociado con figuras geométricas (o "diagramas" de clasificaciones

\footnotetext{
${ }^{88}$ LAURES, H. Les Synésthesies. Paris: Libraries Bloud et C., 1908, pp. 19-63.
} 


\section{Capítulo IV.- Sinestesia.}

anteriores). "Dolor auditivo", cuando una sensación táctil de dolor es asociada a un sonido.

B. De origen visual. Cuando un grafema, o figura percibida visualmente es asociada a un color distinto al "real", como un color asociado intrínsecamente a la forma.

C. De origen gustativo. Dividido en "gusto coloreado", y cuando este se encuentra asociado de forma simultánea a sensaciones secundarias de aroma y textura.

D. De origen olfativo. Cuando el olor percibido desencadena la sensación secundaria.

E. De origen cutáneo. Cuando la sensación primaria percibida tiene que ver con el tacto. El Dr. Wheeler incluye aquí las percepciones primarias de tipo "Propioceptoras" (que tienen que ver con la posición de los músculos) y/o de presión cutánea.

F. De origen Kinestésico. Cuando es el movimiento el que desencadena la sensación secundaria.

G. De origen “orgánico". Que podríamos remitir a las sensaciones afectivas o emocionales como sensación primaria, siendo estas, las detonantes de la sensación sinestésica, usualmente un color o brillo. 


\section{Capítulo IV.- Sinestesia.}

H. Personificaciones. Cuando a una letra, palabra, número o concepto, se le asigna de forma espontánea, constante y automática, características diferentes que no le son propias. $^{89}$

Es una clasificación que parte de la idea del estímulo primario que desencadena la sensación sinestésica, criterio que permanece hasta cierto punto, vigente hasta nuestros días, en que se han comenzado a "vislumbrar" las causas de la sensación sinestésica, llevando a apreciar una posible clasificación, cuyo parámetro sean: "las regiones cerebrales activadas".

En la actualidad, las clasificaciones de tipos de sinestesia tienden a ser más específicas, etiquetando cada forma de asociación por separado, e introduciendo el parámetro de "grados de sinestesia", refiriéndose al número de asociaciones simulltáneas ante un solo estímulo; de esta forma, cuando un estímulo primario produce únicamente una sensación secundaria nos referimos al fenómeno como "sinestesia de primer grado", y cuando el estímulo primario produce dos sensaciones secundarias le llamamos "sinestesia de segundo grado", y así sucesivamente. Vale la pena notar que en la sinestesia de primer grado, un solo estímulo produce dos respuestas perceptivas, la primer respuesta seria la normalmente asociada al estímulo, se nos presenta un color y como consecuencia "vemos" un

\footnotetext{
${ }^{89}$ WHELLER R.H.; y T.D. CUTSFOTH. The Synaesthesia of a blind subject with comparative data from an Asynaesthetic blind subject. Oregon: University of Oregon P., 1922, p. 4.
} 


\section{Capítulo IV.- Sinestesia.}

color, la segunda respuesta (la sensación secundaria) es la sensación sinestésica, no solo "vemos" un color, sino que también lo "escuchamos".

El neurólogo, e investigador de la sinestesia R.E. Cytowic, divide los tipos de sinestesia en dos grandes ramas: "sinestesias comunes" y "sinestesias inusuales" $"$. Entre las sinestesias comunes, podemos encontrar algunas de las "audiciones coloreadas simples". Cytowic divide las sinestesias comunes en cinco: formas de números, letras coloridas (sin hacer una división si la letra es escrita o escuchada), palabras saboreadas (ídem), audición colorida, y la personificación de letras y números.

La sinestesia de formas de números, ha sido reportada desde Galton, a finales del siglo XIX, y es usual encontrarla hasta nuestros días en los testimonios de distintos físicos y matemáticos, quienes se refieren al fenómeno como una especie de "técnica de memorización", que usan desde antes que pueden recordarlo; es conocida también como "sinestesia espacio-secuencia", y consiste en que diferentes series numéricas u operaciones matemáticas, y secuencias similares son "proyectadas" de forma automática en diferentes puntos geográficos en relación con el individuo; el individuo sinestésico podrá ver los números en espiral alrededor de él, formando figuras geométricas, o en tamaños distintos.

\footnotetext{
${ }^{90}$ CYTOWIC R.E. \& EAGLEMAN D.M. Wednesday is indigo blue, discovering the brain of synesthesia. Cambridge: MIT P., 2009, pp. 26-47.
} 


\section{Capítulo IV.- Sinestesia.}

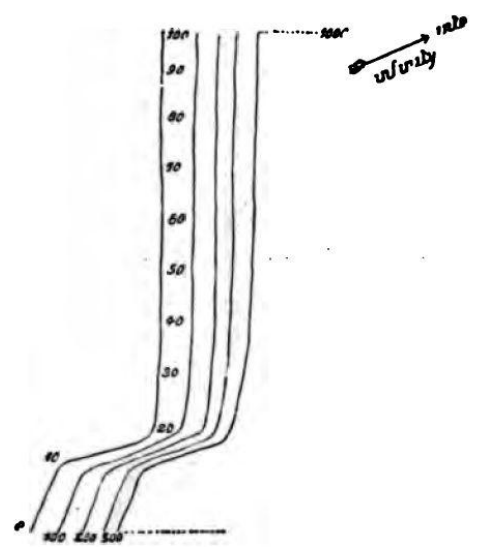

Figura 53. Diagrama de

representación realizado por "T.M."

sobre su sinestesia espacio-

secuencia. "La representación que

llevo en mi mente de las series

numéricas es sumamente distintiva

para mi, de tal forma que no puedo

pensar en un número, sino que lo veo

(como si estuviera) en un lugar

determinado del diagrama... El

diagrama está presente en mi mente

desde la infancia temprana..."

(GALTON, Francis: Inquiries into

Human Faculty and its Development.

Londres : Ed. McMillan \& Co., 1883,

p. 121).

Encontramos la sinestesia de letras coloridas, como una de las

más comunes y con incidencia más alta en la población sinestésica, mucho tiempo fue considerada como producto de asociaciones educativas desarrolladas en la infancia, la conocemos más usualmente como la sinestesia grafema-color, en ella, el individuo asocia colores al grafema escrito o escuchado de manera automática, de forma independiente a la tinta en que la letra fue escrita, los sinestetas describen el fenómeno como el color siendo intrínseco a la forma; uno de los casos más curiosos de sinestetas con este tipo de asociaciones lo constituye el compositor de música contemporánea György Ligeti (1923-2006), que al padecer de este tipo de sinestesia, curiosamente, lo aplicaba de manera creativa en algunas de sus composiciones, por ejemplo, para él, la letra "C" le producía tonos marrones, fenómeno que traducía de forma metafórica a la música, la letra " $\mathrm{C}$ ” equivale al "Do" en el sistema inglés de notación musical; en otras palabras, el compositor utilizaba un fenómeno sinestésico para crear una metáfora 


\section{Capítulo IV.- Sinestesia.}

musical. De manera similar, la artista visual y guitarrista Christine Leahy padece de sinestesia grafema-color, para la guitarrista, la letra "D" (la nota musical "Re") es de color verde, "una sensación de color verde muy vívido", de tal manera que como resultado de su sinestesia grafema-color, asocia el sonido cuando es capaz de reconocerlo. ${ }^{91} \mathrm{La}$ sinestesia grafema-color, aplica igual con los números, siendo distinta a la sinestesia de secuencias numéricas, un individuo reportaba: «Mi peculiaridad consistía en que los numerales del 1 al 9 tienen colores específicos,... el "3" es "rojo ladrillo, pálido,... el "5" es "gris negruzco"...», y de esta forma asociaba un color específico a cada numeral, de forma independiente a la tinta en que este fuera impreso.

Las "palabras saboreadas" son consideradas como una forma de sinestesia en la cual, un conjunto de letras que forman una palabra, desencadenan una sensación secundaria que envuelve al gusto, usualmente desencadenando también sensaciones de aroma y textura; a pesar de ser una forma de sinestesia menos común, existen varios testimonios y estudios sobre este fenómeno en particular, tal es el caso del orador italiano "X", mencionado por los investigadores Jamie Ward, Julie Simner y Vivian Auyeung en un artículo publicado en “Cognitive Neuropsychology” (2005, Psychology Press) en el cual mencionaba el orador que para él, la palabra "Alessandro" le "sabía" a patatas fritas. Es una forma de sinestesia que comprende la unión transmodal de funciones superiores del cerebro, con sentidos en específico.

91 SACKS O. Musicofilia. Relatos de la música y el cerebro. Barcelona: Anagrama, 2009, p. 212. 


\section{Capítulo IV.- Sinestesia.}

La "audición colorida" ha sido uno de los fenómenos de sinestesia más reportados desde los inicios de las investigaciones científicas sobre unión de los sentidos; el término es utilizado para describir la unión de colores, figuras y/o movimientos con el sonido, siendo este la sensación primaria que desencadena los "fotismos" o "diagramas" (entre otras sensaciones secundarias posibles). Encontramos fenómenos curiosos en la audición colorida, como la coincidencia de colores cuando nos referimos a sonidos aislados, fenómeno que la mayoría de investigadores consideran difícil de ocurrir. En un experimento de tipo conductual, realizado a finales del siglo XIX, se le pidió a nueve personas, en diferentes momentos, que asignaran un color a una nota temperada específica y descontextualizada, sus respuestas fueron consistentes, a pesar del lapso temporal, usualmente usado como filtro para sinestetas; de manera extraordinaria, las respuestas fueron muy similares entre los individuos, por ejemplo, cuando se les pidió escuchar un "Do", de los nueve individuos tres lo asociaron con el color "blanco" y tres con el color "amarillo"; de los tres restantes, uno no externó asociación alguna de color con esa nota en particular, el segundo, lo asoció con el rosa y el tercero, con el verde. ${ }^{92}$

La "personificación” de letras y números o "grafemas personificados"93, consiste en la asociación de características de

\footnotetext{
92 FLOURNOY T.H. Des phénomènes de synopsie (audition colorée). Paris: Félix Alcan, 1893, p. 99.

${ }^{93}$ CYTOWIC R.E. \& EAGLEMAN D.M. Wednesday is indigo blue, discovering the brain of synesthesia. Cambridge: MIT P., 2009, p. 40.
} 


\section{Capítulo IV.- Sinestesia.}

personalidad humana unidas a una letra, como si la letra fuera una persona real con características de género; de esta forma, un sinesteta con esta condición puede decir que la letra "M" es masculina y le "gusta" (condición afectiva, asociación realizada por una mujer, cuyo nombre empezaba con "M"), o que el número "4 es una buena dama, complaciente, absorbida por las ocupaciones materiales" $"$.

Cada una de las "sinestesias comunes", son en realidad altamente individuales, cambian de forma constante entre individuos, pero cada individuo permanece con sus mismas asociaciones siempre, y lo que acabamos de representar es solo una pequeña muestra de las variantes posibles de las sinestesias generalizadas aquí. Una de las "sinestesias inusuales" descritas por Cytowic, es la sinestesia "audiomotora". Al respecto un sinesteta decía que ciertos tipos de sonidos que él no era capaz de contextualizar (como palabras en un idioma extranjero) le "obligaban" a asumir ciertas posturas corporales 95 . Exiten reportes de asociaciones con el sistema de escritura "Braille" y la luminosidad (un caso reportado de una persona con ceguera adquirida), quien tenía desde chica sinestesia grafema-color; existen varios casos de sinestesia sonido-tacto, en la cual el sonido produce sensaciones de presión o textura en la región cutánea del sinesteta; sinestesia vista-oído, en la que la sensación primaria es el sentido de la vista y la sensación sinestésica, es la sensación de escuchar.

\footnotetext{
94 FLOURNOY T.H. Des phénomènes de synopsie (audition colorée). Paris: Félix Alcan, 1893, p. 219.

${ }^{95}$ CYTOWIC R.E. \& EAGLEMAN D.M. Wednesday is indigo blue, discovering the brain of synesthesia. Cambridge: MIT P., 2009, p. 41.
} 


\section{Capítulo IV.- Sinestesia.}

Se ha encontrado una variedad considerable de diferentes tipos de sinestesia, algunas de ellas involucran factores como la temperatura, que puede ser asociada a colores o sonidos, sabores con sensaciones táctiles ${ }^{96}$, sabores con sonidos, y un sinnúmero de diferentes combinaciones y parámetros de asociaciones entre diferentes modos de percepción. Por tanto, no puede afirmarse que se ha realizado un listado absoluto sobre los diferentes tipos de sinestesia posibles, sin embargo, la realidad fisiológica del fenómeno parece ser cada vez más incontrovertible. De manera general, el neurólogo Sean Day, investigador del fenómeno, y sinesteta él mismo, ha elaborado una tabla de sinestesias encontradas hasta nuestros días, realizó un muestreo no-aleatorio con 1090 individuos sinestetas, encontrando "un mínimo" de 61 tipos diferentes de sinestesias, la tabla esta ordenada colocando el "estímulo primario" al inicio, seguida de la "percepción secundaria", a continuación el número de sinestetas que reportan la asociación en cuestión, sobre el número de sinestetas investigados, y al final, el porcentaje correspondiente. ${ }^{97}$

\begin{tabular}{|l|r|r|}
\hline $\begin{array}{l}\text { Espacio-secuencia (formas } \\
\text { números) }\end{array}$ & $=77 / 1014$ & $=7.6 \%$ \\
\hline Grafema-color & $=707 / 1090$ & $=64.9 \%$ \\
\hline Unidades Temporales-color & $=252 / 1090$ & $=23.1 \%$ \\
\hline Sonido musical-color & $=207 / 1090$ & $=19.0 \%$ \\
\hline Sonido-color & $=163 / 1090$ & $=15.0 \%$ \\
\hline
\end{tabular}

\footnotetext{
${ }^{96}$ CYTOWIC, R.E. The man who tasted shapes. New York: MIT P., p. 64.

97 DAY, S. "Types of Synesthesia." [en línea]. Disponible en: http://home.comcast.net/ sean.day/html/types.htm [Consulta: 31 Diciembre 2010].
} 
Capítulo IV.- Sinestesia.

\begin{tabular}{|c|c|c|}
\hline Nota musical-color & $=90 / 1090$ & $=8.3 \%$ \\
\hline Fonema-color & $=86 / 1090$ & $=7.9 \%$ \\
\hline Sabor-color & $=69 / 1090$ & $=6.3 \%$ \\
\hline Personalidad-color (auras) & $=69 / 1090$ & $=6.3 \%$ \\
\hline Olor-color & $=68 / 1090$ & $=6.2 \%$ \\
\hline Dolor-color & $=57 / 1090$ & $=5.2 \%$ \\
\hline Tacto-color & $=41 / 1090$ & $=3.8 \%$ \\
\hline Emoción-color & $=28 / 1090$ & $=2.6 \%$ \\
\hline Temperatura-color & $=23 / 1090$ & $=2.1 \%$ \\
\hline Orgasmo-color & $=23 / 1090$ & $=2.1 \%$ \\
\hline Emoción-olor & $=2 / 1090$ & $=0.2 \%$ \\
\hline Grafemas personificados & $=45 / 1090$ & $=4.1 \%$ \\
\hline Objetos personificados & $=17 / 1090$ & $=1.6 \%$ \\
\hline Emoción-sabor & $=2 / 1090$ & $=0.2 \%$ \\
\hline Emoción-dolor & $=2 / 1090$ & $=0.2 \%$ \\
\hline Emoción-olor & $=2 / 1090$ & $=0.2 \%$ \\
\hline Emoción-temperatura & $=1 / 1090$ & $=0.1 \%$ \\
\hline Emoción-tacto & $=1 / 1090$ & $=0.1 \%$ \\
\hline Sabor-sonido & $=2 / 1090$ & $=0.2 \%$ \\
\hline Sabor-temperatura & $=1 / 1090$ & $=0.1 \%$ \\
\hline Sabor-tacto & $=6 / 1090$ & $=0.6 \%$ \\
\hline Grafema-color & $=1 / 1090$ & $=0.1 \%$ \\
\hline Movimiento-sonido & $=4 / 1090$ & $=0.4 \%$ \\
\hline Lexema-sabor & $=27 / 1090$ & $=2.5 \%$ \\
\hline Lexema-tacto & $=1 / 1090$ & $=0.1 \%$ \\
\hline Nota musical-sabor & $=3 / 1090$ & $=0.3 \%$ \\
\hline
\end{tabular}


Capítulo IV.- Sinestesia.

\begin{tabular}{|c|c|c|}
\hline Dolor-sabor & $=1 / 1090$ & $=0.1 \%$ \\
\hline Dolor-sonido & $=1 / 1090$ & $=0.1 \%$ \\
\hline Personalidad-olor & $=5 / 1090$ & $=0.5 \%$ \\
\hline Personalidad-tacto & $=2 / 1090$ & $=0.2 \%$ \\
\hline Fonema-tacto & $=1 / 1090$ & $=0.1 \%$ \\
\hline Olor-sabor & $=2 / 1090$ & $=0.2 \%$ \\
\hline Olor-sonido & $=5 / 1090$ & $=0.5 \%$ \\
\hline Olor-temperatura & $=1 / 1090$ & $=0.1 \%$ \\
\hline Olor-tacto & $=5 / 1090$ & $=0.5 \%$ \\
\hline Sonido-sabor & $=59 / 1090$ & $=5.4 \%$ \\
\hline Sonido-movimiento & $=5 / 1090$ & $=0.5 \%$ \\
\hline Sonido-olor & $=15 / 1090$ & $=1.4 \%$ \\
\hline Sonido-temperatura & $=6 / 1090$ & $=0.6 \%$ \\
\hline Sonido-tacto & $=43 / 1090$ & $=3.9 \%$ \\
\hline Temperatura-sabor & $=1 / 1090$ & $=0.1 \%$ \\
\hline Temperatura-sonido & $=1 / 1090$ & $=0.1 \%$ \\
\hline Tacto-emoción & $=2 / 1100$ & $=0.2 \%$ \\
\hline Tacto-sabor & $=11 / 1090$ & $=1.0 \%$ \\
\hline Tacto-olor & $=3 / 1090$ & $=0.3 \%$ \\
\hline Tacto-sonido & $=6 / 1090$ & $=0.6 \%$ \\
\hline Tacto-temperaturas & $=1 / 1090$ & $=0.1 \%$ \\
\hline Vista-movimientos & $=1 / 1090$ & $=0.1 \%$ \\
\hline Vista-olores & $=14 / 1090$ & $=1.3 \%$ \\
\hline Vista-sonidos & $=25 / 1090$ & $=2.3 \%$ \\
\hline Vista-sabores & $=29 / 1090$ & $=2.7 \%$ \\
\hline Vista-temperaturas & $=2 / 1090$ & $=0.2 \%$ \\
\hline
\end{tabular}




\begin{tabular}{|l|l}
\hline Vista-tacto & $=18 / 1090=1.7 \%$ \\
\hline
\end{tabular}

Hemos eliminado de la tabla las sinestesias que se reportaban "con datos insuficientes", como la sinestesia "tacto en espejo", o la "tickertape" sinestesia en la que el individuo "ve" las palabras como en una colorida cinta de teletipo desenrollándose alrededor de él, que implica en én sí, una combinación de sinestesia espacio-secuencia, que atañe a los grafemas; sinestesias extremadamente inusuales. Como podemos nuevamente observar, la sinestesia Grafema-color, es la asociación más usual, con un $64.9 \%$ de incidencia en la muestra; la sinestesia nota musical-color, es relativamente inusual, (a pesar de ser una de las más reportadas desde el siglo XIX), que marca una incidencia de $8.3 \%$ en la muestra de Day; y de las más inusuales, pero con datos suficientes en el muestreo, encontramos las asociaciones relacionadas con la temperatura y el movimiento, con un porcentaje menor al $1 \%$.

Una muestra importante, pero aún incompleta (como lo marca el mismo investigador Sean Day), sin embargo, siguen realizándose esfuerzos no solo por entender el fenómeno, sino por conseguir un muestreo lo más amplio posible de las diferentes asociaciones intrasensoriales relacionadas con el fenómeno fisiológico de la sinestesia; en estos momentos podemos mencionar los esfuerzos realizados por investigadores como Eagleman, coautor de "Wednesday is Indigo Blue" a través de la Web con su sitio de investigación "The 


\section{Capítulo IV.- Sinestesia.}

Synesthesia Battery"98, la "Asociación Americana de Sinestesia" (A.S.A. por sus siglas en ingléss), e investigadores como Hubbard, Ramachandran, Baron-Cohen y otros, los cuales, continúan no solo con la experimentación en el área de imagenología cerebral y de tipo conductual, sino realizando labor estadística sobre el fenómeno.

Las nuevas herramientas de información digital y comunicación han permitido comenzar a vislumbrar la posibilidad de un listado más cercano a la extensa variedad de sinestesias existentes, la información sigue recopilándose, y es de esperar que en un lapso corto de tiempo, podamos comenzar a entrever un estándar de la variedad de fenómenos de asociación de percepciones humanas, que tengan su inicio en causas fisiológicas, y que contengan las características de lo que es conocido en nuestros días como "percepciones sinestésicas auténticas".

${ }^{98}$ EAGLEMAN D.M.; et al. "The synesthesia battery.” [en línea]. Disponible en: http://www.synesthete.org/ [Consulta: 31 Diciembre 2010]. 


\section{Capítulo IV.- Sinestesia.}

\subsection{Arte Sinestésico.}

Conocemos como "arte sinestésico" las manifestaciones artísticas que han explorado posibles correspondencias entre dos o más sentidos, comúnmente ligado al concepto de "obra de arte total", el arte sinestésico establece correspondencias entre diferentes disciplinas artísticas, y trabaja con las posibilidades de interacción entre diferentes sentidos cuando el público percibe de manera simultánea estímulos de diferente naturaleza. Vale la pena destacar que el arte sinestésico no parece compartir una preocupación de índole social, o política-religiosa-mística, que parece ser una preocupación grande en la obra de arte total; sin excluir la posibilidad, El arte sinestésico toma como parámetro el establecimiento de posibles nexos o correspondencias de índole funcional o significativa entre la luz y el sonido, la poesía y la imagen u otras impresiones de tipo sensorial.

Han existido numerosos exponentes y escuelas del arte sinestésico, desde Kandinsky y la Bauhaus, hasta Alexander Scriabine y Olivier Messiaen; el arte sinestésico no siempre es realizado por "sinestetas auténticos", y tampoco parece tener como requisito el plantear al público la posible "visión sinestésica auténtica", ya que como diversos autores han señalado, la sinestesia es un fenómeno de las personas. Hay personas sinestésicas y personas que no lo son, y la audición (o visualización) de una obra de arte sinestésico no crea el fenómeno en el individuo; por decirlo de otra manera, no es posible 


\section{Capítulo IV.- Sinestesia.}

“crear" sinestesia en los individuos, parecerá ocioso señalarlo, pero nos parece importante remarcarlo. Históricamente el arte ha hecho uso de herramientas de todo tipo para establecer un mensaje o sensación, y el conocimiento del fenómeno de la sinestesia en nuestros días, es una herramienta más, que el conocimiento humano, utiliza en sus ramas creativas.

En realidad, la obra de arte que establece correspondencias entre diferentes estímulos, y que posiblemente haya sido definida como sinestésica, existe en la sociedad occidental desde el mundo antiguo, así como en diferentes sociedades no occidentales, encontramos definiciones del fenómeno desde la misma etimología del fenómeno, la cual proviene del mundo griego. Es con el filósofo griego Pitágoras (582 A.C.-507 A.C.) que encontramos una de las primeras correspondencias entre diferentes fenómenos sensoriales en el mundo occidental. Pitágoras establece una relación de proporciones numéricas entre sonidos (o intervalos sonoros), al descubrir que una cuerda de $x$ longitud produce un sonido que al ser reproducido por una cuerda de la mitad del tamaño, con una tensión igual a la primera cuerda, producirá el sonido de una "octava" musical o el doble de frecuencias sonoras; a través de las proporciones matemáticas, de la idea de los "números como cosas" que eran conceptualizados como el principio creador de todo fenómeno físico, Pitágoras establece una correspondencia entre los sonidos de la escala musical pitagórica y los planetas, en lo que llamo "Armonía de las esferas", trabajando bajo la premisa de que el movimiento de los planetas (o esferas) producía sonidos determinados, los cuales podían ser expresados mediante 


\section{Capítulo IV.- Sinestesia.}

proporciones armónicas perfectas. La correspondencia de Pitágoras, tenía sus fundamentos en las matemáticas, como un todo, que a través del concepto del número permitía la explicación y relación entre cualquier fenómeno perceptivo como el movimiento, la combinación de colores y la armonía musical.

Platón (427 A.C.- 347 A.C.), retoma la idea pitagórica de la universalidad de las cosas y su expresión a través de los números y las proporciones, ${ }^{99}$ siendo la proporción el factor de unión entre todo tipo de fenómeno, ${ }^{100}$ desde la perspectiva platónica de los fenómenos sensoriales, los fenómenos naturales y la percepción de los mismos no pueden ser independientes uno de otro, Platón habla del fenómeno de percepción humana, como intrínsecamente sinestésico ya que cualquier fenómeno es parte del "Todo divino", y puede ser explicado y relacionado por medio de la proporción matemática como el elemento de unión entre las cosas "físicas" o perceptibles. Partiendo del experimento Pitagórico, Platón coloca en los extremos de las proporciones de la luz, los colores negro y blanco, obteniendo el resto de su paleta de las proporciones posibles entre estos, utilizando las mismas proporciones que Pitágoras usó para sus experimentos con cuerdas, para obtener las proporciones musicales, estableciendo de esta forma un correspondencia entre la luz y el sonido.

\footnotetext{
${ }^{99}$ ARCHER-HIND, R.D: The Timaeus of Plato. London: Mac Millan and Co., 1888, p. 97.

${ }^{100}$ Ibidem., p. 255
} 


\section{Capítulo IV.- Sinestesia.}

Aristóteles (384 A.C.-322 A.C.), continúa con el trabajo de sus antecesores y obtiene una mezcla ligeramente distinta de colores que la de Platón, sin embargo, de la misma manera que se convierte en una constante en la escuela filosófica griega, Aristóteles nos habla de un principio universal de las cosas, y como las matemáticas pueden servir de principio unificador de las mismas, de esta forma, Aristóteles nos menciona en De Sensu et de Sensiti:

"Es, pues, posible creer que hay más colores que el simple negro y blanco, y que su número se debe a la proporción de sus componentes; estos, en efecto, pueden agruparse según las proporciones de tres a dos, o de cuatro a tres, o bien en otras proporciones numéricas $-\mathrm{o}$ bien incluso pueden existir en alguna proporción inexpresable, sino en una relación inconmensurable de exceso o efecto-, de tal manera que estos colores vienen determinados de igual manera que los intervalos musicales" ${ }^{\prime 101}$.

Obteniendo de esta manera el principio filosófico para la creación de una interacción entre dos sensaciones distintas; el principio unificador serían los números, en específico, el manejo de la proporción, proporción establecida mediante la experimentación por Pitágoras, al establecer este las relaciones proporcionales que rigen de facto entre los intervalos musicales.

Es posible notar que la correspondencia establecida de esta forma, no es una relación de tono con color, sino de proporción interválica, la traducción práctica sería realizada entre intervalos musicales y colores; es una correspondencia sinestésica cuyas bases

\footnotetext{
${ }^{101}$ ARISTOTELES; Samaranch, F. (trad., prol.). De lo Sentido y lo Sensible; De la Memoria y el Recuerdo. Buenos Aires: Aguilar, 1966. p. 23.
} 


\section{Capítulo IV.- Sinestesia.}

de planteamiento fueron dictadas no por un fenómeno de sinestesia fisiológica, sino por un planteamiento filosófico, que trataba de explicar la naturaleza de las "cosas" y el fenómeno de percepción humano.Encontramos de esta forma, que desde los fundamentos del pensamiento occidental, existe la idea de una posible correspondencia entre distintos fenómenos sensoriales; en el pensamiento griego, esta correspondencia no estaba limitada únicamente al establecimiento de relaciones entre la luz y el sonido, iba mucho más lejos, incluyendo a las sensaciones de tacto, gusto y aroma.

También en el arte tradicional oriental, podemos encontrar múltiples correspondencias entre fenómenos sensoriales de distinta índole; en el caso particular del arte hindú, encontramos que el objeto de arte no es una "cosa" por sí misma, sino una manifestación de los múltiples aspectos de la vida espiritual hindú. ${ }^{102}$ De esta forma, en el arte de la India, existen múltiples simbolismos, los cuales determinan la forma, colores y sonidos de las diferentes disciplinas artísticas, estableciendo entre estas, relaciones intrínsecas con una función místico-religiosa.

El arte hindú no es una mera manifestación de índole religiosa, un intento de representar a una divinidad o una anécdota, existe en la producción del arte hindú el aspecto conocido como "Rasa", o el "sentimiento desapasionado", y el aspecto de la obra es juzgado por el "grado" de "Rasa" que el creador es capaz de comunicar al

102 BHATTACHARYA, B.C. "Indian Art and Iconography" Rupam, an Illustrated Quarterly Journal of Oriental Art. 1920, Vol. 2, p. 19. 


\section{Capítulo IV.- Sinestesia.}

espectador. Este aspecto del arte hindú no es unívoco, de la misma manera que en los diferentes individuos, los estados mentales, de ánimo y de percepción varían de acuerdo a la circunstancia, existen diferentes tipos de Rasa en las manifestaciones artísticas de la India; siendo los diferentes Rasa: la esencia de un poema, una obra teatral, una escultura o la música tradicional, estos eran divididos en nueve: El amor, risa, dolor, tristeza, rabia, animación, miedo, repugnancia y asombro. ${ }^{103}$ Las imágenes, el drama, la escultura y las diferentes disciplinas artísticas, eran realizadas en función de transmitir varios de estos aspectos de la vida espiritual humana, siendo el objeto de arte el punto de unión de esta multiplicidad de "estados" anímicos.

De esta forma, el "gesto" o movimiento en una escultura tenía una carga significativa, y con ello, eran expresados estos diferentes aspectos de índole espiritual, la posición de un brazo o la expresión de un rostro, eran realizados teniendo en mente la expresión de un aspecto simbólico, a diferencia del arte occidental en el cual existía de forma preponderante una preocupación formal unida a una carga racional. En un objeto de arte hindú, existe un cúmulo de interacciones de múltiples sentimientos y percepciones, los que en ocasiones eran de índoles opuestas.

Este aspecto de fondo, resulta fundamental en la forma de las expresiones artísticas hindús, como uno de los resultados más característicos y de mayor influencia en las artes escénicas se

\footnotetext{
${ }^{103}$ Ibidem., p. 21.
} 


\section{Capítulo IV.- Sinestesia.}

encuentra el tratado "Natya Sastra" atribuido a Bharata Natya (200 A.C.-200 D.C.), personaje casi mítico de la India, el cual se cree realizó la compilación de este tratado de las artes escénicas, su función y simbolismos.

En el "Natya Sastra" se describe a la danza como un elemento de cohesión entre las diferentes artes, y la forma en que los "Vedas" (divinidades) esperaban transmitir a la humanidad la forma correcta de vivir; el tratado cubre virtualmente cada aspecto de la representación escénica, desde el maquillaje y vestuario, hasta la posición de diferentes partes corporales, como una inclinación del rostro o la posición de un brazo; y también toca el tema de la música y la escala musical hindú. Este tratado, y las relaciones interdisciplinares que establece, resultó de una importancia y trascendencia tan grandes para las artes de la India, que tratados posteriores de arte como el "Vishnudharmottara", hacen referencia a él con frases como: "Sin conocimiento del arte de la danza, las reglas de la pintura son muy difíciles de comprender"; relaciones establecidas además, en toda disciplina artística, las reglas de fondo que involucraban a las Rasa en la danza, eran las mismas para la pintura, la música, la poesía, y todas las manifestaciones artísticas.

En el libro de Bharata Natya, se establece además, una correspondencia entre colores, música y la fisiología humana a través del concepto de los "Chakras". En la medicina "trántica” de la India, existe la referencia a los "Chakras" cuya traducción aproximada sería "ruedas", que se creía, estaban colocadas en distintos sitios del cuerpo 


\section{Capítulo IV.- Sinestesia.}

humano, y tenían funciones que involucraban desde la respiración humana, a la capacidad perceptivo-sensorial, e influían en aspectos de la salud del hombre. Los Chakras se encontraban colocados en puntos neurálgicos del cuerpo, que la medicina occidental identifica como centros de comunicación nerviosa, de índole perceptiva. El número de Chakras encontrados en el cuerpo humano, de acuerdo a la tradición hindú, varía de autor en autor, en la práctica de disciplinas como el budismo y el yoga, existen siete, los cuales tienen además de una función fisiológica, asignado un color y una frecuencia sonora, unida de forma intrínseca a una frase o mantra, cuya repetición constante, unida a la meditación y frecuencia sonora correcta, se creía “despertaba" esta especie de "órgano" y contribuía a una más clara percepción del mundo.

De acuerdo a Bharata Natya, los Chakras y los intervalos musicales conocidos como shruti, ${ }^{104}$ se encontraban en el cuerpo, y estaban relacionados con el color y la función anatómica del Chakra, el intervalo musical iba ascendiendo de frecuencia, conforme se encontraba en una posición superior del cuerpo, hasta que llegaba al pecho, en donde adquiría la suficiente amplitud para poder ser percibido a 22 shrutis, la frecuencia lumínica correspondiente también cambiaba en relación a la frecuencia sonora y la función anatómica. Los Chakras y sus relaciones eran las siguientes:

${ }^{104}$ Ver cap. "La tonalidad en la música. Otras afinaciones". 


\section{Capítulo IV.- Sinestesia.}

1. Muladhara. Que se encontraba en la próstata, su frase o mantra, es lam, y su color rojo, se le asignaba la frecuencia sonora más grave.

2. Suadhisthana. En el sacro, su mantra es vam, y el color naranja.

3. Manipura. En el plexo solar, el mantra es ram, su color amarillo, este Chakra es el que Bharata Natya ubica a 22 shutis.

4. Anajata. En el corazón y pulmones, el mantra es iam, el color verde.

5. Vishuddha. En la garganta, de color azul y su mantra es jam.

6. Agñá. En la frente, de color añil, su mantra es Khsam.

7. Sajasrara. En la coronilla, de color violeta, su mantra es el conocido como Om. Algunos autores lo ubican a la octava musical del Chakra "Manipura" a 44 shrutis del generador.

De esta forma, en el tratado "Natya Sastra" encontramos el establecimiento de una correspondencia entre colores, intervalos musicales y estados del alma, unidos además a posibilidades de percepción y salud humana; utilizando los conceptos del Chakra y el Rasa, se realizaba una correspondencia no solo entre disciplinas artísticas, sino en aspectos que eran considerados por las sociedades 


\section{Capítulo IV.- Sinestesia.}

orientales, en particular la hindú, como fundamentales en la vida humana. La teoría de los Rasa, era el factor de unión entre los objetos de arte y las disciplinas escénicas, realizando una función similar a la de la proporción, en el arte griego.

Giuseppe Arcimboldo (1527-1593), pintor italiano nacido en Milán, es principalmente conocido como un pintor "manierista", en la actualidad, algunos de sus trabajos más reconocidos comúnmente son sus "caprichos" alegóricos.

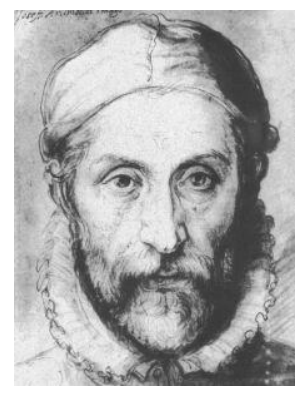

Figura 54. Arcimboldo. Autorretrato.

Arcimboldo radicó y trabajó durante la mayor parte de su vida en Milán, no obstante, parece haber gozado de un importante grado de reconocimiento en vida, de manera que trabajó en las cortes de Rodolfo II, para los Habsburgo, y en la corte de Maximiliano II como retratista, además de haber recibido múltiples encargos de índole eclesiástica. Gozando de una personalidad altamente creativa, Arcimboldo construyó además, varios “inventos” para el entretenimiento de las cortes.

Los "caprichos" alegóricos de Arcimboldo, probablemente sus obras más representativas en nuestros días, son imágenes en las que la 


\section{Capítulo IV.- Sinestesia.}

naturaleza se "funde" para formar por medio de la asociación, figuras antropomorfas; tal es el caso de "Vertumnus", un retrato de Rodolfo II (Emperador de 1576 a 1612), imagen construida a base de vegetales y frutos, con la que crea la analogía del retrato del emperador, o su serie sobre las estaciones del año, con figuras antropomorfas alegóricas a la naturaleza que predomina durante épocas específicas del año.

A finales del siglo XVI, mientras Arcimboldo se encontraba trabajando en Praga en la corte de Rodolfo II, desarrolló una correspondencia de valores entre las notas musicales y el color; mediante la creación de una "tabla de correspondencias", Arcimboldo relacionaba lo que se cree eran sonidos en específico, probablemente relaciones proporcionales entre intervalos musicales pitagóricos, y gradaciones de color; la tabla de correspondencias consistía en cuatro o cinco columnas con diferentes matices de color, los cuales estaban graduados en doce grados de luminosidad acomodados en hileras, equivalentes cada uno al paso de un semitono musical, incluyendo la relación de la doble octava (relación de 4:1) musical Pitagórica.

En la base, equivalente al sonido más grave o generador, se encontraba el blanco, y conforme las relaciones interválicas "ascendían" hacia la octava, se acercaban al negro; los matices utilizados por Arcimboldo contenían en la base la escala de 12 grises (13 incluyendo al blanco), arriba de esta fila, el amarillo, arriba el 


\section{Capítulo IV.- Sinestesia.}

verde, después el azul, y finalizaba con el púrpura o rojo, cada una de las filas graduadas en los mismos grados de luminosidad. ${ }^{105}$

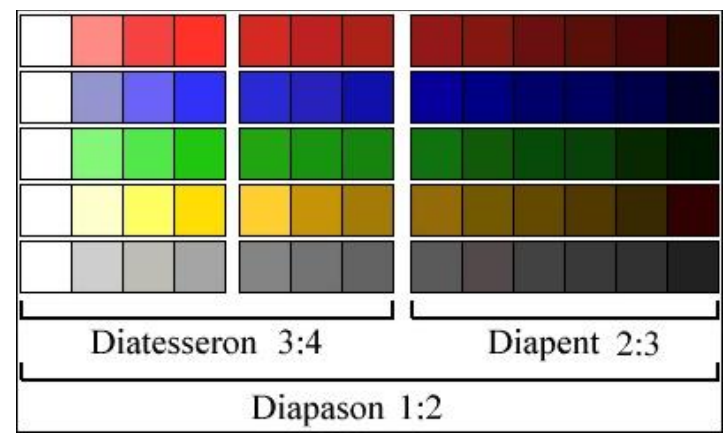

Figura 55. Tabla de correspondencias interválicas del sonido afinado y color de Arcimboldo.

Existen descripciones por músicos como Mauro Cremonese, ejecutante de viola, quien era capaz de tocar las "consonancias" que Arcimboldo dibujó "con colores sobre una hoja de papel”"106, además de mencionar que la tabla descrita utilizaba "modulaciones" del gris al amarillo, y a los otros colores de la tabla, conforme el centro tonal musical cambiaba; el uso de los términos "consonancias" y "modulaciones" nos refiere de manera intrínseca a que la tabla de Arcimboldo tenía un funcionamiento similar al dictado por la escuela de pensamiento griego: una relación interválica; esto unido al pensamiento de la "modulación" nos extiende la posibilidad de que la tabla de relaciones color-sonido, poseía también la característica de

\footnotetext{
105 PAVEY D.A. Color and Humanism. Florida: Universal Publishers, 2008, pp. 129-130.

${ }^{106}$ GAGE, J. Color y Cultura. Madrid: Siruela, 1993, p.230
} 


\section{Capítulo IV.- Sinestesia.}

ser un auxiliar en la enseñanza de la armonía tanto en el lenguaje pictórico, como el musical.

Algo que en esta tabla de relaciones color-sonido notamos como una paradoja, es el hecho de que en la correspondencia de Arcimboldo, creemos que asignaba los colores más brillantes para las notas más graves, y conforme ascendía hacia la octava, descendían en valor lumínico; es posible imaginar la razón histórica de esta gradación "inversa" del color, al tomar en cuenta la construcción de instrumentos y afinaciones en la época de Arcimboldo. Las afinaciones en el siglo XVI en Europa, partían de un tono base inferior al que es usado actualmente, la referencia de tono para afinar las cuerdas de un instrumento como el cembalo era de alrededor de 428 Hz., cuando en la época actual lo usual es que la misma nota se encuentre a $440 \mathrm{~Hz}$. o incluso, a $444 \mathrm{~Hz}$. (Orquesta de Dresde); y no solo esto, las afinaciones con un mayor índice de frecuencias (sonidos más agudos) que implican una mayor tensión en las cuerdas, no siempre producían un efecto "agradable", y en muchos casos, la producción de los armónicos secundarios era muy reducida en comparación con nuestros días; como consecuencia de la afinación y construcción de instrumentos, limitados por los materiales y aleaciones de la época, los sonidos graves eran mucho más sonoros y "ricos" en producción de armónicos que los agudos, en comparación con la concepción actual de los mismos. Es posible, que Arcimboldo haya realizado una referencia a este hecho, al establecer que la mayor 


\section{Capítulo IV.- Sinestesia.}

cantidad de luz se encontraba en las notas más graves, o sonidos base de la armonía.

Marín Cureau de la Chambre (1594-1669), físico y filósofo francés que trabajó para Luis XIV, alrededor de 1640, nos proporciona una explicación más, para la correspondencia de colores graves con los colores más brillantes y la luz; en su libro "Nouvelles Observations et Coniectures sur l'iris", Cureau de la Chambre, nos proporciona las razones de la época para esta aparente paradoja, además de establecer una nueva correspondencia entre los sentidos, cuyas bases se encuentran en el conocimiento de la Grecia clásica.

Cureau de la Chambre, además de ser físico y filósofo, realizó traducciones de diversos textos griegos como "Physica" de Aristóteles, y fue influenciado por pensadores como Galeno (130200), médico griego que ejerció gran influencia en Europa. Partiendo de la idea griega de los "humores" como fluidos vitales presentes en las personas, y los "pneumas" como diferentes tipos de "alma" (como principios de movimiento en el cuerpo humano), Cureau establece la posibilidad de conocer el carácter de una persona a partir de su apariencia, ya que las pasiones y los caracteres, no solo eran de índole moral, sino que tenían influencia en el físico de una persona, el carácter o pasión dominante moldeaban el cuerpo humano. ${ }^{107}$

${ }^{107}$ DE LA CHAMBRE M.C. Les Characteres des passions. Paris: P. Blaise, 1640, pp. 4- 5 . 


\section{Capítulo IV.- Sinestesia.}

Siendo Cureau de la Chambre uno de los fundadores de la Academia Francesa, sus intereses eran amplios, publicando tratados de índole científico sobre diversos temas en los que incluyó el color y el sonido, además de las diversas sensaciones y percepciones humanas. En sus investigaciones sobre el color y el sonido, Cureau parte del conocimiento Pitagórico de la armonía, y la proporción armónica entre los sonidos "agradables" y "desagradables", mencionando de manera repetida el experimento de cuerdas realizado por Pitágoras, en el cual establece las proporciones para los intervalos musicales, como la octava musical, y esta, al tener la proporción más simple (2:1) proporcionaba también la consonancia más agradable, la sensación de mayor refuerzo, al igual que la doble octava (4:1), que a pesar de no poseer una proporción tan perfecta como la octava simple, aun era una proporción agradable y "pura".

Teniendo al número como factor de unión y la proporción como la representación de la armonía, Cureau menciona cómo este conocimiento es fácilmente comprobable, Pitágoras lo realizó con el tendido de diferentes cuerdas del mismo grosor y misma tensión, con diferentes longitudes; y como el sonido es producido por la vibración, o movimiento realizado por las cuerdas saliendo y regresando de su posición original (el fenómeno vibratorio).

Partiendo de este conocimiento previamente comprobado en la Grecia antigua, Cureau establece un paralelismo con la producción del 


\section{Capítulo IV.- Sinestesia.}

sonido y del color, como movimiento vibratorio de la luz, ${ }^{108}$ y de la misma manera en que la producción es similar, retomando a Aristóteles, menciona cómo en la luz existen dos extremos, la luz como el blanco y la ausencia de la misma como el negro, y cómo la combinación de ambos extremos en las mismas proporciones previamente comprobadas en el sonido, producen los diferentes colores. El siguiente paso obvio, era establecer una correspondencia entre ambos fenómenos, cosa que Cureau realizó. Estableciendo una graduación de doce pasos entre el blanco y el negro, y combinándolos, fue el primer paso de Cureau para la creación de los colores en la naturaleza.

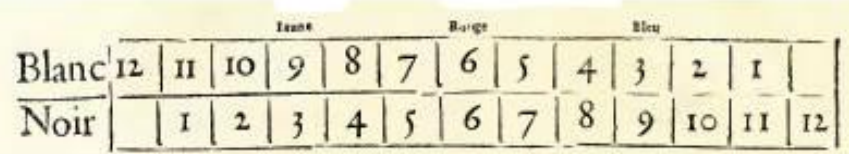

Figura 56. Graduación de doce pasos entre el blanco y el negro. Cureau de la Chambre (DE LA CHAMBRE, Marin C.: Nouvelles Observations et Coniectures sur I'iris. París : Ed. P. Blaise, 1650, p. 64).

Al establecer el blanco como la plenitud de la luz y el negro como la ausencia de la misma, establece el negativismo de la luz como lo más alejado de la naturaleza, puesto que en la misma hay luz. Siguiendo el mismo razonamiento, Cureau menciona cómo los sonidos graves son los más cercanos a la naturaleza, por ser los de más fácil producción y los más fuertes (con mayor amplitud), por lo tanto, más cercanos a la naturaleza del sonido, mientras que los sonidos más agudos son más cercanos al silencio, por ser más débiles; de aquí la

${ }^{108}$ DE LA CHAMBRE M.C. Nouvelles Observations et Coniectures sur l'iris. Paris: P. Blaise, 1650, pp. 199-200. 


\section{Capítulo IV.- Sinestesia.}

primera correspondencia establecida por Cureau como parte del conocimiento de su época, con la que además, nos explica la aparente paradoja presentada por Arcimboldo; el establecimiento del blanco y los sonidos graves como los más cercanos a la naturaleza, y los sonidos agudos con el negro, como los más alejados de la misma; ${ }^{109}$ más cercanos a la ausencia, al silencio y al vacío, lo contra natura.

Cureau va todavía más lejos, estableciendo de la misma manera una correspondencia entre los sabores agradables e insípidos, con el color y el sonido, y las sensaciones táctiles de calor y frío; obteniendo una correspondencia sinestésica multisensorial basada en la idea de lo cercano y lo lejano a la naturaleza, con sus bases en la proporción como factor de unión entre diferentes fenómenos perceptivos, y la idea Platónico-Aristotélica, de la combinación y obtención de colores mediante las proporciones establecidas en la armonía musical.

Recordando las proporciones establecidas por Pitágoras, y mencionadas por Cureau en su libro "Nouvelles Observations et Coniectures sur l'iris", encontramos la octava musical (o Diapasón) en la proporción de 2:1, y la doble octava musical en 4:1, La Quinta (mencionada como Diapente en la época), como la siguiente consonancia más agradable en proporción de 3:2, y la Cuarta (Diatesarón) en proporción de 4:3.

${ }^{109}$ DE LA CHAMBRE M.C. Nouvelles Observations et Coniectures sur l'iris. Paris: P. Blaise, 1650, pp. 193- 194 


\section{Capítulo IV.- Sinestesia.}

Estableciendo las mismas proporciones utilizadas para los sonidos, aplicándolas en el color (de la misma manera que Aristóteles), Cureau menciona que entre los dos extremos del color, el blanco y el negro, se encuentra el Verde, "juzgado por los ojos, y por toda la gente como el más agradable de los colores" ${ }^{" 110}$ en una proporción de 2:1 equivalente a la octava musical.

Continuando con la combinación entre colores para obtener los nuevos, utilizando lo que Cureau llamó como los "triángulos de luz" (prismas), Cureau encuentra los colores Amarillo y Rojo entre el blanco y el verde, estableciendo para estos las proporciones correspondientes a la Cuarta y la Quinta musical. De la misma forma, siendo el negro el fenómeno de color más alejado del blanco, Cureau lo establece como la Quinceava musical, o Doble Octava, la proporción de 4:1, y entre el Verde (la octava musical) y el Negro (la quinceava o doble octava), se encontrarían el Azul, como la Cuarta más Octava (la Oncena musical), y el Púrpura, como la Quinta más Octava (la Doceava musical). De esta forma, Cureau nos proporciona el siguiente esquema de su correspondencia sinestésica entre colores y sonidos, en específico, intervalos musicales, unidos a la "manera" griega, por la proporción interválica.

${ }^{110}$ DE LA CHAMBRE M.C. Nouvelles Observations et Coniectures sur l'iris. Paris: P. Blaise, 1650, p.208 

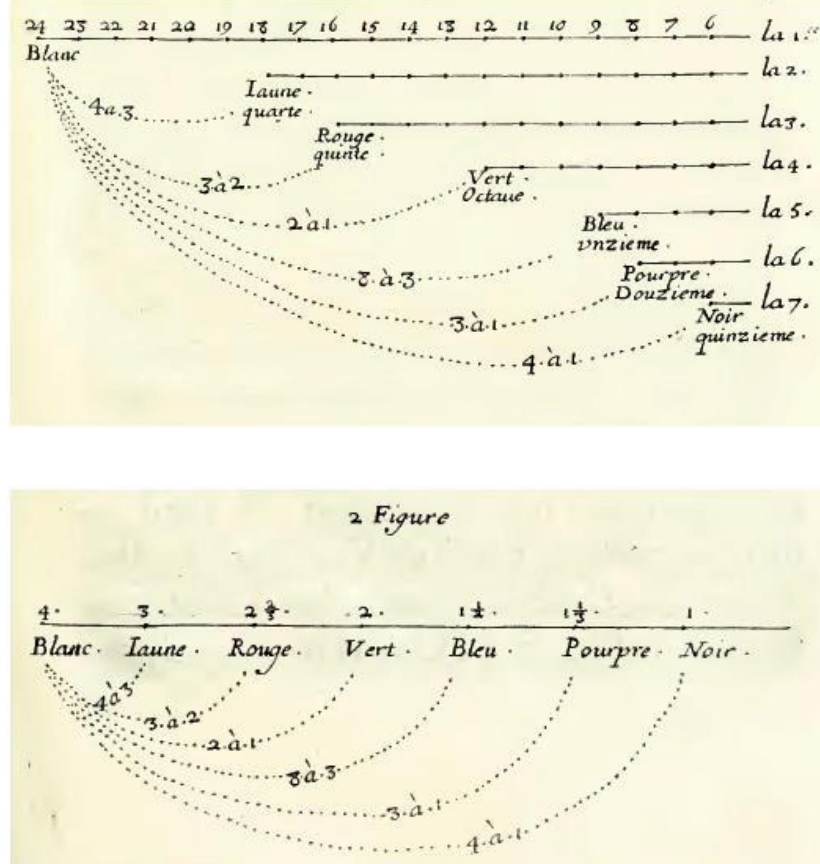

Figuras 57 y 58. Esquemas de correspondencia interválica entre color y sonido de Cureau de la Chambre (DE LA CHAMBRE, Marin C.: Nouvelles Observations et Coniectures sur l'iris. París : Ed. P. Blaise, 1650, p. 215).

En su tratado del Iris, Cureau nos menciona como mediante el manejo de la proporción comprobada por las cuerdas Pitagóricas, es posible establecer las correspondencias que existen entre todos los sentidos, y utilizarlas para la creación artística, con una base fuertemente arraigada en el mundo griego, Cureau realiza una exhaustiva elaboración de las tablas de correspondencias "lumínicosonoras" así como establece una armonía de colores basada en el manejo proporcional de la luz. 


\section{Capítulo IV.- Sinestesia.}

Es en esta época, (el siglo XV), que diversos autores comienzan a establecer la afinación "temperada" en oposición a la afinación Pitagórica, que servía mejor a los propósitos de la música escrita en esos días; hasta que a principios del siglo XVI, esta comienza a convertirse en universalmente aceptada. De la misma forma, es en el siglo XV, que Europa reconoce como a uno de sus máximos representantes de la ciencia de los colores, en Isaac Newton (1642-1727).

Newton abarcó un campo grande de intereses, desde la alquimia y los colores, a la matemática; es universalmente conocida su aportación de la "teoría de la gravitación universal", que fue considerada exacta hasta que comenzó a demostrar ctrofallas en el mundo moderno, y dio paso a la "teoría cuántica" y sus consecuencias en la mecánica, astronomía y física; además, Newton realizó aportaciones en la química, y por supuesto, con su tratado sobre la luz “Opticks" establece no solo las posibles propiedades de la luz y su comportamiento, además, menciona una posible relación de los colores con la música, a consecuencia de una necesidad de medición de las bandas del espectro lumínico.

Como breve ejemplo de las múltiples aportaciones de Newton en campos del conocimiento, se pueden mencionar sus estudios sobre el cálculo matemático, el teorema del binomio, y una teoría sobre el comportamiento de la temperatura, la cual conocemos actualmente como la "ley de la convección térmica". 


\section{Capítulo IV.- Sinestesia.}

En su libro "Opticks" en el cual Newton realiza una exploración de la luz basada en la experimentación, comienza por establecer diferentes definiciones y axiomas del comportamiento observado, para realizar posteriormente la comprobación experimental de las mismas. ${ }^{111} \mathrm{El}$ experimento más sencillo, y probablemente el más trascendental en la memoria humana, que Newton realizó para este tratado, es la descomposición de la luz blanca a través de prismas; haciendo pasar un rayo de luz a través de un prisma, y con una superficie plana de color blanco para proyectar. Newton notó que un rayo de luz natural podía ser "descompuesto" en "bandas" de colores, que conceptualizó como el espectro lumínico, ${ }^{112}$ del cual, el mismo menciona "La imagen es colorida, encontrándose en uno de los extremos el rojo y en el otro el violeta, y el amarillo, verde y azul en los espacios intermedios". 113

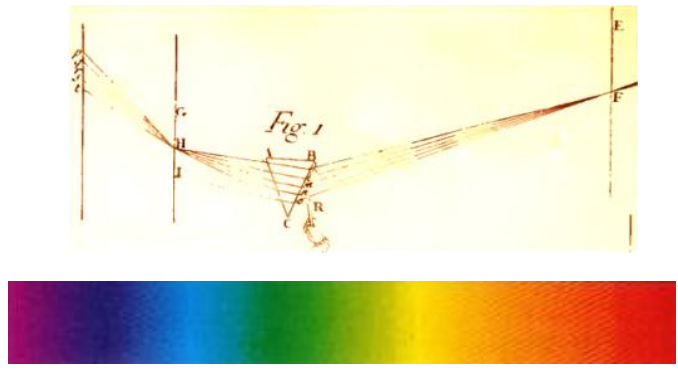

Figuras 59 y 60. Arriba, ilustración de Newton sobre sus experimentos de descomposición de la luz blanca con prismas. Abajo, colores resultantes, por el investigador (NEWTON, Isaac: Opticks: Or a Treatise of the Reflexions, Refractions, Inflexions and Colours of Light. Londres: Ed. Royal Society, 1704, $p$. 385).

\footnotetext{
${ }^{111}$ NEWTON I. Opticks: Or a Treatise of the Reflexions, Refractions, Inflexions and Colours of Light. London: Royal Society, 1704, p.1.

${ }^{112}$ NEWTON I. Opticks: Or a Treatise of the Reflexions, Refractions, Inflexions and Colours of Light. London: Royal Society, 1704, p.18

113 Ídem p. 22
} 


\section{Capítulo IV.- Sinestesia.}

Newton continuó experimentado con prismas en formas cada vez más detalladas, y anotando las observaciones derivadas del uso de más prismas para realizar diferentes refracciones del espectro lumínico, hasta que en uno de sus experimentos anota la observación de los colores "naranja" e "índigo" en el espectro, quedando este de una forma definitiva con siete colores: rojo, naranja, amarillo, verde, azul, índigo y violeta.

En la segunda parte del primer libro "Opticks", Newton aborda el problema de la medida de las bandas del espectro lumínico. Delineando de forma previa una figura a manera de instrumento de medición en un papel, Newton le pidió a un asistente "cuyos ojos para distinguir color sean más críticos que los míos"114 que le ayudara a revisar y dibujar las divisiones de las "bandas" de colores que el espectro lumínico le proporcionaba; es al realizar este experimento que Newton realiza un aporte de manera casi fortuita a la historia del arte sinestésico, nos menciona que después de varias observaciones para la buena medición y comprobación de las mismas, "las líneas de división eran a la manera de un acorde musical" 115 y que podían ser representadas en las siguientes proporciones: 1, 8/9, 5/6, 3/4, 2/3, 3/5, 9/10, 1/2; como el mismo Newton menciona, corresponden a las proporciones del Tono musical (el entero como un tono de partida), la

\footnotetext{
${ }^{114}$ NEWTON. p.92

115 Ídem
} 


\section{Capítulo IV.- Sinestesia.}

tercera menor, la cuarta, la quinta, la sexta mayor, la séptima y la octava por arriba del tono.

En experimentos posteriores, Newton notó cómo dependiendo del acomodo del prisma, los colores eran "reversibles", dependiendo de la posición del refractor de luz, el violeta o el rojo aparecían en el extremo superior, por lo cual consideró esta como una escala de correspondencia entre la música y el color, podía funcionar en ambas direcciones, con el violeta como la octava del tono generador, y el rojo cumpliendo la misma función.

Vale la pena hacer notar, que es en vida de Newton que comienza a nivel internacional, a abandonarse la escala Pitagórica en la música para dar paso al uso de la afinación justa, o "temperada", y uno de los principales expositores fue el alemán J.S. Bach; esto explica la inclusión de la tercera menor en la proporción newtoniana de correspondencias sinestésicas.

En principio, la idea fue abordada con extrema precaución por Newton, a pesar de haberla reflejado en su tratado de óptica, siempre mencionando que esta correspondencia podía no ser así, ya que después de todo, tanto la luz como el sonido son fenómenos de distinta naturaleza; sin embargo, de manera esporádica continuó trabajando con la idea de una posible correspondencia proporcional entre las vibraciones de una cuerda y la "sensación" de color que causa el espectro lumínico en el ojo. A pesar de la precaución con que Newton aborda la idea de una sinestesia "natura dada" parece ser que 


\section{Capítulo IV.- Sinestesia.}

la idea le resultaba como mínimo atrayente; en la parte final de su tratado de óptica, Newton realiza una serie de "preguntas", consecuencia de la interrupción de las últimas partes de su investigación de óptica, preguntas que él menciona como propuestas de investigación "a ser realizada por otros", ${ }^{116}$ y en algunas de sus preguntas, plantea la posibilidad de una "sinestesia en la naturaleza", casi como una evolución del pensamiento clásico griego; en sus "preguntas" 13 y 14, Newton se pregunta si "Acaso no, diferentes tipos de rayos producen vibraciones de diferentes tamaños, y de acuerdo a su tamaño, excitan sensaciones de diferentes colores, de la misma manera que las vibraciones en el aire, de acuerdo a su tamaño, excitan la sensación de diferentes sonidos...?", ${ }^{117}$ y continuando con la posibilidad de una relación matemática entre los diferentes estímulos de la naturaleza, menciona “Acaso no, la armonía o discordancia de los colores nace de las proporciones de las vibraciones propagadas..., de la misma forma que la armonía y discordancia del sonido nace de las proporciones de las vibraciones en el aire? Pues algunos colores son agradables, como el dorado y el índigo...” puesto que la proporción entre estos colores son el equivalente a una quinta musical, y ambas sensaciones son consonantes o agradables.

Como podemos observar, el arte sinestésico, las equivalencias entre estímulos de diferente especie, han tenido sus inicios desde los fundamentos del pensamiento clásico occidental, y la idea de que sea posible unirlos a través de un concepto abstracto, en este caso, los

116 NEWTON. p. 132

${ }^{117}$ NEWTON. p. 136 


\section{Capítulo IV.- Sinestesia.}

números y la proporción entre ellos, continuó a través de la historia con equivalencias, las que ahora llamamos sinestésicas, pero que hasta el siglo XVII y XVIII, eran consideradas como el aproximamiento a la naturaleza.

Las primeras posibilidades para manifestar a un público estas correspondencias las encontramos en Arcimboldo, con su tabla de correspondencias de colores, la cual, más que plantear la posibilidad de una proyección al público de una correspondencia sonido-color, planteaba una posibilidad al instrumentista y/o estudiante para la enseñanza y la composición musical y pictórica.

Sin embargo, un contemporáneo de Newton, planea uno de los primeros proyectos de trascendencia histórica para presentar en forma escénica las correspondencias música-color, planteadas en teoría, este artista fue Louis-Bertrand Castel (1688-1757). Nacido en Montpellier, y miembro de la orden Jesuita desde los quince años, fue miembro del personal docente de varias instituciones de enseñanza pertenecientes a la orden; Castel parece haber desarrollado un gusto particular desde temprana edad por la física y las matemáticas, y después de años de enseñanza en las provincias francesas y de haber escrito algunos ensayos de carácter científico para la publicación Mémoires de Trevoux, que parecen haber llamado favorablemente la atención hacia el autor, recibió la comanda del general de la orden Jesuita de trasladarse a París para enseñar en el Collège Louis-le-Grand, en donde se ocupó de un número considerable de asignaturas entre las que se cuentan las matemáticas, arquitectura, relojería, pirotécnia, y 


\section{Capítulo IV.- Sinestesia.}

óptica. Añadido a sus ocupaciones docentes, ocupó un lugar entre los editores de la revista Mémoires de Trevoux, ocupación que realizó desde 1720 hasta 1746.

En vida, Castel fue influenciado en gran medida por Newton, así como por Athanasius Kircher; la influencia de Newton le fue tan grande que copió el libro Principia Mathematica del mismo, y elaboró varias teorías propias sobre temas anteriormente abordados por Newton, en algunas de ellas, en desacuerdo con él mismo; sin embargo, existe un punto en común importante en el campo de la óptica entre ambos autores, y fue la posibilidad de considerar tanto a la luz como al sonido, como fenómenos de la misma índole, fenómenos vibratorios, idea que Castel ilustró en su libro Optique des Couleurs, y que posteriormente publicó en la revista Mercure de France en 1725.

En su carta al Mercure de France, Castel busca probar la correspondencia entre luz y sonido, y siendo más específico, entre tonos musicales y color; mediante el argumento de la "similar naturaleza de los fenómenos", menciona que siendo el color una alteración en la luz y el sonido una alteración en el aire, una analogía entre ambos fenómenos es implícita. Castel parte de este argumento y de la correspondencia dictada por Newton entre las bandas del espectro lumínico y las proporciones de la escala musical para proponer su propia escala de tonos musicales y color; más allá de esto, Castel menciona que el uso de las proporciones y la determinación de sensaciones "agradables" y "desagradables" (consonancias y 


\section{Capítulo IV.- Sinestesia.}

disonancias) es la misma en todos los órganos de percepción, y contempla la posibilidad de la creación de una música de olores y/o sabores, y las correspondencias posibles entre todos los tipos de sensación, todas regidas por las mismas proporciones.

La escala "música-color" propuesta por Castel es diferente a la estipulada por Newton en su libro de óptica, Castel utiliza las proporciones de la escala mayor (con una "tercera mayor" musical a partir de la nota generadora); en lugar de la escala menor propuesta por Newton, curiosamente, a pesar de que Newton propone su escala a partir de la observación y las proporciones que puede ver en las bandas del espectro lumínico, Castel toma las proporciones de la escala mayor, que son "emanadas" del fenómeno natural de los armónicos.

Castel inició la construcción de un instrumento que pudiera ilustrar la teoría de una correspondencia entre los sentidos y partiendo de la idea de Kircher, sobre las posibles sensaciones que crearían en el público si este pudiera "ver" las vibraciones sonoras en un concierto, ${ }^{118}$ fue que Castel se decidió a emprender la construcción del instrumento,que denominó como: "Clavecin pour les yeux" o "Clavecín Ocular".

Procediendo a la construcción del instrumento, Castel necesitaba establecer la escala "música-color" a ser utilizada; además

\footnotetext{
118 PEACOCK K. "Instruments to perform color-music. Two centuries of technological experimentation.” Leonardo, Vol. 21, 1988, num. 4, p.399.
} 


\section{Capítulo IV.- Sinestesia.}

del hecho de haber cambiado el "modo" de la escala establecida por Newton del "modo menor" al "modo mayor", inclinándose por una aproximación a la naturaleza de los armónicos del sonido, Castel también planta un desacuerdo con Newton en cuanto al "tono generador" de la correspondencia música-color. Newton proponía que el "tono generador" debía ser el violeta, por encontrarse este en la base de la banda de colores del espectro lumínico, cuando por medio de prismas este era invertido; sin embargo, Castel rechaza la idea por encontrar que en la práctica el violeta no es un color primario, sino producido por la combinación de otros colores, y establece el azul como el color "base", ya que vemos todos los otros colores contra el fondo azul del cielo; además, establece como tono "fundamental" de la música como generalidad la nota "Do", ya que la menciona como la nota "base" de la voz humana.

Habiendo señalado el modo "natural" de su escala "músicacolor" como el "modo mayor" y su nota base como la nota "Do", Castel toma en cuenta el contexto histórico de su época y el uso universal de la escala "temperada" en la música, y procede a establecer cuáles serían las equivalencias absolutas entre los semitonos musicales y el color, así como entre los "colores musicales" de las distintas sensaciones de las proporciones de 2:1 (la octava musical).

Para el establecimiento de los colores de los semitonos musicales, Castel utiliza el sistema de comparación entre colores y sus analogías, de la misma forma que posteriormente se utilizó el 


\section{Capítulo IV.- Sinestesia.}

"Espacio de Color NCS"119 asignando de esta forma, el color que se encuentra "entre" los dos colores asignados de forma "natural" a su escala musical de "Do mayor", la cual había sido construida de la siguiente manera:

1. Do.

2. Re.

3. Mi.

4. Fa.

5. Sol.

6. La.

7. Si.
Azul

Verde

Amarillo

Amarillo-Naranja

Rojo

Violeta

Indigo

Después de haber asignado los colores a las notas de la escala de "Do mayor", procedió a señalar los colores que se encontraban en los semitonos entre los anteriormente establecidos, resultando de esta manera, la escala cromática de doce semitonos utilizada en el música temperada, hasta nuestros días, con el siguiente resultado:

1. Do.

2. Do sostenido.

3. Re.
Azul

Azul Verde

Verde

${ }^{119}$ Ver "3.2 Teoría del color". 


\section{Capítulo IV.- Sinestesia.}

4. Re sostenido.

5. Mi.

6. Fa.

7. Fa sostenido.

8. Sol.

9. Sol sostenido.

10. La.

11. La sostenido.

12. Si.
Verde Oliva

Amarillo

Amarillo-Naranja

Naranja

Rojo.

Carmesí

Violeta

Ágata

Indigo

Castel perfeccionó aún más la asignación de colores a la afinación temperada de la música; utilizando el recurso del "claroscuro", asignó diferentes niveles de luminosidad a cada "octava" del teclado de su clavecín, de esta forma, el azul correspondiente al "Do" más grave del teclado sería más oscuro que el siguiente "Do" que se encuentra al doble de hertzios del primero, y así sucesivamente, aplicándolo a todos los colores; de esta manera, Castel obtenía además, una correspondencia de luminosidad con las "Octavas" musicales o tesitura, asignando la mayor cantidad de blanco a las regiones más agudas del teclado.

Posteriormente, Castel se concentró en la construcción del instrumento, que le ocupó la mayor parte del resto de su vida, con resultados que parecen no haberlo satisfecho en lo absoluto, ni a él, ni al público al que eran presentados; el planteamiento del instrumento 


\section{Capítulo IV.- Sinestesia.}

implicaba que al presionar una tecla del clavecín, este no solo diera una nota determinada, como normalmente lo hace un instrumento de teclado, sino que además, proyectara al público el color asignado a esa nota; para conseguir esto, Castel experimentó con pantallas de colores hechas con cristal, con telas, y casi cualquier otro material traslúcido que estuviera a su alcance, utilizando como fuente de luz antorchas y/o velas en gran cantidad, que serían "descubiertas" añadiendo un mecanismo extra de poleas y palancas al sistema mecánico del clavecín. El principal problema al que se enfrentó Castel, fue la falta de fondos económicos, lo que lo llevó a construir el instrumento, casi enteramente por sí solo.

Por exigencia de algunos de sus esporádicos patrocinadores, Castel tuvo que realizar algunos "conciertos" muestras con el funcionamiento del clavecín ocular, siempre sin haberlo perfeccionado, toda vez qur el clavecín ocular no proyectaba todos los colores requeridos, o con la agilidad necesaria, dejando insatisfecho al autor, y en ocasiones, al público. ${ }^{120}$

Castel muere sin haber concluido su proyecto de construcción del clavecín ocular, sin embargo, la influencia que sus teorías sobre la correspondencia sinestésica de la luz y el sonido proyectaron en la Europa de su época fueron grandes, influenciando y recibiendo el beneplácito incluso, del compositor Georg Phillip Telemann (1681-

\footnotetext{
120 FRANSSEN M.: "The Ocular Harpsichord of Louis-Bertrand Castel. The Science and Aesthetics of an Eighteenth-Century Cause Célèbre" Univesiteit van Amsterdam. Tractrix 3, 1991, pp.27-33.
} 


\section{Capítulo IV.- Sinestesia.}

1767), quien dedicó halagos a la idea del clavecín ocular, y a numerosos artistas y teóricos del arte, teniendo como resultado, que la idea de un instrumento musical multimedial continua trabajándose hasta nuestros días.

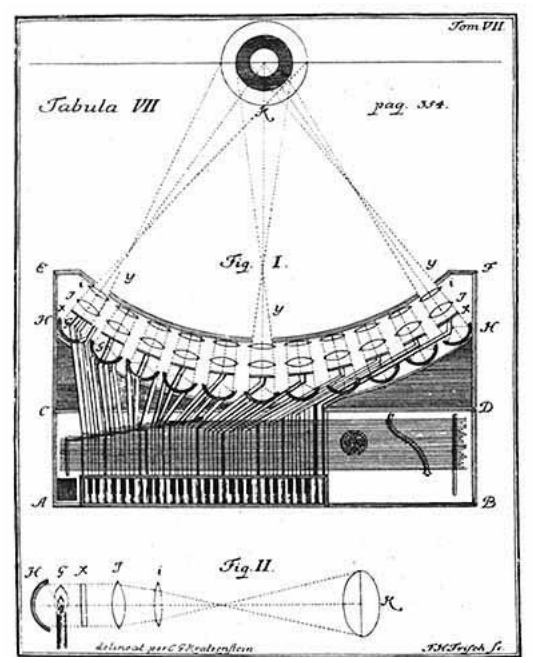

Figura 61. Clavecin Ocular
diseñado por Krüger J.G.,
sobre la idea de Castel.
(FRANSSEN M.: The Ocular
Harpsichord of Louis-
Bertrand Castel.
Amsterdam: Ed. Univesiteit
van Amsterdam. Tractrix:
Yearbook for the History of
Science, Medicine,
Technology and
Mathematics 3, , 1991, p.
34).

El clavecín ocular de Castel, puede ser considerado un precursor de la construcción de los llamados “Órganos de colores”, los cuales fueron abordados por artistas, físicos y teóricos desde entonces.

Una de las primeras realizaciones la encontramos con Johann Gottlob Krüger (1715-1759), quien retomó de forma directa la idea de Castel, de un Clavecín cuyo propio mecanismo tuviera la posibilidad de proyección audiovisual. Conforme la tecnología aportó avances en las áreas de construcción de instrumentos y proyección lumínica, la idea del "órgano de colores" adquirió una mayor solidez y practicidad, lo cual, implicó la posibilidad de una construcción más fácil y rápida 


\section{Capítulo IV.- Sinestesia.}

del instrumento, y a menores costos; algunas de las invenciones que permitieron visualizar posibilidades concretas de la realización de la música de colores las encontramos a finales del siglo XVIII, con la invención de la lámpara de aceite "Argand" conocida como "Quinqué", la cual reemplazó al tradicional candil, y por sus posibilidades de luminosidad y distribución regulada del combustible permitían pensar en la realización adecuada de un instrumento de proyección audiovisual. La electricidad como herramienta para el uso de la proyección audiovisual, también comenzó a ser planteada a finales del siglo XVIII y durante el siglo XIX.

El uso de la electricidad aplicado en el arte sinestésico puede ser encontrado en Estados Unidos de América en 1877, con el instrumento de Bainbridge Bishop, al qué le llamó simplemente "Órgano de color".

Recibiendo influencia de los trabajos clásicos de Grecia, en particular de Aristóteles, así como de la teoría de armonía de colores de Chevreul y Field; Bainbridge manifestó un interés temprano por la posibilidad del establecimiento de una correspondencia sinestésica entre el sonido afinado y los colores, realizando sus primeros bocetos de correspondencia a partir de las proporciones armónicas del sonido. Años después, decidió retomar la idea de "pintar la música", ${ }^{121}$

\footnotetext{
${ }^{121}$ BISHOP B. A Souvenir of the color organ, with some suggestions in regard to the soul of the rainbow and the harmony of light. New York: The De Vinne P., 1893, p. 2
} 


\section{Capítulo IV.- Sinestesia.}

decidió partir de la construcción del instrumento, y paralelamente, trabajar la correspondencia.

Trabajando a partir de un órgano de modelo alemán (con pedalera o teclado para los pies), con un enfoque bastante similar al de Castel, Bainbridge añadió un mecanismo extra a la mecánica ya existente del órgano, de forma que, el instrumento no solo produjera una nota determinada al presionar una tecla, sino que además, tuviera la posibilidad de proyectar o producir un color, el cual correspondiera a la misma ${ }^{122}$. Después de realizar varios bocetos de la construcción del instrumento, el modelo de Bainbridge consistía en lo siguiente: Un órgano tubular con pedalera, al cual le colocó una pantalla de vidrio esmerilado de alrededor de 152 centímetros, enmarcada como un cuadro, y que servía para proyectar los colores; el instrumento tenía además, pequeñas ventanas con cristales de diferentes colores, cada una con una cortina, las cuales, mediante un sistema de palancas y poleas, añadidas al mecanismo de cada tecla del órgano, movían la cortina correspondiente a la tecla presionada para permitir ver el color.

Las "notas" de la pedalera, que en un órgano corresponden usualmente al registro más grave, producían un color de fondo, sobre el cual, a manera de pedal armónico, eran proyectados los demás colores del teclado manual. La luz que el teclado manual permitía entrar, era difundida y reflejada sobre una pantalla blanca que se encontraba detrás del vidrio esmerilado.

${ }^{122}$ DUPLAIX S. Sons \& Lumières. Paris: Centre Pompidou, 2004, p. 32 


\section{Capítulo IV.- Sinestesia.}

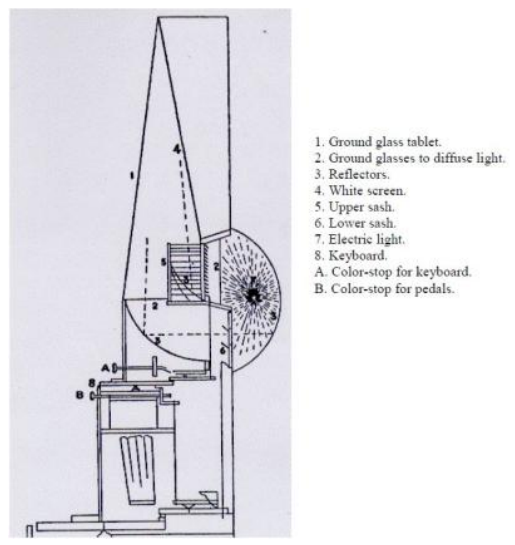

Figura 62. Esquema técnico del órgano de colores de Bainbridge Bishop. (BISHOP, B.: A souvenir of the color organ, with some suggestions in regard to the soul of the rainbow and the Harmony of light. New York: Ed. The De Vinne Press, 1893, p. 4).

En principio, el órgano de color debía estar frente a una ventana que permitiría una buena entrada de luz solar, utilizando la luz natural como fuente de proyección lumínica; sin embargo, el mismo Bainbridge menciona que "una luz eléctrica podía ser usada atrás del órgano". ${ }^{123}$

Como una importante novedad al instrumento, Bainbridge añadió un diferencial al órgano de color, por medio de una palanca permitía desconectar el mecanismo del teclado, y la pedalera ya fuera de los tubos (productores de sonido) o de las cortinas (entradas de la luz), que convertía al órgano de colores ya en un instrumento "normal", ya que únicamente producía sonido, o en un proyector de luz, desvinculado de la producción de sonido. La posibilidad de convertir al órgano de color en un proyector de luz sin sonido, le permitió a Bainbridge experimentar con gente a su alrededor,

\footnotetext{
${ }^{123}$ BISHOP B. A Souvenir of the color organ, with some suggestions in regard to the soul of the rainbow and the harmony of light. New York: The De Vinne P., 1893, p.5.
} 


\section{Capítulo IV.- Sinestesia.}

buscando la posibilidad del reconocimiento de una melodía musical a partir de la proyección de colores.

La correspondencia sinestésica de luz y sonido, de Bainbridge, a pesar de utilizar como punto de partida algunas de las ideas de Newton, sobre el espectro lumínico y las proporciones correspondientes a cada banda de color, es bastante diferente a esta; Bainbridge parte del fenómeno del arcoíris en el cielo, fenómeno de la luz que es bastante similar al de la descomposición del espectro lumínico por medio de prismas.

Bainbridge en su "Memoria del órgano de color", nos menciona: "Un día mientras caminaba, vi un brillante despliegue de arcoíris; alrededor y entre ellos, el cielo era de un cálido rojo grisáceo", esta imagen parece haber tenido un efecto por demás poderoso en Bainbridge, quien dijo haber sido "golpeado por una revelación", sintiendo cómo el cielo en esa configuración particular, era exactamente como un acorde y/o serie de armónicos dados por un órgano. De acuerdo a Bainbridge, por medio de una observación cuidadosa del espectro lumínico, cuando este es presentado de forma natural en un arcoíris, es posible ver que el "color fundamental" es el rojo, y curiosamente se encuentra también en la "base" del espectro lumínico.

A partir de este hecho, Bainbridge realiza un "salto creativo" y asigna este color a la nota "Do" como la nota base de la escala natural, emulando de esta forma la nota fundamental de la correspondencia de 


\section{Capítulo IV.- Sinestesia.}

Castel, considerando la escala mayor como la escala natural, por ser la síntesis horizontal del fenómeno de los armónicos del sonido, tal como eran comprendidos en esa época. Solo podemos conjeturar la razón de que ambos autores consideraran la nota "Do" como fundamental, ya que la serie de armónicos como podía ser comprendida antes de principios del siglo $\mathrm{XX}$, permite considerar cualquier nota como una nota fundamental o generadora, la relación interválica es la misma en todo sonido producido, lo cual permitiría establecer cualquier nota como fundamental de cualquier "escala mayor"; sin embargo, ambos autores trabajaron en instrumentos de teclado, y la construcción occidental de un instrumento musical de este tipo está hecha a partir de la "escala mayor de Do", y se ve reflejado en el teclado, que permite que mediante la ejecución de las teclas "blancas" del mismo, se ejecute de manera prácticamente inconsciente la "escala mayor de Do".

Una vez estableciendo la correspondencia del "Do" con el color rojo, Bainbridge asigna el resto de los colores del arcoíris a las notas de las serie de armónicos, asignando de esta forma el azul del arcoíris (encasillado por Bainbridge como azul verdoso o aguamarina) como la nota "Sol", correspondiente al armónico 3, primera nota "diferente" de la nota generadora; el siguiente armónico que es un "Do" una octava más alta que el segundo, o a una quinceava de la nota generadora sería de un rojo más claro; el "Mi" o armónico 5, de color amarillo o dorado verdoso; El siguiente "Sol" o armónico 6, 


\section{Capítulo IV.- Sinestesia.}

sería un azul más claro mientras que el armónico 7, "Si bemol” sería color violeta.

Figura 63. Correspondencia establecida por Bainbridge

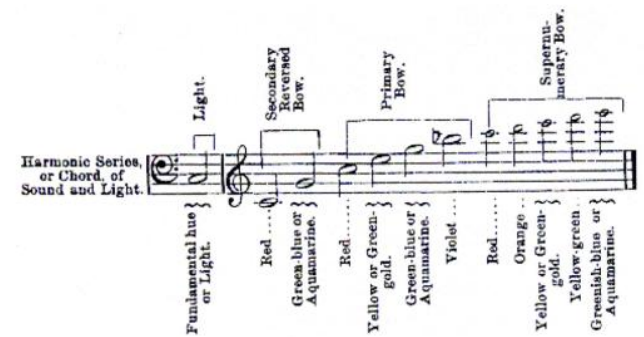
Bishop, entre los armónicos del sonido y los colores del arcoiris.(BISHOP, B.: $A$ souvenir of the color organ, with some suggestions in regard to the soul of the rainbow and the Harmony of light. New York: Ed. The De Vinne Press, 1893, p. 8).

Tomando como punto de partida esta correspondencia entre el arcoíris y la serie de armónicos del sonido, Bainbridge asignó los semitonos correspondientes de color a las notas que se encontraban "en medio" de la "escala natural de Do" y asignando un color más elevado de luminosidad a cada octava musical, mientras esta iba haciéndose más aguda. El resultado de la correspondencia sinestésica de colores con la escala cromática, fue el siguiente:

1. Do Rojo

2. Do sostenido Rojo-naranja

3. $\operatorname{Re}$

Naranja

4. Re sostenido Dorado o Amarillo-naranja

5. $\mathrm{Mi}$ Amarillo o Verde-dorado

6. $\mathrm{Fa} \quad$ Amarillo-Verde

7. Fa sostenido Verde

8. Sol Azul-verde o aguamarina

9. Sol sostenido Azul 


\section{Capítulo IV.- Sinestesia.}
10. $\mathrm{La}$
Índigo o violeta-azul
11. Si bemol
Violeta
12. Si natural
Violeta-rojo

Es importante hacer notar, que Bainbridge no consideraba los colores puros como "naturales" o que fueran contenidos en el arcoíris, excepción hecha para el violeta, ya que como él mismo ejemplifica: "Un verde puro y crudo, parece estar fuera de lugar en un paisaje, y si es visto, generalmente produce un efecto duro y disonante". ${ }^{124}$

Bainbridge comenzó a trabajar en su órgano de colores en 1875, terminando la construcción del primer modelo alrededor de 1880, realizando una presentación en Nueva York, sintiéndose insatisfecho con los resultados, trabajó en la construcción de otros dos modelos, que sí le dieron los resultados que él esperaba. ${ }^{125}$ Los otros dos modelos, no solo proyectaban los colores del teclado manual, con los colores correspondientes y "entintados" con el color de la pedalera, sino que además, conforme el sonido se hacía más agudo proyectaban de manera efectiva valores de mayor luminosidad, y creaban una banda lumínica de menor tamaño, imitando al espectro lumínico.

${ }^{124}$ BISHOP B. A Souvenir of the color organ, with some suggestions in regard to the soul of the rainbow and the harmony of light. New York: The De Vinne P., 1893, pp.9-10.

125 Ídem p. 10 


\section{Capítulo IV.- Sinestesia.}

Bainbridge parece haber gozado de un oído musical bastante privilegiado o como mínimo, muy bien educado, ya que al final de su "Memoria del órgano de color", menciona la posibilidad de asignar como nota fundamental de la música, a la nota " $\mathrm{Fa"} \mathrm{en} \mathrm{sustitución} \mathrm{del}$ "Do" ya que la gran mayoría de los sonidos de la naturaleza parece estar en la escala de Fa, o bastante cerca de ella, llegando a escribir incluso pasajes metafóricos de fenómenos naturales como, el trueno o el sonido de las olas.

Los órganos de Bishop se perdieron, al menos uno de ellos fue propiedad del empresario de espectáculos, P.T. Barnum, el cual se quemó cuando la casa del empresario en Bridgeport sufrió un incendio, aparentemente, otros tres órganos sufrieron destinos similares. Bainbridge termina sus Memorias mencionando posibilidades futuras del órgano de colores, las que podían ser visualizadas gracias a la invención de la electricidad y su uso práctico, así como relacionando mediante su correspondencia de colores, posibles explicaciones a escalas folclóricas de diferentes regiones, comparándolas con los colores de los paisajes que rodeaban a los nativos del lugar. Bainbridge, mediante su invención del órgano de colores, no solo da continuidad a la idea de un instrumento de proyección sinestésica, sino que ilustra el uso de la tecnología en el arte intermedial, abriendo un camino de exploración tecnológica en el arte sinestésico.

A principios del siglo XX, numerosos pintores retoman la idea de la correspondencia sinestésica en las artes, en principio, como un 


\section{Capítulo IV.- Sinestesia.}

medio para conseguir una nueva expresión que no fuera encontrada en el mundo académico de la forma y la pintura realista, como una herramienta para la abstracción en la pintura.

Un importante exponente, fue el pintor futurista ruso Wladimir Baranoff-Rossiné (1888-1944) quien trabajó la idea de la geometría en la forma pictórica; retomando el camino de un instrumento musical que pudiera proyectar colores, o en su caso, formas y movimiento. Rossiné nombró a su instrumento como "Piano Optofónico", con el que llevó a cabo numerosas presentaciones, estrenándolo en una exhibición a manera de solista en Oslo.

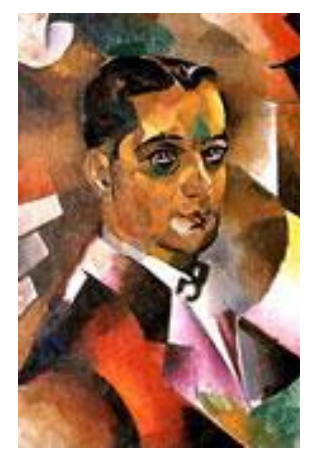

Figura 64. Rossiné, Autorretrato. (Fundación Rossiné.)

Contemporáneo de Kandinsky, Chagall, Arp, y otros precursores del abstraccionismo en la pintura, Rossiné describía su "Piano Optofónico" de la siguiente manera:

"(...)imagina que cada tecla de un piano u órgano se pueda detener en una determinada posición y con esto cree un elemento específico de una serie de filtros transparentes que se mueven a diferentes velocidades, traspasados por un rayo de $\operatorname{luz}(\ldots)^{\prime 126}$.

\footnotetext{
${ }^{126}$ BARANOFF-ROSSINÉ W. “Autobiografía” [en línea]. http://www.baranoffrossine.com [Consulta: 31 Diciembre 2010].
} 


\section{Capítulo IV.- Sinestesia.}

El instrumento contaba con filtros traslucidos de colores, además de varios elementos ópticos como prismas, lentes, o espejos; así como figuras y líneas, todos estos elementos eran proyectados por medio de un foco de energía eléctrica, que era accionado previamente, y el elemento correspondiente a la tecla presionada era colocado de forma que fuera proyectado, todo por el mecanismo del teclado del piano.

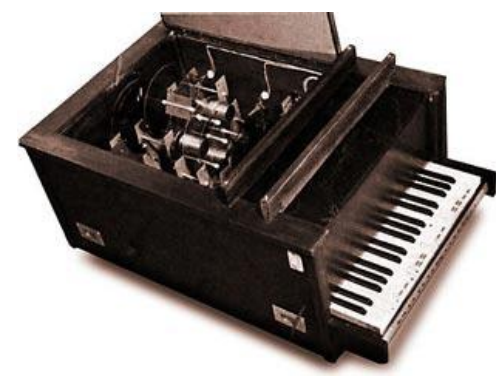

Figura 65. Piano Optofónico de Rossiné. (Fundación Rossiné).

El Piano Optofónico de Rossiné no producía sonido, el elemento sinestésico utilizado por el autor era meramente creativo, Rossiné “ejecutaba” partituras en el Piano Optofónico, composiciones clásicas de Beethoven y otros autores, creando de esta manera lo que él consideraba que era la equivalencia de los elementos visuales contenidos en la música; él mismo mencionaba que no existía un “traductor” establecido, ya que un compositor de música no señala usualmente elementos visuales que sean implícitos a gestos musicales. Sin embargo, Rossiné consideraba que estaba realizando un principio, una muestra de lo que podía llegar a ser un elemento unificador del arte, para cuando este contara con las correspondencias visuales implícitas en los gestos musicales. 


\section{Capítulo IV.- Sinestesia.}

Un "parte aguas" del uso del color en la música puede ser considerado Alexander Scriabine (1872-1915) compositor ruso contemporáneo a Rachmaninof, cuyos documentos musicales expresaron ideas no solo en el arte sinestésico, sino en planos que nos llevan a replantear la idea de una "obra de arte total" y el uso de la tecnología en el arte sinestésico. Nacido en Moscú, en el seno de una familia acomodada, fue educado con principios de tipo aristocrático; su madre, pianista, muere cuando Scriabine solamente tenía un año de edad, mientras su padre pasaba largas temporadas en el servicio diplomático de su país. Scriabine muestra talento como ejecutante de piano desde temprana edad, ingresando al conservatorio de Moscú en 1884, en donde tuvo notables compañeros de estudio como Sergei Rachmaninof, y recibió clases de Taneyev, Nikolai Zverev, Arensky y Safonov; durante sus años en el conservatorio, Scriabine comienza a mostrar interés en la poesía, interés que conservó durante toda su vida componiendo muchas veces poemas cortos para algunas de sus composiciones musicales, además de comenzar a componer música desde sus años de estudiante de piano en el conservatorio.

Figura 66. Retrato de Scriabine.

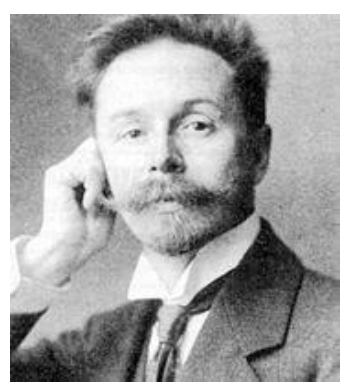




\section{Capítulo IV.- Sinestesia.}

Scriabine realizó varios viajes al extranjero, conociendo a personalidades como Nietzsche, además de entrar en contacto con la "Teosofía" de Helen Blavatsky (1831-1891) ${ }^{127}$, algunos de cuyos conceptos parecen haber trascendido en la personalidad creativa del compositor; como producto de las influencias recibidas en sus constantes viajes, Scriabine abordó la idea del artista como una especie de "mesías", como un conductor de ideas, casi a manera de "médium", transmisor de un lenguaje divino. Como consecuencia a sus ideas del arte, y de la función del artista dentro de la sociedad, asî como su lugar dentro de la civilización, Scriabine, considera la idea de las correspondencias de la música con el color, estableciendo asociaciones entre la música, el color, y lo que él llamaba "estados del alma" o emociones.

La música de Scriabine sufrió de múltiples críticas mientras el compositor vivió, en parte porque representaba la vanguardia de la época, y una evolución del lenguaje musical insertado en la estética "romántica" a música altamente personal, con contenidos individuales y concepciones únicas en el manejo de la armonía y la forma musical.

Parte del "germen" creador de Scriabine, fue su correspondencia de colores a los "campos armónicos" de su música, la correspondencia de Scriabine, a diferencia de la correspondencia de

127 Sociedad Scriabine de América. "Biografía de Scriabine" [en línea]. http://www.scriabinsociety.com/biography.html [Consulta: 31 Diciembre 2010]. 


\section{Capítulo IV.- Sinestesia.}

Castel o Bishop, no era absoluta, sino relativa al campo armónico utilizado durante un lapso temporal en la obra; como resultado, el color no cambia con cada nota ejecutada, sino que es hasta cierto punto estático, y corresponde a los cambios o contrastes tonales de la música; Scriabine consideraba que el uso del color, aplicado al campo armónico, no solo ayudaría al público a tener mayor consciencia del manejo tonal de la obra, sino que además, constituía un acercamiento a un lenguaje artístico más completo, a la unión del hombre con la divinidad.

La correspondencia de "color-tonalidad musical", de Scriabine, parece ser emanada de los experimentos de color de Newton, comenzando con el rojo en la base hasta llegar al violeta como la última banda de color; Scriabine asigna el color rojo a la nota "Do", que es el primer centro tonal que usualmente es enseñado a un pianista por razones de facilidad técnica-pedagógica, además de que en el “círculo de quintas" armónico, usualmente se encuentra como primer centro tonal.
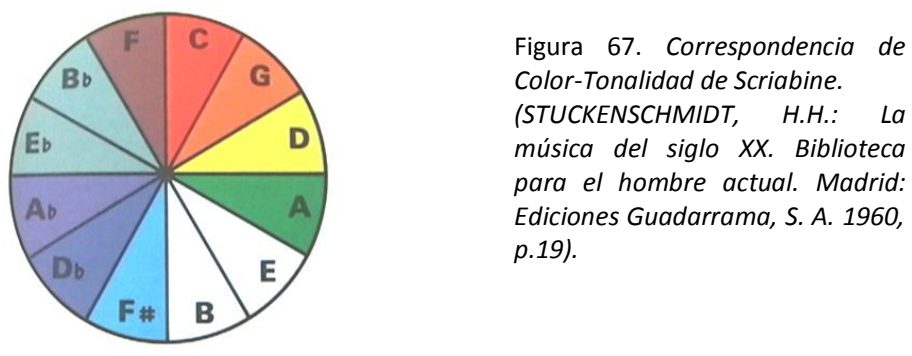


\section{Capítulo IV.- Sinestesia.}

A su correspondencia de color-tonalidad musical, Scriabine añade un elemento más, la emoción humana, casi a manera de Rasas hindús, y que constituye también una muestra de la influencia que las filosofías orientales marcaron en el compositor, realizando de esta forma, una correspondencia sinestésica tripartita. La correspondencia sinestésica de Scriabine, tal como es expresada en la partitura orquestal "Prometheus", es la siguiente:

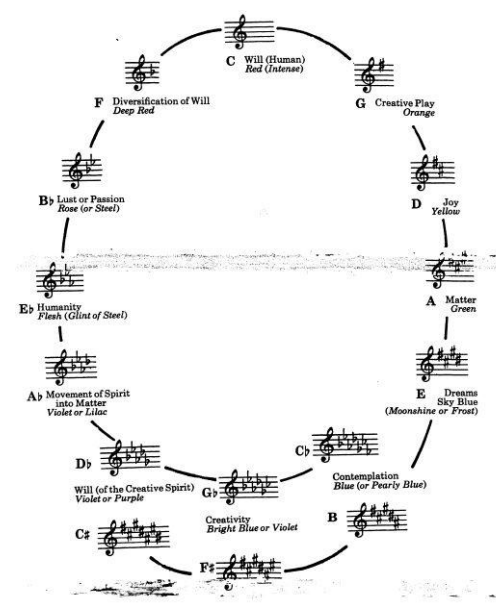

Figura 68. Correspondencia de Color-Tonalidad-Estado del alma. De Scriabine, como es indicado en la primera página de su obra "Prometeo".(SCRIABIN A.: Poem of Ecstasy and -Prometheus: Poem of Fire. New York: Ed. Dover, 1995, p. 2).

En la tabla existe una correspondencia entre el "Do sostenido" y el "Re bemol", la cual, desde la perspectiva de Scriabine como pianista, resulta implícita en un instrumento de afinación temperada, como lo es el piano, las notas anteriormente descritas son la mismas; el pianista presiona la misma tecla, y el sonido resultante es el mismo.

Esta correspondencia color- tonalidad musical- emoción, no parecen tener relación a las descritas por "sinestetas clínicos", sino ser emanadas de la subjetividad de Scriabine, así como el haberse asistido 


\section{Capítulo IV.- Sinestesia.}

del círculo de colores de Newton, la filosofía artística hindú y la teosofía. Desde del inicio de Scriabine, como compositor, este parece haber comenzado bocetos de una obra de arte total a la cual tituló "Mysterium", trabajo inconcluso y que ha tenido múltiples reconstrucciones en el siglo XX; el hecho de que desde sus años de estudiante y sus primeros viajes contemplara la producción de una obra multimedial, nos permite suponer que la correspondencia sinestésica, le acompañó como un germen compositivo con gran parte de su obra.

Podemos conjeturar la idea, a partir del análisis de una de sus obras características tempranas, la "Sonata" opus 19, su segunda sonata para piano, que él mismo subtituló de dos formas: como "Sonata Fantaisie" (Sonata Fantasía), en la que Scriabine hace referencia al molde formal y manejo motívico-temático de la obra, y "Sonata Méditérranee" (Sonata Mediterráneo).

Scriabine hacía alusión a su segunda "Sonata Méditérranee", por medio de un escrito que acompañaba a la obra, en el que establecía metáforas visuales de índole filosófico-espiritual ,con los dos movimientos de la obra, de una forma que no era la usual, esta sonata es "programática", casi a manera de "poema sinfónico" ,y de la cual, existe un "guión" que subyace en la música. Scriabine escribe:

"El primer movimiento (Andante) representa la quieta noche sureña en la playa. La sección de desarrollo es el oscuro, agitado, océano profundo. La sección en "Mi mayor" representa la acariciante luz de la luna después de la primera oscuridad de la noche. El segundo movimiento (Presto) 


\section{Capítulo IV.- Sinestesia.}

representa la ancha, tempestuosa, agitada, vasta expansión del océano." 128

Esta Sonata fue escrita de 1892 a 1897, a pesar de la duración relativamente corta de la obra, y una instrumentación "escueta" (piano solo), Scriabine se tomó cinco años para la composición de la obra, en pocas obras invirtió tanto tiempo; además de ser una de las obras que más interpretó durante su vida. Para el análisis armónico de la obra, realizaremos un esquema cuya referencia temporal es lo que en el lenguaje musical es llamado "compás", que representa las unidades temporales de una obra musical; en el caso que nos ocupa, en el primer movimiento cada compas equivale a tres segundos de acuerdo a lo escrito por el autor en la partitura, compases de $3 / 4$ á 60 pulsaciones por minuto de acuerdo a lo establecido en un metrónomo convencional como la indicación "Andante"; en el segundo movimiento, cada compás equivale a un segundo de acuerdo a lo escrito por el autor con la indicación "Presto" con compases de 3/2, siendo la unidad temporal la nota de 1/2 o blanca.

La "Tonalidad" de la sonata es "Sol sostenido menor", relativa de la escala o tono de "Si mayor" lo cual sitúa el color general de esta obra en Azul, o Azul perlado, mientras que "La sección en "Mi mayor" representa la acariciante luz de la luna después de la primera

\footnotetext{
128 SCHLAUCH B. y ELIZABETH A. “Alexander Scriabin's Ten Piano Sonatas: Their Philosophical Meaning, and its musical expression." [Doctoral Document]. Ohio State University, 1985. p.55. Texto original: "The first movement (Andante) represents the quiet southern night at the seashore. The development section is the dark, agitated, deep ocean. The E major section represents the caressing moonlight after the first darkness of the night. The second movement (Presto) represents the wide, tempestuous, agitated, vast expanse of the ocean."
} 


\section{Capítulo IV.- Sinestesia.}

oscuridad de la noche", sección que se encuentra al final del primer movimiento, sería de color Azul cielo (claro de luna o nieve), de acuerdo al círculo de quintas o correspondencia color-tonalidad musical de Scriabine; estas relaciones tonales no son las convencionales para un primer movimiento de Sonata, ya que, es esperado encontrar la misma tonalidad en la primera y última sección de la obra. 
Sonata no.2 Alexander Scriabine. (1892-1897).

\section{Primer Movimiento}

\section{Compás}

$1-11$

12

$13-59$

$60-61$

62

63-70

$70-76$

77

78

$79-83$

$86-89$

$90-98$

$98-99$

$100-121$

\section{Color y campo tonal}

Azul - Sol sostenido menor.

Gris - Mi bemol

Azul - Si.

Amarillo - Re.

Naranja - Sol.

Rojo profundo-Fa.

Rosa o acero - Si bemol.

Naranja - Sol.

Violeta-Do sostenido.

Rosa o acero - Si bemol.

Azul - Sol sostenido menor.

Azul cielo - Mi.

Verde - La.

Azul cielo - Mi.
Emoción o Concepto

Contemplación.

Humanidad

Contemplación

Alegría

Juego creativo

Diversificación de la voluntad

Pasión o lujuria

Juego creativo

Voluntad del espíritu creativo

Pasión o lujuria

Contemplación

Sueños

Materia

Sueños

\section{Segundo Movimiento}

\section{Compás \\ Color y campo tonal}

1-8

9-15

16

$17-21$

25-32

33

34

35-36

37

38

39

$41-49$

53

54

55

56

57

58

59

63-70

$71-78$

92

$93-94$

$95-97$

$98-101$

$102-110$
Azul - Sol sostenido

Violeta-Do sostenido.

Azul - Sol sostenido

Azul cielo - Mi

Azul - Sol sostenido

Verde - La

Rosa o acero - Si bemol

Azul - Sol sostenido

Azul - Si

Gris - Mi bemol

Azul - Sol sostenido

Gris - Mi bemol

Azul - Sol sostenido

Naranja - Sol

Rojo intenso - Do

Violeta- Do sostenido.

Rojo intenso - Do

Violeta-Do sostenido.

Azul - Si

Violeta-Do sostenido.

Azul - Mi

Azul - Sol sostenido

Verde - La

Azul - Sol sostenido

Verde - La

Azul - Sol sostenido

\section{Emoción o Concepto}

Contemplación

Voluntad del espíritu creativo

Contemplación

Sueños

Contemplación

Materia

Pasión o lujuria

Contemplación

Contemplación

Humanidad

Contemplación

Humanidad

Contemplación

Juego creativo

Voluntad humana

Voluntad del espíritu creativo

Voluntad humana

Voluntad del espíritu creativo

Contemplación

Voluntad del espíritu creativo

Contemplación

Contemplación

Materia

Contemplación

Materia

Contemplación 


\section{Capítulo IV.- Sinestesia.}

Como puede notarse, la correspondencia de los campos colortonalidad musical, con el escrito de Scriabine, en el programa de la obra son notoriamente relativos el uno al otro; la sonata se mueve en campos armónicos de colores predominantemente azules, con tonalidades pasajeras de colores que van del rojo, naranja y violeta, a colores rosa, gris y verde; todo teniendo como "guión" subyacente el mar mediterráneo y los colores que es posible contemplar en una puesta de sol en la playa, o como una especie de espectador virtual contemplando "La ancha, tempestuosa, agitada, vasta expansión del océano".

En 1910, Scriabine escribe la que es conocida como su "Quinta Sinfonía" titulada como "Prometheus" acompañada del subtítulo "Le poeme de feu" (El poema de fuego), obra representativa del autor en la que, no solo manifiesta muchas de sus ideas en los ramos de la filosofía y telología, sino además, verdaderas novedades en el uso de la armonía y la presentación escénica de la obra para que escribe en el "score" general de la obra, una parte indicada como "Luce", indicando el manejo lumínico en tiempo real, que acompaña la ejecución de la obra.

La obra "Prometheus" fue estrenada para el público en Moscú en 1911 sin la parte de luz, por el mal funcionamiento de la máquina lumínica. ${ }^{129}$ La primera presentación de la obra incluyendo la parte de Luce fue realizada en Nueva York, en 1915, la ejecución de la parte

\footnotetext{
129 PEACOCK; K.. "Instruments to perform color-music. Two centuries of technological experimentation." Leonardo, Vol. 21, 1988, num. 4, p. 402.
} 


\section{Capítulo IV.- Sinestesia.}

lumínica fue realizada por una máquina construída ex profeso para el estreno norteamericano de la obra. Scriabine pretendía que el color “inundara" al público, y se convirtiera en una parte integral de la obra, con la misma importancia que podría tener un instrumento más de la orquesta, sin embargo, el estreno de "Prometheus" con la “instrumentación” completa (incluyendo a Luce), proyectaba los colores únicamente en una pantalla blanca que se encontraba frente al director, ocasionando un efecto distante del esperado por el compositor.

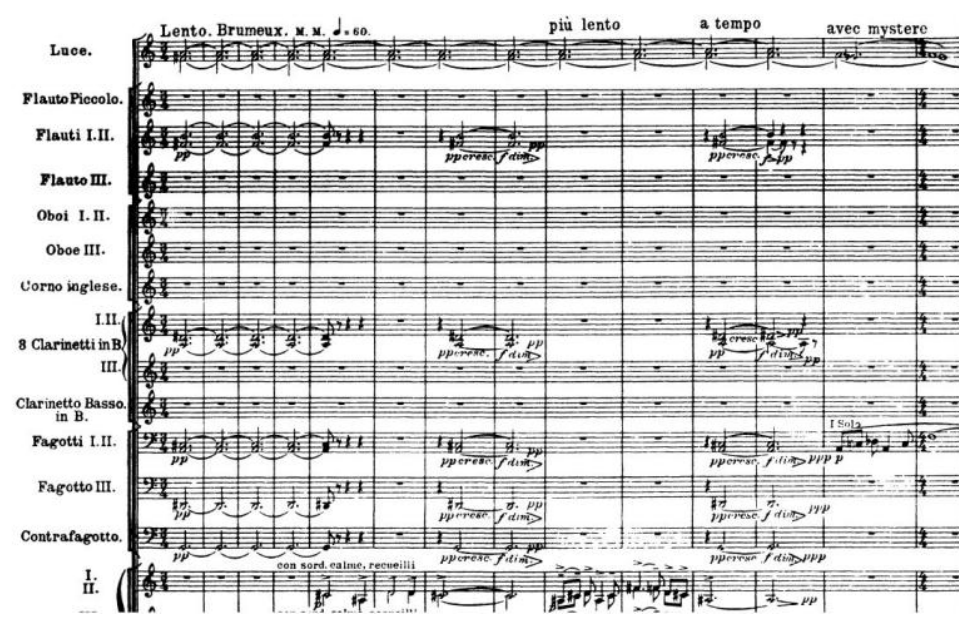

Figura 69. Inicio de la obra "Prometeo" de Scriabine. Fragmento.(SCRIABIN A.: Poem of Ecstasy and -Prometheus: Poem of Fire. New York: Ed. Dover, 1995).

La parte de Luce, comienza con dos notas, el "Fa sostenido"violeta o Azul brillante-Creatividad, y “La"-Verde-Materia; sin embargo, la orquesta comienza con un acorde de seis sonidos que no corresponde con las tonalidades anteriormente mencionadas ("Fa sostenido" o "La"), el acorde musical que es escuchado tiene como 


\section{Capítulo IV.- Sinestesia.}

generador, el tono de "Sol" por su peso armónico; ejecutando la nota "Sol" encontramos a los contrabajos en la tesitura más grave (lo cual posee el mayor peso armónico y la generación de armónicos que afectarán al resto de los instrumentos), además de ser duplicado el "Sol" por los Fagot y el Timbal; ${ }^{130}$ probocando con esto, que el resto de las notas escuchadas se encuentre en función al "Sol".

Mucho ha sido escrito sobre el acorde del inicio de Prometheus, existiendo versiones de que es un acorde cuyo generador es el "Do", y considerado como un acorde construido por "Cuartas musicales", cuyas referencias incluso le llaman: "Acorde de Prometeo" o "Acorde Místico de Scriabine”.Observando la estructura del acorde encontrada en la partitura, comenzando por el sonido generador en la región más grave y duplicado por los instrumentos de mayor "peso" en la orquesta como los contrabajos, el fagot y el timbal; arriba del "Sol" encontramos una "quinta aumentada" (Re sostenido) ejecutada por una de las secciones de los contrabajos y “doblada" por los fagot, una "novena mayor" (La) ejecutada por los cellos y primeros fagot; continuando hacia la región "media" de afinación orquestal, las violas vuelven a duplicar la nota generadora (Triplicando de esta forma la nota generadora o "Sol"), y la primera sección de violas ejecuta la "oncena aumentada" (Do sostenido); estas dos últimas notas (Sol y Do sostenido) son también “dobladas” por los

\footnotetext{
${ }^{130}$ Ver la nota de Schoenberg sobre "formaciones acórdicas hexacordales" y la explicación sobre la nota generadora. En: SCHOENBERG A. Theory of Harmony. California: University of California P., Traducción al inglés de la tercera edición alemana de 1922, p.419
} 


\section{Capítulo IV.- Sinestesia.}

clarinetes, mientras que las flautas tocan la "Séptima mayor" (Fa sostenido) y la "Tercera Mayor" (Si).

De esta manera, obtenemos que el acorde inicial de Prometheus, en realidad dista de estar construido por "cuartas" y encontramos un acorde con la siguiente estructura: Tercera Mayor, Quinta aumentada, Séptima mayor, Novena mayor y Oncena aumentada; es hasta el compás número trece de la obra (a los 39 segundos del inicio) que aparece un "Mi bemol" (el que coincide con la aparición de la misma nota con el instrumento Luce), cuando una Trecena menor (continuando con el "Sol" como nota generadora) aparece en la obra. Entonces nos encontramos con un acorde mayor con Quinta aumentada, la cual es en realidad la enarmonía de la Trecena menor. Muchos de los intervalos dentro de la estructura de este acorde pueden ser considerados como emanados de la serie de armónicos del sonido, exceptuando a la Séptima mayor, pero encontramos sumamente difícil englobar este acorde en una construcción de "Cuartas" o como un acorde sui generis llamado "Místico".

Queda la cuestión de la aparente desvinculación entre los campos armónicos-color que proporciona Luce, de acuerdo al esquema que tradicionalmente acompaña la partitura de la obra. La nota generadora es "Sol" en la música; sin embargo, los colores corresponden a los tonos Violeta y Azul (Fa sostenido y La de). Uno los primeros problemas que fueron enfrentados para el estreno norteamericano de Prometheus fue que Scriabine no dio instrucciones 


\section{Capítulo IV.- Sinestesia.}

específicas para los colores que Luce debía proyectar, y los colores que fueron proyectados, así como el esquema que hasta nuestros días acompañan a la partitura de la obra, fueron extraídos de una revista londinense de varios años antes del estreno ruso de la obra. Existe la posibilidad de que Scriabine hubiera considerado una correspondencia de "colores-campos tonales", distinta. ${ }^{131}$

Existe también la posibilidad de que Luce, estuviera vinculado a los armónicos alejados de la nota generadora; siendo que la orquesta producía un acorde de "Sol con oncena" la proyección de color que ejecutaba las notas "Fa sostenido" y "La" corresponde con los armónicos números nueve y trece producidos por el "Sol" como generador. La correspondencia de Scriabine también toca los "estados del alma", (como el compositor les llamaba), en una correspondencia que recuerda a los “Rasas" hindús, con lo cual nos proporcionaría una correspondencia de índole anímica directamente relacionada con el mito griego de Prometeo; los colores proyectados corresponderían a la "Creatividad" y la "Materia", como inicio: Al segundo 39 de la obra, Luce proyectaría la correspondencia "Creatividad" (Fa sostenidoVioleta), simultáneamente con "Humanidad" (Mi bemol-carne); en el segundo 45 (compás 15) el "Mi bemol" se desplaza a la nota "Do", mientras mantiene el "Fa sostenido", manteniendo de esta forma la "Creatividad" ahora en unión con la "Voluntad humana".

131 PEACOCK; K.. "Instruments to perform color-music. Two centuries of technological experimentation." Leonardo, Vol. 21, 1988, num. 4, p. 403. 
Capítulo IV.- Sinestesia.

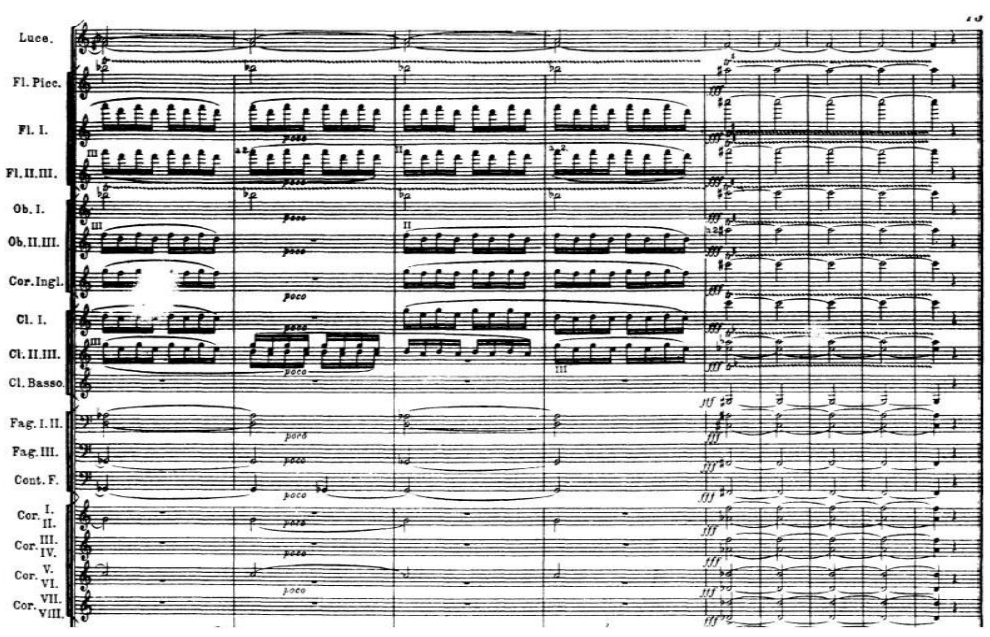

Figura 70. Final de la obra "Prometeo" de Scriabine. Fragmento.

SCRIABIN A.: Poem of Ecstasy and -Prometheus: Poem of Fire. New York: Ed. Dover, 1995.

El acorde final de Prometheus, es el acorde "mayor" de "Fa sostenido", mientras que Luce, en una correspondencia exacta con la nota generadora, continúa proyectando el color violeta o la "Creatividad"; en los segundos anteriores también la nota "La" el verde o "Materia"; realizando de esta manera una metáfora en toda la obra sobre el papel del artista como el portador del fuego, el triunfo de la creatividad humana.

Prometheus, al igual que el resto de la obra de Scriabine, continúa ejecutándose en nuestros días en incontables conciertos públicos. Para el manejo lumínico de la obra, se utilizan actualmente herramientas digitales y análogas; así como proyecciones monumentales del color de la obra de acuerdo al esquema dictado por Scriabine; la obra no siempre es ejecutada con la parte de Luce, y esto nos lleva a una reflexión sobre la autonomía de la parte musical en 


\section{Capítulo IV.- Sinestesia.}

referencia a la parte lumínica de la misma; sin embargo, Prometheus continúa representando un ícono del arte sinestésico y de la música de Scriabine, así como de sus ideas relativas a la correspondencia entre color-música y los "estados del alma".

Hacia el final de su vida, a principios del siglo XX, Scriabine comenzó los esbozos de una obra de arte, la cual excedía incluso la idea de "obra de arte total" que se tenía hasta esos momentos; le llamó "Mysterium".

En "Mysterium", Scriabine aborda la idea del arte total con la participación del público y el carácter místico-religioso, y con trascendencia social que encontramos en la obra de arte total desde Grecia. Scriabine concebía la obra como un rito religioso, contemplando que duraría alrededor de siete días. "Mysterium" se desarrollaría en un templo construido ex profeso en la India, involucraría todas las artes y todos los sentidos, y en palabras de Scriabine, el público no existiría, todos serían celebrantes del ritual:

"No habría un solo espectador. Todos serían participantes. El trabajo requiere de gente especial, artistas especiales y una cultura completamente nueva. La instrumentación incluye una orquesta, un gran coro mixto, un instrumento para efectos visuales, bailarines, una procesión, incienso, y una articulación rítmica gestual. La catedral en donde se llevaría a cabo no sería de un solo tipo de piedra, sino que cambiaria constantemente de acuerdo a la atmosfera y movimiento del Mysterium. Esto se realizaría con la ayuda de humo y luces, las cuales contribuirían a modificar los contornos 


\section{Capítulo IV.- Sinestesia.}

arquitectónicos... Vivirías esta música con todas las sensaciones, armonía de sonidos, de colores, de fragancias."132

El "Mysterium”, estaba planeado como su obra magna, que conocemos bajo reconstrucciones abordadas por diferentes compositores contemporáneos, ya que la obra no fue terminada, quedaron bocetos del primer acto de la obra. A pesar de la aparente imposibilidad de la obra, (que el mismo Scriabine parece hacer referencia), con su necesidad de "una cultura completamente nueva", llegó a comprar tierras en la India para comenzar la construcción de la catedral del "Mysterium",y esto, nos induce a pensar que Scriabine tenía contemplada la realización de la obra. ${ }^{133}$

Es en esta obra, que podemos encontrar referencia al llamado “acorde místico", un acorde construido por "cuartas" musicales, en el que Scriabine construye el acorde inicial de la obra, añadiendo frecuencias por cuartas musicales a partir de la nota generadora, hasta abarcar los doce sonidos de la escala musical temperada occidental.

Scriabine concebía la idea de que el mundo cambiaría para dar lugar a una especie de holocausto a principios del siglo XX, y que la "comunión" artística de los participantes del Mysterium, contribuiría a la formación de una nueva cultura mediante la comunión espiritual que el arte crearía en los participantes; un cambio de índole social

\footnotetext{
${ }^{132}$ SCRIABINE, cit. por EVANS T.R.: "The Mysterium of Alexander Scriabin." [Doctoral Document]. Ed. Washington State University P., 2009, p. 43.

${ }^{133}$ GARCÍA E.E.: "Scriabin's Mysterium and the birth of genius." New York: American Psychoanalytic Association, 2005, p. 9.
} 


\section{Capítulo IV.- Sinestesia.}

mediante la obra de arte total. Scriabine muere prematuramente de septicemia, dejando inconclusa no solo esta obra, sino varias de corte orquestal y para piano solo; no queda más que conjeturar sobre la imposibilidad o no, de la realización del Mysterium en caso de que el compositor hubiera continuado vivo.

Las correspondencias sinestésicas continuaron siendo de interés en los artistas simbolistas de finales del siglo XIX y principios del siglo XX, no solo en el ramo de la "música de colores", sino en disciplinas como: la poesía, teatro, ópera y danza; así como en la pintura, como una manifestación abstracta. Un importante representante, de lo que podríamos considerar como correspondencias en el sentido opuesto de la "música de colores", creando una "pintura musical”, sería Kandinsky.

Wassily Kandinsky (1866-1944), pintor ruso nacido en Moscú, es considerado como precursor del abandono de la figura por el arte abstracto, a pesar de ser conocido principalmente por su pintura, fue también artista gráfico y teórico del arte. 1871 entra a la Universidad de Moscú para estudiar Derecho y Economía, y a pesar de haber sido exitoso en ambos ramos, comenzó a pintar a la tardía edad de 30 años, realizando principalmente "estudios" de índole anatómico y figurativo.

Alrededor de 1896 se muda a Múnich, en donde comienza estudios formales de pintura en la Academia de Bellas Artes; regresa a 


\section{Capítulo IV.- Sinestesia.}

Moscú en 1914, para volver a Alemania en 1921. Posteriormente, comienza actividades como maestro en la Escuela de Arte y Arquitectura "Bauhaus" desde 1922 a 1933, momento en que la escuela fue clausurada por el movimiento Nazi.

A consecuencia del cierre de la Bauhaus, Kandinsky se muda a Francia, país en el que establece su residencia por el resto de su vida, consiguiendo la nacionalidad francesa en 1939.

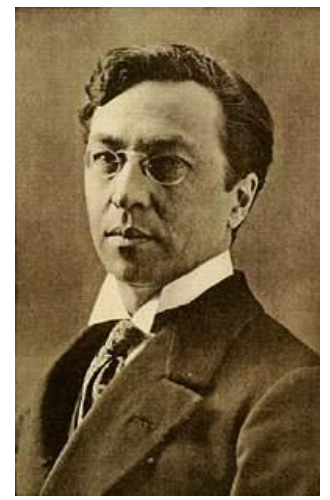

Figura 71. Retrato de Kandinsky.

En su autobiografía, Kandinsky nos describe un atardecer en Moscú, el cual, le recordaba el poema sinfónico "Lohengrin" de Richard Wagner, cuya música le parecía:

“Una perfecta realización de este Moscú... los violines, los profundos tonos del bajo...contenían toda la fuerza de las primeras horas del atardecer... Vi todos los colores en mi mente, aparecieron justo frente a mis ojos. Líneas salvajes, casi de locura aparecieron frente a mí... Se volvió claro para mí, que el arte era mucho más poderoso de lo que había 


\section{Capítulo IV.- Sinestesia.}

imaginado, y que la pintura era capaz de desarrollar poderes iguales a la música" ${ }^{, 134}$

Esta sensación o intuición, de que la pintura era capaz de desarrollar los mismos "poderes" que otro arte, fue algo que acompañó a Kandinsky durante gran parte de su vida artística, y terminó por dar forma a su impulso creador pictórico en la forma de arte abstracto. Kandinsky estaba convencido de que las artes, sin importar la disciplina o especialización, compartían todas los mismos "medios" o mundo interno-espiritual, para: "a su vez, utilizar los suyos... según el principio que le sea propio exclusivamente" ${ }^{\natural 35}$. Kandinsky estaba convencido de que los colores tenían una correspondencia sonora, así como diferentes elementos y símbolos pictóricos tenían una funcionalidad correspondiente con todas las demás artes, de hecho, una gran parte de su lenguaje pictórico, fue construido a partir de ideas extra-pictóricas, en particular, musicales.

Para la creación de su lenguaje pictórico, Kandinsky parte de un cuidadoso análisis de los "elementos básicos" de la pintura y las artes, además del mundo "espiritual” del hombre y su relación directa con las artes, mencionando cómo la tendencia hacia lo abstracto en el arte, tiene una correspondencia directa con la "naturaleza interior" humana, la psique; es por medio de este búsqueda interna de lo

\footnotetext{
${ }^{134}$ MAUR, K. The sound of painting. Music in modern art. Múnich: Prestel, 1999, p. 30.

${ }^{135}$ KANDINSKY, W.W. De lo espiritual en el arte. México D.F.: Premiá, 1981, p. 38.
} 


\section{Capítulo IV.- Sinestesia.}

espiritual y atemporal en las artes, que Kandinsky crea un "puente" entre las mismas.

Comenzando por el efecto psicológico de los colores, Kandinsky, menciona una serie de comparaciones entre diferentes sensaciones perceptivas, así como la "vibración anímica", el cambio en el "estado del alma", que tiene implícito un color: "El estridente amarillo limón duele a la vista como el tono alto de una trompeta al oído..." ${ }^{136}$ y prosigue, relacionando mediante la existencia de la realidad espiritual, la posibilidad de "asociaciones" intrínsecas entre los fenómenos perceptivos, como una sinestesia natural en todos los hombres. Kandinsky toma como ejemplo un caso del Dr. Freudenberg, sobre sinestesia "sabor-color", y partiendo de numerosos ejemplos, (algunos de índole subjetiva), afirma que todos los sentidos están relacionados uno con otro. ${ }^{137}$

Continuando con su análisis de los elementos pictóricos y su relación con las demás artes y/o fenómenos de percepción humana, Kandinsky traza una clasificación de los colores; su función psicológica mediante una asociación de color-movimiento, relacionándola además, con las alturas musicales y/o espaciales. En su clasificación más básica, Kandinsky establece dos puntos de diferenciación de los colores:

\footnotetext{
${ }^{136}$ Ibidem, p. 42

${ }^{137}$ Ibidem, p. 43.
} 


\section{Capítulo IV.- Sinestesia.}

1. Lo cálido o frio del color.

2. Lo claro u oscuro.

Kandinsky relaciona lo cálido de manera intrínseca con el amarillo y lo frio con el azul, asignando además, un movimiento intrínseco al color, siendo el amarillo excéntrico y el azul concéntrico; el amarillo además propone un movimiento "físico" hacia el espectador, mientras el azul lo aleja del mundo físico hacia el mundo espiritual; al mismo tiempo, relaciona el color amarillo con las afinaciones agudas, mientras el azul con lo grave.

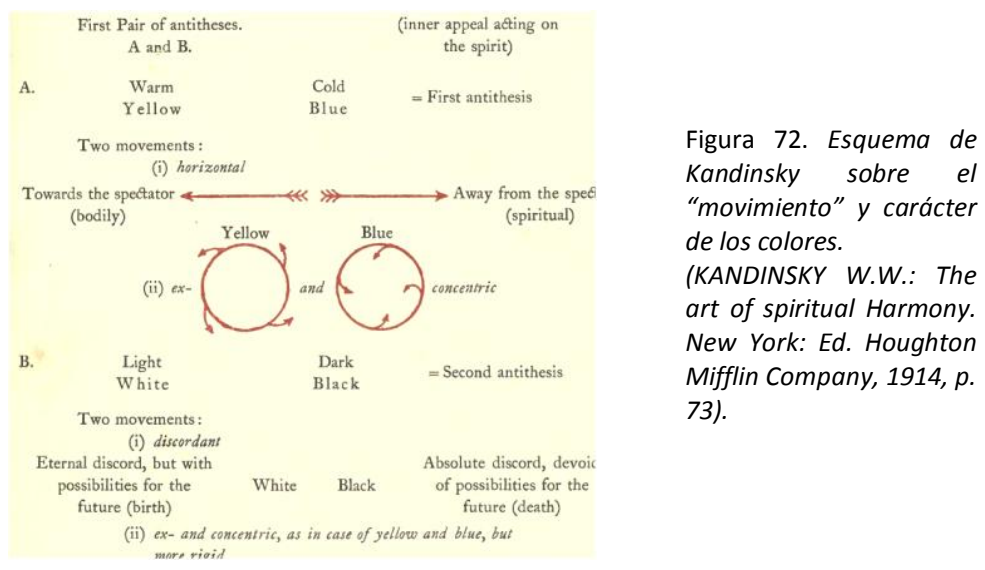

Esto lo lleva a establecer una serie de asociaciones entre los colores y fenómenos musicales, estableciendo una correspondencia entre el color y la combinación de timbre, con afinación musical; así como había relacionado el amarillo con lo agudo y el timbre de una 


\section{Capítulo IV.- Sinestesia.}

trompeta o clarín, continúa con las correspondencias estableciendo, el azul claro, como equivalente a una flauta y el azul oscuro, al violoncello; mientras el azul se vuelve más oscuro, correspondería a "Los maravillosos tonos del contrabajo... comparable al de un órgano"; el verde, como tono medio entre el amarillo (movimiento excéntrico) y el azul (movimiento concéntrico) le simboliza la calma, la falta de movimiento, y como tal, lo asocia a "Los tonos tranquilos, alargados y semi-profundos del violín”; el blanco estaría relacionado con el silencio, un "no-sonido", pero en comparativa con el negro, el blanco le resulta a Kandinsky una "negación precursora", en sus propias palabras: "La nada anterior al nacimiento", mientras que el negro es: "La nada sin posibilidades"; el rojo, "Saturno", correspondería a un "Sonar de trompetas acompañadas de tubas"; mientras que el marrón, sería el "Redoble de un tambor". ${ }^{138}$

Kandinsky de manera subjetiva, crea una primer correspondencia, por medio del análisis del color entre éste, el sonido y los estados anímicos; dejando abierta la posibilidad de una correspondencia sinestésica entre absolutamente todo orden de percepción.

Continuando con el análisis de los elementos pictóricos, Kandinsky nos lleva de igual manera, al análisis de fenómenos figurativos en su manera más simple, comenzando con el Punto como

\footnotetext{
${ }^{138}$ KANDINSKY, W.W. De lo espiritual en el arte. México D.F.: Premiá, 1981, pp 69-77.
} 


\section{Capítulo IV.- Sinestesia.}

un "ente abstracto",139, y en función en la escritura; como "silencio". Desde esta perspectiva, Kandinsky nos lleva a considerar el Punto como un "ente por sí mismo", con información autocontenida y significado propio; a la par, mencionando que este posee fuerzas que podrían muy bien compararse con el azul, y como símbolo pictórico, es perceptible con una carga mínima temporal, por medio de la repetición; comparándolo con "La percusión de un tambor". ${ }^{140}$

Es al mencionar esta carga temporal del Punto, que Kandinsky realiza una de sus más importantes contribuciones al análisis de los elementos pictóricos y al arte sinestésico, considerando al Punto como la mínima forma temporal en la pintura, destruye de facto una de las clasificaciones del arte que se encontraban vigentes en su época, la cual separaba la pintura de la música como arte "espacial” o "temporal"; añadiendo una carga temporal al significado de un símbolo pictórico, nos encontramos con un nuevo concepto de la pintura, que la une con la música, la danza y las artes de ejecución escénica.

Estableciendo la temporalidad del Punto, Kandinsky se encuentra con todo un mundo de posibilidades pictóricas; la repetición de un punto, entonces posee de forma intrínseca la posibilidad del establecimiento de un ritmo musical, o incluso la comparativa de un instrumento musical como un creador de símbolos pictóricos, como lo

139 KANDINSKY, W.W. Punto y línea sobre el plano. Argentina: Andrómeda, 1998 , p. 29.

140 KANDINSKY, W.W. Punto y línea sobre el plano. Argentina: Andrómeda, 1998, p. 40. 


\section{Capítulo IV.- Sinestesia.}

menciona para el piano, que "Realiza la confrontación y repetición de meros símbolos puntuales". Para establecer este tipo de correspondencias entre un símbolo pictórico y los sucesos temporales, y lograr las traducciones entre distintas disciplinas artísticas, en realidad solo hay un paso: La realización. Kandinsky aborda de manera simplemente ejemplificativa la traducción de "sucesos" o "pasajes" de diferentes artes como la danza, la arquitectura y la música a símbolos pictóricos, asignando alturas musicales al espacio geográfico en el plano, volúmenes al tamaño del punto, y líneas a notas "ligadas", por instrumentos de aliento.

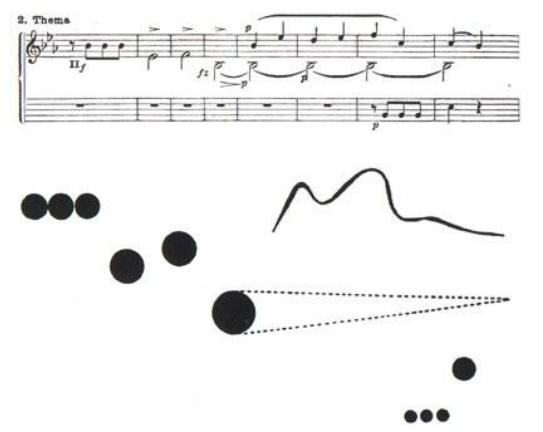

Figura 73. Traducción de Kandinsky de sucesos musicales a símbolos pictóricos a partir de un pasaje de la Quinta Sinfonía de Beethoven. (KANDINSKY, Wassily: Punto y línea sobre el plano. Barcelona: Ed. Paidos, 1998, p.39).

Kandinsky continúa con el análisis de los elementos pictóricos de la Línea y el Plano, asignando diferentes funciones subjetivas a estos elementos y sus posibles variaciones con elementos funcionales comunes a todas las artes, y es por estos medios con los que crea su 


\section{Capítulo IV.- Sinestesia.}

propio lenguaje pictórico; que lo lleva a afirmar que: “Así como en la música cada construcción posee su propio ritmo...igual sucede con la pintura". ${ }^{141}$

Kandinsky realiza una exposición en Londres en 1913, con una serie de cuadros no-figurativos, abandonando por completo la figura para conseguir un efecto sonoro con su pintura, y en palabras del crítico Roger Fry, “... son pura música visual, y no tengo duda sobre la posibilidad de expresión emocional con tales signos visuales abstractos". 142

Como resultado de esta concepción del arte como un todo, con elementos comunes a todas las disciplinas, es que Kandinsky realiza varios de sus cuadros bajo títulos, como: Composición, Improvisación, Melodía, Impresiones; muchos de estos términos están relacionados tradicionalmente con la música, por ejemplo, el término Improvisación, hace referencia a un músico que crea música al tiempo que la ejecuta, sin seguir las instrucciones referidas en una partitura; que lleva a Kandinsky a trazar un paralelismo más entre la pintura y la música, mediante el enfoque creativo del fenómeno musical, aplicado al pictórico:

“(...) estos ejemplos proceden de tres fuentes diferentes: 1 . La impresión directa de la naturaleza externa, expresada de manera gráfico-pictórica. Llamo a estos cuadros "impresiones"; 2. La expresión principalmente inconsciente, generalmente súbita, de procesos de carácter interno, es decir,

${ }^{141}$ KANDINSKY, W.W. De lo espiritual en el arte. México D.F.: Premiá, 1981, p. 118.

${ }^{142}$ Arte abstracto y arte figurativo. Barcelona: Salvat, 1973, p. 21. 


\section{Capítulo IV.- Sinestesia.}

impresión de la naturaleza interna. Estos cuadros son improvisaciones; 3 . La expresión de tipo parecido, pero creada con extraordinaria lentitud y que analizo y elaboro larga y pacientemente después del primer esbozo. A este tipo de cuadro lo llamo "Composición". 143

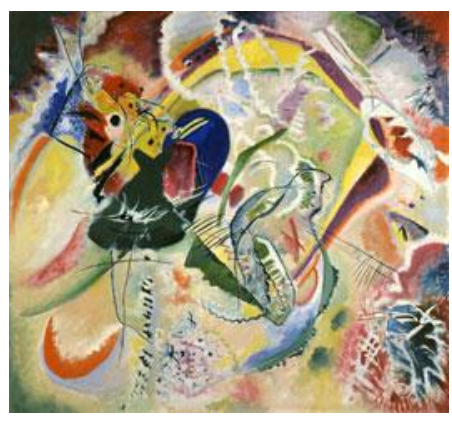

Figura 74. Improvisación no. 85. Kandinsky. Museo de Bellas Artes de Basilea.

No existe una referencia que señale a Kandinsky como un sinesteta clínico, a pesar de las múltiples correspondencias trazadas en sus análisis de las diferentes disciplinas artísticas, y de las posibilidades de representación temporal y sonora de su pintura, así como de las correspondencias que estableció para sus colores. Existen cartas de Kandinsky al músico compositor Arnold Schoenberg (18741951), con quien tuvo una importante colaboración intelectual, y Schoenberg en su libro de "Armonía”, describe:

"Todo acorde, toda progresión musical es posible. Pero presiento ya hoy que también aquí existen determinadas condiciones de las que depende si utilizo esta o aquella disonancia"144

${ }^{143}$ KANDINSKY, W.W. De lo espiritual en el arte. México D.F.: Premiá, 1981, p. 120.

${ }^{144}$ Ibidem, p. 32. 


\section{Capítulo IV.- Sinestesia.}

Y esto lleva a Kandinsky a considerar a Schoenberg como un descubridor de verdaderas fuentes de nueva belleza. Para Kandinsky, estas fuentes eran las mismas para todas las artes, y que se encontraban en parte, en el mundo espiritual e interior de la psique humana. Mundo espiritual, que se convierte su fuente creativa, y que era compartida por Schoenberg.

Schoenberg, creador de la técnica compositiva conocida como "dodecafonismo", en la cual propone el abandono del concepto de la tonalidad musical, como era concebida en el ordenamientos de "series dodecafónicas"; propone un nuevo concepto de la concepción misma de la música, al final de su libro de "Armonía" dedicado a Gustav Mahler, de manera póstuma.

Tomando como punto de partida el uso de acordes "hexacordales" o de seis sonidos, en un contexto aún fuera del uso de la técnica dodecafónica, Schoenberg hace referencia a dos combinaciones hexacordales del "Vier lieder" de uno de sus alumnos, Alan Berg:

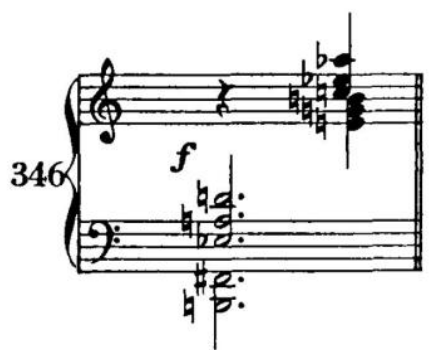

Figura 75. Acordes de Alban Berg a los que hace referencia Schoenberg en su libro de Armonía.(Alban Berg. Vier Lieder op. 2 no. 4. Cuatro compases antes del final. En SCHOENBERG A.: Theory of Harmony. Ed. University of California Press, p.420. 


\section{Capítulo IV.- Sinestesia.}

Schoenberg menciona cómo pesar de las disonancias establecidas en este acorde, funciona y tiene contenido estético: "Porque es de esta manera y porque funciona, no puedo explicarlo..."145. Pero Schoenberg, maneja la posibilidad de leyes intrínsecas para el funcionamiento de este tipo de combinaciones hexacordales, las cuales, no puede más que intuir en ese momento; escapando de cierta manera a la auto- impuesta "responsabilidad" de tratar de explicar posibles leyes naturales, al uso de las disonancias, que se encontraban en uso en la música de vanguardia de su época. Schoenberg transmite otra idea, sobre la calidad y parámetros de la música, que describe como la afinación, el "color" o timbre, y el volumen.

Schoenberg consideraba que el parámetro que se encontraba aún más lejano de un sistema de ordenamiento era el "color" o timbre musical, al que llamó "color tonal" (Klangfarbe), refiriéndose a la afinación, y a las leyes de la armonía, las consideró como una mera subdivisión del manejo del "color tonal"; y como una "mira al futuro" a la posibilidad de una "melodía de colores", basada en la "unidad" del color tonal, que "Nos llevará más cerca a la materia ilusoria de los sueños" ${ }^{146}$, conectándonos a lo que considera como una "vida más completa".

145 SCHOENBERG, A. Theory of Harmony. Berkeley: University of California P., Traducción al inglés de la tercera edición alemana de 1922, p.420

146 SCHOENBERG, A. Theory of Harmony. Berkeley: University of California P., Traducción al inglés de la tercera edición alemana de 1922, p. 421. 


\section{Capítulo IV.- Sinestesia.}

Al pasar los inicios del siglo XX, la "pintura musical", o lo que podría considerarse en un concepto más amplio, la "pintura temporal", por poseer elementos de representación temporal, así como posibles traducciones de música a pintura, continuó siendo elaborado por diferentes artistas y escuelas, entre los que podemos mencionar a Paul Klee (1879-1940), que exploró la traducción música-pintura; el compositor de música Matthias Hauer (1883-1959), cuya máxima contribución en el ramo de la música, fue una técnica "dodecafónica" (anterior y diferente a la de Arnold Schoenberg), habiendo realizado traducciones de la música a elementos pictóricos, mediante correspondencias preestablecidas entre la pintura y la música.

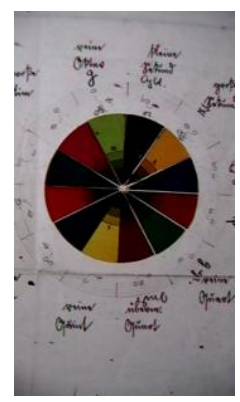

Figura 76. Esquema de correspondencias color-sonido elaborado por Hauer. (DUPLAIX, Sophie: Sons \& Lumières. Paris : Ediciones del Centre Pompidou, 2004, $p$. 163).

Henry Nouveau (1901-1959), pintor francés que trabajó pinturas con títulos como "improvisación", y que con su simbología de índole abstracta, recuerda al análisis de los elementos pictóricos realizado por Kandinsky; Josef Albers (1888-1976) pintor abstracto, cuya pintura geométrica y repetición de elementos pictóricos, así como el análisis de partituras musicales, le llevaron a la traducción pictórica de música de J.S. Bach, así como a la elaboración de pintura "rítmica"; Piet Mondrian (1872-1944), fundador del movimiento 


\section{Capítulo IV.- Sinestesia.}

"neoplasticismo", y pintor abstracto, con su obra, como "Victoria Boogie-Woogie", hace referencia directa a composiciones musicales; Giacomo Balla (1874-1958), pintor representativo del movimiento "futurista" italiano, que exploró las posibilidades pictóricas del movimiento y el dinamismo, en numerosos cuadros de índole geométrico-abstracta, creando movimiento mediante la repetición de elementos visuales.

El siguiente adelanto tecnológico en crear nuevos caminos en el arte sinestésico, fue el "cinematógrafo", con la posibilidad de proyección de imágenes en movimiento, creó nuevas vertientes exploradas por compositores, como: Alexander László (1895-1970), y cineastas como Oskar Fischinger (1900-1967).

Fischinger creó lo que él consideraba como auténtica "música visual", por medio del recurso de la proyección de imágenes en movimiento, además de haber explorado también en las áreas de la pintura y escultura, Fischinger recibió una fuerte influencia de Walter Ruttmann (1887-1941), cineasta precursor del concepto del "cine absoluto", cine abstracto-experimental, en particular, de sus trabajos tempranos como: "Light Play Op.1" .

Los trabajos de Fischinger, nos enfrentan a figuras abstractas con ritmo y movimiento, como una sola unidad. A partir de 1929, realizó una serie de 17 "Estudios" fílmicos, para resolver ciertas dificultades técnicas implícitas en la representación del abstraccionismo en movimiento, trazando de esta forma los 


\section{Capítulo IV.- Sinestesia.}

paralelismos entre el concepto de "Estudio" en la composición musical y el cine; por ejemplo, en el "Estudio no. 8" realizó los paralelismos entre la densidad orquestal y la densidad figurativa. ${ }^{147}$

Fischinger se enfrentó a múltiples dificultades económicas, además de problemas para recibir una remuneración económica por sus trabajos; un caso ejemplar, fue con su cortometraje "Allegretto" una de las obras más representativas de la "música visual" que realizó en 1936, acompañada por música de Ralph Rainger, por el cual, no solo no recibió nada a cambio, sino que tuvo que utilizar una beca otorgada por la fundación Guggenheim para poder comprar el cortometraje de vuelta a la compañía "Paramount".

En "Allegretto" el espectador contempla figuras geométricas como rombos y círculos, figuras abstractas, cuyo movimiento está supeditado a la música, una comunión sin la cual no es posible el filme, una correspondencia de imagen en movimiento y sonido desde la concepción misma del trabajo, que se convirtió en el eje central creativo de los trabajos abstractos de Fischinger.
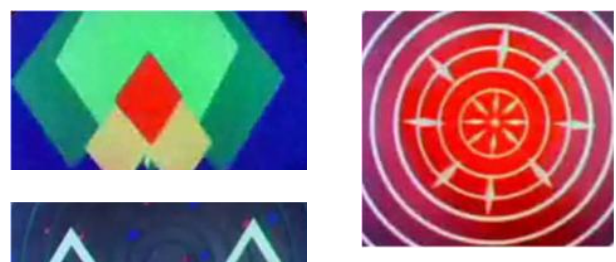

Figuras 77, 78 y 79. Imágenes del video "Allegretto" de Oscar Fischinger. (Fischinger Trust).

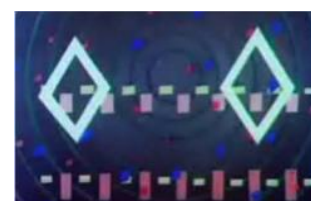

Fischinger. (Fischinger Trust).

147 The Fischinger Trust: "Fischinger Biography." [en línea]. Disponible en: http://www.oskarfischinger.org/OFBioLong.htm [Consulta: 31 Diciembre 2010]. 


\section{Capítulo IV.- Sinestesia.}

Fischinger escribió varios "manifiestos" sobre su obra y proceso creativo, en algunos de ellos nos relata el inicio de su concepto sobre el "cine absoluto" y el concepto de "cine como arte". Fischinger menciona el "génesis" de su obra en el área del cine abstracto como los bocetos que realizó para una ponencia pública que tenía que dar sobre una obra de Shakespeare; comenzó a "analizar el trabajo literario en una forma gráfica" ${ }^{, 148}$ poniendo mediante líneas y curvas en un esquema lineal, las emociones y sucesos que acontecían escena tras escena. De esta forma Fischinger conseguía un esquema gráfico-lineal correspondiente a las "emociones" de la obra literaria. El siguiente paso mencionado por Fischinger, era la necesidad del movimiento, para poder mostrar de una forma más "clara y convincente" las "emociones" involucradas en el trabajo literario, por ende, el elemento cinemático tenía que ser añadido.

Fischinger menciona este trabajo como su primer "filme absoluto" o primer trabajo en el área de "cine absoluto"; de una manera casi intrínseca, considera la necesidad de la música para acompañar las imágenes en movimiento, y con ello obtenía resultados más prometedores. Al hacer uso de la música como un elemento más del "cine absoluto", Fischinger establece de facto, correspondencias entre la acústica, el movimiento y la imagen, con la aplicación de "leyes de la acústica a la expresión óptica" ${ }^{149}$, mencionando cómo el "Fluido de sentimientos" que aparece unido en la música, permitía

\footnotetext{
${ }^{148}$ FISCHINGER O.: “My statements are in my work." [en línea]. Disponible en: http://www.oskarfischinger.org [Consulta: 31 Diciembre 2010].

${ }^{149}$ Ídem.
} 


\section{Capítulo IV.- Sinestesia.}

incorporar de una manera más efectiva y clara una carga estética y significativa al "cine absoluto", como forma de arte.

Fischinger comenzó a trabajar algunos de sus trabajos “experimentales” en el cine, alrededor de 1920, en Múnich, de esta época data su filme sin música en blanco y negro: "Espirales", explorando los efectos de la repetición de elementos pictóricos en movimiento para crear ilusiones de profundidad y de movimientos concéntricos y excéntricos; posteriormente incorporando el color y la música, obtiene resultados de correspondencias de índole emocional, entre música e imagen, en trabajos como sus "Estudios" y el representativo "Allegretto".

Fischinger trabajó con el compositor húngaro László, en Múnich, con multiproyecciones y experimentación, sobre diferentes tipos de superficie de proyección, incluyendo además, el "órgano de colores" de László, mediante el cual proyectaba diferentes luces de colores, además de formas geométricas en espacios predeterminados; Fischinger define estas proyecciones como una nueva forma de arte en la cual "Todo era antiguo y nuevo a la vez: la Plástica-Danza-Pintura y Música, convirtiéndose en una", creando un nuevo arte, al cual denominó Raumlichtmusik o "Espacio de luz y música". ${ }^{150}$

Fischinger consideraba que el cine podía ser una forma de arte, cuando este utiliza procesos creativos como un todo, no como una

\footnotetext{
${ }^{150}$ KEEFER C.: “Raumlichtmusik” Early 20th Century Abstract Cinema Immersive Environments. [en línea]. Massachusetts: Leonardo Electronic Almanac. Disponible en: http://www.oskarfischinger.org [Consulta: 31 Diciembre 2010].
} 


\section{Capítulo IV.- Sinestesia.}

representación figurativa; cuando el filme "no está cortado, sino es una verdad absoluta y continua",151 deseando llenar las "necesidades espirituales y emocionales de nuestra era". ${ }^{152}$

El "cine absoluto" plantea correspondencias entre las leyes de la acústica y de la óptica; el movimiento de las imágenes y sus cambios en formas y colores, corresponde a cambios en la instrumentación, amplitud sonora, y "movimiento sonoro". Como un nuevo camino en el arte sinestésico, las posibilidades de interacción entre las imágenes en movimiento y la música como arte temporal, y las leyes que le son propias; dotó de un panorama completamente nuevo al arte sinestésico teniendo como nueva herramienta, el movimiento:

“(...) cuando estos artistas de origen preferentemente pictórico, se plantean una pintura en movimiento que tecnológicamente ya se lo permitía la filmación fotograma a fotograma, chocan con el tiempo cinematográfico ¿Se puede hacer una película sin contar una historia? ¿Qué sentido tiene moverse una pintura? Para resolver este dilema, recurren a un lenguaje no mimético que utiliza el tiempo, y ese es la música. Pero no para utilizarla como ilustración sonora de las imágenes, sino para crear una conexión estructural con su lenguaje. De esta forma recogen formas transdisciplinares comunes a los dos: el ritmo, la armonía..., como otras propias del lenguaje musical: sinfonía, fuga, preludio, ballet, etc." ${ }^{153}$

151 FISCHINGER, O. “True creation." [en línea]. Disponible en: http://www.oskarfischinger.org [Consulta: 31 Diciembre 2010].

${ }^{152}$ Ídem.

${ }^{153}$ MOLINA, Miguel. “¿Narciso enamorado de Eco? Cuando la imagen visual móvil persigue a la música: del absolute film a los Vj's”. $18^{\circ}$ Encontro da Associação

Nacional de Pesquisadores em Artes Plásticas Transversalidades nas Artes Visuais. Salvador de Bahia-Brasil, 2009, p. 3-4 


\section{Capítulo IV.- Sinestesia.}

La herramienta digital y sus posibilidades de conjuntar en un solo "paquete" diferentes tipos de estímulos visuales y sonoros, son una de las últimas manifestaciones trascendentes encontradas en el arte sinestésico del siglo XX; continuando la misma línea propuesta por Fischinger y múltiples cineastas del "cine absoluto", el arte sinestésico creado con herramientas digitales hace uso de la animación y las correspondencias entre estímulos de diferente índole.

Como toda herramienta nueva, el uso de la plataforma digital permite nuevos tipos de interacciones y usos de los elementos ya existentes, tal es el caso del procesamiento en "tiempo real", mediante el cual, es posible crear animaciones cuyo movimiento esté supeditado a los parámetros emitidos en el momento por la música, o viceversa. Las posibilidades del procesamiento en tiempo real, han creado además nuevas manifestaciones que manejan correspondencias de índole "Física" entre diferentes tipos de estímulos, como lo es la cultura "Vj" (Videojockey), cuyos exponentes procesan imágenes en el momento mismo de la ejecución musical, estableciendo parámetros de alteración o animación de la imagen de acuerdo a la información provista por la música o sonido. Para conseguir esto, es necesario de facto el establecimiento de correspondencias entre el sonido y la imagen, correspondencias que mediante el "filtrado" de los parámetros de uno de los estímulos, altera la emisión del otro estímulo; la música siendo alterada por los parámetros de la imagen, o más comúnmente en la cultura "Vj", es a la inversa, la imagen y/o animación, siendo alterada en tiempo real, por la música. 


\section{Capítulo IV.- Sinestesia.}

El arte sinestésico lo contemplamos desde el inicio mismo del concepto de "arte" tanto en la sociedad occidental como oriental; y consiste en el establecimiento de correspondencias de cualquier índole sensorial. Existe también en vertientes como en la poesía de Baudelaire (1821-1867) o poetas japoneses, como Matsuo Bashó (1644-1694), creador de “Haiku” o (poemas miniatura), en uno de sus poemas establece correspondencias de índole sinestésico, entre sonidos y colores:

"El mar se oscurece-

la llamada del pato salvaje

es ligeramente blanco"154

Encontrando también manifestaciones sinestésicas creando correspondencias mediante la literatura, en el poema: “Correspondances”, de Baudelaire:

“(...) Como ecos prolongados que a lo lejos se ahogan en una tenebrosa y profunda unidad, inmensa cual la noche y cual la claridad, perfumes y colores y sonidos se corresponden.

${ }^{154}$ BASHÓ, M. “Haiku.” [en línea]. Disponible en: http://home.comcast.net/ sean.day/html/pseudo-syn_authors.html "Umi kurete- kamo no koe- honoka ni shiroshi" [Consulta: 31 Diciembre 2010]. 


\section{Capítulo IV.- Sinestesia.}

Laten frescas fragancias como carnes de infantes, verdes como praderas, dulces como el oboe, y hay otras corrompidas, gloriosas y triunfantes, $(\ldots)^{\prime 155}$

Baudelaire establece un "diálogo" entre "perfumes, colores y sonidos" y correspondencias de índole subjetiva entre estímulos de diferente índole. Estas correspondencias sinestésicas fueron una constante en varios de sus poemas, así como de varios artistas de diferentes disciplinas a finales del siglo XIX, y principios del siglo XX:

"Stravinsky ya había señalado tiempo atrás la idea de que la música se percibía tanto por los oídos como por los ojos. De la misma opinión es el enunciado de Cage que señala que la separación imaginaria de la escucha respecto a los otros sentidos no existe" 156

El arte sinestésico contiene en sí mismo la posibilidad de múltiples variantes e interacciones entre diferentes disciplinas artísticas, encontramos tantas variantes como posibilidades de

155 GAUTIER, F.F. (ed.). Oeuvres Complètes de Charles Baudelaire. Paris: Nouvelle Revue Française, 1918, pp. 29-30. Texto original:

“(...)

Comme de longs échos qui de lom se confondent,

Dans une ténébreuse et profonde unité,

Vaste comme la nuit et comme la clarté.

Les parfums, les couleurs et les sons se répondent.

Il est des parfums frais comme des chairs d'enfants,

Doux comme les hautbois, verts comme les prairies,

- Et d'autres, corrompus, riches et triomphants."

${ }^{156}$ ARIZA, Javier. Las imágenes del sonido. Cuenca: Ediciones de la Universidad de Castilla-La Mancha, 2003, p. 94 


\section{Capítulo IV.- Sinestesia.}

combinaciones sensoriales existen en el cuerpo humano, y sus posibilidades imaginativas; el arte sinestésico no es exclusivamente realizado por "sinestetas clínicos", sino por artistas, seres humanos con capacidad imaginativa, técnica y oficio en su propia disciplina, lo cual, los lleva a expandir su campo de trabajo hasta concretar esta "invasión" establecida por medio de "correspondencias" de otros lenguajes artísticos, además del que les es propio. 


\section{Capítulo IV.- Sinestesia.}

\section{4 ¿Qué colores asignan los sinestésicos?}

La sinestesia "sonidos musicales-color", es relativamente escasa, siendo presentada por solo el $8.4 \%$ de la población sinestésica de acuerdo al investigador Sean Day; ${ }^{157}$ y esto tiene como consecuencia implícita, que sean pocos los individuos que presentan este tipo de sinestesia en específico, número de individuos que se reduce todavía más, al tomar en cuenta que de acuerdo a algunos investigadores, el porcentaje de sinestetas clínicos, al ser comparados con la población mundial, es de una persona cada dos mil, existiendo la creencia de que "podría ser más común". ${ }^{158}$ Existe de facto una restricción más en la sinestesia sonido musical-color, es el oído absoluto.

Conocemos como oído absoluto, la característica humana de poder identificar la afinación de un sonido de manera instantánea y con certeza absoluta; siendo la sinestesia sonido musical- color, una correspondencia instantánea, implica que el individuo es capaz de determinar con certeza la afinación del sonido escuchado.

La correspondencia de sonidos musicales-color, y/o nota afinada - color, o incluso tonalidad musical - color, que estos

\footnotetext{
157 DAY, S. "Types of Synesthesia." [en línea]. Disponible en: http://home.comcast.net/ sean.day/html/types.htm [Consulta: 31 Diciembre 2010]. Listado actualizado el 19 de Septiembre de 2010.

${ }^{158}$ SACKS O. Musicofilia. Relatos de la música y el cerebro. Barcelona: Anagrama, 2009, p. 204
} 


\section{Capítulo IV.- Sinestesia.}

individuos presentan, es diferente a la de la mayoría de los ejemplos que encontramos a través de la historia del arte sinestésico; las correspondencias dictadas por los sinestetas clínicos no tienen su base en correspondencias de índole física, no hay una proporción entre las "leyes" de los fenómenos del color y del sonido que hayan preestablecido de forma matemática o intuitiva, sino que las correspondencias establecidas por estos individuos son de índole subjetiva y altamente individualizada, ya que sus correspondencias tienen su nacimiento en un fenómeno neurológico, el cual les acompaña de manera automática, permanente, y sin que ellos hayan realizado un esfuerzo consciente o racional para establecer sus correspondencias.

Como otra característica que comparten las correspondencias dictadas por el fenómeno de la sinestésica clínica, es que en muchos de los casos los colores, o sensación secundaria producida por el estímulo "real" o primario, son sumamente particulares, muchos de los sinestetas describen los colores con mucho cuidado, en ocasiones utilizando más de tres calificativos para tratar de describir con mayor exactitud un color, o la sensación secundaria producida; en algunos casos esto se exacerba al grado de describir colores que "nunca habían visto sus ojos". ${ }^{159}$

El investigador francés, TH. Flournoy, nos describe una tabla realizada con individuos de diferentes edades y sexos, que poseían

${ }^{159}$ SACKS O. Musicofilia. Relatos de la música y el cerebro. Barcelona: Anagrama, 2009, p. 207. 


\section{Capítulo IV.- Sinestesia.}

sinestesia: las correspondencias dictadas por estos individuos fueron comparadas a través de lapsos temporales largos, para poder determinar lo instantáneo de la correspondencia, así como el hecho de que la misma no cambiaba a través del tiempo; las correspondencias dictas por estos individuos, no eran el resultado de un esfuerzo de memorización, sino una sensación secundaria instantánea y duradera. Muchas de las correspondencias encontradas en investigaciones "clásicas" fueron realizadas estableciendo la correspondencia de color, con una escala musical específica, en este caso la escala musical de "Do mayor", estudio realizado en nueve personas de diferentes sexos y edades.

$\begin{array}{lllllll}\text { Do } & \text { Re } & \text { Mi } & \text { Fa } & \text { Sol } & \text { La } & \text { Si } \\ \text { Amarillo } & \text { blanco } & \text { rosa } & \text { verde } & \text { café } & \text { azul } & \text { gris } \\ i ? & \text { amarillo azul } & i ? & \text { rojizo } & \text { violeta } & i ? \\ \text { Blanco } & i ? & \text { rosa } & \text { azul } & \text { verde } & i ? & \text { marrón } \\ \text { Blanco } & \text { rojo } & \text { azul } & \text { violeta } & \text { amarillo rojo } & \text { verde } \\ \text { Blanco } & \text { azul } & \text { rojo } & \text { violeta } & \text { verde } & \text { amarillo gris } \\ \text { Rosa } & \text { gris } & \text { rosa } & \text { oscuro } & \text { claro } & \text { rosa } & \text { rojo } \\ \text { Amarillo } & i ? & \text { blanco } & \text { negro } & \text { rosa } & \text { verde } & i ? \\ \text { Verde } & i ? & \text { amarillo } & \text { ? } & \text { rojo } & \text { verde } & \text { amarillo } \\ \text { Amarillo } & \text { negro } & \text { rosa } & \text { marrón } & \text { azul } & \text { lila } & \text { violeta }\end{array}$

Flournoy, también menciona el caso de un sinesteta múltiple (con más de una asociación por estímulo), quien manifestaba la asociación exactamente inversa, la sensación del color le provocaba la

${ }^{160}$ FLOURNOY T.H. Des phénomènes de synopsie (audition colorée). Paris: Félix Alcan, 1893, p. 99. 


\section{Capítulo IV.- Sinestesia.}

sensación secundaria de la escala musical occidental, el individuo en cuestión, un sinesteta múltiple de 25 años, realiza la siguiente correspondencia.

\section{Estímulo primario Sensación secundaria (sonido).}

Blanco

Azul cielo

Violeta

Rojo

Naranja

Verde

Amarillo

"Color más obscuro"
Do agudo

$\mathrm{Si}$

$\mathrm{La}$

Sol

$\mathrm{Fa}$

Mi

$\operatorname{Re}$

Do grave

Otro caso que vale la pena ser mencionado, es cuando el músico sinesteta posee una correspondencia de sonidos afinados con el color de manera "indirecta": el individuo en cuestión no era músico profesional, sin embargo, poseía oído absoluto como consecuencia de una correcta educación musical temprana, su maestra de piano la hacía "adivinar" el nombre de las notas desde sus primeros años, lo cual la llevó a "pensar" el nombre de la nota de manera automática cuando escuchaba la nota en cuestión. Como consecuencia la combinación de su sinestesia con el sonido de las vocales y el color, con el factor 


\section{Capítulo IV.- Sinestesia.}

educativo musical, terminó por asignar de forma automática colores a los sonidos de la escala temperada occidental; una especie de "sinestesia creada" por relacionar su sinestesia natural con asociaciones educativas.

En otro estudio realizado a una mujer francesa, de 30 años, esta manifestaba tener sinestesia de sonidos de las vocales con el color, la sensación secundaria del color era provocada por el sonido de las vocales.La correspondencia que esta mujer francesa poseía entre los sonidos de las vocales y el color, era la siguiente:

\section{Estimulo primario Sensación secundaria}

A

É

$\grave{\mathrm{E}}$

I

$\mathrm{O}$

$\mathrm{U}$
Negro y blanco

"Beige" pálido.

"Beige" fuerte

Rojo

Negro gris

Verde

Como consecuencia de esta asociación, la sinestesia que le provocaba el sonido de las notas, relacionándolo con el sonido de las vocales "escuchadas" en el nombre de las notas, era bastante similar, con algunos ligeros cambios que le eran inexplicables, simplemente, poseía estas correspondencias de manera automática. 


\section{Capítulo IV.- Sinestesia.}

Nota Musical

Do

"Ré"

Mi

$\mathrm{Fa}$

Sol

$\mathrm{La}$

$\mathrm{Si}$
Color

Negro y Blanco

Marrón, muy oscuro

Rojo

Gris

Rojo

Gris

Rojo $^{161}$

Similar a lo manifestado por algunos compositores contemporáneos como el caso de György Ligeti (1923-2006), compositor húngaro, representativo de la música de la segunda mitad del siglo $\mathrm{XX}$, el cual, manifestaba poseer sinestesia grafema-color, y por asociación de la correspondencia, con las notas musicales:

"No poseo oído absoluto (...) Cuando digo que el tono de "do menor" tiene un color rojizo-café-oxidado, y que "re menor" es café, esto no viene de la afinación, sino de las letras "C" y "D". Creo que esto viene de mi infancia (...)"162

El compositor ruso Nikolay Rimsky-Korsakov (18441908), poseía una sinestesia sonido musical-color "verdadera"; el sonido afinado le producía la sensación secundaria del color de forma automática, además de haber gozado de oído absoluto desde niño ${ }^{\mathbf{1 6 3}}$; Korsakov manejaba una correspondencia entre las dos sensaciones, que era

\footnotetext{
${ }^{161}$ LAURES, H. Les Synésthesies. Paris: Librairie Bloud et C., 1908, p. 29.

${ }^{162}$ ROBERTSON L.C.; y N. SAGIV. Synesthesia: Perspectives from cognitive neuroscience. New York: Oxford University P., 2005 p.24.

${ }^{163}$ NATHAN, M.M. Rimsky-Korsakov. New York: Duffield and co. 1917, p. 14.
} 


\section{Capítulo IV.- Sinestesia.}

bastante diferente a la de Scriabine u otros representantes del arte sinestésico, dado que no eran sinestetas clínicos; pero que elaboraron correspondencias música-color, por medio de esfuerzos conscientes; y esto llevó a Korsakov a tener discusiones con Scriabine y Rachmaninof sobre el "color de la tonalidad". La correspondencia de Korsakov, es la siguiente:

Sonido afinado Sensación secundaria-Color.

Do

Re bemol

$\operatorname{Re}$

Mi bemol

$\mathrm{Mi}$

$\mathrm{Fa}$

Fa sostenido

Sol

La bemol

La

Si bemol

$\mathrm{Si}$
Blanco

Cálido, Obscuro

Amarillo real

Gris Azul

Azul zafiro, brillante

Verde

Verde grisáceo

Dorado, café

Violeta

Rosa

Obscuro

Azul obscuro 


\section{Capítulo IV.- Sinestesia.}

La compositora norteamericana, Amy Beach (1867-1944), reunía varias de las características representativas de la sinestesia sonido afinado-color, y también poseía oído absoluto, y desde chica manejaba una correspondencia entre escalas musicales y los colores que le desencadenaban:

$\begin{array}{ll}\text { Sonido afinado } & \text { Sensación secu } \\ \text { Do } & \text { Blanco } \\ \text { Re bemol } & \text { Violeta o púrpura } \\ \text { Mi bemol } & \text { Rosa } \\ \text { Mi } & \text { Amarillo } \\ \text { Fa sostenido } & \text { Negro } \\ \text { Sol } & \text { Rojo } \\ \text { La bemol } & \text { Azul } \\ \text { La } & \text { Verde }\end{array}$

Por último, encontramos las mismas características del oído absoluto y una correspondencia directa entre sonido afinado y colores, en el guitarrista de jazz, vivo en nuestros días, Tony deCaprio, el cual ha sido diagnosticado con sinestesia; expositor en el "Segundo Congreso Internacional Sinestesia, Ciencia y Arte" (Granada, España, 2007), quien además, ha impartido conferencias y clases maestras en 
las Universidades de Nevada y Hawai, nos menciona "Soy capaz de ver los doce tonos en sus respectivos colores". 164

Tony deCaprio, utiliza la siguiente correspondencia:

\section{Sonido afinado Sensación secundaria-Color.}

Do

Re bemol

$\operatorname{Re}$

Mi bemol

Mi

$\mathrm{Fa}$

Fa sostenido

Sol

La bemol

$\mathrm{La}$

Si bemol

$\mathrm{Si}$
Blanco

Naranja, Obscuro

Amarillo

Gris

Negro

Café

Verde claro

Verde

Magenta

Azul

Morado

Rosa

Son notorias las diferencias encontradas en las tablas anteriormente descritas entre diferentes sinestetas clínicos, sin embargo, es posible observar "tendencias" en las correspondencias de ciertas notas en específico, con ciertos colores, como la más notoria:

164 DECAPRIO, T. "Super Symmetry." [en línea]. Disponible en: www.tonydecaprio.com/supersymmetry.htm [Consulta: 31 Diciembre 2010]. 


\section{Capítulo IV.- Sinestesia.}

La tendencia de relacionar la nota "Do" con el color "Blanco". Las tablas expuestas, representan no solo a músicos profesionales, sino a músicos amateurs, con el suficiente conocimiento de música para poder establecer por medio de "dictados musicales", la nota escuchada; además, estas correspondencias representan diferentes épocas y localizaciones geográficas, lo que hace que las semejanzas o "tendencias" que puedan existir en las diferentes tablas, excluyan al factor educativo o cultural compartido. Son visiones altamente personales, de personas que comparten una misma condición fisiológica. 


\section{Propuesta personal y ejemplos.}

La propuesta personal de esta investigación gira en torno al establecimiento de una nueva correspondencia entre sonidos afinados y el color, que contenga su base en el fenómeno clínico conocido como sinestesia, la visión que la gente menciona poseer y que es posible "diagnosticar" como "sinestetas clínicos"

Para obtener esta nueva correspondencia, hemos establecido primero, el hecho de que la sinestesia es un fenómeno que implica una actividad cerebral distinta que el común denominador de las personas, cuando son expuestas a los mismos estímulos en condiciones controladas, fenómeno que ha podido ser establecido por medio de las nuevas tecnologías en materia de exploración y visualización del cerebro vivo.

Las "visiones" sinestésicas, son altamente individuales, en realidad no hay dos correspondencias idénticas entre dos sinestetas que posean sinestesia del mismo tipo; los individuos que "padecen" de sinestesia grafema-color, tienen diferentes correspondencias de color para los mismo grafemas, de la misma manera, con la sinestesia sonido afinado-color, y el resto de las sinestesias que impliquen correspondencias entre un estímulo primario y la sensación secundaria de color; la individualización de las correspondencias sinestésicas nos ha llevado a la necesidad de acotar las correspondencias que serán utilizadas para la creación de una nueva correspondencia sinestésica 


\section{Capítulo V. Propuesta personal y ejemplos.}

audiovisual, por tal motivo, utilizaremos únicamente aquellas correspondencias dictadas por sinestetas que poseen sinestesia de sonido afinado-color, de los cuales existan indicios mínimos de sinestesia clínica.

Para establecer nuestra propuesta personal, lo primero a ser realizado, será el extraer las correspondencias sinestésicas de algunas de las visiones de sinestetas con correspondencias de sonido afinadocolor, y obtener patrones o "tendencias" por cada nota-color que estos individuos ofrecen en sus tablas, en los casos que no sea posible asignar una tendencia, realizaremos una sumatoria de los colores asignados a la misma nota por diferentes individuos; asignaremos un color a cada nota de la escala temperada occidental, ya que es la escala temperada occidental la más aceptada universalmente en nuestros días, y que permite una mejor difusión de la música escrita, además de aun influir en la construcción de instrumentos musicales y afinaciones de agrupaciones musicales como la orquesta sinfónica y las orquestas de cámara, y diferentes ensambles.

El siguiente paso de la propuesta personal, emanada de esta investigación, es la construcción de un lenguaje musical, el cual tenga sus bases en la armonía de colores, permitida por los anteriormente establecidos en la correspondencia sinestésica. El propósito es la creación de nuevas relaciones musicales las cuales tengan su génesis en la teoría del color, la creación de nuevas escalas y acordes, que nos permitan la composición de música nueva y que realmente pueda 


\section{Capítulo V. Propuesta personal y ejemplos.}

afirmarse que está construida en base a los fenómenos del color y la sinestesia.

En busca de la utilidad de la nueva correspondencia sinestésica de sonidos afinados y color, también realizaremos una traducción de los elementos del lenguaje musical, como son establecidos académicamente, al color; ¿Qué colores tienen las escalas mayores, los acordes, los armónicos? Así como los diferentes elementos que son utilizados en la música tradicional; esto nos permitirá realizar traducciones de la música tradicional al color, la creación de cuadros y animaciones cuyo punto de partida sea una partitura musical, la creación de pinturas musicales.

Mediante la creación de pinturas musicales, esperamos también obtener una herramienta didáctica para el análisis musical; la música como arte temporal tiene de forma implícita dificultades únicas para el análisis formal y armónico de los componentes presentes en una pieza de música, la música no puede ser retenida, una vez que una nota es ejecutada, esta desaparece después de un lapso temporal corto; al establecer las relaciones de afinaciones presentes en una pieza de música mediante un elemento tangible y atemporal como lo es el color plasmado por diferentes medios como la luz fija en una imagen digital, o tintas y pigmentos en un cuadro, esperamos tener "a la vista" los elementos formales de un arte temporal.

Como propuesta artística, la "correspondencia sinestésica" será también probada con la creación de música nueva de diferentes 


\section{Capítulo V. Propuesta personal y ejemplos.}

formatos, se crearán miniaturas para instrumento solista, y una pieza de largo formato para ensamble, utilizando exclusivamente las escalas y acordes permitidos por la interacción entre la correspondencia sinestésica y la teoría del color, además de realizar una propuesta escénica la cual permita el visionado de la correspondencia sinestésica para el público, mediante recursos como la animación y/o iluminación en vivo, las cuales interactuarán en tiempo real en escena, o en video.

Es cierto que es "peligroso" sostener una relación documentable y definida entre fenómenos distintos en el arte ${ }^{165}$, sin embargo, la sinestesia color-sonido es un fenómeno documentado en nuestros días. Además, las investigaciones recientes realizadas por distintos investigadores en el ramo de la neurología como Ramachandran, Hubbard ${ }^{166}$, Cytowic y S. Day, llevan un nexo en común: La sinestesia es un fenómeno involuntario, duradero, y neurológico; todo sinestésico verá los mismos colores ante el mismo estímulo durante toda su vida.

El fenómeno de la sinestesia nos da un público, un punto en común para la transmisión de ideas; existe la posibilidad de que más de diez personas vean los mismos colores (o similares) ante las mismas notas musicales, lo cual sirve para ilustrarnos mediante la metáfora sobre las relaciones sinestésicas, además de permitirnos la

165 DORFLES, G. El devenir de las artes. México D.F:: Fondo de Cultura Económica, 1993, p. 152

166 Psiquiatría. México D.F.: Organización Panamericana de la Salud. 2006, p. 227. 


\section{Capítulo V. Propuesta personal y ejemplos.}

construcción organizada de un concepto de la "Tonalidad" entre diferentes disciplinas como lo es la pintura y la música.

Como consecuencia de la unión de estímulos en escena, esperamos obtener un elemento más, la interacción por sí misma entre el color y el sonido, el sonido convirtiéndose en atemporal y tangible mediante el uso del color plasmado atemporalmente, así como la sensación de "movimiento afinado" del color, un elemento fijo y que por sí mismo, no crea la sensación de movimiento en el público, la imagen por sí misma, no posee la capacidad de temporalidad, como fue establecido por algunos de los más importantes exponentes del arte sinestésico, depende del contexto presentado para crear la sensación de movimiento; mediante la unión organizada bajo el concepto jerárquico de "Tonalidad" esperamos dotar de un elemento implícito a ambos fenómenos físicos; el color como elemento temporal, y la música como elemento tangible. 


\subsection{De la música al color.}

Como primer paso de la propuesta de una nueva correspondencia entre sonidos afinados y color, organizados bajo el concepto de "Tonalidad, realizaremos la organización y traducción de los conceptos tradicionales de la música a sus correspondientes colores; primero la asignación de cada una de las notas de la escala cromática temperada, la usada comúnmente en la música occidental, y herramienta con la cual podremos traducir el resto de los conceptos musicales al lenguaje del color: las series de armónicos, los acordes utilizados comúnmente en la música clásica occidental, y las escalas "mayores" y "menores".

Todas estas herramientas son las que conforman el concepto de "Tonalidad" como es utilizado de forma académica en la música, y su traducción a los colores que le corresponderían de acuerdo al fenómeno de la sinestesia, es lo que nos permitirá realizar la idea de una "Tonalidad Sinestésica" la cual esté organizada bajo un concepto de organización jerárquica, similar a la utilizada en la música académica, que goza de los beneficios que vienen implícitos con la organización de las notas en grados de importancias y relaciones proporcionales entre ellas. Traduciendo cada herramienta musical al color, se obtendrán las combinaciones colorísticas necesarias para 
Capítulo V. Propuesta personal y ejemplos.

realizar con facilidad traducciones de la música académica a la pintura o el mundo visual. 


\subsubsection{La creación de una escala cromática audiovisual.}

Para la asignación de colores a nuestra escala cromática, extraeremos los colores de las correspondencias sinestésicas anteriormente mencionadas; tomando en cuenta el alto grado de individualización de las correspondencias dictadas por los sinestetas clínicos, no siempre será posible extraer una correspondencia unívoca para cada afinación musical.

En los casos que pueda ser observada una tendencia, una visión mayoritaria de un mismo color para una misma nota musical, ese color será el asignado a la afinación en cuestión, cuando esto no sea posible, se realizara una sumatoria de las visiones sinestésicas más representativas, obteniendo de esta forma notas musicales que podremos considerar como "nota bicolor" o en el peor de los casos como "nota tricolor", con lo cual obtendremos un beneficio añadido al obtener mayores libertades para la combinación de notas musicales bajo criterios colorísticos.

Las "correspondencias sinestésicas" de sonido-color, obtenidas hasta el momento, provienen de las siguientes fuentes: Los estudios “clásicos" realizados por Henry Laures y por Flournoy, y las correspondencias de los músicos Rimsky-Korsakov, Amy Beach, y Tony deCaprio; esto nos permite obtener correspondencias de diferentes épocas y culturas. 


\section{Capítulo V. Propuesta personal y ejemplos.}

En el caso de las "correspondencias sinestésicas" encontradas por Flournoy, es necesario realizar una primera síntesis ya que el investigador nos provee con las correspondencias de nueve personas anónimas francesas de finales del siglo XX, por razones prácticas, se extraerá una síntesis representativa, que denominaremos como la correspondencia de Flournoy.

Los sinestetas investigados por Flournoy, nueve individuos franceses con una educación musical básica, mencionan las correspondencias en base a una escala musical "mayor" específica, la escala de "Do mayor", cuyo centro tonal es la nota "Do", y posee siete notas antes de repetir el color tonal u octava musical. Es posible advertir tendencias en las correspondencias encontradas por Flournoy, una marcada tendencia a relacionar el "Do" con el color blanco o el color amarillo, de nueve sinestetas investigados, tres mencionan el blanco y tres el amarillo, uno menciona el rosa, uno el color verde y el otro no relaciona color con la nota específica; por lo que asignaremos en la "Correspondencia de Flournoy" el binomio "blanco-amarillo" a la nota "Do":

En el caso de la nota "Re" existe una tendencia al acromatismo, un sinesteta menciona el blanco, otro el gris y un tercero el negro; tres de los restantes sinestetas mencionan colores diferentes y tres no mencionaron color alguno en el estudio, de esta forma, por marcar una diferencia con la nota "Do" la cual en la "Correspondencia de Flournoy" es de color blanco, a la nota "Re" la mencionaremos 


\section{Capítulo V. Propuesta personal y ejemplos.}

como "gris obscuro" realizando una síntesis con las visiones sinestésicas representativas para la nota en cuestión.

Existe una tendencia aún más marcada para la nota "Mi" en el estudio de Flournoy, cuatro de nueve sinestetas la mencionan como color rosa, lo cual automáticamente nos lleva a asignar ese color para la nota mencionada. En la nota "Fa" la tendencia marca el color "violeta" con únicamente dos coincidencias en las correspondencias mencionadas; las otras siete correspondencias no presentan ninguna coincidencia, pero sí similitudes; es curioso observar que además del color violeta, es mencionado el azul, un color "obscuro", el color marrón, y el color negro.

En el caso de la nota "Sol” se vuelve necesaria la asignación de otro binomio de colores, un sinesteta menciona el color "rojizo" para la nota escuchada, mientras que otro menciona "rojo", con fines prácticos, podemos considerar el color rojo como mencionado en dos ocasiones, mientras que dos sinestetas mencionan el color verde; el resto de los sinestetas mencionan colores diferentes, por tanto, asignamos el "Sol" como nota bicolor rojo-verde.

Para la nota "La" encontramos una tendencia al verde con dos casualidades, y una similitud en el hecho de que dos sinestetas mencionan colores bastante parecidos; un sinesteta menciona el color violeta y otro el color "lila", ambos colores, resultados de una mezcla substractiva de azul y rojo con diferentes proporciones; en el caso de la nota en cuestión, la mencionaremos como: verde. 


\section{Capítulo V. Propuesta personal y ejemplos.}

Por último, la nota "Si" tiene una tendencia al gris, con dos sinestetas mencionando ese "color" para la nota en cuestión, dos de los sinestetas investigados no mencionan correspondencia para la nota, y los cinco individuos restantes, mencionan colores diferentes.

Con esta síntesis obtenemos una correspondencia extraída de las visiones de nueve sinestetas estudiados por Flournoy, con lo cual obtenemos una "correspondencia sinestésica de sonido afinado-color, correspondiente a una escala "mayor" musical, esta correspondencia en específico es la que de ahora en adelante denominaremos como la “Correspondencia de Flournoy”, y será la siguiente: Do-Blanco, Regris obscuro, Mi-Rosa, Fa-violeta, Sol-rojo/verde, La-verde, Si-gris.

La unificación de la "Correspondencia de Flournoy", nos permite realizar la exposición y síntesis de las correspondencias sinestésicas representativas a utilizar. Para la denominación de los colores, utilizaremos las tres o cuatro primeras letras de cada uno de ellos a manera de abreviatura, de esta forma, el color rojo será mencionado como "roj.", mientras que el color azul será “az"; para los calificativos de color como "Obscuro", "Claro", "Brillante" y otros, utilizaremos las primeras cuatro letras, uniendo el color con el calificativo mediante un "guión", así, obtenemos que "marrón obscuro" será designado como "Mar-Obsc"; las notas musicales "bicolores" serán mencionadas con una separación por medio de una diagonal, de la misma manera que lo hemos realizado para la nota "Sol" en la "Correspondencia de Flournoy", utilizando además las abreviaturas, de esta manera, la nota "Sol” será acompañada de los 


\section{Capítulo V. Propuesta personal y ejemplos.}

colores "roj/ver", lo que significa que a la nota "Sol", le son asignados los colores rojo y verde.

Para denominar a los exponentes de la correspondencia sinestésica en cuestión, también utilizaremos abreviaturas, designando la correspondencia expuesta por Laures como "L.", la "Correspondencia de Flournoy", será denominada como "C.F."; la de Korsakov como "K.", las correspondencias de Amy Beach como “A.B." y la de Tony deCaprio como "T.C."; para poder, de esta manera, tener una exposición esquematizada de las correspondencias sinestésicas que consideramos como representativas, y obtener así, una tabla comparativa práctica, para poder realizar una síntesis posterior de manera efectiva, y proceder con esto, a la realización de la "escala cromática audiovisual".

Sonido

Do

Do sostenido

$\operatorname{Re}$

Re sostenido

Mi

$\mathrm{Fa}$

\section{Colores}

L.

Neg/Blan

Mar-Obsc

Roj

Gri
C.F.

Blan

Gri-Obsc

Ros

Vio 
Fa sostenido

Sol

Roj

Roj/Ver

La bemol

La

Gri

Ver

Si bemol

Si

Roj

Gri

Sonido

$\begin{array}{llll} & \text { K. } & \text { A.B. } & \text { T.C. } \\ \text { Do } & \text { Blan } & \text { Blan } & \text { Blan } \\ \text { Do sostenido } & \text { Cali-Obsc } & & \\ & & & \\ \text { Re } & \text { Ama-Real } & - & \text { Nar-Obsc } \\ \text { Re sostenido } & \text { Gri/Azu } & \text { Ros } & \text { Ama } \\ \text { Mi } & \text { Azu-Bril } & \text { Ama } & \text { Neg } \\ \text { Fa } & \text { Ver } & - & \text { Caf }\end{array}$

167 Korsakov menciona el color correspondiente al "Do sostenido" con dos calificativos "Cálido Obscuro" por ello la abreviatura "Cali-Obsc" (Nota del autor). 
Fa sostenido

Sol

La Bemol

La

Si Bemol

$\mathrm{Si}$
Ver-Gris

Caf/Dor

Vio

Ros

Obsc

Azu-Obsc
Neg

Ver-Clar

Roj

Ver

$\mathrm{Azu}$

Mag

Ver

$\mathrm{Azu}$

Mor

Ros

Las abreviaturas correspondientes a cada color son las siguientes: $\quad$ Blanco $=$ Blan, Negro $=\mathrm{Neg}, \quad$ Gris $=$ Gri, Marrón=Mar, Dorado=Dor, Rojo=Roj, Naranja=Nar, Azul=Azu, Verde=Ver, Amarillo=Ama, Café $=$ Caf, Rosa $=$ Ros, Magenta $=$ Mag, Morado=Mor, Violeta=Vio, Púrpura=Pur; en el caso de los calificativos las abreviaturas utilizadas son las siguientes: Obscuro=Obsc, Brillante $=$ Bril, Claro=Clar; en el caso de la nota "Re" en la correspondencia de Korsakov, menciona el color "Amarillo Real", por ello, la abreviatura utilizada es "Ama-Real".

Una vez expuestas las correspondencias sinestésicas representativas entre sonido musical-color, podemos proceder a realizar una síntesis en una sola "escala cromática audiovisual", utilizando el mismo procedimiento que fue utilizado para obtener la “Correspondencia de Flournoy”, mediante la observación de 


\section{Capítulo V. Propuesta personal y ejemplos.}

coincidencias y similitudes; de la misma forma, utilizaremos como límite la asignación de tres colores distintos a una misma nota, procurando la asignación de un solo color como representativo de cada nota musical; podemos observar tendencias en varias de las correspondencias descritas, sin embargo, la asignación de más de una "nota bicolor", se manifiesta mediante una observación rápida de la exposición de correspondencias; para la síntesis de la "escala cromática audiovisual", utilizaremos las mismas abreviaturas utilizadas tanto para el color, como para los calificativos del mismo.

La tendencia a relacionar el color blanco con la nota "Do" se hace manifiesta de forma clara y contundente, de las cinco correspondencias observadas, cuatro coinciden de forma directa en relacionar el blanco con el "Do", mientras una sola menciona tanto el negro como el blanco. En el caso de la nota "Do sostenido", observamos una coincidencia con las correspondencias de Korsakov y de Tony deCaprio, Korsakov mencionando un color "Cálido Obscuro" y deCaprio "Naranja Obscuro" por lo cual, para la nota "Do" sostenido, utilizaremos el color naranja.

La nota "Re" obtiene una sola coincidencia, por lo que se vuelve mayoritaria, es la asignación del color amarillo para la nota descrita; mientras que las correspondencias "L." y C.F." son similares, mencionando una el color marrón obscuro y la otra el gris obscuro; la correspondencia de Korsakov y de Tony deCaprio coinciden con el mismo color exacto. 


\section{Capítulo V. Propuesta personal y ejemplos.}

La nota "Re sostenido" presenta similitudes, la correspondencia "K." relaciona la nota con el "gris azul", la correspondencia "A.B." con el color "rosa" y la correspondencia “T.C." marca "gris", mientras que en las correspondencias "L." y "C.F." no se nos proporcionan datos. La similitud es encontrada en las correspondencias "K." y "T.C.” y el punto común es el color gris, color que asignaremos a la nota mencionada.

Para la nota musical "Mi" encontramos problemas, ya que las correspondencias de cada una de las tablas representativas tomadas en cuenta son disímbolas, se nos mencionan los siguientes colores para la nota: rojo, rosa, azul brillante, amarillo y negro; es posible encontrar dos similitudes utilizando la herramienta de la teoría del color, los colores rojo, azul y amarillo, nos brindan la posibilidad de asignar ese trinomio a la nota mencionada, por ser colores clasificados como "primarios" de las mezclas substractivas de color; la otra similitud encontrada, es en los colores rojo y rosa, los cuales en la clasificación de colores establecida por Munsell, el rosa es en realidad un color rojo "con bajo valor de Chroma y alta luminosidad"168, y este, en la clasificación del "árbol de Munsell”, se encontraría en las coordenadas 5R 5/4, mientras que un color rojo casi "puro", se ubicaría en las coordenadas 5R 5/14; para obtener un punto medio representativo de las visiones sinestésicas mencionadas para la nota "Mi", utilizaremos como representativo el trinomio de los colores "primarios" de la mezcla substractiva: rojo, azul y amarillo, por establecer una

\footnotetext{
${ }^{168}$ MUNSELL, A.H. A color notation. Boston: H. Ellis co., Boston, 1905, p.79
} 


\section{Capítulo V. Propuesta personal y ejemplos.}

diferencia con la nota que se encuentra a la "quinta musical" de esta, la nota "Si", que posee una gran similitud de colores asignados con esta nota.

La nota "Fa" también es abordada a partir de visiones diferentes por cada una de las correspondencias, se nos proporcionan los colores gris, violeta, verde y café; de estos cuatro colores, los que encontramos más representativos por sus similitudes son el color verde y el café, un color secundario con uno neutro, binomio que utilizaremos para la nota en cuestión.

El "Fa sostenido", es mencionado con tres colores distintos: verde gris, negro y verde claro; el valor cromático del color asignado es unívoco, es el verde, mientras que en los tres casos este mismo es intervenido por los valores acromáticos que van del negro al blanco; la solución encontrada es una sumatoria de calificativos para el valor cromático, el color asignado como unidad, será el verde-obscuro-grisclaro.

El sonido temperado denominado como "Sol", presenta tres coincidencias, el color rojo es el asignado de forma mayoritaria a la nota musical con tres coincidencias, razón por la que asignaremos de forma directa ese color a la nota mencionada; por otro lado, la nota “La bemol”, presenta características casi únicas en la exposición de correspondencias, ya que presenta tres colores distintos, pero bastante similares: violeta, azul y magenta; paleta de colores cuyo punto en 


\section{Capítulo V. Propuesta personal y ejemplos.}

común es el color azul, por similitud, asignaremos el trinomio entero a la nota.

Existe una coincidencia para la nota "La", en las visiones sinestésicas abordadas, es el color verde, con una coincidencia, no hemos observado algún calificativo que acompañe al color mencionado, por lo tanto, consideraremos la nota "La" como de un color verde con un valor elevado de "Chroma", un color verde casi "puro".

Para el "Si bemol", encontramos un color y un calificativo, Korsakov menciona la nota como de color "Obscuro" mientras que Tony deCaprio asigna el color morado a la misma; realizando una sumatoria simple, asignaremos el color morado-obscuro al " $\mathrm{Si}$ bemol". Por último, la nota "Si" presenta únicamente una similitud, en la tabla de Laures es mencionada como de color rojo, mientras que en la tabla de Tony deCaprio se le asigna el color rosa; como fue mencionado para la nota "Mi", los colores rojo y el rosa se encuentran en el mismo valor tonal, con diferencias en valores de luminosidad e intensidad; por lo que asignaremos el binomio anteriormente mencionado para esta nota.

Con el procedimiento anteriormente descrito, obtenemos nuestra "escala cromática audiovisual", con la que realizaremos nuestras traducciones de la música al color, de los elementos del lenguaje musical conocido académicamente; además de aplicarla para las labores compositivas que serán utilizadas para experimentar la 


\section{Capítulo V. Propuesta personal y ejemplos.}

utilidad de la herramienta de traducción audiovisual. Cabe mencionar, que la asignación de colores al sonido será absoluta, el color o colores son asignados a la nota en cuestión, no a la escala o campo armónico, estableciendo así, una diferencia con correspondencias anteriormente utilizadas por representantes del arte sinestésico como Scriabine, o la escuela griega, que partían de la proporción interválica entre las notas para la asignación de valores de color. La "escala cromática audiovisual", utilizada para establecer una "tonalidad sinestésica", será la siguiente:

\section{Sonido}

Do

Do sostenido

$\operatorname{Re}$

Re sostenido

Mi

$\mathrm{Fa}$

Fa sostenido

Sol

La Bemol

\section{Colores}

Blanco

Naranja

Amarillo

Gris

Rojo/Azul/Amarillo

Verde/Café

Verde-Obscuro-Gris-Claro

Rojo

Violeta/Azul/Magenta 
Capítulo V. Propuesta personal y ejemplos.

La

Si Bemol

$\mathrm{Si}$
Verde

Morado-Obscuro

Rojo/Rosa 


\subsubsection{Series Sinestésicas de Armónicos}

Recordando la serie de armónicos, como las frecuencias secundarias que acompañan al sonido producido o generador; serán el primer elemento musical a traducir a colores, ya que son también el primer elemento de construcción de la armonía y escalas musicales, siendo posible concebir los acordes y escalas propios de la música del periodo clásico, como síntesis o conceptualizaciones realizadas en el mundo occidental, a partir del fenómeno natural del sonido.

Haremos referencia a las series de armónicos por sus sonidos temperados, es decir, sin diferencias en Cents en la medida del sonido producido; que es también la forma en que han sido utilizados para la concepción del sistema musical, recordando siempre, que los armónicos no son temperados, el comportamiento de las frecuencias secundarias implica diferencias con el sonido temperado, en medidas menores, al semitono; por lo que en nuestros días son medidos en Hertz, o acompañando una comparativa con el sonido temperado esperado, estableciendo la diferencia por medio de Cents. En el caso que nos ocupa, para poder establecer un color que fue relacionado con una nota temperada, se mantendrá el mismo formato, realizando todas las traducciones y composiciones de la propuesta, con la escala musical temperada, la "tonalidad sinestésica" será por lo tanto, una tonalidad que puede ser encasillada como temperada y occidental. 
Capítulo V. Propuesta personal y ejemplos.

Serie sinestésica de armónicos de "Do"

Sonido

Do

Do

Sol

Do

Mi

Sol

Si bemol

Do

$\operatorname{Re}$

Mi

$\mathrm{Fa}$

Sol

La

Si bemol

$\mathrm{Si}$

Do

\section{Color}

Blanco

Blanco

Rojo

Blanco

Rojo/Azul/Amarillo

Rojo

Morado Obscuro

Blanco

Amarillo

Rojo/Azul/Amarillo

Verde/Café

Rojo

Verde

Morado Obscuro

Rojo/Rosa

Blanco 
Capítulo V. Propuesta personal y ejemplos.

Serie sinestésica de armónicos de "Sol"

Sonido

Sol

Sol

$\operatorname{Re}$

Sol

$\mathrm{Si}$

$\operatorname{Re}$

$\mathrm{Fa}$

Sol

La

$\mathrm{Si}$

Do

$\operatorname{Re}$

$\mathrm{Mi}$

$\mathrm{Fa}$

Fa sostenido

Sol

\section{Color}

Rojo

Rojo

Amarillo

Rojo

Rojo/Rosa

Amarillo

Verde/Café

Rojo

Verde

Rojo/Rosa

Blanco

Amarillo

Rojo/Azul/Amarillo

Verde/Café

Verde-Obscuro-Gris-Claro

Rojo 
Capítulo V. Propuesta personal y ejemplos.

Serie sinestésica de armónicos de "Re"

Sonido

$\operatorname{Re}$

$\operatorname{Re}$

$\mathrm{La}$

$\operatorname{Re}$

Fa sostenido

La

Do

$\operatorname{Re}$

Mi

Fa sostenido

Sol

La

$\mathrm{Si}$

Do

Do sostenido

$\operatorname{Re}$

\section{Color}

Amarillo

Amarillo

Verde

Amarillo

Verde-Obscuro-Gris-Claro

Verde

Blanco

Amarillo

Rojo/Azul/Amarillo

Verde-Obscuro-Gris-Claro

Rojo

Verde

Rojo/Rosa

Blanco

Naranja

Amarillo 
Capítulo V. Propuesta personal y ejemplos.

Serie sinestésica de armónicos de "La"

Sonido

$\mathrm{La}$

La

Mi

$\mathrm{La}$

Do sostenido

Mi

Sol

$\mathrm{La}$

$\mathrm{Si}$

Do sostenido

$\operatorname{Re}$

$\mathrm{Mi}$

Fa sostenido

Sol

Sol sostenido

$\mathrm{La}$

\section{Color}

Verde

Verde

Rojo/Azul/Amarillo

Verde

Naranja

Rojo/Azul/Amarillo

Rojo

Verde

Rojo/Rosa

Naranja

Amarillo

Rojo/Azul/Amarillo

Verde-Obscuro-Gris-Claro

Rojo

Violeta/Azul/Magenta

Verde 
Capítulo V. Propuesta personal y ejemplos.

Serie sinestésica de armónicos de "Mi"

Sonido

$\mathrm{Mi}$

$\mathrm{Mi}$

$\mathrm{Si}$

$\mathrm{Mi}$

Sol sostenido

$\mathrm{Si}$

$\operatorname{Re}$

Mi

Fa sostenido

Sol sostenido

$\mathrm{La}$

$\mathrm{Si}$

Do sostenido

$\operatorname{Re}$

Re sostenido

Mi

\section{Color}

Rojo/Azul/Amarillo

Rojo/Azul/Amarillo

Rojo/Rosa

Rojo/Azul/Amarillo

Violeta/Azul/Magenta

Rojo/Rosa

Amarillo

Rojo/Azul/Amarillo

Verde-Obscuro-Gris-Claro

Violeta/Azul/Magenta

Verde

Rojo/Rosa

Naranja

Amarillo

Gris

Rojo/Azul/Amarillo 
Capítulo V. Propuesta personal y ejemplos.

Serie sinestésica de armónicos de "Si"

Sonido

$\mathrm{Si}$

$\mathrm{Si}$

Fa sostenido

$\mathrm{Si}$

Re sostenido

Fa sostenido

$\mathrm{La}$

$\mathrm{Si}$

Do sostenido

Re sostenido

Mi

Fa sostenido

Sol sostenido

$\mathrm{La}$

La sostenido

$\mathrm{Si}$

\section{Color}

Rojo/Rosa

Rojo/Rosa

Verde-Obscuro-Gris-Claro

Rojo/Rosa

Gris

Verde-Obscuro-Gris-Claro

Verde

Rojo/Rosa

Naranja

Gris

Rojo/Azul/Amarillo

Verde-Obscuro-Gris-Claro

Violeta/Azul/Magenta

Verde

Morado Obscuro

Rojo/Rosa 
Capítulo V. Propuesta personal y ejemplos.

Serie sinestésica de armónicos de "Fa sostenido"

\section{Sonido}

Fa sostenido

Fa sostenido

Do sostenido

Fa sostenido

La sostenido

Do sostenido

$\mathrm{Mi}$

Fa sostenido

Sol sostenido

La sostenido

$\mathrm{Si}$

Do sostenido

Re sostenido

$\mathrm{Mi}$

Mi sostenido

Fa sostenido

\section{Color}

Verde-Obscuro-Gris-Claro

Verde-Obscuro-Gris-Claro

Naranja

Verde-Obscuro-Gris-Claro

Morado Obscuro

Naranja

Rojo/Azul/Amarillo

Verde-Obscuro-Gris-Claro

Violeta/Azul/Magenta

Morado Obscuro

Rojo/Rosa

Naranja

Gris

Rojo/Azul/Amarillo

Verde/Café

Verde-Obscuro-Gris-Claro 
Capítulo V. Propuesta personal y ejemplos.

Serie sinestésica de armónicos de "Fa"

Sonido

$\mathrm{Fa}$

$\mathrm{Fa}$

Do

$\mathrm{Fa}$

La

Do

Mi bemol

$\mathrm{Fa}$

Sol

$\mathrm{La}$

Si bemol

Do

$\operatorname{Re}$

Mi bemol

Mi

$\mathrm{Fa}$

\section{Color}

Verde/Café

Verde/Café

Blanco

Verde/Café

Verde

Blanco

Gris

Verde/Café

Rojo

Verde

Morado Obscuro

Blanco

Amarillo

Gris

Rojo/Azul/Amarillo

Verde/Café 
Capítulo V. Propuesta personal y ejemplos.

Serie sinestésica de armónicos de "Si bemol"

Sonido

Si bemol

Si bemol

$\mathrm{Fa}$

Si bemol

$\operatorname{Re}$

$\mathrm{Fa}$

La bemol

Si bemol

Do

$\operatorname{Re}$

Mi bemol

$\mathrm{Fa}$

Sol

La bemol

$\mathrm{La}$

Si bemol

\section{Color}

Morado Obscuro

Morado Obscuro

Verde/Café

Morado Obscuro

Amarillo

Verde/Café

Violeta/Azul/Magenta

Morado Obscuro

Blanco

Amarillo

Gris

Verde/Café

Rojo

Violeta/Azul/Magenta

Verde

Morado Obscuro 
Capítulo V. Propuesta personal y ejemplos.

Serie sinestésica de armónicos de "Mi bemol"

Sonido

Mi bemol

Mi bemol

Si bemol

Mi bemol

Sol

Si bemol

Re bemol

Mi bemol

$\mathrm{Fa}$

Sol

La bemol

Si bemol

Do

Re bemol

$\operatorname{Re}$

Mi bemol

\section{Color}

Gris

Gris

Morado Obscuro

Gris

Rojo

Morado Obscuro

Naranja

Gris

Verde/Café

Rojo

Violeta/Azul/Magenta

Morado Obscuro

Blanco

Naranja

Amarillo

Gris 
Capítulo V. Propuesta personal y ejemplos.

Serie sinestésica de armónicos de "La bemol"

Sonido

La bemol

La bemol

Mi bemol

La bemol

Do

Mi bemol

Sol bemol

La bemol

Si bemol

Do

Re bemol

Mi bemol

$\mathrm{Fa}$

Sol bemol

Sol

La bemol

\section{Color}

Violeta/Azul/Magenta

Violeta/Azul/Magenta

Gris

Violeta/Azul/Magenta

Blanco

Gris

Verde-Obscuro-Gris-Claro

Violeta/Azul/Magenta

Morado Obscuro

Blanco

Naranja

Gris

Verde/Café

Verde-Obscuro-Gris-Claro

Rojo

Violeta/Azul/Magenta 
Capítulo V. Propuesta personal y ejemplos.

Serie sinestésica de armónicos de "Re bemol"

Sonido

Re bemol

Re bemol

La bemol

Re bemol

$\mathrm{Fa}$

La bemol

Do bemol

Re bemol

Mi bemol

$\mathrm{Fa}$

Sol bemol

La bemol

Si bemol

Do bemol

Do

Re bemol

\section{Color}

Naranja

Naranja

Violeta/Azul/Magenta

Naranja

Verde/Café

Violeta/Azul/Magenta

Rojo/Rosa

Naranja

Gris

Verde/Café

Verde-Obscuro-Gris-Claro

Violeta/Azul/Magenta

Morado Obscuro

Rojo/Rosa

Blanco

Naranja 


\section{Capítulo V. Propuesta personal y ejemplos.}

Existen fenómenos notorios en el comportamiento de la escala cromática audiovisual cuando esta es "acomodada" en las series naturales de armónicos del sonido, ocasiona una interacción por demás "singular" con el sonido y las sensaciones de consonancia y disonancia, como son consideradas académicamente en las disciplinas de la música y la pintura.

Los armónicos 1, la nota generadora, y el 3, la quinta musical, la relación proporcional de frecuencias de 3:2, proporciona la sensación de mayor consonancia y/o refuerzo acústico a una nota, justo después de la sensación de octava musical o relación proporcional de 2:1; mientras que la sensación de mayor disonancia o mayor contraste en la música temperada occidental, se encuentra en el intervalo de séptima mayor musical, los armónicos 1 y 15, la relación proporcional de 15:8.

En muchos de los casos, las sensaciones de mayor consonancia se corresponden entre el color y el sonido, cuando son relacionados con la escala cromática audiovisual, en el caso de la serie sinestésica de armónicos de "Do-Blanco", su sensación de mayor consonancia es producida en el sonido por el "Sol-Rojo", la quinta musical de este "sonido-color" es el "Re-Amarillo"; combinaciones que encontramos en numerosos ejemplos de combinaciones colorísticas básicas.

Un esquema de las sensaciones de quinta musical o consonancias más naturales, es el siguiente: 


\section{Capítulo V. Propuesta personal y ejemplos.}

Do

Sol

$\operatorname{Re}$

La

$\mathrm{Mi}$

$\mathrm{Si}$

Fa sostenido

Re bemol

La bemol

Mi bemol

Si bemol

$\mathrm{Fa}$

Do
Blanco

Rojo

Amarillo

Verde

Rojo/Azul/Amarillo

Rojo/Rosa

Verde-Obscuro-Gris-Claro

Naranja

Violeta/Azul/Magenta

Gris

Morado Obscuro

Verde/Café

Blanco

La mayor parte de ellas consonantes también en la combinación de color, con marcadas excepciones como es el caso de las relaciones de quinta entre la nota "La", cuyo color verde lo ubica como color secundario y la nota "Mi" que contiene los primarios que lo forman; otra excepción ocurre entre el "Fa sostenido" colores verdes del claro al obscuro, y el "Re bemol" color naranja, los cuales se vuelven contrastantes o disonantes; mismo caso de las notas "Si bemol" al "Fa", que a pesar de ser quintas musicales, y como tales, consideradas como altamente consonantes, les corresponden la 


\section{Capítulo V. Propuesta personal y ejemplos.}

combinación de colores "Morado-Obscuro", combinándolo con "Verde/Café", una combinación de colores no considerada como altamente consonante.

Similitudes y excepciones que encontramos también en la sensación de mayor disonancia con el intervalo de séptima musical, que produce el mayor contraste en el sonido, y se encuentra en los armónicos más alejados que pueden ser conceptualizados dentro de la música temperada, la nota generadora y el armónico 15, la séptima mayor de la nota generadora; observamos también un comportamiento similar a las disonancias en los colores asignados; por ejemplo, entre las notas "Re sostenido" y "Re" un color acromático, el gris en combinación con el amarillo; el "Sol-Rojo" con el "Fa sostenidoverde obscuro o gris o claro; la nota "Si bemol-Morado obscuro" con el "La-verde". También podemos encontrar combinaciones de consonancia de color, interactuando con la sensación de disonancia musical, como en el caso de la séptima musical de "Re-amarillo" con el "Do sostenido-naranja"; colores de la misma gama cuyas diferencias cromáticas son mínimas, y sin embargo, se encuentran en la relación proporcional más alejada de la música temperada. 


\subsubsection{Acordes, de la música al color.}

Los acordes "emanados" de forma natural de la síntesis de las series de armónicos del sonido, son denominados como el acorde "Dominante", cuya estructura es única en el repertorio de acordes existentes en la música académica.

La estructura de un acorde es determinada por los intervalos que conforman la agrupación de notas, contabilizadas desde la nota generadora del mismo, ${ }^{169}$ o la nota más grave, cuando el acorde se encuentra en su posición "perfecta" acomodado por terceras musicales. De esta manera, se deduce que la estructura del acorde "Dominante" o el emanado por la serie de armónicos, tal como fue, y continúa siendo usado en la música tonal clásica, consiste en una “tercera mayor", o la nota generadora (N.G.) más 400 cents, (N.G.+400cts.), una "quinta justa" (N.G.+700cts.), la "séptima menor" (N.G.+1000cts.), "novena mayor" (N.G.+1400cts.), "oncena justa" (N.G.+1700cts.), y “trecena mayor” (N.G. +2100 cts.).

Existen diferencias en el intervalo de "oncena justa" ya que en la música del siglo XX, fue muy utilizada la "oncena aumentada" (N.G.+1800cts.), intervalo que es considerado más cercano a la

${ }^{169}$ SCHOENBERG, A. Theory of Harmony. Berkeley: University of California P., Traducción al inglés de la tercera edición alemana de 1922, p.32. 


\section{Capítulo V. Propuesta personal y ejemplos.}

naturaleza de la serie de armónicos como es escuchada de forma natural; como ha sido establecido por la tradición musical "clásica", el intervalo de "oncena" fue utilizado como "justo" a una distancia de 1700 cents de la nota generadora, y en el caso de la música tonal, continúa siendo utilizado así; las traducciones realizadas en esta propuesta parten de la tradición clásica temperada, razón por la que las traducciones de las series de armónicos, a la par que de los acordes y escalas realizados, utilizan el intervalos de "oncena justa" y no la "oncena aumentada"; además de que mediante el uso de los cents, la concepción de la "oncena aumentada" se vuelve realmente innecesaria. Como pudimos establecer en la investigación sobre el fenómeno de la tonalidad en la música, en realidad la serie de armónicos naturales del sonido, no es temperada en prácticamente ninguno de sus componentes, lo cual nos convence de la inutilidad de, en el contexto establecido, considerar los intervalos de "oncena" e incluso de "trecena" de otra manera, de como es posible observarlos en la música del periodo clásico.

Como primer agrupamiento de frecuencias, o acorde, realizaremos la traducción a colores del acorde "dominante" por ser el primer acorde que podemos encontrar conceptualizado a partir del fenómeno natural de los armónicos, se continuará con las traducciones del resto de los acordes utilizados a partir de las escalas musicales “clásicas", las escalas "mayor" y "menor" con sus diferentes modos; los acordes en la música clásica fueron utilizados prioritariamente hasta el intervalo de "séptima" ya fuera "menor" o 
“mayor"(N.G.+1000cts. o N.G.+1100cts.) por lo que la tabla de traducciones expuesta se limitará a ese intervalo.

Acordes dominantes con séptima.

Nota generadora

Do

Re bemol

Re

Mi bemol

$$
\begin{aligned}
& \text { N.G.+0cts. } \\
& \text { N.G.+400cts. } \\
& \text { N.G.+700cts. }
\end{aligned}
$$

\section{Colores}

Blan

Roj/Azu/Ama

Roj

Mor-Obsc

Nar

Ver/Caf

Vio/Azu/Mag

Roj/Ros

Ama

Ver-Obsc-Clar

Ver

Blan

Gri

Roj

Mor-Obsc 


$$
\text { N.G.+1000cts. Nar }
$$

$\mathrm{Mi}$

N.G.+0cts.

Roj/Azu/Ama

N.G.+400cts.

Vio/Azu/Mag

N.G.+700cts.

Roj/Ros

N.G.+1000cts.

Ama

$\mathrm{Fa}$

N.G.+0cts.

Ver/Caf

N.G.+400cts.

Ver

N.G. +700 cts.

Blan

N.G.+1000cts.

Gri

Fa sostenido N.G.+0cts.

Ver-Obsc-Clar

N.G.+400cts.

Mor-Obsc

N.G. +700 cts.

Nar

N.G.+1000cts.

Roj/Azu/Ama

Sol

N.G.+0cts.

Roj

N.G.+400cts.

Roj/Ros

N.G.+700cts.

Ama

N.G.+1000cts.

Ver/Caf

La bemol

N.G.+0cts.

Vio/Azu/Mag

N.G.+400cts.

Blan

N.G.+700cts.

Gri 
N.G.+1000cts. Ver-Obsc-Clar

$\mathrm{La}$

N.G.+0cts.

Ver

N.G.+400cts.

Nar

N.G.+700cts.

Roj/Azu/Ama

N.G.+1000cts.

Roj

Si bemol N.G.+0cts

Mor-Obsc

N.G.+400cts.

Ama

N.G. +700 cts.

Ver/Caf

N.G.+1000cts.

Vio/Azu/Mag

$\mathrm{Si}$

N.G.+0cts.

Roj/Ros

N.G.+400cts.

Gri

N.G.+700cts.

Ver-Obsc-Clar

N.G.+1000cts.

Ver

La siguiente estructura de acordes ha establecer es la de los denominados como "acordes mayores", la estructura del acorde "mayor", es bastante similar al acorde "dominante" con la única diferencia del intervalo de "séptima menor" (N.G.+1000cts.), que en el caso del acorde "mayor" es de "séptima mayor" (N.G.+1100cts.). Esos acordes pueden ser considerados como un subproducto de la síntesis de la serie de armónicos en forma de una escala musical, así como el acorde "dominante", se considera en la tradición musical 


\section{Capítulo V. Propuesta personal y ejemplos.}

clásica como el "quinto grado", por encontrarse en la quinta nota de la "escala mayor"; los acordes "mayores", son considerados como primer y cuarto grado de la misma escala, por encontrarse en las posiciones "geográficas" mencionadas, teniendo como referencia la "escala mayor".

Las traducciones correspondientes de los acordes mayores son las siguientes:

Acordes mayores con séptima mayor.

Nota generadora

Do

Re bemo

$\operatorname{Re}$

N.G.+0cts.

N.G.+400cts.

N.G.+700cts.

\section{Colores}

Blan

Roj/Azu/Ama

Roj

Roj/Ros

Nar

Ver/Caf

Vio/Azu/Mag

Blan

Ama

Ver-Obsc-Clar

Ver 
N.G.+1100cts. Nar

Mi bemol

N.G.+0cts.

Gri

N.G.+400cts.

Roj

N.G. +700 cts.

Mor-Obsc

N.G.+1100cts.

Ama

Mi

N.G.+0cts.

Roj/Azu/Ama

N.G.+400cts.

Vio/Azu/Mag

N.G.+700cts.

Roj/Ros

N.G.+1100cts.

Gri

$\mathrm{Fa}$

N.G.+0cts.

Ver/Caf

N.G.+400cts.

Ver

N.G.+700cts.

Blan

N.G.+1100cts.

Roj/Azu/Ama

Fa sostenido N.G.+0cts.

Ver-Obsc-Clar

N.G.+400cts.

Mor-Obsc

N.G. +700 cts.

Nar

N.G.+1100cts.

Ver/Caf

Sol

N.G.+0cts.

Roj

N.G. +400 cts.

Roj/Ros

N.G.+700cts.

Ama 
N.G.+1100cts. Ver-Obsc-Clar

La bemol N.G.+0cts.

Vio/Azu/Mag

N.G. +400 cts.

Blan

N.G. +700 cts.

Gri

N.G.+1100cts. Roj

$\mathrm{La}$

N.G.+0cts.

Ver

N.G.+400cts.

Nar

N.G. +700 cts.

Roj/Azu/Ama

N.G.+1100cts.

Vio/Azu/Mag

Si bemo

N.G.+0cts.

Mor-Obsc

N.G.+400cts.

Ama

N.G. +700 cts.

Ver/Caf

N.G.+1100cts.

Ver

$\mathrm{Si}$

N.G.+0cts.

$\operatorname{Roj} / \operatorname{Ros}$

N.G.+400cts.

Gri

N.G. +700 cts.

Ver-Obsc-Clar

N.G.+1100cts.

Mor-Obsc

Los acordes "menores" considerados hasta el intervalo de "séptima" son típicos de los grados II, III, y VI de la escala "mayor" en la música del periodo clásico, se encuentran construyendo un 


\section{Capítulo V. Propuesta personal y ejemplos.}

acorde en la segunda, tercera y sexta nota de la escala; la estructura de los acordes menores consiste en una "tercera menor" (N.G.+300cts.) que es el intervalo característico del acorde, la "quinta justa" (N.G.+700cts.) y una "séptima menor" (N.G.+1000cts.). Los colores correspondientes, son los que siguen.

Acordes menores con séptima menor.

Nota generadora

Do

$\begin{array}{lll} & \text { N.G.+300cts. } & \text { Gri } \\ & \text { N.G.+700cts. } & \text { Roj } \\ \text { N.G.+1000cts. } & \text { Mor-Obsc } \\ \text { Re bemol } & \text { N.G.+0cts. } & \text { Nar } \\ & \text { N.G.+300cts. } & \text { Roj/Azu/Ama } \\ & \text { N.G.+700cts. } & \text { Vio/Azu/Mag } \\ & \text { N.G.+1000cts. } & \text { Roj/Ros } \\ & & \\ \text { Re } & & \\ \text { N.G.+0cts. } & \text { Ama } \\ \text { N.G.+300cts. } & \text { Ver/Caf } \\ \text { N.G.+700cts. } & \text { Ver }\end{array}$

Colores

N.G.+0cts. Blan

N.G.+300cts. $\quad$ Gri

N.G.+700cts. $\quad$ Roj

N.G.+1000cts. Mor-Obsc

N.G.+700cts. Ver 
N.G. +1000 cts. Blan

Mi bemol

N.G.+0cts.

Gri

N.G.+300cts

Ver-Obsc-Clar

N.G.+700cts

Mor-Obsc

N.G.+1000cts.

Nar

Mi

N.G.+0cts.

Roj/Azu/Ama

N.G.+300cts.

Roj

N.G.+700cts.

Roj/Ros

N.G.+1000cts.

Ama

$\mathrm{Fa}$

N.G.+0cts.

Ver/Caf

N.G.+300cts.

Vio/Azu/Mag

N.G.+700cts

Blan

N.G.+1000cts.

Gri

Fa sostenido N.G.+0cts.

Ver-Obsc-Clar

N.G.+300cts

Ver

N.G.+700cts.

Nar

N.G.+1000cts.

Roj/Azu/Ama

Sol

N.G.+0cts.

Roj

N.G.+300cts.

Mor-Obsc

N.G.+700cts

Ama 
N.G.+1000cts. Ver/Caf

La bemol

N.G.+0cts.

N.G.+300cts.

N.G.+700cts.

N.G.+1000cts.

La

N.G.+0cts.

N.G.+300cts.

N.G.+700cts.

N.G.+1000cts.

Si bemol

N.G.+0cts.

N.G.+300cts.

N.G. +700 cts.

N.G.+1000cts.

$\mathrm{Si}$

N.G.+0cts.

N.G.+300cts

N.G.+700cts.

N.G.+1000cts.
Vio/Azu/Mag

Roj/Ros

Gri

Ver-Obsc-Clar

Ver

Blan

Roj/Azu/Ama

Roj

Mor-Obsc

Nar

Ver/Caf

Vio/Azu/Mag

Roj/Ros

Ama

Ver-Obsc-Clar

Ver

En los séptimos grados de la escala mayor, encontramos el acorde denominado como "disminuido", es una acorde menor cuyo intervalo característico es el uso de una "quinta disminuida" 
(N.G.+600cts.); es bastante utilizado también el acorde conocido como de "séptima disminuida", característico de la escala "menor armónica", que posee la misma estructura del acorde "disminuido", y aparece también en el "séptimo grado", con las diferencias de ser característico de la escala "menor", y su intervalo de "séptima" ser “disminuido" (N.G.+900cts.). Las traducciones a color de los acordes mencionados, son como siguen:

Acordes disminuidos con séptima menor.

Nota generadora

Do

$\begin{array}{lll} & \text { N.G.+300cts. } & \text { Gri } \\ \text { N.G.+600cts. } & \text { Ver-Obsc-Clar } \\ \text { N.G.+1000cts. } & \text { Mor-Obsc } \\ \text { Re bemol } & \text { N.G.+0cts. } & \text { Nar } \\ & \text { N.G.+300cts. } & \text { Roj/Azu/Ama } \\ & \text { N.G.+600cts. } & \text { Roj } \\ & \text { N.G.+1000cts. } & \text { Roj/Ros } \\ \text { Re } & & \\ & \text { N.G.+0cts. } & \text { Ama } \\ \text { N.G. }+300 c t s . & \text { Ver/Caf } \\ \text { N.G. }+600 c t s . & \text { Vio/Azu/Mag } \\ \text { N.G.+1000cts. } & \text { Blan }\end{array}$

\section{Colores}

N.G.+0cts. Blan

N.G.+300cts. Gri

N.G.+600cts. Ver-Obsc-Clar

N.G.+1000cts. Mor-Obsc

Nar

Roj/Azu/Ama

Roj

Roj/Ros

Ama

Blan 
Mi bemol

Mi

$\mathrm{Fa}$

Fa sostenido

N.G.+300cts

N.G.+600cts.

N.G.+1000cts.

Sol

N.G.+0cts.

N.G.+300cts

N.G.+600cts.

N.G.+1000cts.
Gri

Ver-Obsc-Clar

Ver

Nar

Roj/Azu/Ama

Roj

Mor-Obsc

Ama

Ver/Caf

Vio/Azu/Mag

Roj/Ros

Gri

Ver-Obsc-Clar

Ver

Blan

Roj/Azu/Ama

Roj

Mor-Obsc

Nar

Ver/Caf 
Capítulo V. Propuesta personal y ejemplos.

La bemol

La

Si bemol

$\mathrm{Si}$

Acordes de séptima disminuida.

Nota generadora

Do
N.G.+300cts.
N.G.+600cts.
N.G.+1000cts.
tima disminuida.

N.G.+0cts.
Vio/Azu/Mag

Roj/Ros

Ama

Ver-Obsc-Clar

Ver

Blan

Gri

Roj

Mor-Obsc

Nar

Roj/Azu/Ama

Vio/Azu/Mag

Roj/Ros

Ama

Ver/Caf

N.G.+1000cts. Ver

\section{Colores}

Blan 
Capítulo V. Propuesta personal y ejemplos.

N.G.+300cts. Gri

N.G.+600cts. Ver-Obsc-Clar

N.G.+900cts. Ver

Re bemol N.G.+0cts. Nar

N.G.+300cts. Roj/Azu/Ama

N.G.+600cts. Roj

N.G.+900cts. Mor-Obsc

Re N.G.+0cts. $\quad$ Ama

N.G.+300cts. Ver/Caf

N.G.+600cts. Vio/Azu/Mag

N.G.+900cts. Roj/Ros

Mi bemol N.G.+0cts. Gri

N.G.+300cts. Ver-Obsc-Clar

N.G.+600cts. Ver

N.G.+900cts. Blan

Mi

N.G.+0cts. Roj/Azu/Ama

N.G.+300cts. Roj

N.G.+600cts. Mor-Obsc

N.G.+900cts. Nar 
$\mathrm{Fa}$

Fa sostenido N.G.+0cts.

N.G.+300cts.

N.G.+600cts.

N.G.+900cts.

Sol

La bemol

$\mathrm{La}$

N.G.+0cts.

N.G.+300cts

N.G.+600cts

N.G.+900cts
Ver/Caf

Vio/Azu/Mag

Roj/Ros

Ama

Ver-Obsc-Clar

Ver

Blan

Gri

Roj

Mor-Obsc

Nar

Roj/Azu/Ama

Vio/Azu/Mag

Roj/Ros

Ama

Ver/Caf

Ver

Blan

Gri

Ver-Obsc-Clar 
Si bemol

N.G.+0cts.

Mor-Obsc

N.G.+300cts.

Nar

N.G.+600cts.

Roj/Azu/Ama

N.G.+900cts.

Roj

$\mathrm{Si}$

N.G.+0cts.

Roj/Ros

N.G. +300 cts.

Ama

N.G.+600cts.

Ver/Caf

N.G.+900cts.

Vio/Azu/Mag

En el tercer grado de la escala menor armónica encontramos el acorde denominado como "aumentado", denominación que obtiene a partir de su intervalo característico, la "quinta aumentada" (N.G.+800cts.), la estructura de este acorde es la siguiente: "tercera mayor" (N.G.+400cts.), "quinta aumentada" (N.G.+800cts.), y “séptima mayor" (N.G.+1100cts.); como podemos observar, la estructura del acorde "aumentado", es casi exactamente la misma que la del acorde mayor, excepción de la segunda nota del acorde o "quinta", que en este caso, tiene un semitono más de distancia.

Acordes aumentados.

Nota generadora

Do

N.G.+0cts.

Colores

Blan 
Capítulo V. Propuesta personal y ejemplos.

N.G.+400cts. Roj/Azu/Ama

N.G.+800cts. Vio/Azu/Mag

N.G.+1100cts. Roj/Ros

Re bemol N.G.+0cts. Nar

N.G.+400cts. Ver/Caf

N.G.+800cts. Ver

N.G.+1100cts. Blan

Re N.G.+0cts. Ama

N.G.+400cts. Ver-Obsc-Clar

N.G.+800cts. Mor-Obsc

N.G.+1100cts. Nar

Mi bemol N.G.+0cts. Gri

N.G.+400cts. Roj

N.G.+800cts. Roj/Ros

N.G.+1100cts. Ama

Mi

N.G.+0cts. Roj/Azu/Ama

N.G.+400cts. Vio/Azu/Mag

N.G.+800cts. Blan

N.G.+1100cts. Gri

$\mathrm{Fa}$

N.G.+0cts.

Ver/Caf 


$\begin{array}{ll}\text { N.G.+400cts. } & \text { Ver } \\ \text { N.G.+800cts. } & \text { Nar } \\ \text { N.G.+1100cts. } & \text { Roj/Azu/Ama }\end{array}$

Fa sostenido N.G.+0cts.

Ver-Obsc-Clar

N.G.+400cts.

Mor-Obsc

N.G.+800cts.

Ama

N.G.+1100cts.

Ver/Caf

Sol

N.G.+0cts.

Roj

N.G.+400cts.

Roj/Ros

N.G.+800cts

Gri

N.G.+1100cts.

Ver-Obsc-Clar

La bemol N.G.+0cts.

Vio/Azu/Mag

N.G.+400cts.

Blan

N.G.+800cts.

Roj/Azu/Ama

N.G.+1100cts.

Roj

La

N.G.+0cts.

Ver

N.G.+400cts.

Nar

N.G.+800cts.

Ver/Caf

N.G.+1100cts.

Vio/Azu/Mag

Si bemol N.G.+0cts.

Mor-Obsc 


$\begin{array}{ll}\text { N.G.+400cts. } & \text { Ama } \\ \text { N.G.+800cts. } & \text { Ver-Obsc-Clar } \\ \text { N.G.+1100cts. } & \text { Ver } \\ \text { N.G.+0cts. } & \text { Roj/Ros } \\ \text { N.G.+400cts. } & \text { Gri } \\ \text { N.G.+800cts. } & \text { Roj } \\ \text { N.G.+1100cts. } & \text { Mor-Obsc }\end{array}$

Como la última de las estructuras de acordes que se encuentran de forma "natural" en las escalas musicales clásicas, está el acorde "menor con séptima mayor", no es un acorde que sea considerado como de uso común en la música del periodo clásico, sin embargo, es posible encontrarlo en diversas piezas del periodo; como su denominación lo establece, es un acorde con una estructura similar al acorde menor, con la única diferencia del intervalo de "séptima" el cual es "mayor" (N.G.+1100cts.); es posible ubicarlo en la primera nota de la escala "menor armónica", cuando se construye un acorde de "séptima" sobre la misma.

Acordes menores con séptima mayor.

Nota generadora

Do
N.G.+0cts. Blan

N.G.+300cts.

\section{Colores}

Gri 
N.G.+700cts. Roj

N.G.+1100cts. Roj/Ros

Re bemol N.G.+0cts. Nar

N.G.+300cts. Roj/Azu/Ama

N.G.+700cts. Vio/Azu/Mag

N.G.+1100cts. Blan

$\operatorname{Re}$

N.G.+0cts.

Ama

N.G.+300cts. Ver/Caf

N.G.+700cts. Ver

N.G.+1100cts. Nar

Mi bemol N.G.+0cts. Gri

N.G.+300cts. Ver-Obsc-Clar

N.G.+700cts. Mor-Obsc

N.G.+1100cts. Ama

Mi

N.G.+0cts. Roj/Azu/Ama

N.G.+300cts. Roj

N.G.+700cts. Roj/Ros

N.G.+1100cts. Gri

$\mathrm{Fa}$

N.G.+0cts.

Ver/Caf

N.G.+300cts.

Vio/Azu/Mag 
N.G.+700cts. Blan

N.G.+1100cts. Roj/Azu/Ama

Fa sostenido N.G.+0cts.

Ver-Obsc-Clar

N.G.+300cts.

Ver

N.G.+700cts.

Nar

N.G.+1100cts.

Ver/Caf

Sol

N.G.+0cts.

Roj

N.G.+300cts.

Mor-Obsc

N.G.+700cts.

Ama

N.G.+1100cts.

Ver-Obsc-Clar

La bemol N.G.+0cts.

Vio/Azu/Mag

N.G.+300cts.

Roj/Ros

N.G.+700cts.

Gri

N.G.+1100cts.

Roj

$\mathrm{La}$

N.G.+0cts.

Ver

N.G.+300cts.

Blan

N.G.+700cts.

Roj/Azu/Ama

N.G.+1100cts.

Vio/Azu/Mag

Si bemol N.G.+0cts.

Mor-Obsc

N.G.+300cts.

Nar 


\section{Capítulo V. Propuesta personal y ejemplos.}

$\begin{array}{ll}\text { N.G.+700cts. } & \text { Ver/Caf } \\ \text { N.G.+1100cts. } & \text { Ver } \\ \text { N.G.+0cts. } & \text { Roj/Ros } \\ \text { N.G.+300cts. } & \text { Ama } \\ \text { N.G.+700cts. } & \text { Ver-Obsc-Clar } \\ \text { N.G.+1100cts. } & \text { Mor-Obsc }\end{array}$

A pesar de no ser una estructura "natural" de las escalas "mayores" y "menores", sino un acorde "alterado", el acorde denominado como "sexta aumentada", es también un acorde de uso común en la música académica; existe cierto grado de polémica en cuanto a la estructura del acorde, y depende en gran parte del contexto en que es utilizado, así como de la forma en que es escrito; la versión de la estructura que presentamos aquí es la provista por el Mtro. Héctor Quintanar Prieto, miembro de la "Sociedad de Autores y Compositores de México" y de "Música de Concierto" subsidiaria de la misma institución, el Mtro. Quintanar, fue alumno de Carlos Chávez, y "heredero" suyo del primer "Taller de Composición” del "Conservatorio Nacional de Música" de México, además de fundador del primer "Laboratorio de electroacústica" de Iberoamérica. ${ }^{170} \mathrm{La}$ versión del Mtro. Quintanar sobre la estructura del acorde de "sexta aumentada", es la siguiente:

\footnotetext{
170 S.A.C.M. "Biografías, Héctor Quintanar." [en línea]. http://www.sacm.org.mx/archivos/biografias.asp?txtSocio=00241 [Consulta: 31 Diciembre 2010].
} 


\section{Capítulo V. Propuesta personal y ejemplos.}

"Un acorde de segundo grado (menor), el cual es alterado para convertirlo en dominante, se continúa alterando disminuyendo la quinta y la novena se altera para hacerla menor; se omite el generador". ${ }^{171}$

Al omitir el generador, el resultado es en realidad un acorde "dominante", que depende por entero de la escritura y el contexto musical alrededor del mismo, para poder ser considerado o "escuchado" como una sexta aumentada; sin embargo, al utilizarlo con el generador presente, nos encontramos con una estructura sui generis.

De acuerdo a esta versión de la sexta aumentada, la estructura del acorde, será la siguiente: "tercera mayor" (N.G.+400cts.), "quinta disminuida" (N.G.+600cts.), “séptima menor" (N.G.+1000cts.) y "novena menor" (N.G.+1300cts.); este acorde es usualmente utilizado sin la nota generadora, sin embargo, es posible encontrar múltiples usos del acorde utilizando la nota generadora, lo que respalda la versión dada por la escuela de Carlos Chávez y el Mtro. Quintanar. De igual manera, autores como Schumann, Granados (en la "Suite" de "Danzas Españolas"172) y Wagner, utilizan el acorde con la nota generadora presente, y es posible observar ejemplos específicos en la "Sonata op.57" de Beethoven, compositor del periodo clásico. ${ }^{173}$

\footnotetext{
${ }^{171}$ Transmitido de forma oral por el mtro. Quintanar durante los trabajos en el "Taller de composición" de la Universidad de Guanajuato.

172 GRANADOS, E. Danzas Españolas. Barcelona: Casa Dostesio, 1912. Danza no. 11 "Arabesca", compás 30.

${ }^{173}$ BEETHOVEN, L.V. Sonaten III. Budapest: Könemann Music, 1994. Sonata no. 23, primer movimiento, compás 42.
} 
Capítulo V. Propuesta personal y ejemplos.

Acordes de sexta aumentada con generador.

Nota generadora

Do

Re bemo

$\operatorname{Re}$

Mi bemol

N.G.+0cts.

N.G.+400cts.

N.G.+600cts.

N.G.+600cts.

N.G.+400cts.

N.G.+600cts.

\section{Colores}

Blan

N.G.+400cts.

Roj/Azu/Ama

Ver-Obsc-Clar

N.G.+1000cts.

Mor-Obsc

N.G.+1300cts.

Nar

Nar

Ver/Caf

Roj

N.G.+1000cts. Roj/Ros

N.G.+1300cts.

Ama

Ama

N.G.+400cts.

Ver-Obsc-Clar

N.G.+600cts.

Vio/Azu/Mag

N.G.+1000cts.

Blan

N.G.+1300cts.

Gri

Gri

Roj

Ver 
Capítulo V. Propuesta personal y ejemplos.

N.G.+1000cts. Nar

N.G.+1300cts. Roj/Azu/Ama

$\mathrm{Mi}$

N.G.+0cts.

Roj/Azu/Ama

N.G.+400cts.

Vio/Azu/Mag

N.G.+600cts.

Mor-Obsc

N.G.+1000cts.

Ama

N.G.+1300cts.

Ver/Caf

$\mathrm{Fa}$

N.G.+0cts.

Ver/Caf

N.G.+400cts.

Ver

N.G.+600cts.

Roj/Ros

N.G.+1000cts.

Gri

N.G.+1300cts.

Ver-Obsc-Clar

Fa sostenido N.G.+0cts.

Ver-Obsc-Clar

N.G.+400cts

Mor-Obsc

N.G.+600cts.

Blan

N.G.+1000cts.

Roj/Azu/Ama

N.G.+1300cts.

Roj

Sol

N.G.+0cts.

Roj

N.G.+400cts.

Roj/Ros

N.G.+600cts.

Nar 
$\begin{array}{ll}\text { N.G.+1000cts. } & \text { Ver/Caf } \\ \text { N.G.+1300cts. } & \text { Vio/Azu/Mag }\end{array}$

La bemol N.G.+0cts.

Vio/Azu/Mag

N.G.+400cts.

Blan

N.G.+600cts.

Ama

N.G.+1000cts.

Ver-Obsc-Clar

N.G.+1300cts.

Ver

La

N.G.+0cts.

N.G.+400cts.

N.G.+600cts.

N.G.+1000cts.

N.G.+1300cts.

Si bemol

N.G.+0cts.

N.G.+400cts.

N.G.+600cts.

N.G.+1000cts.

N.G.+1300cts.

$\mathrm{Si}$

N.G.+0cts.

N.G.+400cts.

N.G.+600cts.
Mor-Obsc

Ama

Roj/Azu/Ama

Vio/Azu/Mag

Roj/Ros

Roj/Ros

Gri

Ver/Caf 


$$
\begin{array}{ll}
\text { N.G. }+1000 \text { cts. } & \text { Ver } \\
\text { N.G. }+1300 \text { cts. } & \text { Blan }
\end{array}
$$

Los ejemplos anteriores, constituyen una exposición de los acordes de uso común en la música clásica, existen múltiples formaciones simultáneas de frecuencias sonoras, que no han sido expuestas aquí, aun en el ámbito de la música académica, pero estos constituyen el repertorio de acordes usuales. y mediante las correspondencias anteriores, realizadas mediante el uso de la escala cromática audiovisual, es posible mediante un cuidadoso análisis armónico de la música, realizar las traducciones correspondientes de los campos armónicos presentes en la música, al ámbito de la pintura. 


\section{Capítulo V. Propuesta personal y ejemplos.}

\subsubsection{Escalas mayores y menores, sus colores.}

El siguiente elemento básico de la música clásica al cual incorporar la escala cromática audiovisual son las escalas musicales utilizadas usualmente en la música clásica.

La escala musical es una sucesión de notas continuas las cuales, en la música occidental clásica, mantienen la característica de ser una serie que combina los pasos de semitono (N.G.+100cts) o tono (N.G.+200cts.), La escala "mayor", puede ser conceptualizada como una síntesis horizontal de la serie de armónicos, cuando son utilizados los primeros trece; al igual que en el caso de los acordes "clásicos", los armónicos once y trece son utilizados de forma "temperada", es decir, utilizados como un intervalo de "oncena justa" y "trecena mayor".

En el caso de las escalas "menores", y sus tres diferentes modos, "Natural”, “Armónica" y "Melódica", pueden ser consideradas agrupaciones "artificiales" que tienen su origen en la escala "eólica" griega. Por necesidades compositivas y cuestiones de estilo en la música clásica, la escala "eólica" o menor natural, es modificada para obtener ciertas funciones tonales que emulan las de la escala mayor, como el uso de una nota "sensible" que se encuentre a 1100 cents de la nota generadora y proporcione la sensación subjetiva de tendencia de resolución a la "Tónica" en el caso de la escala "menor armónica", 


\section{Capítulo V. Propuesta personal y ejemplos.}

o en el caso de la escala "menor melódica" que contribuye a evitar un intervalo melódico de 300 cents entre dos de las notas de la escala, intervalo que aparece como un subproducto derivado de la intervención de la escala eólica cuando se busca obtener la sensación de una nota "sensible", y que constituía un problema de estilo en la escuela clásica de música al tener una fuerte carga regional extra europea.

Escalas Mayores.

\section{Tónica o Generadora}

Do

$\begin{array}{lll}\text { Do } & \text { (N.G.+0cts. } & \text { Blan } \\ & \text { (N.G.+200cts.) } & \text { Ama } \\ & \text { (N.G.+400cts.) } & \text { Roj/Azu/Ama } \\ & \text { (N.G.+500cts.) } & \text { Ver/Caf } \\ & \text { (N.G.+700cts.) } & \text { Roj } \\ & \text { (N.G.+900cts.) } & \text { Ver } \\ & \text { (N.G.+1100cts.) } & \text { Roj/Ros } \\ & & \\ \text { Re bemol } & \text { (N.G.+0cts.) } & \text { Nar } \\ & \text { (N.G.+200cts.) } & \text { Gri } \\ & \text { (N.G.+400cts.) } & \text { Ver/Caf } \\ & \text { (N.G.+500cts.) } & \text { Ver-Obsc-Clar }\end{array}$

\section{Colores}

Blan 
Capítulo V. Propuesta personal y ejemplos.

$\begin{array}{ll}\text { (N.G.+700cts.) } & \text { Vio/Azu/Mag } \\ \text { (N.G.+900cts.) } & \text { Mor-Obsc } \\ \text { (N.G.+1100cts.) } & \text { Blan }\end{array}$

$\operatorname{Re}$

$\begin{array}{ll}\text { (N.G.+0cts.) } & \text { Ama } \\ \text { (N.G.+200cts.) } & \text { Roj/Azu/Ama } \\ \text { (N.G.+400cts.) } & \text { Ver-Obsc-Clar } \\ \text { (N.G.+500cts.) } & \text { Roj } \\ \text { (N.G.+700cts.) } & \text { Ver } \\ \text { (N.G.+900cts.) } & \text { Roj/Ros } \\ \text { (N.G.+1100cts.) } & \text { Nar }\end{array}$

Mi bemo

(N.G.+0cts.)

Gri

$\begin{array}{ll}\text { (N.G.+200cts.) } & \text { Ver/Caf } \\ \text { (N.G.+400cts.) } & \text { Roj } \\ \text { (N.G.+500cts.) } & \text { Vio/Azu/Mag } \\ \text { (N.G.+700cts.) } & \text { Mor-Obsc } \\ \text { (N.G.+900cts.) } & \text { Blan } \\ \text { (N.G.+1100cts.) } & \text { Ama }\end{array}$


Capítulo V. Propuesta personal y ejemplos.

Mi

$\begin{array}{ll}\text { (N.G.+0cts.) } & \text { Roj/Azu/Ama } \\ \text { (N.G.+200cts.) } & \text { Ver-Obsc-Clar } \\ \text { (N.G.+400cts.) } & \text { Vio/Azu/Mag } \\ \text { (N.G.+500cts.) } & \text { Ver } \\ \text { (N.G.+700cts.) } & \text { Roj/Ros } \\ \text { (N.G.+900cts.) } & \text { Nar } \\ \text { (N.G.+1100cts.) } & \text { Gri }\end{array}$

$\mathrm{Fa}$

(N.G.+0cts.)

Ver/Caf

(N.G.+200cts.)

Roj

(N.G.+400cts.)

Ver

(N.G.+500cts.)

Mor-Obsc

(N.G.+700cts.)

Blan

(N.G.+900cts.)

Ama

(N.G.+1100cts.)

Roj/Azu/Ama

Fa sostenido (N.G.+0cts.)

Ver-Obsc-Clar

(N.G.+200cts.)

Vio/Azu/Mag

(N.G.+400cts.)

Mor-Obsc

(N.G.+500cts.)

Roj/Ros 
Capítulo V. Propuesta personal y ejemplos.

$\begin{array}{ll}\text { (N.G.+700cts.) } & \text { Nar } \\ \text { (N.G.+900cts.) } & \text { Gri } \\ \text { (N.G.+1100cts.) } & \text { Ver/Caf }\end{array}$

Sol

$\begin{array}{ll}\text { (N.G.+0cts.) } & \text { Roj } \\ \text { (N.G.+200cts.) } & \text { Ver } \\ \text { (N.G.+400cts.) } & \text { Roj/Ros } \\ \text { (N.G.+500cts.) } & \text { Blan } \\ \text { (N.G.+700cts.) } & \text { Ama } \\ \text { (N.G.+900cts.) } & \text { Roj/Azu/Ama } \\ \text { (N.G.+1100cts.) } & \text { Ver-Obsc-Clar }\end{array}$

La bemol (N.G.+0cts.)

Vio/Azu/Mag

(N.G.+200cts.)

Mor-Obsc

(N.G.+400cts.)

Blan

(N.G.+500cts.)

Nar

(N.G.+700cts.)

Gri

(N.G.+900cts.)

Ver/Caf

(N.G.+1100cts.)

Roj 
Capítulo V. Propuesta personal y ejemplos.

La

$\begin{array}{ll}\text { (N.G.+0cts.) } & \text { Ver } \\ \text { (N.G.+200cts.) } & \text { Roj/Ros } \\ \text { (N.G.+400cts.) } & \text { Nar } \\ \text { (N.G.+500cts.) } & \text { Ama } \\ \text { (N.G.+700cts.) } & \text { Roj/Azu/Ama } \\ \text { (N.G.+900cts.) } & \text { Ver-Obsc-Clar } \\ \text { (N.G.+1100cts.) } & \text { Vio/Azu/Mag }\end{array}$

Si bemol

(N.G.+0cts.)

Mor-Obsc

(N.G.+200cts.)

Blan

(N.G.+400cts.)

Ama

(N.G.+500cts.)

Gri

(N.G.+700cts.)

Ver/Caf

(N.G.+900cts.)

Roj

(N.G.+1100cts.)

Ver

$\mathrm{Si}$

(N.G.+0cts.)

Roj/Ros

(N.G.+200cts.)

Nar

(N.G.+400cts.)

Gri

(N.G.+500cts.)

Roj/Azu/Ama 
Capítulo V. Propuesta personal y ejemplos.

$\begin{array}{ll}\text { (N.G.+700cts.) } & \text { Ver-Obsc-Clar } \\ \text { (N.G.+900cts.) } & \text { Vio/Azu/Mag } \\ \text { (N.G.+1100cts.) } & \text { Mor-Obsc }\end{array}$

Escalas Menores Melódicas.

Tónica o Generadora

Do

$\begin{array}{ll}\text { (N.G.+0cts.) } & \text { Blan } \\ \text { (N.G.+200cts.) } & \text { Ama } \\ \text { (N.G.+300cts.) } & \text { Gri } \\ \text { (N.G.+500cts.) } & \text { Ver/Caf } \\ \text { (N.G.+700cts.) } & \text { Roj } \\ \text { (N.G.+900cts.) } & \text { Ver } \\ \text { (N.G.+1100cts.) } & \text { Roj/Ros }\end{array}$

Re bemol

$$
\begin{aligned}
& \text { (N.G.+0cts.) } \\
& \text { (N.G.+200cts.) } \\
& \text { (N.G.+300cts.) } \\
& \text { (N.G.+500cts.) }
\end{aligned}
$$

\section{Colores}


Capítulo V. Propuesta personal y ejemplos.

$\begin{array}{ll}\text { (N.G.+700cts.) } & \text { Vio/Azu/Mag } \\ \text { (N.G.+900cts.) } & \text { Mor-Obsc } \\ \text { (N.G.+1100cts.) } & \text { Blan }\end{array}$

$\operatorname{Re}$

$\begin{array}{ll}\text { (N.G.+0cts.) } & \text { Ama } \\ \text { (N.G.+200cts.) } & \text { Roj/Azu/Ama } \\ \text { (N.G.+300cts.) } & \text { Ver/Caf } \\ \text { (N.G.+500cts.) } & \text { Roj } \\ \text { (N.G.+700cts.) } & \text { Ver } \\ \text { (N.G.+900cts.) } & \text { Roj/Ros } \\ \text { (N.G.+1100cts.) } & \text { Nar }\end{array}$

Mi bemo

(N.G.+0cts.)

Gri

$\begin{array}{ll}\text { (N.G.+200cts.) } & \text { Ver/Caf } \\ \text { (N.G.+300cts.) } & \text { Ver-Obsc-Clar } \\ \text { (N.G.+500cts.) } & \text { Vio/Azu/Mag } \\ \text { (N.G.+700cts.) } & \text { Mor-Obsc } \\ \text { (N.G.+900cts.) } & \text { Blan } \\ \text { (N.G.+1100cts.) } & \text { Ama }\end{array}$


Capítulo V. Propuesta personal y ejemplos.

Mi

$\begin{array}{ll}\text { (N.G.+0cts.) } & \text { Roj/Azu/Ama } \\ \text { (N.G.+200cts.) } & \text { Ver-Obsc-Clar } \\ \text { (N.G.+300cts.) } & \text { Roj } \\ \text { (N.G.+500cts.) } & \text { Ver } \\ \text { (N.G.+700cts.) } & \text { Roj/Ros } \\ \text { (N.G.+900cts.) } & \text { Nar } \\ \text { (N.G.+1100cts.) } & \text { Gri }\end{array}$

$\mathrm{Fa}$

(N.G.+0cts.)

Ver/Caf

(N.G.+200cts.)

Roj

(N.G.+300cts.)

Vio/Azu/Mag

(N.G.+500cts.)

Mor-Obsc

(N.G.+700cts.)

Blan

(N.G.+900cts.)

Ama

(N.G.+1100cts.)

Roj/Azu/Ama

Fa sostenido (N.G.+0cts.)

Ver-Obsc-Clar

(N.G.+200cts.)

Vio/Azu/Mag

(N.G.+300cts.)

Ver

(N.G.+500cts.)

Roj/Ros 
Capítulo V. Propuesta personal y ejemplos.

$\begin{array}{ll}\text { (N.G.+700cts.) } & \text { Nar } \\ \text { (N.G.+900cts.) } & \text { Gri } \\ \text { (N.G.+1100cts.) } & \text { Ver/Caf }\end{array}$

Sol

$\begin{array}{ll}\text { (N.G.+0cts.) } & \text { Roj } \\ \text { (N.G.+200cts.) } & \text { Ver } \\ \text { (N.G.+300cts.) } & \text { Mor-Obsc } \\ \text { (N.G.+500cts.) } & \text { Blan } \\ \text { (N.G.+700cts.) } & \text { Ama } \\ \text { (N.G.+900cts.) } & \text { Roj/Azu/Ama } \\ \text { (N.G.+1100cts.) } & \text { Ver-Obsc-Clar }\end{array}$

La bemol

$\begin{array}{ll}\text { (N.G.+0cts.) } & \text { Vio/Azu/Mag } \\ \text { (N.G.+200cts.) } & \text { Mor-Obsc } \\ \text { (N.G.+300cts.) } & \text { Roj/Ros } \\ \text { (N.G.+500cts.) } & \text { Nar } \\ \text { (N.G.+700cts.) } & \text { Gri } \\ \text { (N.G.+900cts.) } & \text { Ver/Caf } \\ \text { (N.G.+1100cts.) } & \text { Roj }\end{array}$




\begin{tabular}{|c|c|c|}
\hline $\mathrm{La}$ & (N.G.+0cts.) & Ver \\
\hline & (N.G.+200cts.) & Roj/Ros \\
\hline & (N.G.+300cts.) & Blan \\
\hline & (N.G.+500cts.) & Ama \\
\hline & (N.G.+700cts.) & Roj/Azu/Ama \\
\hline & (N.G.+900cts.) & Ver-Obsc-Clar \\
\hline & (N.G.+1100cts.) & Vio/Azu/Mag \\
\hline Si bemol & (N.G.+0cts.) & Mor-Obsc \\
\hline & (N.G.+200cts.) & Blan \\
\hline & (N.G.+300cts.) & Nar \\
\hline & (N.G.+500cts.) & Gri \\
\hline & (N.G.+700cts.) & Ver/Caf \\
\hline & (N.G.+900cts.) & Roj \\
\hline & (N.G.+1100cts.) & Ver \\
\hline $\mathrm{Si}$ & (N.G.+0cts.) & Roj/Ros \\
\hline & (N.G.+200cts.) & Nar \\
\hline & (N.G.+300cts.) & Ama \\
\hline
\end{tabular}


Capítulo V. Propuesta personal y ejemplos.

$\begin{array}{ll}\text { (N.G.+500cts.) } & \text { Roj/Azu/Ama } \\ \text { (N.G.+700cts.) } & \text { Ver-Obsc-Clar } \\ \text { (N.G.+900cts.) } & \text { Vio/Azu/Mag } \\ \text { (N.G.+1100cts.) } & \text { Mor-Obsc }\end{array}$

Escalas Menores Armónicas.

Tónica o Generadora

Do

Re bemol

$$
\begin{aligned}
& \text { (N.G.+0cts.) } \\
& \text { (N.G.+200cts.) } \\
& \text { (N.G.+300cts.) } \\
& \text { (N.G.+500cts.) } \\
& \text { (N.G.+700cts.) }
\end{aligned}
$$

\section{Colores}

Blan

Ama

Gri

Ver/Caf

Roj

Vio/Azu/Mag

Roj/Ros 
Capítulo V. Propuesta personal y ejemplos.
(N.G.+800cts.)
Ver
(N.G.+1100cts.)
Blan

$\operatorname{Re}$

$\begin{array}{ll}\text { (N.G.+0cts.) } & \text { Ama } \\ \text { (N.G.+200cts.) } & \text { Roj/Azu/Ama } \\ \text { (N.G.+300cts.) } & \text { Ver/Caf } \\ \text { (N.G.+500cts.) } & \text { Roj } \\ \text { (N.G.+700cts.) } & \text { Ver } \\ \text { (N.G.+800cts.) } & \text { Mor-Obsc } \\ \text { (N.G.+1100cts.) } & \text { Nar }\end{array}$

Mi bemol

(N.G.+0cts.)

Gri

(N.G.+200cts.)

Ver/Caf

(N.G.+300cts.)

Ver-Obsc-Clar

(N.G.+500cts.)

Vio/Azu/Mag

(N.G.+700cts.)

Mor-Obsc

(N.G.+800cts.)

Roj/Ros

(N.G.+1100cts.)

Ama 
Capítulo V. Propuesta personal y ejemplos.

Mi

$\begin{array}{ll}\text { (N.G.+0cts.) } & \text { Roj/Azu/Ama } \\ \text { (N.G.+200cts.) } & \text { Ver-Obsc-Clar } \\ \text { (N.G.+300cts.) } & \text { Roj } \\ \text { (N.G.+500cts.) } & \text { Ver } \\ \text { (N.G.+700cts.) } & \text { Roj/Ros } \\ \text { (N.G.+800cts.) } & \text { Blan } \\ \text { (N.G.+1100cts.) } & \text { Gri }\end{array}$

$\mathrm{Fa}$

$\begin{array}{ll}\text { (N.G.+0cts.) } & \text { Ver/Caf } \\ \text { (N.G.+200cts.) } & \text { Roj } \\ \text { (N.G.+300cts.) } & \text { Vio/Azu/Mag } \\ \text { (N.G.+500cts.) } & \text { Mor-Obsc } \\ \text { (N.G.+700cts.) } & \text { Blan } \\ \text { (N.G.+800cts.) } & \text { Nar } \\ \text { (N.G.+1100cts.) } & \text { Roj/Azu/Ama }\end{array}$

Fa sostenido (N.G.+0cts.)

Ver-Obsc-Clar

(N.G.+200cts.)

Vio/Azu/Mag

(N.G.+300cts.)

Ver

(N.G.+500cts.)

Roj/Ros 
Capítulo V. Propuesta personal y ejemplos.

$\begin{array}{ll}\text { (N.G.+700cts.) } & \text { Nar } \\ \text { (N.G.+800cts.) } & \text { Ama } \\ \text { (N.G.+1100cts.) } & \text { Ver/Caf }\end{array}$

Sol

$\begin{array}{ll}\text { (N.G.+0cts.) } & \text { Roj } \\ \text { (N.G.+200cts.) } & \text { Ver } \\ \text { (N.G.+300cts.) } & \text { Mor-Obsc } \\ \text { (N.G.+500cts.) } & \text { Blan } \\ \text { (N.G.+700cts.) } & \text { Ama } \\ \text { (N.G.+800cts.) } & \text { Gri } \\ \text { (N.G.+1100cts.) } & \text { Ver-Obsc-Clar }\end{array}$

La bemol (N.G.+0cts.)

Vio/Azu/Mag

(N.G.+200cts.)

Mor-Obsc

(N.G.+300cts.)

Roj/Ros

(N.G.+500cts.)

Nar

(N.G.+700cts.)

Gri

(N.G.+800cts.)

Roj/Azu/Ama

(N.G.+1100cts.)

Roj 
Capítulo V. Propuesta personal y ejemplos.

$\mathrm{La}$

$\begin{array}{ll}\text { (N.G.+0cts.) } & \text { Ver } \\ \text { (N.G.+200cts.) } & \text { Roj/Ros } \\ \text { (N.G.+300cts.) } & \text { Blan } \\ \text { (N.G.+500cts.) } & \text { Ama } \\ \text { (N.G.+700cts.) } & \text { Roj/Azu/Ama } \\ \text { (N.G.+800cts.) } & \text { Ver/Caf } \\ \text { (N.G.+1100cts.) } & \text { Vio/Azu/Mag }\end{array}$

Si bemol

(N.G.+0cts.)

Mor-Obsc

(N.G.+200cts.)

Blan

(N.G.+300cts.)

Nar

(N.G.+500cts.)

Gri

(N.G.+700cts.)

Ver/Caf

(N.G.+800cts.)

Ver-Obsc-Clar

(N.G.+1100cts.)

Ver

$\mathrm{Si}$

(N.G.+0cts.)

Roj/Ros

(N.G.+200cts.)

Nar

(N.G.+300cts.)

Ama 
Capítulo V. Propuesta personal y ejemplos.

$\begin{array}{ll}\text { (N.G.+500cts.) } & \text { Roj/Azu/Ama } \\ \text { (N.G.+700cts.) } & \text { Ver-Obsc-Clar } \\ \text { (N.G.+800cts.) } & \text { Roj } \\ \text { (N.G.+1100cts.) } & \text { Mor-Obsc }\end{array}$

Escalas Menores Naturales o Escala Eólica.

Tónica o Generadora

Do

$\begin{array}{ll}\text { N.G.+0cts.) } & \text { Blan } \\ \text { (N.G.+200cts.) } & \text { Ama } \\ \text { (N.G.+300cts.) } & \text { Gri } \\ \text { (N.G.+500cts.) } & \text { Ver/Caf } \\ \text { (N.G.+700cts.) } & \text { Roj } \\ \text { (N.G.+800cts.) } & \text { Vio/Azu/Mag } \\ \text { (N.G.+1000cts.) } & \text { Mor-Obsc }\end{array}$

Re bemol

(N.G.+0cts.)

Nar

(N.G.+200cts.)

Gri

(N.G.+300cts.)

Colores

(1)


Capítulo V. Propuesta personal y ejemplos.

$\begin{array}{ll}\text { (N.G.+500cts.) } & \text { Ver-Obsc-Clar } \\ \text { (N.G.+700cts.) } & \text { Vio/Azu/Mag } \\ \text { (N.G.+800cts.) } & \text { Ver } \\ \text { (N.G.+1000cts.) } & \text { Roj/Ros }\end{array}$

$\operatorname{Re}$

$\begin{array}{ll}\text { (N.G.+0cts.) } & \text { Ama } \\ \text { (N.G.+200cts.) } & \text { Roj/Azu/Ama } \\ \text { (N.G.+300cts.) } & \text { Ver/Caf } \\ \text { (N.G.+500cts.) } & \text { Roj } \\ \text { (N.G.+700cts.) } & \text { Ver } \\ \text { (N.G.+800cts.) } & \text { Mor-Obsc } \\ \text { (N.G.+1000cts.) } & \text { Blan }\end{array}$

Mi bemol (N.G.+0cts.) Gri

$\begin{array}{ll}\text { (N.G.+200cts.) } & \text { Ver/Caf } \\ \text { (N.G.+300cts.) } & \text { Ver-Obsc-Clar } \\ \text { (N.G.+500cts.) } & \text { Vio/Azu/Mag } \\ \text { (N.G.+700cts.) } & \text { Mor-Obsc } \\ \text { (N.G.+800cts.) } & \text { Roj/Ros } \\ \text { (N.G.+1000cts.) } & \text { Nar }\end{array}$


Mi

(N.G.+0cts.) Roj/Azu/Ama

(N.G.+200cts.)

Ver-Obsc-Clar

(N.G.+300cts.) Roj

(N.G.+500cts.) Ver

(N.G.+700cts.) Roj/Ros

(N.G.+800cts.) Blan

(N.G.+1000cts.) Ama

$\mathrm{Fa}$

(N.G.+0cts.)

Ver/Caf

(N.G.+200cts.)

Roj

(N.G.+300cts.)

Vio/Azu/Mag

(N.G.+500cts.)

Mor-Obsc

(N.G.+700cts.)

Blan

(N.G.+800cts.)

Nar

(N.G.+1000cts.)

Gri

Fa sostenido (N.G.+0cts.)

Ver-Obsc-Clar

(N.G.+200cts.)

Vio/Azu/Mag

(N.G.+300cts.)

Ver 
Capítulo V. Propuesta personal y ejemplos.

$\begin{array}{ll}\text { (N.G.+500cts.) } & \text { Roj/Ros } \\ \text { (N.G.+700cts.) } & \text { Nar } \\ \text { (N.G.+800cts.) } & \text { Ama } \\ \text { (N.G.+1000cts.) } & \text { Roj/Azu/Ama }\end{array}$

Sol

$\begin{array}{ll}\text { (N.G.+0cts.) } & \text { Roj } \\ \text { (N.G.+200cts.) } & \text { Ver } \\ \text { (N.G.+300cts.) } & \text { Mor-Obsc } \\ \text { (N.G.+500cts.) } & \text { Blan } \\ \text { (N.G.+700cts.) } & \text { Ama } \\ \text { (N.G.+800cts.) } & \text { Gri } \\ \text { (N.G.+1000cts.) } & \text { Ver/Caf }\end{array}$

La bemol

(N.G.+0cts.)

Vio/Azu/Mag

(N.G.+200cts.)

Mor-Obsc

(N.G.+300cts.)

Roj/Ros

(N.G.+500cts.)

Nar

(N.G.+700cts.)

Gri

(N.G.+800cts.)

Roj/Azu/Ama

(N.G.+1000cts.)

Ver-Obsc-Clar 


\begin{tabular}{|c|c|c|}
\hline $\mathrm{La}$ & (N.G.+0cts.) & Ver \\
\hline & (N.G.+200cts.) & Roj/Ros \\
\hline & (N.G.+300cts.) & Blan \\
\hline & (N.G.+500cts.) & Ama \\
\hline & (N.G.+700cts.) & Roj/Azu/Ama \\
\hline & (N.G.+800cts.) & Ver/Caf \\
\hline & (N.G.+1000cts.) & Roj \\
\hline Si bemol & (N.G.+0cts.) & Mor-Obsc \\
\hline & (N.G.+200cts.) & Blan \\
\hline & (N.G.+300cts.) & Nar \\
\hline & (N.G.+500cts.) & Gri \\
\hline & (N.G.+700cts.) & Ver/Caf \\
\hline & (N.G.+800cts.) & Ver-Obsc-Clar \\
\hline & (N.G.+1000cts.) & Vio/Azu/Mag \\
\hline $\mathrm{Si}$ & (N.G.+0cts.) & Roj/Ros \\
\hline & (N.G.+200cts.) & Nar \\
\hline & (N.G.+300cts.) & Ama \\
\hline
\end{tabular}




$\begin{array}{ll}\text { (N.G.+500cts.) } & \text { Roj/Azu/Ama } \\ \text { (N.G.+700cts.) } & \text { Ver-Obsc-Clar } \\ \text { (N.G.+800cts.) } & \text { Roj } \\ \text { (N.G.+1000cts.) } & \text { Ver }\end{array}$

Los anteriores esquemas constituyen una traducción de los elementos básicos de la música utilizados de forma común en los periodos históricos barroco y clásico, pueden ser utilizados como herramientas para realizar una traducción eficaz y sencilla de cualquier pieza musical de los periodos anteriormente mencionados, e incluso, de periodos anteriores al barroco y posteriores al clásico; únicamente habrá que realizar una análisis de elementos utilizados. Las series de armónicos, acordes y escalas esquematizados de esta manera, constituyen el lenguaje musical clásico, y por añadidura, la base del lenguaje musical académico que es enseñado en nuestros días en las instituciones de enseñanza superior de música, conservatorios y departamentos universitarios. Utilizando los elementos anteriores es posible realizar traducciones de una pieza musical a un elemento atemporal en la forma de una pintura. 


\section{Capítulo V. Propuesta personal y ejemplos.}

\subsection{De color a la música.}

El uso de la escala cromática audiovisual nos permite trabajar también en el sentido inverso utilizado hasta estos momentos, la traducción de los colores a elementos musicales. Utilizando criterios de combinación de colores, es posible obtener combinaciones de acordes y escalas musicales que constituyan una aportación nueva a los elementos musicales académicos; haremos uso de los criterios establecidos en la teoría del color, y la armonía del color, en particular mediante el uso del circulo cromático de colores, para establecer nuestros elementos del lenguaje musical.

Las posibles combinaciones de colores son prácticamente innumerables, hemos de facto realizado una primera discriminación de colores mediante el establecimiento de una escala cromática audiovisual, lo cual ha limitado el uso de las combinaciones de colores a 12 grupos de colores; en lo posible, utilizaremos colores denominados como "sólidos", es decir colores con un valor de intensidad alto, sin mezclarlos con otros en su denominación (dentro de lo posible, el color Azul será lo más puro posible, el color Violeta implica una mezcla de colores), y estableciendo un valor medio de luminosidad para la mayoría de ellos, con excepción de los colores establecidos para la notas "Fa sostenido", "Si bemol", y "Si" en las cuales impera la necesidad de establecer diferentes valores de luminosidad; en los casos anteriormente mencionados, los valores de 


\section{Capítulo V. Propuesta personal y ejemplos.}

luminosidad serán utilizados para coadyuvar en la buena combinación de colores, o el establecimiento de un contraste.

No es deseable el desuso del contraste en las combinaciones de colores a proponer, al igual que en la música, el contraste en el color impera como un elemento de atención el cual está supeditado al buen funcionamiento de un fenómeno estético; se procurará que los contrastes se encuentren dentro de un contexto de combinaciones "armónicas", en el sentido clásico de "agradables" lo cual contribuirá al buen funcionamiento del esquema audiovisual propuesto.

Las combinaciones de colores establecerán los siguientes criterios para la creación de los elementos musicales:

1. Un color combinará con los que se encuentran próximos a él, en el círculo cromático de colores.

2. Se considerará que también combinan los colores que se encuentran en la misma mitad del círculo cromático.

3. Se considerarán colores contrastantes aquellos que se encuentran diametralmente opuestos en el círculo cromático de colores, o aquellos que se encuentran en diferentes mitades del círculo.

4. Se procurará que entre colores contrastantes haya un color blanco. 
Capítulo V. Propuesta personal y ejemplos.

5. Se procurará que los "acordes de color" y otros elementos musicales, sean creados en un contexto mayoritariamente "armónico" o agradable, con la existencia de elementos de contraste. 


\subsubsection{La creación de nuevos acordes, del color a la música.}

Como primer elemento a establecer, utilizaremos el acorde, el uso de varios sonidos simultáneos, los cuales serán establecidos por la combinación o contraste de los colores establecidos en la escala cromática audiovisual, únicamente tomaremos en cuenta una consideración, en el caso que los colores establezcan un acorde que pueda ser considerado como establecido anteriormente por la armonía musical clásica, este acorde, será discriminado y no será tomado en cuenta.

Las combinaciones que serán establecidas para los acordes necesitan de un criterio absoluto, muchos de los acordes a ser presentados funcionan como acordes musicales cuyos colores combinan, cuando son presentados en cierto orden; si el orden de presentación de notas es cambiado, estos acordes pueden perder la combinación de colores establecida, o invocar la idea de algún acorde de índole académica. Los acordes presentados son absolutos.

Existe otra consideración a ser tomada en cuenta, la idea de la "Tonalidad", como habíamos establecido en capítulos anteriores, la Tonalidad es un concepto jerarquizador, y esto implica la funcionalidad de los acordes y notas a ser utilizados en cierto periodo temporal. Tradicionalmente, la tonalidad de una pieza musical, es establecida por las funciones armónicas, el contexto en que son 


\section{Capítulo V. Propuesta personal y ejemplos.}

presentados los acordes e incluso el orden en que son presentados los mismos; por otro lado, el establecimiento de una Tonalidad en los elementos visuales, está relacionada con la frecuencia lumínica preponderante para la vista, el color o color base mayormente percibido, en un espacio bidimensional o tridimensional.

Para establecer el concepto de una Tonalidad Sinestésica, utilizaremos el recurso de la repetición, los acordes a establecer carecen de la carga funcional establecida a través de la tradición musical occidental, sin embargo, al repetir mayoritariamente una notacolor, estamos estableciendo una frecuencia lumínica preponderante y al mismo tiempo, creando una sensación de importancia de la frecuencia sonora, cuyo intervalo de repetición sea el más corto.

El primer elemento a establecer, serán acordes denominados como "triadas", agrupaciones de tres notas-color, se continuará con el establecimiento de acordes de cuatro notas, y algunos ejemplos posibles de acordes de doce notas. 
Capítulo V. Propuesta personal y ejemplos.

Acordes de tres colores "triadas".

\section{$\begin{array}{ll}\text { Colores } & \text { Sonidos }\end{array}$}

Acordes cuyo sonido más grave sea el "Do".

Blan

Do

Nar

Do sostenido

Ama

$\operatorname{Re}$

Blan

Do

Ama

$\operatorname{Re}$

Roj/Azu/Ama

Mi

Blan

Do

Gri

Re sostenido

Vio/Azu/Mag

La Bemol

Blan

Do

Roj/Azu/Ama

Mi

Ver/Caf

$\mathrm{Fa}$ 
Capítulo V. Propuesta personal y ejemplos.

Blan

Ver/Caf

Ver-Obsc-Clar

Blan

Ver-Obsc-Clar

Roj/Azu/Ama

Blan

Roj

Vio/Azu/Mag

Blan

Vio/Azu/Mag

Mor-Obsc

Blan

Ver

Nar
Do

$\mathrm{Fa}$

Fa sostenido

Do

Fa sostenido

Mi

Do

Sol

La Bemol

Do

La Bemol

Si Bemol

Do

$\mathrm{La}$

Do sostenido 
Capítulo V. Propuesta personal y ejemplos.

Blan

Do

Mor-Obsc

Si Bemol

$\operatorname{Roj} / \operatorname{Ros}$

$\mathrm{Si}$

Blan

Do

Roj/Ros

$\mathrm{Si}$

Nar

Do sostenido

Acordes cuyo sonido más grave sea el "Do sostenido".

$\mathrm{Nar}$

Ama

Roj/Azu/Ama

Nar

Ama

Ver/Caf
Do sostenido

$\mathrm{Re}$

Mi

Do sostenido

$\operatorname{Re}$

$\mathrm{Fa}$ 
Capítulo V. Propuesta personal y ejemplos.

Nar

Roj/Azu/Ama

Ver/Caf

Nar

Ver/Caf

Roj/Ros

Nar

Roj

Vio/Azu/Mag

Nar

Roj

Ama
Do sostenido

Mi

$\mathrm{Fa}$

Do sostenido

$\mathrm{Fa}$

$\mathrm{Si}$

Do sostenido

Sol

La Bemol

Do sostenido

Sol

$\operatorname{Re}$ 
Capítulo V. Propuesta personal y ejemplos.

Acordes cuyo sonido más grave sea el "Re".

Ama

$\operatorname{Re}$

Roj/Azu/Ama

Mi

Ver/Caf

$\mathrm{Fa}$

Ama

$\operatorname{Re}$

Blan

Do

Roj

Sol

Ama

$\operatorname{Re}$

Nar

Do sostenido

Roj

Sol

Ama

$\mathrm{Re}$

Ver/Caf

$\mathrm{Fa}$

Ver-Obsc-Clar

Fa sostenido

Ama

$\operatorname{Re}$

Roj

Sol

Ver

La 
Capítulo V. Propuesta personal y ejemplos.

Ama

Blan

Gri

Ama

Vio/Azu/Mag

Ver

Ama

Vio/Azu/Mag

Mor-Obsc

Ama

Roj/Ros

Nar

Ama

Gri

Vio/Azu/Mag
$\operatorname{Re}$

Do

Re sostenido

$\operatorname{Re}$

La Bemol

$\mathrm{La}$

$\operatorname{Re}$

La Bemol

Si Bemol

$\operatorname{Re}$

$\mathrm{Si}$

Do sostenido

$\operatorname{Re}$

Re sostenido

La Bemol 
Acordes cuyo sonido más grave sea el "Re sostenido".

Gri

Blan

Ver-Obsc-Clar

Gri

Blan

Ama

Gri

Blan

Nar

Gri

Vio/Azu/Mag

Ver

Gri

Roj/Azu/Ama

Ver/Caf
Re sostenido

Do

Fa sostenido

Re sostenido

Do

$\mathrm{Re}$

Re sostenido

Do

Do sostenido

Re sostenido

La Bemol

La

Re sostenido

Mi

$\mathrm{Fa}$ 
Capítulo V. Propuesta personal y ejemplos.

Gri

Roj/Azu/Ama

Vio/Azu/Mag

Gri

Roj/Azu/Ama

Mor-Obsc

Gri

Roj/Azu/Ama

Roj/Ros

Gri

Ver-Obsc-Clar

Ama

Gri

Vio/Azu/Mag

Mor-Obsc
Re sostenido

Mi

La Bemol

Re sostenido

Mi

Si Bemol

Re sostenido

Mi

Si

Re sostenido

Fa sostenido

$\operatorname{Re}$

Re sostenido

La Bemol

Si Bemol 
Capítulo V. Propuesta personal y ejemplos.

Acordes cuyo sonido más grave sea el "Mi".

Roj/Azu/Ama

Mi

Ver/Caf

$\mathrm{Fa}$

Ver-Obsc-Clar

Fa sostenido

Roj/Azu/Ama

Mi

Ver/Caf

$\mathrm{Fa}$

Roj

Sol

Roj/Azu/Ama

Mi

Ver/Caf

$\mathrm{Fa}$

Vio/Azu/Mag

La Bemol

Roj/Azu/Ama

Mi

Ver/Caf

$\mathrm{Fa}$

Ver

$\mathrm{La}$

Roj/Azu/Ama

Mi

Ver/Caf

$\mathrm{Fa}$

Roj/Ros

$\mathrm{Si}$ 
Capítulo V. Propuesta personal y ejemplos.

$\begin{array}{ll}\text { Roj/Azu/Ama } & \mathrm{Mi} \\ \text { Ver/Caf } & \mathrm{Fa} \\ \text { Blan } & \text { Do } \\ & \mathrm{Mi} \\ \text { Roj/Azu/Ama } & \mathrm{Fa} \\ \text { Ver/Caf } & \mathrm{Re} \\ \text { Ama } & \end{array}$

Roj/Azu/Ama $\quad$ Mi

Ver/Caf $\quad \mathrm{Fa}$

Gri $\quad$ Re sostenido

Roj/Azu/Ama $\quad$ Mi

Ver-Obsc-Clar $\quad$ Fa sostenido

Ver La

Roj/Azu/Ama $\quad \mathrm{Mi}$

Ver-Obsc-Clar $\quad$ Fa sostenido

Mor-Obsc Si Bemol 
Capítulo V. Propuesta personal y ejemplos.

Roj/Azu/Ama $\quad$ Mi

Ver-Obsc-Clar Fa sostenido

Blan Do

Roj/Azu/Ama $\quad$ Mi

Ver-Obsc-Clar $\quad$ Fa sostenido

Ama $\quad \operatorname{Re}$

Roj/Azu/Ama $\quad$ Mi

Ver-Obsc-Clar $\quad$ Fa sostenido

Gri $\quad$ Re sostenido

Roj/Azu/Ama $\quad$ Mi

Blan Do

Nar Do sostenido

Roj/Azu/Ama $\quad \mathrm{Mi}$

Blan Do

Ama $\quad \operatorname{Re}$ 
Capítulo V. Propuesta personal y ejemplos.

Roj/Azu/Ama

Blan

Gri

Roj/Azu/Ama

Blan

Ver/Caf

Roj/Azu/Ama

Blan

Ver-Obsc-Clar

Roj/Azu/Ama

Ama

Nar

Roj/Azu/Ama

Ama

Ver/Caf
Mi

Do

Re sostenido

Mi

Do

$\mathrm{Fa}$

Mi

Do

Fa sostenido

Mi

$\operatorname{Re}$

Do sostenido

Mi

$\mathrm{Re}$

$\mathrm{Fa}$ 
Capítulo V. Propuesta personal y ejemplos.

Acordes cuyo sonido más grave sea el "Fa".

Ver/Caf

Ver-Obsc-Clar

Roj

Ver/Caf

Ver-Obsc-Clar

Ver

Ver/Caf

Ver-Obsc-Clar

Roj/Ros

Ver/Caf

Ver-Obsc-Clar

Blan

Ver/Caf

Ver-Obsc-Clar

Ama
$\mathrm{Fa}$

Fa sostenido

Sol

$\mathrm{Fa}$

Fa sostenido

La

$\mathrm{Fa}$

Fa sostenido

$\mathrm{Si}$

$\mathrm{Fa}$

Fa sostenido

Do

$\mathrm{Fa}$

Fa sostenido

$\operatorname{Re}$ 
Capítulo V. Propuesta personal y ejemplos.

Ver/Caf

Roj

Vio/Azu/Mag

Ver/Caf

Roj

Ver

Ver/Caf

Roj

Mor-Obsc

Ver/Caf

Roj

Roj/Ros

Ver/Caf

Roj

Blan
$\mathrm{Fa}$

Sol

La Bemol

$\mathrm{Fa}$

Sol

$\mathrm{La}$

$\mathrm{Fa}$

Sol

Si Bemol

$\mathrm{Fa}$

Sol

Si

$\mathrm{Fa}$

Sol

Do 
Capítulo V. Propuesta personal y ejemplos.

Ver/Caf

Roj

Nar

Ver/Caf

Roj

Ama

Ver/Caf

Blan

Nar

Ver/Caf

Blan

Ver-Obsc-Clar

Ver/Caf

Blan

Roj
$\mathrm{Fa}$

Sol

Do sostenido

$\mathrm{Fa}$

Sol

$\operatorname{Re}$

$\mathrm{Fa}$

Do

Do sostenido

$\mathrm{Fa}$

Do

Fa sostenido

$\mathrm{Fa}$

Do

Sol 
Capítulo V. Propuesta personal y ejemplos.

$\begin{array}{ll}\text { Ver/Caf } & \mathrm{Fa} \\ \text { Blan } & \text { Do } \\ \text { Roj/Ros } & \mathrm{Si}\end{array}$

Acordes cuyo sonido más grave sea el "Sol".

Roj

Sol

Vio/Azu/Mag

La Bemol

Ver

$\mathrm{La}$

Roj

Sol

Vio/Azu/Mag

La Bemol

Mor-Obsc

Si Bemol

Roj

Sol

Vio/Azu/Mag

La Bemol

Roj/Ros

$\mathrm{Si}$

Roj

Sol

Roj/Ros

$\mathrm{Si}$

Blan

Do 
Capítulo V. Propuesta personal y ejemplos.

Roj

Nar

Ama

Roj

Nar

Ver/Caf

Roj

Ama

Roj/Azu/Ama

Roj

Ama

Vio/Azu/Mag

Roj

Roj/Azu/Ama

Ver/Caf
Sol

Do sostenido

$\operatorname{Re}$

Sol

Do sostenido

$\mathrm{Fa}$

Sol

$\operatorname{Re}$

Mi

Sol

$\operatorname{Re}$

La Bemol

Sol

Mi

$\mathrm{Fa}$ 
Capítulo V. Propuesta personal y ejemplos.

$\begin{array}{ll}\text { Roj } & \text { Sol } \\ \text { Roj/Azu/Ama } & \mathrm{Mi} \\ \text { Vio/Azu/Mag } & \text { La Bemol } \\ & \\ \text { Roj } & \text { Sol } \\ \text { Roj/Azu/Ama } & \text { Mi } \\ \text { Mor-Obsc } & \text { Si Bemol }\end{array}$

Acordes cuyo sonido más grave sea el "La bemol".

Vio/Azu/Mag

La Bemol

Mor-Obsc

Si Bemol

Roj/Ros

$\mathrm{Si}$

Vio/Azu/Mag

La Bemol

Mor-Obsc

Si Bemol

Blan

Do

Vio/Azu/Mag

La Bemol

Mor-Obsc

Si Bemol

Nar

Do sostenido 
Capítulo V. Propuesta personal y ejemplos.

Vio/Azu/Mag

Mor-Obsc

Gri

Vio/Azu/Mag

Mor-Obsc

Roj/Azu/Ama

Vio/Azu/Mag

Mor-Obsc

Roj

Vio/Azu/Mag

Roj/Ros

Blan

Vio/Azu/Mag

Roj/Ros

Nar
La Bemol

Si Bemol

Re sostenido

La Bemol

Si Bemol

Mi

La Bemol

Si Bemol

Sol

La Bemol

$\mathrm{Si}$

Do

La Bemol

$\mathrm{Si}$

Do sostenido 
Capítulo V. Propuesta personal y ejemplos.

Vio/Azu/Mag
Roj/Ros

Nar

Vio/Azu/Mag

Roj/Ros

Roj/Azu/Ama

Vio/Azu/Mag

Roj/Ros

Roj

Vio/Azu/Mag

Blan

Nar

Vio/Azu/Mag

Blan

Ama
La Bemol

$\mathrm{Si}$

Do sostenido

La Bemol

$\mathrm{Si}$

Mi

La Bemol

$\mathrm{Si}$

Sol

La Bemol

Do

Do sostenido

La Bemol

Do

$\operatorname{Re}$ 
Capítulo V. Propuesta personal y ejemplos.

$\begin{array}{ll}\text { Vio/Azu/Mag } & \text { La Bemol } \\ \text { Ama } & \text { Re } \\ \text { Roj } & \text { Sol }\end{array}$

Acordes cuyo sonido más grave sea el "La".

Ver

$\mathrm{La}$

$\operatorname{Roj} / \operatorname{Ros}$

$\mathrm{Si}$

Blan

Do

Ver

$\mathrm{La}$

Roj/Ros

$\mathrm{Si}$

Nar

Do sostenido

Ver

La

Ama

$\operatorname{Re}$

Roj/Azu/Ama

Mi

Ver

La

Ama

$\mathrm{Re}$

Roj

Sol 
Capítulo V. Propuesta personal y ejemplos.

Ver

Ama

Vio/Azu/Mag

Ver

Roj/Azu/Ama

Roj/Ros

Ver

Roj/Azu/Ama

Ver/Caf

Ver

Roj/Azu/Ama

Ver-Obsc-Clar

Ver

Ver/Caf

Ver-Obsc-Clar
$\mathrm{La}$

$\mathrm{Re}$

La Bemol

$\mathrm{La}$

Mi

$\mathrm{Si}$

$\mathrm{La}$

Mi

$\mathrm{Fa}$

$\mathrm{La}$

Mi

Fa sostenido

La

$\mathrm{Fa}$

Fa sostenido 
Capítulo V. Propuesta personal y ejemplos.

Acordes cuyo sonido más grave sea el "Si bemol".

Mor-Obsc

$\operatorname{Roj} / \operatorname{Ros}$

Blan

Mor-Obsc

Roj/Ros

Nar

Mor-Obsc

Roj/Ros

Ama

Mor-Obsc

Roj/Ros

Gri

Mor-Obsc

Roj/Ros

Roj/Azu/Ama
Si Bemol

Si

Do

Si Bemol

$\mathrm{Si}$

Do sostenido

Si Bemol

$\mathrm{Si}$

$\operatorname{Re}$

Si Bemol

Si

Re sostenido

Si Bemol

$\mathrm{Si}$

Mi 
Capítulo V. Propuesta personal y ejemplos.

Mor-Obsc

Roj/Ros

Roj

Mor-Obsc

Roj/Ros

Vio/Azu/Mag

Mor-Obsc

Blan

Nar

Mor-Obsc

Blan

Ama

Mor-Obsc

Blan

Gri
Si Bemol

$\mathrm{Si}$

Sol

Si Bemol

$\mathrm{Si}$

La Bemol

Si Bemol

Do

Do sostenido

Si Bemol

Do

$\operatorname{Re}$

Si Bemol

Do

Re sostenido 
Mor-Obsc

Blan

Ver/Caf

Mor-Obsc

Blan

Ver-Obsc-Clar

Mor-Obsc

Blan

Vio/Azu/Mag

Mor-Obsc

Gri

Roj/Azu/Ama

Mor-Obsc

Gri

Roj
Si Bemol

Do

$\mathrm{Fa}$

Si Bemol

Do

Fa sostenido

Si Bemol

Do

La Bemol

Si Bemol

Re sostenido

Mi

Si Bemol

Re sostenido

Sol 
Capítulo V. Propuesta personal y ejemplos.

Mor-Obsc

Roj

Vio/Azu/Mag
Si Bemol

Sol

La Bemol

Acordes cuyo sonido más grave sea el "Si”"

Roj/Ros

Blan

Nar

Roj/Ros

Blan

Ama

Roj/Ros

Blan

Gri

Roj/Ros

Blan

Roj/Azu/Ama
$\mathrm{Si}$

Do

Do sostenido

$\mathrm{Si}$

Do

$\operatorname{Re}$

$\mathrm{Si}$

Do

Re sostenido

$\mathrm{Si}$

Do

Mi 
Capítulo V. Propuesta personal y ejemplos.

Roj/Ros

Blan

Ver/Caf

Roj/Ros

Blan

Ver-Obsc-Clar

Roj/Ros

Blan

Roj

Roj/Ros

Blan

Vio/Azu/Mag

Roj/Ros

Blan

Ver
$\mathrm{Si}$

Do

$\mathrm{Fa}$

$\mathrm{Si}$

Do

Fa sostenido

$\mathrm{Si}$

Do

Sol

Si

Do

La Bemol

$\mathrm{Si}$

Do

$\mathrm{La}$ 
Capítulo V. Propuesta personal y ejemplos.

Roj/Ros

Blan

Mor-Obsc

Roj/Ros

Nar

Ama

Roj/Ros

Nar

Roj/Azu/Ama

Roj/Ros

Nar

Roj

Roj/Ros

Roj

Vio/Azu/Mag
$\mathrm{Si}$

Do

Si Bemol

$\mathrm{Si}$

Do sostenido

$\operatorname{Re}$

$\mathrm{Si}$

Do sostenido

Mi

$\mathrm{Si}$

Do sostenido

Sol

Si

Sol

La Bemol 


\section{Capítulo V. Propuesta personal y ejemplos.}

Roj/Ros

Roj

Mor-Obsc
$\mathrm{Si}$

Sol

Si Bemol

Como puede observarse, las posibles combinaciones de "notascolor" para la formación de "acordes-color", son prácticamente innumerables, más aún, si se toma en cuenta el elemento de contraste para fines del lenguaje musical. Los acordes que hemos presentado aquí, son solo una muestra del extenso repertorio de agrupaciones de frecuencias posibles, todos partiendo del criterio de las combinaciones más "accesibles" desde el punto de vista del color que combina.

Es necesario resaltar que los criterios de elaboración de acordes recién presentada, reviste la necesidad de que las notas mantengan el orden presentado, la primera nota de la triada debe ser la más grave, la segunda debe ser siempre la intermedia y la tercera nota la más aguda; estos acordes no permiten la inversión de sus notas, sin correr el riesgo de invocar la idea de la tonalidad académico-clásica.

La efectividad de los acordes presentados para hacer patente la idea de una "Tonalidad Sinestésica" audiovisual, depende del contexto en que serán presentados, dependen del oficio del compositor que los utilice. 


\section{Capítulo V. Propuesta personal y ejemplos.}

\section{Acordes de cuatro colores.}

Siguiendo los criterios establecidos anteriormente para la formación de "acordes de color" en la música, presentaremos una breve muestra de posibles acordes que involucren cuatro sonidos en su formación; al igual que en el caso de los acordes anteriores, los acordes a ser presentados no permitirán la inversión de sus notas, la primera nota a ser presentada será la más grave y la última nota presentada en el grupo, será la más aguda.

Blan

Nar

Ama

Roj/Azu/Ama

Blan

Nar

Ama

Ver/Caf
Do

Do sostenido

$\mathrm{Re}$

Mi

Do

Do sostenido

$\operatorname{Re}$

$\mathrm{Fa}$ 
Blan

Ama

Roj/Azu/Ama

Ver/Caf

Blan

Ama

Ver/Caf

Ver-Obsc-Clar

Blan

Gri

Vio/Azu/Mag

Mor-Obsc

Blan

Roj

Vio/Azu/Mag

Mor-Obsc
Do

$\operatorname{Re}$

Mi

$\mathrm{Fa}$

Do

$\operatorname{Re}$

$\mathrm{Fa}$

Fa sostenido

Do

Re sostenido

La Bemol

Si Bemol

Do

Sol

La Bemol

Si Bemol 
Capítulo V. Propuesta personal y ejemplos.

Nar

Ama

Roj

Roj/Ros

Ama

Roj/Azu/Ama

Roj

Vio/Azu/Mag

Ama

Roj/Azu/Ama

Vio/Azu/Mag

Mor-Obsc

Gri

Vio/Azu/Mag

Mor-Obsc

Roj/Ros
Do sostenido

$\operatorname{Re}$

Sol

$\mathrm{Si}$

$\operatorname{Re}$

Mi

Sol

La Bemol

$\operatorname{Re}$

Mi

La Bemol

Si Bemol

Re sostenido

La Bemol

Si Bemol

$\mathrm{Si}$ 
Capítulo V. Propuesta personal y ejemplos.

Gri

Roj/Azu/Ama

Vio/Azu/Mag

Mor-Obsc

Roj/Azu/Ama

Ver/Caf

Ver-Obsc-Clar

Ver

Roj/Azu/Ama

Vio/Azu/Mag

Mor-Obsc

Roj/Ros

Ver/Caf

Ver-Obsc-Clar

Ver

Blan
Re sostenido

Mi

La Bemol

Si Bemol

Mi

$\mathrm{Fa}$

Fa sostenido

$\mathrm{La}$

Mi

La Bemol

Si Bemol

$\mathrm{Si}$

$\mathrm{Fa}$

Fa sostenido

$\mathrm{La}$

Do 
Capítulo V. Propuesta personal y ejemplos.

Ver/Caf

Ver-Obsc-Clar

Ver

Blan

Ver-Obsc-Clar

Vio/Azu/Mag

Mor-Obsc

Blan

Ver-Obsc-Clar

Ver

Roj/Azu/Ama

Ver/Caf

Roj

Vio/Azu/Mag

Mor-Obsc

Roj/Ros
$\mathrm{Fa}$

Fa sostenido

$\mathrm{La}$

Do

Fa sostenido

La Bemol

Si Bemol

Do

Fa sostenido

$\mathrm{La}$

Mi

$\mathrm{Fa}$

Sol

La Bemol

Si Bemol

$\mathrm{Si}$ 
Capítulo V. Propuesta personal y ejemplos.

Roj

Vio/Azu/Mag

Roj/Ros

Blan

Vio/Azu/Mag

Mor-Obsc

Roj/Ros

Ama

Vio/Azu/Mag

Roj/Ros

Ama

Roj

Ver

Blan

Nar

Ama
Sol

La Bemol

$\mathrm{Si}$

Do

La Bemol

Si Bemol

Si

$\operatorname{Re}$

La Bemol

$\mathrm{Si}$

$\mathrm{Re}$

Sol

La

Do

Do sostenido

$\operatorname{Re}$ 
Capítulo V. Propuesta personal y ejemplos.

Ver

Blan

Ver/Caf

Ver-Obsc-Clar

Mor-Obsc

Roj/Ros

Blan

Nar

Mor-Obsc

Gri

Roj/Azu/Ama

Roj

Roj/Ros

Blan

Ama

Roj
$\mathrm{La}$

Do

$\mathrm{Fa}$

Fa sostenido

Si Bemol

$\mathrm{Si}$

Do

Do sostenido

Si Bemol

Re sostenido

Mi

Sol

$\mathrm{Si}$

Do

$\operatorname{Re}$

Sol 


\section{Capítulo V. Propuesta personal y ejemplos.}

$\begin{array}{ll}\text { Roj/Ros } & \text { Si } \\ \text { Blan } & \text { Do } \\ \text { Roj } & \text { Sol } \\ \text { Vio/Azu/Mag } & \text { La Bemol }\end{array}$

Como peculiaridades del comportamiento de la interacción entre el sonido y el color mediante el uso de la escala cromática audiovisual, podemos añadir la posibilidad de crear acordes "característicos" de paletas tradicionales de colores, como en el caso de los siguientes:

Blan

Do

Gri

Re sostenido

Vio/Azu/Mag

La Bemol

Mor-Obsc

Si Bemol

Nar

Do sostenido

Ama

$\operatorname{Re}$

Roj/Azu/Ama

Mi

Roj

Sol 


\section{Capítulo V. Propuesta personal y ejemplos.}

$\begin{array}{ll}\text { Roj/Azu/Ama } & \mathrm{Mi} \\ \text { Roj } & \text { Sol } \\ \text { Vio/Azu/Mag } & \text { La Bemol } \\ \text { Roj/Ros } & \mathrm{Si}\end{array}$

Se presentará a continuación, posibles combinaciones de acordes de doce sonidos, estos acordes "dodecafónicos" revisten una peculiar característica, que es común al uso de la música que utiliza todos los sonidos de la escala cromática occidental, cada acorde contiene en sí mismo, a todos los acordes, aseveración que se hace patente, por el hecho de que, en cada acorde son utilizadas todas las notas de la escala.

Para establecer una diferencia en el "color" característico de cada acorde de doce sonidos, se hace más necesaria que nunca, la regla de que las notas del acorde no sean invertidas; el color característico del acorde será de esta forma proporcionado por la nota base, la primera escrita en la presentación del acorde, la más grave; y por el orden de las notas presentadas, la última nota será la más aguda. Se utilizarán los mismos criterios para la formación de los acordes que en los anteriores ejemplos; como serán utilizadas todas las notas de la gama cromática, el contraste en el color se vuelve una condición, sin la cual, no es posible formar el acorde completo. 
Acordes de doce sonidos.

Blan

Do

Nar

Do sostenido

Ama

$\operatorname{Re}$

Roj/Azu/Ama

$\mathrm{Mi}$

Ver/Caf

$\mathrm{Fa}$

Ver-Obsc-Clar

Fa sostenido

Ver

$\mathrm{La}$

Gri

Re sostenido

Roj

Sol

Vio/Azu/Mag

La Bemol

Mor-Obsc

Si Bemol

Roj/Ros

$\mathrm{Si}$

Nar

Do sostenido

Ama

$\operatorname{Re}$

Roj/Azu/Ama

Mi

Roj

Sol

Vio/Azu/Mag

La Bemol

Mor-Obsc

Si Bemol

Roj/Ros

$\mathrm{Si}$ 
Blan

Gri

Ver/Caf

Ver-Obsc-Clar

Ver

Ama

Roj

Vio/Azu/Mag

Mor-Obsc

Roj/Ros

Nar

Roj/Azu/Ama

Blan

Gri

Ver/Caf

Ver-Obsc-Clar

Ver

Gri

Vio/Azu/Mag
Do

Re sostenido

$\mathrm{Fa}$

Fa sostenido

$\mathrm{La}$

$\operatorname{Re}$

Sol

La Bemol

Si Bemol

Si

Do sostenido

Mi

Do

Re sostenido

$\mathrm{Fa}$

Fa sostenido

La

Re sostenido

La Bemol 
Capítulo V. Propuesta personal y ejemplos.

Mor-Obsc

Roj/Ros

Roj

Roj/Azu/Ama

Nar

Blan

Ama

Ver/Caf

Ver-Obsc-Clar

Ver

Roj/Azu/Ama

Ver/Caf

Ver-Obsc-Clar

Ver

Ama

Nar

Roj/Ros

Roj

Blan

Vio/Azu/Mag
Si Bemol

$\mathrm{Si}$

Sol

Mi

Do sostenido

Do

$\operatorname{Re}$

$\mathrm{Fa}$

Fa sostenido

La

Mi

$\mathrm{Fa}$

Fa sostenido

$\mathrm{La}$

$\operatorname{Re}$

Do sostenido

$\mathrm{Si}$

Sol

Do

La Bemol 
Mor-Obsc

Gri

Ver/Caf

Ver-Obsc-Clar

Ver

Roj/Azu/Ama

Roj

Roj/Ros

Blan

Vio/Azu/Mag

Mor-Obsc

Nar

Ama

Gri

Ver-Obsc-Clar

Ver

Roj/Azu/Ama

Ver/Caf

Roj
Si Bemol

Re sostenido

$\mathrm{Fa}$

Fa sostenido

$\mathrm{La}$

Mi

Sol

$\mathrm{Si}$

Do

La Bemol

Si Bemol

Do sostenido

$\operatorname{Re}$

Re sostenido

Fa sostenido

La

Mi

$\mathrm{Fa}$

Sol 
Capítulo V. Propuesta personal y ejemplos.

\begin{tabular}{|c|c|}
\hline Roj/Ros & $\mathrm{Si}$ \\
\hline Nar & Do sostenido \\
\hline Ama & $\mathrm{Re}$ \\
\hline Blan & Do \\
\hline Gri & Re sostenido \\
\hline Vio/Azu/Mag & La Bemol \\
\hline Mor-Obsc & Si Bemol \\
\hline Roj & Sol \\
\hline Roj/Ros & $\mathrm{Si}$ \\
\hline Roj/Azu/Ama & $\mathrm{Mi}$ \\
\hline Nar & Do sostenido \\
\hline Ama & $\mathrm{Re}$ \\
\hline Ver/Caf & $\mathrm{Fa}$ \\
\hline Ver-Obsc-Clar & Fa sostenido \\
\hline Ver & $\mathrm{La}$ \\
\hline Blan & Do \\
\hline Gri & Re sostenido \\
\hline Vio/Azu/Mag & La Bemol \\
\hline Mor-Obsc & Si Bemol \\
\hline
\end{tabular}


Capítulo V. Propuesta personal y ejemplos.

Vio/Azu/Mag

Mor-Obsc

Roj/Ros

Gri

Blan

Roj/Azu/Ama

Nar

Ama

Ver/Caf

Ver-Obsc-Clar

Ver

Roj

Ver

Ver-Obsc-Clar

Ver/Caf

Roj/Azu/Ama

Roj

Roj/Ros

Vio/Azu/Mag

Mor-Obsc
La Bemol

Si Bemol

$\mathrm{Si}$

Re sostenido

Do

Mi

Do sostenido

$\operatorname{Re}$

$\mathrm{Fa}$

Fa sostenido

$\mathrm{La}$

Sol

La

Fa sostenido

$\mathrm{Fa}$

Mi

Sol

$\mathrm{Si}$

La Bemol

Si Bemol 
Gri

Blan

Nar

Ama

Mor-Obsc

Vio/Azu/Mag

Gri

Roj/Ros

Roj

Nar

Ama

Blan

Gri

Ver/Caf

Ver-Obsc-Clar

Ver

Roj/Ros

Mor-Obsc

Vio/Azu/Mag
Re sostenido

Do

Do sostenido

$\operatorname{Re}$

Si Bemol

La Bemol

Re sostenido

$\mathrm{Si}$

Sol

Do sostenido

$\operatorname{Re}$

Do

Re sostenido

$\mathrm{Fa}$

Fa sostenido

$\mathrm{La}$

$\mathrm{Si}$

Si Bemol

La Bemol 
Capítulo V. Propuesta personal y ejemplos.

$\begin{array}{ll}\text { Roj } & \text { Sol } \\ \text { Roj/Azu/Ama } & \mathrm{Mi} \\ \text { Nar } & \text { Do sostenido } \\ \text { Ama } & \mathrm{Re} \\ \text { Ver } & \mathrm{La} \\ \text { Ver-Obsc-Clar } & \text { Fa sostenido } \\ \text { Ver/Caf } & \text { Fa } \\ \text { Blan } & \text { Do } \\ \text { Gri } & \text { Re sostenido }\end{array}$




\section{Capítulo V. Propuesta personal y ejemplos.}

\subsubsection{Escalas de color.}

Como un elemento básico de elaboración de un lenguaje musical que parta de la aplicación de la escala cromática audiovisual, encontramos las escalas, la sucesión de notas que contribuyan a elaborar el elemento melódico.

En el caso de las escalas que presentaremos, la nota con la función de “Tónica” será la primera a ser presentada, las demás notas serán presentadas en sucesión, hasta llegar a la nota más aguda, la cual será la última presentada. No puede, ni es el deseo, establecer las funciones tonales clásicas mientras se persigue el establecimiento de una "Tonalidad Sinestésica"; pero sí es deseable, el establecimiento de una función de importancia para poder afirmar que existe una tonalidad, la "tónica sinestésica" en las escalas presentadas, será la primera nota, ya que a partir de las combinaciones de colores que esta permita, se asignarán las demás notas. Diferentes autores podrán establecer diferentes funciones "tonales" de acuerdo a sus necesidades musicales, el criterio que será usado en esta propuesta para el establecimiento de una tonalidad, será únicamente el de la repetición. La nota establecida como "Tónica sinestésica", será la nota más repetida. 
Capítulo V. Propuesta personal y ejemplos.

Escalas de Color.

Blan

Nar

Ama

Roj/Azu/Ama

Ver/Caf

Ver-Obsc-Clar

Roj

Ver

Roj/Ros

Nar

Ama

Roj/Azu/Ama

Ver/Caf

Roj

Ver

Roj/Ros

Blan
Do

Do sostenido

$\operatorname{Re}$

Mi

$\mathrm{Fa}$

Fa sostenido

Sol

La

$\mathrm{Si}$

Do sostenido

$\operatorname{Re}$

Mi

$\mathrm{Fa}$

Sol

$\mathrm{La}$

$\mathrm{Si}$

Do 


$\begin{array}{ll}\text { Ama } & \text { Re } \\ \text { Roj/Azu/Ama } & \mathrm{Mi} \\ \text { Ver-Obsc-Clar } & \text { Fa sostenido } \\ \text { Roj } & \text { Sol } \\ \text { Vio/Azu/Mag } & \text { La Bemol } \\ \text { Ver } & \text { La } \\ \text { Mor-Obsc } & \text { Si Bemol } \\ \text { Roj/Ros } & \text { Si } \\ \text { Blan } & \text { Do }\end{array}$

Gri Re sostenido

Roj/Azu/Ama

Mi

Ver/Caf

$\mathrm{Fa}$

Ver-Obsc-Clar

Fa sostenido

Roj

Sol

Ver

La

Roj/Ros

$\mathrm{Si}$

Blan

Do

Nar

Do sostenido 


\begin{tabular}{ll} 
Roj/Azu/Ama & Mi \\
Ver-Obsc-Clar & Fa sostenido \\
Roj & Sol \\
Ver & La \\
Mor-Obsc & Si Bemol \\
Roj/Ros & Si \\
Blan & Do \\
Ama & Re \\
& \\
Ver/Caf & Fa \\
Ver-Obsc-Clar & Fa sostenido \\
Roj & Sol \\
Ver & La \\
Mor-Obsc & Si Bemol \\
Roj/Ros & Si \\
Blan & Do \\
Ama & Mi \\
Roj/Azu/Ama & \\
\hline
\end{tabular}


Capítulo V. Propuesta personal y ejemplos.

Ver-Obsc-Clar

Roj

Ver

Roj/Ros

Blan

Nar

Ama

Roj/Azu/Ama

Roj

Ver

Mor-Obsc

Roj/Ros

Blan

Nar

Ama

Roj/Azu/Ama

Ver/Caf
Fa sostenido

Sol

La

$\mathrm{Si}$

Do

Do sostenido

$\operatorname{Re}$

Mi

Sol

La

Si Bemol

$\mathrm{Si}$

Do

Do sostenido

$\operatorname{Re}$

Mi

$\mathrm{Fa}$ 
Capítulo V. Propuesta personal y ejemplos.

$\begin{array}{ll}\text { Vio/Azu/Mag } & \text { La Bemol } \\ \text { Ver } & \text { La } \\ \text { Mor-Obsc } & \text { Si Bemol } \\ \text { Roj/Ros } & \text { Si } \\ \text { Blan } & \text { Do } \\ \text { Ama } & \text { Re } \\ \text { Gri } & \text { Re sostenido } \\ \text { Roj/Azu/Ama } & \text { Mi } \\ \text { Ver-Obsc-Clar } & \text { Fa sostenido } \\ \text { Ver } & \text { La } \\ \text { Mor-Obsc } & \text { Si Bemol } \\ \text { Roj/Ros } & \text { Si } \\ \text { Blan } & \text { Do } \\ \text { Ama } & \text { Re } \\ \text { Roj/Azu/Ama } & \text { Mi } \\ \text { Ver-Obsc-Clar } & \text { Fol sostenido } \\ \text { Roj } & \end{array}$


Mor-Obsc

Roj/Ros

Nar

Gri

Roj/Azu/Ama

Ver-Obsc-Clar

Roj

Ver

Roj/Ros

Blan

Ama

Roj/Azu/Ama

Ver/Caf

Ver-Obsc-Clar

Roj

Ver

Mor-Obsc
Si Bemol

$\mathrm{Si}$

Do sostenido

Re sostenido

Mi

Fa sostenido

Sol

La

$\mathrm{Si}$

Do

$\operatorname{Re}$

Mi

$\mathrm{Fa}$

Fa sostenido

Sol

$\mathrm{La}$

Si Bemol 


\section{Capítulo V. Propuesta personal y ejemplos.}

\subsection{Trabajo creativo personal.}

Para ilustrar el uso de la herramienta denominada "escala cromática audiovisual", y su uso para el establecimiento de una "Tonalidad Sinestésica" se trabajará en dos vertientes: La traducción directa de música académica a colores, y la creación de música nueva con criterios de combinación del color.

Una de las configuraciones propuestas para la traducción de la música a un fenómeno espacial, es el uso de la partitura a manera de "plantilla", aprovechando de esta manera algunos de los elementos que le son propios a un documento musical escrito; la localización geográfica del símbolo indicativo de una afinación, está en relación directa con la altura espacial escrita, y la temporalidad de una nota, está indicada no solo por medio de diferentes símbolos que indican el ritmo o duración temporal del fenómeno sonoro, además, la temporalidad de una nota, está indicada por su localización geográfica en la partitura; en imitación a la escritura occidental, suenan primero las notas que están escritas a la izquierda, y la lectura va de izquierda a derecha, en el caso de la música es bastante similar, con el añadido que sonidos que son ejecutados de manera simultánea, son escritos uno arriba del otro. A grandes rasgos, un documento musical escrito puede ser expresado, por medio de un plano cartesiano bidimensional.

Como mencionábamos, se utilizará en principio la partitura a manera de plantilla, y se colocará el primer símbolo pictórico 


\section{Capítulo V. Propuesta personal y ejemplos.}

considerado por Kandinsky, como la "mínima forma temporal”, el punto $^{174}$, en las localizaciones geográficas indicadas por el documento musical escrito; este "punto de color musical" permanecerá con su forma esférica en las notas de menor temporalidad de la pieza a ser traducida, cuando el gesto musical en cuestión posea un contenido temporal mayor, el punto se alargará para formar una "línea de color musical". Con los recursos anteriormente descritos, podemos expresar tanto la afinación musical por medio del color, como la temporalidad escrita en la música, por medio del símbolo pictórico y su localización geográfica, tal y como son expresados dentro de una partitura.

Ofrecemos tres ejemplos de traducciones de música al color, utilizando la escala cromática audiovisual como herramienta de traducción, por las características temporales de la música, consideramos como la visualización ideal, la realizada a través del recurso de la animación; cada uno de los ejemplos ofrecidos a continuación será presentado en tres configuraciones. La primera configuración nos permitirá visualizar el documento musical escrito, y por arriba de los símbolos musicales, serán “coloreados” los símbolos pictóricos, como fue anteriormente mencionado, el color indicará la afinación escrita, y la combinación del punto y la línea junto con la localización geográfica del símbolo pictórico, poseerán la carga significativa de la temporalidad musical.

174 KANDINSKY, W.W. Punto y línea sobre el plano. Argentina: Andrómeda, 1998, p. 40. 


\section{Capítulo V. Propuesta personal y ejemplos.}

La segunda configuración de las traducciones de la música a color, utilizará las mismas herramientas creativas utilizadas bajo los mismos criterios, la única diferencia consistirá en el abandono de la partitura en la visualización final; el documento musical escrito no será percibido por el público final, con esto, se buscará crear una mayor sensación de interacción entre la música y el color; de este modo, la sensación de ser la música "escuchada" la que realiza los símbolos pictóricos es acrecentada para la audiencia, equilibrando además, el uso de elementos pertenecientes a la música y a la pintura, la música será escuchada y el color será visto, sin la aparente “contaminación visual” del documento musical escrito.

La última configuración para estas traducciones de la música al color, consistirá en plasmar el elemento temporal en el espacial, ofrecer la música como una imagen fija, se utilizarán las mismas herramientas y los mismos criterios de uso de las mismas para la realización de la imagen fija. Con esta última configuración realizamos además de la traducción de la música al color, el cambio de la naturaleza del elemento en cuestión; la música como elemento temporal, presentada como un elemento espacial, el cual contiene en su carga significativa, todos los elementos que son característicos de la música.

La tercera configuración de las traducciones música-color será presentada en el cuerpo de este trabajo, las animaciones (primera y segunda configuración), serán presentadas en formato de video lineal en el "Disco de Video Digital" (DVD) anexo a esta investigación. 


\section{Capítulo V. Propuesta personal y ejemplos.}

Los autores y obras seleccionados en los tres ejemplos a presentar, son representativos de diferentes épocas de la historia de la música occidental, hemos procurado además, que las piezas seleccionadas sean representativas del autor, en el sentido de que sean piezas que el público en general sea capaz de identificar con el compositor seleccionado. Utilizaremos los siguientes autores: Johan Sebastian Bach (1685-1750), con el "Minueto en Sol" encontrado en el libro de Anna Magdalena Bach; ${ }^{175}$ Claude Debussy (1862-1918), con la pieza para flauta sola "Syrinx"; y Arnold Schoenberg (18741951), con su miniatura para piano solo opus 19 número 6.

Como primer ejemplo, de J.S. Bach, "Minueto en Sol” (1725), documento extraído del cuaderno de Anna Magdalena Bach.

175 Existe una disputa sobre la autoría del trabajo, sin embargo, la pieza es universalmente referenciada como de J.S. Bach. 

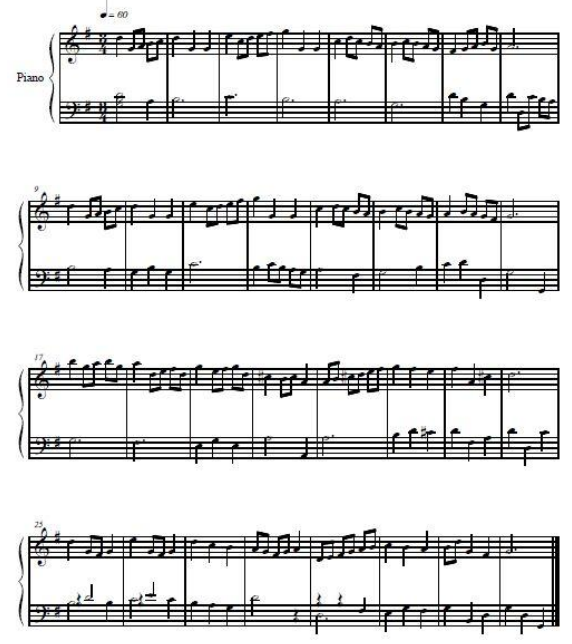

Figura 80. J.S.

Bach,"Minueto en Sol" para instrumento de teclado.

(Tipografiada por Fco. Javier González Compeán).

La misma partitura, en su traducción a colores por medio de la “correspondencia sinestésica":

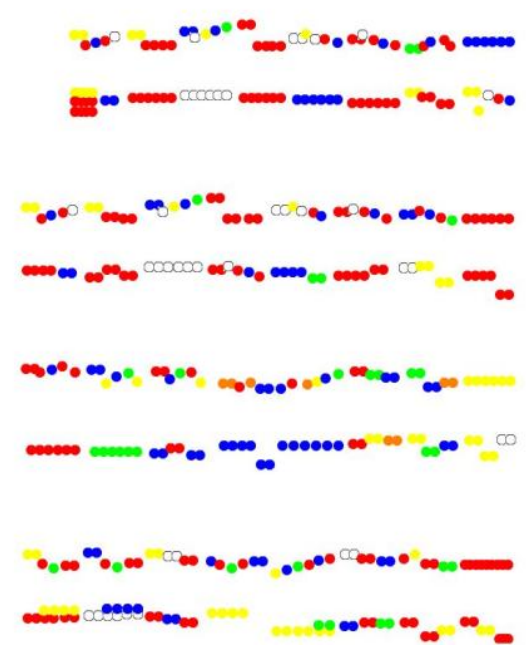

Figura

Traducción a colores

del "Minueto en

Sol" de J.S. Bach.

(Imagen realizada

por Fco. Javier

González Compeán). 


\section{Capítulo V. Propuesta personal y ejemplos.}

De Claude Debussy, su pieza para flauta sola "Syrinx" (1913), la partitura:
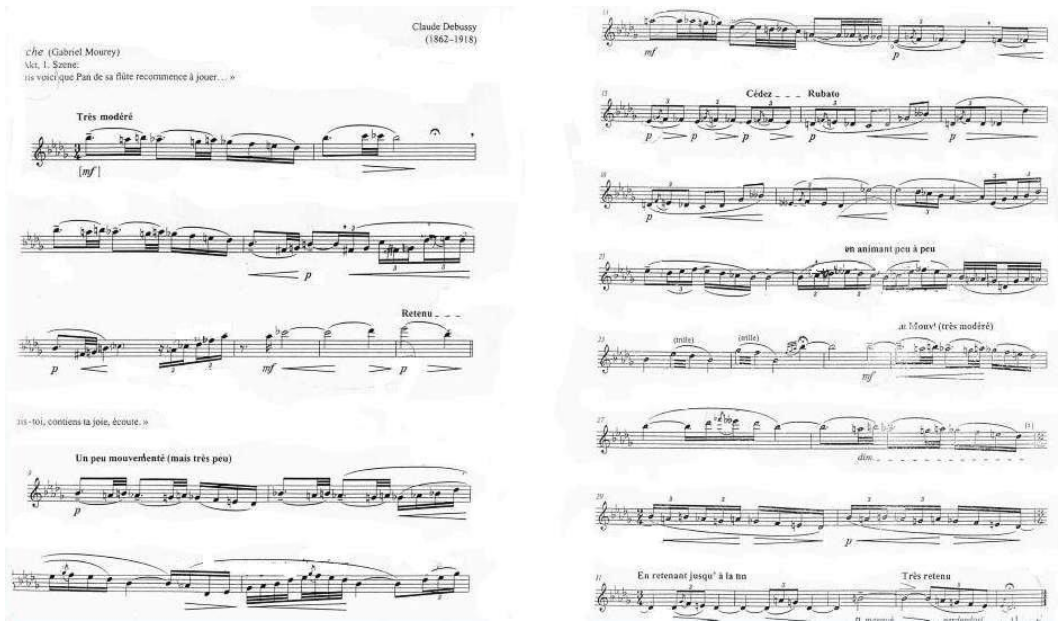

Figura 82. C.A. Debussy, "Syrinx" para flauta sola. (Tipografiada por Fco. Javier González Compeán).

Su correspondencia de colores:

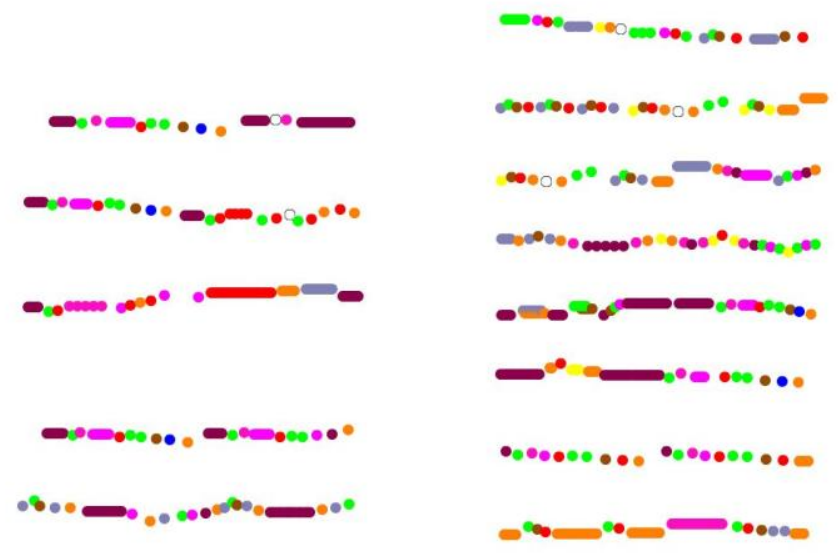

Figura 83. Traducción a colores de "Syrinx" de C.A. Debussy.

(Imagen realizada por Fco. Javier González Compeán). 


\section{Capítulo V. Propuesta personal y ejemplos.}

De Arnold Schoenberg, su pieza denominada como "Atonal" pequeña pieza opus 19 número 6 :
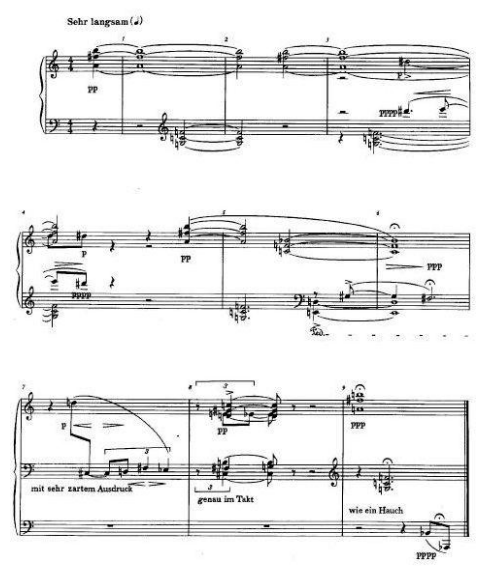

Figura 84. A. Schoenberg, “op. 19 no. 6” para piano solo.

(Schoenberg, Arnold: Sechs Kleine Klavier Stücke op.19. Viena: Ed. Universal, 1913).

La traducción:

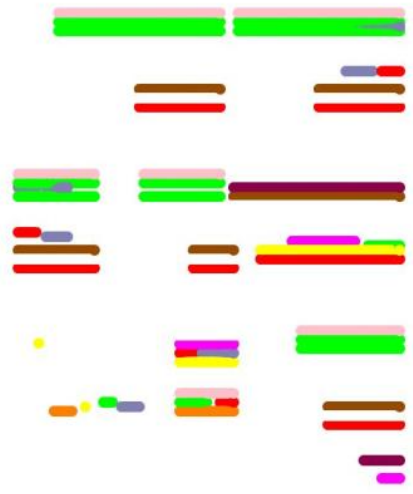

Figura 85. Traducción a colores del "op. 19 no. 6" de A. Schoenberg. (Imagen realizada por Fco. Javier González Compeán). 


\section{Capítulo V. Propuesta personal y ejemplos.}

La segunda vertiente práctica de esta investigación es la creación de música nueva, la cual tenga su punto de partida la “armonía de colores" como es conceptualizada por las artes visuales, con lo cual, esperamos obtener nuevas relaciones entre afinaciones musicales, y un nuevo manejo de la tonalidad en la música, por medio de la interacción del concepto del tono utilizado en un medio diferente de donde es aplicado.

Como primera prueba de la herramienta de "Tonalidad Sinestésica" para la composicion musical, realizaremos una “Miniatura de Colores en Gris-Azul” para piano solo; los acordes y escalas a ser utilizados para la composicion de esta miniatura para piano, serán determinados por nuestra "escala cromática audiovisual" y algunos de los "acordes de colores" construidos anteriormente. Utilizaremos únicamente dos "acordes de tres colores", para la realización de esta miniatura:

1. Gris - Re sostenido (Mi bemol por enarmonización).

Rojo/Azul/Amarillo - Mi.

Morado-Obscuro - Si bemol.

2. Gris - Re sostenido.

Violeta/Azul/Magenta - La bemol.

La - Verde. 


\section{Capítulo V. Propuesta personal y ejemplos.}

La elección de los acordes provee de facto la tonalidad resultante en este primer trabajo compositivo realizado por medio de la "Tonalidad Sinestésica"; hemos utilizado el color gris como punto en común con la armonía musical y de color para la pieza, mientras que para establecer un contraste en la sección central de la pieza, el segundo acorde posee el color verde. El contraste resultante del uso del segundo "acorde de color", contribuirá a la buena construcción formal de la miniatura; utilizaremos un molde formal académico, una forma "Tripartita" o en tres partes, siendo las partes del inicio y del final similares, y la sección central contrastante.

El color predominante en esta pieza es el "Gris - Re sostenido", por lo cual, utilizaremos el sonido en cuestión para las notas generadoras de la armonía, ubicándolas preferentemente en la región grave del piano; además, nos encontramos con dos "trinomios" de correspondencia color-música, la nota "Mi-Rojo/Azul/Amarillo" y la nota "La bemol-Violeta/Azul/Magenta", en ambos casos, utilizaremos el color azul, que se encuentra presente en ambas correspondencias sinestésicas, esto nos proveerá con un nexo en la armonía de color, y un punto de cohesión en la forma musical; como consecuencia de la elección de colores, los dos colores predominantes serán el gris y el azul, lo cual nos lleva denominar esta pieza como escrita en una tonalidad "Gris-Azul”. 


\section{Capítulo V. Propuesta personal y ejemplos.}

La partitura "En Gris Azul”:
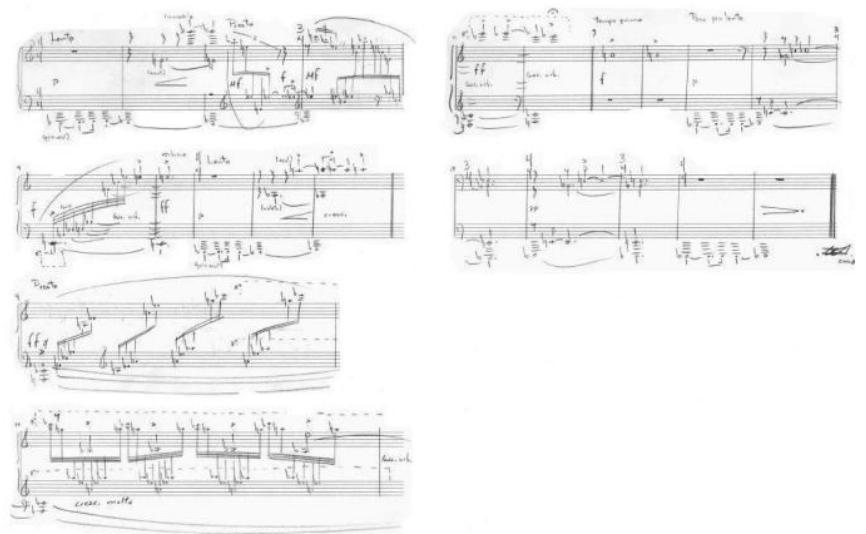

Figura 86. F. Javier G. Compeán "En gris azul" para piano solo. (Manuscrito por el compositor).

Su Imagen en Colores:

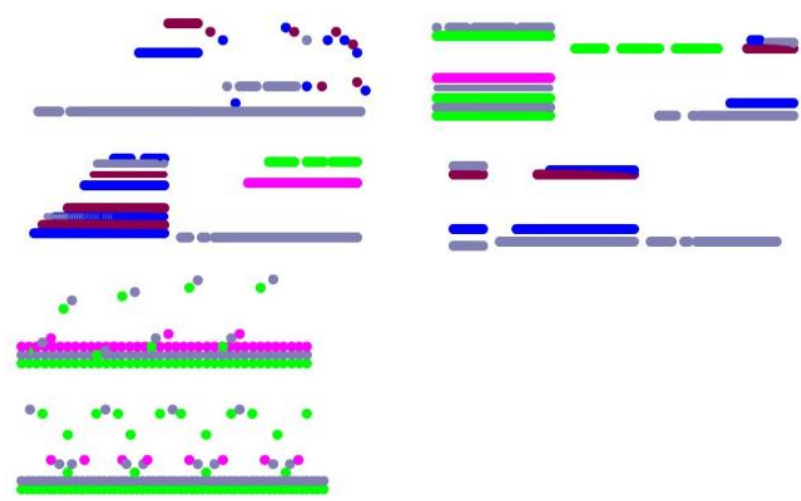

Figura 87. Traducción a colores de "En gris azul" de F. Javier G. Compeán. (Imagen realizada por Fco. Javier González Compeán). 


\section{Capítulo V. Propuesta personal y ejemplos.}

Una vez probada la efectividad de la "Tonalidad Sinestésica" en la traducción de piezas musicales al color, así como en la composicion de música nueva en pequeño formato; probaremos la herramienta en la construcción de una pieza de gran formato, con su posterior estreno en escena para el público.

Para la composición de esta pieza de gran formato, utilizaremos instrumentos de teclado, que nos permiten una alta precisión en el "ataque" de la ejecución musical; realizaremos un "Trío" para Marimba y dos Vibráfonos, lo cual nos añade la ventaja de probar la "Tonalidad Sinestésica" en la composición de música de cámara.

La puesta en escena de una pieza musical, que interactúe con imágenes que deben ser sincronizadas, tiene dificultades particulares; los músicos son un elemento humano, y en el estreno de una pieza musical en escena pública, se encuentran concentrados en el instrumento y el documento musical escrito, usualmente no tienen la posibilidad de visualizar la animación o imágenes proyectadas, al mismo tiempo que realizan una ejecución de música de cámara, ${ }^{176}$ por consiguiente, para la buena realización del estreno público del "Trío" en cuestión, no será utilizado el recurso de la animación previamente realizada.

\footnotetext{
${ }^{176}$ Dificultad particular de la música del contexto camerístico, existen numerosos ejemplos de coordinación audiovisual en la música orquestal, y en particular en la Ópera.
} 


\section{Capítulo V. Propuesta personal y ejemplos.}

Para la correcta coordinación de la música con los colores de la "Correspondencia Sinestésica”, utilizaremos los recursos de la iluminación en vivo, así como la proyección de los colores en pantalla por medio del recurso del " $V j$ " ("videojockey").

Al utilizar el recurso del " $V j$ " nos referimos a un ejecutante extra musical; siendo este, el que, en un recurso que emana directamente del "órgano de colores", utiliza herramientas digitales para por medio de un ordenador proyectar en vivo y en el momento, las imágenes o videos deseados; en el caso del estreno del "Trío", se utilizarán predominantemente imágenes fijas con los colores correspondientes a cada nota ejecutada por los músicos.

En un contexto de música de cámara contemporánea, usualmente son más de dos notas las escuchadas simultáneamente, en particular en la obra en cuestión; lo que lleva a una nueva toma de criterios para la proyección de los colores de la "Correspondencia Sinestésica".

Para las notas "melódicas", utilizaremos la pantalla de proyección, las notas con función melódica, son usualmente las que el público percibe de forma directa, son las melodías las que son recordadas e incluso recreadas en el imaginario del público, razón por la cual, utilizaremos el medio de visualización más directo, el color en la pantalla, "moviéndose" junto con la melodía.

Para las notas de función armónica, así como para establecer diferencias de contraste en la forma musical y contrastes en la 


\section{Capítulo V. Propuesta personal y ejemplos.}

"dinámica" o diferencias contrastantes en el número de decibeles escuchado, utilizaremos la iluminación en vivo, con lo cual, podremos "inundar" al público con la sensación del color en la obra musical.

La presentación escénica del "Trío" para marimba y dos Vibráfonos, tiene una referencia directa a obras históricas del arte sinestésico como la obra sinfónica "Prometeo" de Scriabine, o el uso del órgano de colores en diferentes configuraciones históricas; las herramientas actuales del manejo lumínico en escena realizado en tiempo real, así como la proyección de imágenes por medios digitales, permiten crear la metáfora de una correspondencia de índole sinestésica entre la música y el color de una manera efectiva, y con relativa facilidad de ejecución.

Realizando una comparativa sobre el manejo "tonal" de las piezas realizadas por medio de la "Correspondencia Sinestésica" y la música "académica", las funciones armónicas no pueden ser expresadas de la manera convencional, con relaciones armónicas de "dominante - tónica", ya que estas relaciones entre acordes musicales, utilizan recursos que tienen que ver de forma directa con la estructura interválica de los acordes en cuestión, además, de utilizar la estructura melódica de la escala musical clásica. El manejo tonal de las piezas realizadas como música nueva, por medio de las relaciones de la armonía de colores aplicada en la música, será puesta en evidencia por el recurso de la repetición, la nota o notas musicales que quieran ser utilizadas con una función jerárquica de mayor importancia serán presentadas con un intervalo de repetición más corto, que al ser 


\section{Capítulo V. Propuesta personal y ejemplos.}

acompañado del color, tendrá como subproducto el hecho de que el color asignado sea repetido con mayor insistencia para la audiencia, creándose así, el efecto de una verdadera "Tonalidad Sinestésica", ya que la sensación de color que sea más repetida será de forma implícita la frecuencia lumínica preponderante, el tono de color y música de la pieza.
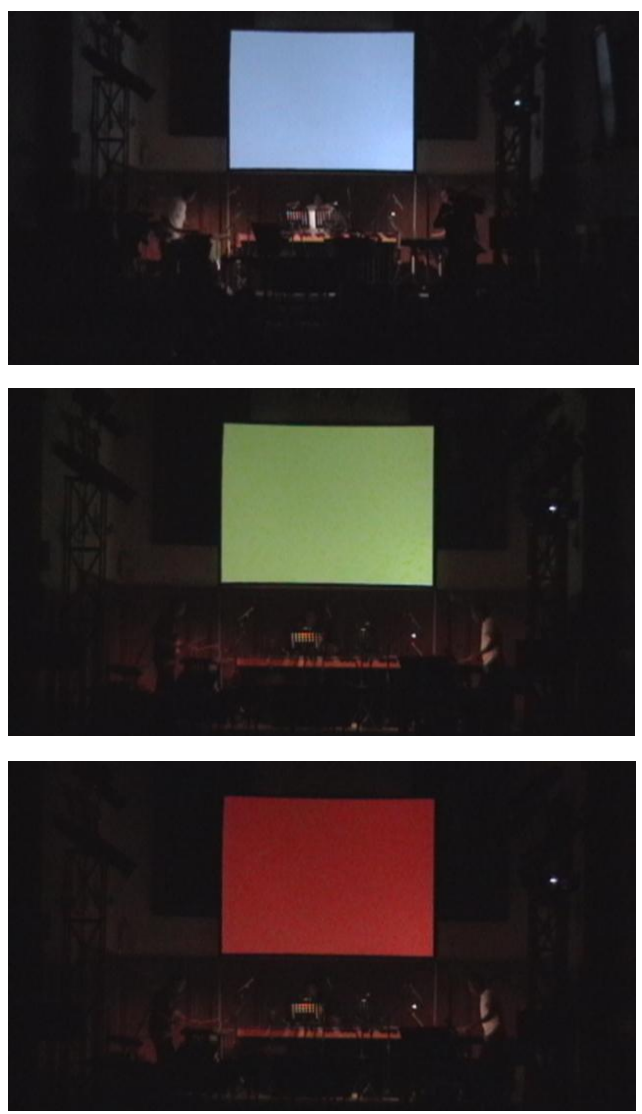

Figuras 88, 89, 90. Presentación en vivo del "Trío" música de colores de F. Javier G. Compeán, Festival Internacional Cervantino 2010, "Ensamble Tumkul", “Colores en vivo" por el autor. Ciudad de Guanajuato-México. 


\section{Conclusiones.}

Es posible por medio de una revisión de la historia del arte occidental y oriental, que las propuestas artísticas realizadas con la premisa de conseguir una unión entre los medios pictórico y musical han sido numerosas, puede incluso afirmarse que la idea de un arte "global", en el sentido de la unión de estímulos de diferente índole, existe anteriormente a la idea de la especialización de las disciplinas artísticas; una parte considerable del "arte sinestésico", nace de la especulación sobre la naturaleza de los estímulos recibidos por el ser humano, así como de la subjetividad del creador en lo particular.

La mayor parte de las propuestas artísticas que han ocupado la idea de correspondencias entre la luz y el sonido, obtienen un tercer elemento nacido de la unión de los anteriores, la interacción creada de la correspondencia entre diferentes estímulos. En el caso de la “Tonalidad Sinestésica", la interacción resultante se hace presente por medio de un color específico asignado a cada nota, e incluso, en algunas de las configuraciones de la obra personal, por el sitio geográfico en que es colocado el color, el cual corresponde a la localización de la nota musical escrita; al realizar las traducciones de música a color, se obtiene de forma atemporal el manejo tonal del estilo musical de la pieza en cuestión, con lo que se se consigue una herramienta pedagógica de ayuda al análisis musical, cuando la música queda en evidencia de forma visual, mostrando las afinaciones 


\section{Conclusiones}

y proporciones de la obra en un plano menos efímero, que contribuye a la permanencia en la memoria del que visualiza la traducción.

La "Tonalidad Sinestésica" ha demostrado además, su utilidad como herramienta creativa, al momento de escribir "Música de Colores", y como música, está basada en las relaciones propias de la armonía de colores y los criterios académicos de combinación y contraste, como son utilizados en el área de las artes visuales. El manejo tonal-musical que impone este criterio ha resultado novedoso, permitiendo la creación de escalas y acordes sui-generis, con los que se puede crear música en diferentes formatos temporales y de instrumentación, como quedó demostrado en la parte de experimentación práctica mediante la composición de música en forma miniatura para piano solo, y una pieza de gran formato para instrumentos de percusión.

Existe además, una relación intrínseca entre el "arte sinestésico" y la tecnología: Representantes históricos del manejo de correspondencias entre luz y sonido se enfrentaron de forma constante a la dificultad de tener que crear la tecnología que les permitiera unir los medios lumínico y sonoro; casos representativos de esta dificultad, los encontramos desde la creación de los primeros órganos de colores, algunos de los cuales no pudieron ser concretados, hasta las presentaciones de "Prometeo" de Scriabine, en las cuales, se tuvieron que invertir una cantidad considerable de recursos para poder aproximarse a los requerimientos dados por el compositor. Actualmente, la dificultad tecnológica ha quedado superada, cuando el 


\section{Conclusiones}

propósito es únicamente la unión de diferentes estímulos perceptivos, mediante recursos como la animación digital y el " $V j$ ” es posible obtener con relativa facilidad, la visualización de una correspondencia entre los medios lumínico y sonoro. $\mathrm{Si}$ a esto se añaden las posibilidades actuales de iluminación escénica, con consolas de iluminación programable, el obtener la sensación de una correspondencia entre luz y sonido en el público, es ahora posible, con una relativa economía de recursos.

En la parte teórica de la investigación se ha establecido la realidad y objetividad del fenómeno sinestésico en el humano, por medio de la experimentación conductual y la tecnología de imagenología cerebral, es posible establecer que en ciertos individuos, se activan regiones cerebrales especializadas que provocan diferentes sensaciones perceptivas, ante un solo estímulo de índole especializada.

Es posible extraer patrones creativos del fenómeno de la sinestesia. La investigación en las áreas de la Psicología y Neurología, actualmente cuenta con un censo de sinestetas y tipos de sinestesia, que permite la obtención de patrones de correspondencias, de los cuales es posible extraer herramientas que han demostrado su utilidad para la creación artística. El censo sobre tipos de sinestesia, y las relaciones particulares y subjetivas que cada individuo alega "ver", aún se encuentra en proceso por investigadores como Sean Day, Cytowic, Sacks, entre otros, y coinciden en que es un censo aún incompleto, ya que la condición sinestésica, usualmente no llama la atención del médico, no es una enfermedad que lleve al paciente a un 


\section{Conclusiones}

consultorio, o un impedimento que dificulte la vida en sociedad; es una característica más, que forma parte de la personalidad de ciertos individuos.

Incompleto a nuestros días, el censo sobre la sinestesia, sin embargo, se remonta al siglo XIX, y numerosos investigadores han recopilado además, las correspondencias particulares de los diferentes sinestetas, la información provista por estas investigaciones, ha sido suficiente para poder obtener una tabla de correspondencias que nos ha permitido establecer el concepto de "Tonalidad Sinestésica", por medio de la extracción de patrones creativos de la condición, y ha sido posible obtener traducciones de la música al color, y componer música con criterios colorísticos con las correspondencias extraídas del fenómeno sinestésico. Todo lo anterior, ha confirmado nuestra hipótesis.

La extracción de patrones creativos de la sinestesia, no solo ha servido de herramienta creativa, además ha demostrado su utilidad en el campo de la pedagogía, al crear relaciones alrededor de un concepto, se ha contribuido a reforzar la memoria, así como al análisis musical, y a la permanencia en la memoria del público, el cual, no solo "escucha" la obra musical, sino que además la "ve".

En los capítulos sobre la tonalidad en la música, y la tonalidad en la pintura, se ha podido constatar que existen numerosas similitudes en los conceptos y formas de trabajo en ambos campos, en los dos medios, se hace necesario de forma implícita el 


\section{Conclusiones}

establecimiento de relaciones armónicas y de contraste, que en numerosos ejemplos, son de índole de proporción interválica. También resulta implícito en ambos campos, que la "Tonalidad" es un concepto presente, ya sea por la definición o confirmación del mismo, o por la ausencia de él. En el caso de música "atonal" o pintura que esté regida por relaciones lumínicas de contraste más que de armonía, se han realizado esfuerzos por violentar el concepto de tonalidad, estos esfuerzos crean el concepto en "negativo", por la deconstrucción del concepto de tonalidad, este se hace presente por su ausencia.

Al incorporar el fenómeno de la sinestesia en el arte, se le añade un elemento humano, un punto de comunicación con el público, las correspondencias entre colores y música no nacen de una especulación científica sobre la naturaleza de fenómenos físicos o de índole mística, como en el caso del arte hindú, nace de un fenómeno de percepción humana, una condición perceptiva, la cual es compartida por un porcentaje relativamente significativo de la población humana; si bien, es cierto que las correspondencias de los sinestetas son altamente individuales y subjetivas, la objetividad del fenómeno ha sido establecida por la Neurología, y el censo existente actualmente sobre las correspondencias sinestésicas, permiten obtener una tabla de correspondencias, que pueda considerarse como representativa de las visiones sinestésicas establecidas por más de dos sinestetas.

Mediante la extracción de patrones creativos de la sinestesia, y el establecimiento de un concepto conocido como "Tonalidad 


\section{Conclusiones}

Sinestésica", hemos ensanchado nuestro lenguaje artístico, al incorporar elementos pertenecientes a disciplinas extra-musicales. Se han creado interacciones nuevas, ya que los colores establecidos como correspondientes a las notas musicales, no pertenecen a la subjetividad del artista, ni como en numerosos casos, al círculo de colores de Newton, o a los colores del arcoíris o la naturaleza; se han establecido nuevos canales de comunicación con el público, que permite la transmisión de nuevas ideas y emociones. 


\section{Bibliografía.}

ABNEY, W.W. Colour Vision. New York: William Wood \& Company, 1895.

ACHA, Juan.; Carlos Blas Galindo (pról.) Crítica del Arte: Teoría y Práctica. México D.F.: Trillas, 1997.

ADOBE. "Color Systems Technical Guides" [en línea]. Disponible en: http://dba.med.sc.edu/price/irf/Adobe_tg/models/ciexyz.html [Consulta: 31 Diciembre 2010].

ALBET, Montserrat. Música contemporánea. Barcelona: Salvat, 1973.

ALCOVER ALCODORI, Fco. Y LAFUENTE AVEDILLO, Rafael. La música y los instrumentos desde el barroco hasta el siglo XX.

Valencia: UMA Editores, 2011.

ALDWELL, Edward; y Carl SCHACHTER. Harmony \& Voice Leading. 3a ed. New York: Schirmer, 2004.

ALLEN, Grant. The Colour-Sense. London: Trübner \& Co., 1879.

AMERICAN PUBLIC MEDIA. "Performance Today: Synesthesia" [en línea]. Disponible en:

http://performancetoday.publicradio.org/features/2009/02/synesthesia/ [Consulta: 31 Diciembre 2010].

ARCHER-HIND, R.D. The Timaeus of Plato. London: McMillan \& Co., 1888.

ARIAS, M.J.R. (text.). Los movimientos pop. Barcelona: Salvat, 1973.

ARISTOTELES; Francisco de P. Samaranch (trad. y prol.). De lo Sentido y lo Sensible; De la Memoria y el Recuerdo. $2^{\mathrm{a}}$ ed. Buenos Aires: Aguilar, 1966. 
ARIZA, Javier. Las imágenes del sonido. Cuenca: Ediciones de la Universidad de Castilla-La Mancha. 2003.

ARNALDO, Javier (comis.). Analogías musicales. Kandinsky y sus contemporáneos. [Catálogo]. Madrid: Fundación Colección Museo Thyssen-Bornemisza, 2003.

ISBN 8488474954

ASCOTT, Roy. Art, Technology, Consciousness: mind@large. London: Intellect Books, 2000.

BACON, J. The Theory of colouring. 3a ed. rev. and enlarg. London: Geo. Rowney \& Co., 1872.

BAILEY, T. "Amy Beach and Me" [en línea]. Disponible en: http://www.amybeachandme.com/AmyBeach_Synesthesia_Page05.ht ml [Consulta: 31 Diciembre 2010].

BALDWIN, J. M. Senses and Intellect. New York: Henry Holt and Company, 1890.

BARANY-SCHLAUCH, E. Alexander Scriabin's Ten Piano Sonatas, their Philosophical Meaning and their Musical Expression. [Doctoral Document]. Ohio State University, 1985.

BARBA, R.R. "Un Extraño Fenómeno Perceptivo: La Sinestesia." Revista Internacional de los Estudios Vascos, Tomo 36, 1991, núm. 1, pp. 11-21.

BASBAUM S.R. Sinestesia arte e tecnología: fundamentos da cromossomia. Sao Paulo: Annablume, 2002. (Semiótica).

BASHÓ M. “Haiku.” [en línea]. Disponible en:

http://home.comcast.net/ sean.day/html/pseudo-syn_authors.html [Consulta: 31 Diciembre 2010].

BASSET, A.B. An ElementaryTreatise on: Hydrodynamics and Sound. London: Ed. George Bell \& Sons, 1890. 
BEETHOVEN, L.V. Sonaten III. Budapest: Könemann Music, 1994.

BEETHOVEN, L.V. Ludwig van Beethoven's Werke, Serie I, Symphonien no 5. Leipzig: Breitkopf \& Härtel, 1862.

BERNSTEIN, J. The Five Senses of Man. New York: Appleton and Company, 1876.

BIANCHI, L.; James H. McDonald (trad.); C. Lloyd Morgan (pról.). The Mechanism of the Brain and the function of the Frontal Lobes. Edinburgh: E. \& S. Livingstone, 1922.

BISHOP, B. A souvenir of the color organ, with some suggestions in regard to the soul of the rainbow and the Harmony of light. New York: The De Vinne Press, 1893.

BOCHENSKY, I.M.; Eugenio Ímaz (trad.). La Filosofía Actual. $2^{\mathrm{a}}$ ed. México D.F.: Fondo de Cultura Económica, 1983.

ISBN 968-16-0245-5

BUTLER, Samuel.; Marcus Hartog (pról.). Unconscious Memory. $2^{\mathrm{a}}$ ed. London: A.C. Fifield, 1910.

CABRAL DE MELO NETO, Joao.; Hugo Gola (dir.); Víctor Sosa (trad.). Poesía y composición y otros ensayos sobre arte y literatura. México D.F.: Universidad Iberoamericana, 1999. (Colección Poesía y Poética).

CALABRESE, O.; Umberto Eco (dir.); Rosa Premat (trad.); Lorenzo Vilches (superv.). El lenguaje del arte. Barcelona: Paidós, 1997. (Instrumentos Paidós; 1).

CALERO, P. G. La música del color y el color del sonido. Málaga: Maestro, 2006.

CAMPEN, V.C. Artistic and Psychological Experiments with Synesthesia. Leonardo, Vol. 32, 1999, núm. 1, pp. 9-14. 
CARLSON, F.C. Center for Imaging Science. Disponible en:

http://www.cis.rit.edu/ [Consulta: 31 Diciembre 2010].

CASELLA, Alfredo; y Virgilio Mortari.; A. Jurafsky (trad.); et al (consult.). La técnica de la Orquesta Contemporánea. Buenos Aires: Ricordi, 1950. (Manuales Musicales).

CASTEL, P. Esprit, Saillies et Singularitès. Amsterdam: Chez Vincent, 1763.

CENTER FOR VISUAL MUSIC. “Visual Music" Disponible en: http://www.centerforvisualmusic.org/

[Consulta: 31 Diciembre 2010].

CHANG, Chia-Lun. Five Preludes Opus 74 by Alexander Scriabin: The Mystic Chord as a Basis for new means of Harmonic Progression. [Treatise]. The University of Texas at Austin, 2006.

CHEVREUL, M.E. De la Loi du Contraste Simultané des Couleurs. Paris: Pitois-Levrault et C., 1889.

CHEVREUL, M.E. Leçons de Chimie appliquée a la Teinture. Paris: Pichon et Didier, 1830.

CHION, Michel.; Enrique Folch González (trad.). El Sonido Música, cine, literatura. Barcelona: Paidós, 1999. (Paidós Comunicación; 107).

CHURCH, A.H. Colour. 2a ed. rev. and enlarg. London: Cassell and Company Limited, 1897.

CLARE, I.S.; et al. Library of Universal History. Vol. 1: Ancient Oriental Nations. New York: R.S. Peale-J.A. Hill, 1897.

CLEMENTI, M. Six Sonatinas op. 36. New York: Schirmer, Inc., 1904.

Color Harmony. Massachusetts: Rockport, 2007 
Color Imaging Lab - Universidad de Granada. "Granada Daylight Spectral Database" [en línea]. Disponible en:

http://www.ugr.es/ colorimg/database.html

[Consulta: 31 Diciembre 2010].

CONTI, L. La entonación justa en la acústica de Helmholtz.

Perspectiva Interdisciplinaria de Música, vol. 1, 2006, núm. 1.

CORNELL, J.H. A Primer of Modern Musical Tonality. 3a ed. rev. and improv. New York: Schirmer, 1904.

CORNING, J.L. Brain Exhaustion, with some preliminary considerations on Cerebral Dynamics. New York: Appleton and Company, 1884.

CORRÓNS, A.; et al. La Comisión Internacional de Iluminación (CIE). [Ensayo]. Departamento de Metrología del Instituto de Física Aplicada de Madrid, Departamento de Óptica de la Facultad de Ciencias de la Universidad de Granada, 2007.

COUSIN, Victor (trad.). Oeuvres de Platon. Paris: Pichon et Didier, 1831.

CROZIER, W.R.; y A.J. Chapman. Cognitive Processes in the Perception of Art. Amsterdam: Elsevier Science Publishers, 1984. (Advances in Psychology; 19).

ISBN 0444875018

CYTOWIC, R.E. "Cytowic - Punset" [en línea]. Disponible en: http://www.rtve.es/tve/b/redes2007/semanal/prg232/entrevista.htm [Consulta: 31 Diciembre 2010].

CYTOWIC, R.E. “Enciclopedia de Sinestesia” [en línea]. Disponible en:

http://cytowic.net/Synesthesia/Synesth_Encyclo_/synesth_encyclo_ .HTM [Consulta: 31 Diciembre 2010]. 
CYTOWIC, R.E.; Jonathan Cole (pról.). The Man who tasted shapes. New York: MIT P, 2003.

CYTOWIC, R.E. Synesthesia. A Union of the Senses. 2a ed. Massachusetts: MIT P, 2002.

CYTOWIC, R.E. Synesthesia: Phenomenology And Neuropsychology A Review Of Current Knowledge.

Psyche, Vol. 2, 1995, núm. 10.

CYTOWIC, R.E. The Clinician's Paradox. Journal of Counsciousness Studies, Vol. 10, 2003, núm. 9-10.

CYTOWIC R.E.; y David Eagleman.; Dmitri Nabokov (epí.). Wednesday is indigo blue, discovering the brain of synesthesia. Cambridge: MIT P, 2009.

DANTO, A. C.; Ángel y Aurora Mollá Román (trad.). La transfiguración del lugar común Una Filosofía del arte. Barcelona: Paidós, 2002. (Paidós Estética; 31).

DA VINCI, Leonardo.; Giusti, Ferrario et al (pról.); Carlo Amoretti (memorie storiche). Trattato della pittura. Milano: Società Tipografica de'Classici Italiani, 1804.

DARIAS, J. Homenaje a Paul Hindemith. En RUVIRA, Josep: Javier Darias. Obra de composición e investigación musical. Valencia: Generalitat Valenciana, 1990.

DAY, Sean A. "Breve historia de la Sinestesia y la música" [en línea]. Disponible en:

http://www.thereminvox.com/article/articleview/33/3/5/

[Consulta: 31 Diciembre 2010].

DAY S. Types of Synesthesia. [en línea]. Disponible en: http://home.comcast.net/ sean.day/html/types.htm [Consulta: 31 Diciembre 2010]

DEBUSSY, Claude A. Complete Preludes. New York: Dover, 1989. 
DeCAPRIO, T. “Super Symmetry” [en línea]. Disponible en: http://www.tonydecaprio.com/supersymmetry.htm [Consulta: 31 Diciembre 2010].

DE LA CHAMBRE, Marin C. Les Characteres des passions. Paris: P. Blaise, 1640.

DE LA CHAMBRE, Marin C. Nouvelles Observations et Coniectures sur l'iris. Paris: P. Blaise, 1650

DÉRIBÉRÉ, Maurice.; Adolfo A. de Alba (trad.). El Color. México D.F.: Diana, 1967. (Colección Moderna; 103).

DORFLES, Gillo; Roberto Fernández Balbuena; y Jorge Ferreiro (trad.). El devenir de las artes. $2^{\mathrm{a}}$ ed. corr. México D.F.: Fondo de Cultura Económica. 1993. (Breviarios).

ISBN 968-16-0927-1

DOWSE, Thomas S. The brain and Diseases of the Nervous System. Vol. 1: Syphilis of the brain and spinal cord, showing the part that this agent plays in the production of paralysis, epilepsy, insanity, headache, neuralgia, hysteria, hypochondriasis, and other mental and nervous derangements. London: Baillière, Tindall and Cox, 1881.

DRAYTON, H.S.; y James McNeill. Brain and Mind. New York: Wells \& Co., 1880.

DUPLAIX , Sophie (comis.).; Marcella Lista (comis. asoc.).

Sons \& Lumières Une histoire du son dans l'art du XXe siècle. [Catálogo]. Paris: Editions du Centre Pompidou, 2004.

EAGLEMAN D.M.; et al. "The synesthesia battery." [en línea]. Disponible en: http://www.synesthete.org/

[Consulta: 31 Diciembre 2010].

ECHO PRODUCTIONS. Virtual Colour Museum. [en línea]. http://www.colorsystem.com/

[Consulta: 31 Diciembre 2010] 
ECKER, Alexander; John C. Galton (trad. and pról.). On the Convolutions of the Human Brain. London: Smith, Elder \& Co., 1873.

EDRIDGE-GREEN, F.W. Colour-Blindness and Colour-Perception. London: Kegan Paul,Trench, Trübner \& Co., 1891.

El Tiempo. México D.F.: TIME-LIFE, 1976.

ELLIS, J.A.; On the Musical Scales of Various Nations. Edited by Kay Kaufman Shelemay. A Century of Ethnomusicological Thought. The Garland Library of Readings in Ethnomusicology: A Core Collection of Important Ethnomusicological Articles, Vol. 7, 2006.

EVANS, T.R. The Mysterium of Alexander Scriabine. [Doctoral Document]. Washington State University P., 2009.

EVERETT, J.D. Vibratory Motion and Sound. Boston: Ginn, Heath \& Co., 1882.

FISCHINGER TRUST. "Fischinger Biography". [en línea]. Disponible en: http://www.oskarfischinger.org/OFBioLong.htm [Consulta: 31 Diciembre 2010].

FISCHINGER O. "My statements are in my work" [en línea]. Disponible en: http://www.oskarfischinger.org [Consulta: 31 Diciembre 2010].

FISCHINGER O. “True creation.” [en línea]. Disponible en: http://www.oskarfischinger.org [Consulta: 31 Diciembre 2010].

FLOURNOY, T.H. Des phénomènes de synopsie (audition colorée). Paris: Félix Alcan, 1893.

FORKEL, J.N.; Adolfo Salazar (trad.). Juan Sebastián Bach. México D.F.: Fondo de Cultura Económica, 1998. (Breviarios). 
FRANSSEN, M. "The Ocular Harpsichord of Louis-Bertrand Castel. The Science and Aesthetics of an Eighteenth-Century Cause Célèbre." Universiteit van Amsterdam, Departamento de Filosofía, Tractrix 3, 1991, pp. 15-77.

FRANZ, I.; J. Mark Baldwin; y J. McKeen Cattell (eds.). Localization of brain function. New York: McMillan Co., 1901.

FRATICOLA, P.L. “Normalización del Color” [en línea]. http://www.imageandart.com/tutoriales/teoria/colores/color_03.htm [Consulta: 31 Diciembre 2010].

FUNDACIÓN ROSSINÉ. Wladimir Baranoff-Rossiné. [en línea]. http://www.baranoffrossine.com [Consulta: 31 Diciembre 2010].

GAGE, John. Color y Cultura. Madrid: Siruela, 1993.

GALTON, Francis. Inquiries into Human Faculty and its Development. London: McMillan \& Co., 1883.

GARCÍA, E.E. Scriabin's Mysterium and the Birth of Genius.

En: Mid-Winter Meeting of the American Psychoanalytic Association (New York, 19 January 2005). American Psychoanalytic Association, 2005 .

GAUTIER, F.F. (ed.). Oeuvres Complètes de Charles Baudelaire. Paris: Nouvelle Revue Française, 1918.

GOETSCHIUS, P. The Larger Forms of Musical Composition. New York. Schirmer Inc., 1915.

GOLDSTEIN, E. B.; Julio Lilo Jover (trad.). Sensación y Percepción. Madrid: Debate, 1993.

GOWERS, William R. Subjective Sensations of Sight and Sound. Philadelphia: Blakiston's Son \& Co., 1904.

GRANADOS, E. Danzas Españolas. Barcelona: Casa Dostesio, 1912. 
GROTE, George.; Alexander Bain; y Croom Robertson (eds.). Aristotle. London: John Murray, 1872. 2v.

GUBERN, Román (text.). Cine Contemporáneo. Barcelona: Salvat, 1973.

GUTIÉRREZ SACRISTÁN, J.L. “Aproximación Científica a los Sonidos Musicales” [en línea]. Disponible en:

http://www.lpi.tel.uva.es/ nacho/docencia/ing_ond_1/trabajos_02_03/ Sonido_musical/sonido_musical.htm

[Consulta: 31 Diciembre 2010].

HAROLD, R.W. An Introduction to Appearance Analysis.

Graphic Arts Technical Foundation, Second Sight núm. 84, 2001.

HARRISON, John.; Ramón de la Fuente (dir.); Irlanda Villegas (trad.); Héctor Pérez-Rincón (rev.). El Extraño Fenómeno de la Sinestesia. México D.F.: Fondo de Cultura Económica, 2004. (Biblioteca de Psicología, Psiquiatría y Psicoanálisis).

HAWKING, S. W.; Carl Sagan (intro.); Miguel Ortuño (trad.); Ron Miller (ilustr.). et al. Historia del Tiempo. Del Big Bang a los agujeros negros. México D.F.: Planeta-Agostini, 1992. (Obras Maestras del Pensamiento Contemporáneo; 1).

HEGEL, Georg W.F.; Alfredo Llanos (trad). Lecciones de Estética. México D.F.: Coyoacán, 2005. (Arte; 58).

HELMHOLTZ, Hermann.; Alexander J. Ellis (trad. and rev.). On the Sensations of Tone as a physiological basis for the Theory of Music.London: Longmans Green \& Co., 1895.

HERING, Ewald. Die Lehre vom Binocularen Sehen. Leipzig: Engelmann, 1868.

HERING, Ewald. On Memory, and the specific energies of the nervous system. Chicago: Open Court Publishing Company, 1897. 
HERING, Ewald. Zur Lehre vom Lichtsinne. Wien: Carl Gerold's Sohn, 1878.

HICKS, R.D. (trad. and intro.). Aristotle, De Anima. Cambridge: Cambridge U.P., 1907.

HERTZ Paul. "Synesthetic Art, an Imaginary Number?" [en línea]. Disponible en:

http://adrianwinter.co.uk/logbooks/303\%20Logbook/pdf/imagm.pdf [Consulta: 31 Diciembre 2010].

HIGGINS, D. "Synesthesia and Intersenses: Intermedia" [en línea]. Disponible en:

http://www.ubu.com/papers/higgins_intermedia.html

[Consulta: 31 Diciembre 2010].

HOCHEL, M. Sinestesia: Sentidos sin Fronteras.

[Tesis Doctoral Inédita]. Departamento de Psicología Experimental y Fisiología del Comportamiento, Universidad de Granada. 2008.

HOLLANDER, B.; Jul. Morel (pról.). The Mental Symptoms of Brain Disease. London: Rebman Limited, 1910.

HOUSTOUN, R.A. A Treatise on Light. New York: Longman's Green and Co, 1915.

HURVICH, L.M.; and Dorothea Jameson. "Perceived Color, Induction Effects, and Opponent-Response Mechanisms." [en línea]. Disponible en:

http://jgp.rupress.org Department of Phsycology, New York University, 1960. [Consulta: 30 Enero 2011].

HUTCHISON, N. "Colour Music” [en línea].

http://home.vicnet.net.au/ colmusic/welcome.htm

[Consulta: 31 Diciembre 2010].

INSTITUTO PROMETHEUS - KAZÁN. "Synesthesia" [en línea]. http://synesthesia.prometheus.kai.ru/index_e.html

[Consulta: 31 Diciembre 2010]. 
I.C.C. International Color Consortium [en línea].

http://www.color.org/index.xalter

[Consulta: 31 Diciembre 2010].

IRTEL, H.: “Color Systems” [en línea].

http://www.uni-mannheim.de/fakul/psycho/irtel/colsys.html

[Consulta: 31 Diciembre 2010].

JAUSS, H.R.; Daniel Innerarity (intro. y trad.); Manuel Cruz (dir.). Pequeña Apología de la experiencia estética. Barcelona: Paidós, 2002. (Pensamiento Contemporáneo; 67).

ISBN 84-1189-6

JOWETT, B. (trad. and intro.). The Dialogues of Plato. Oxford: Clarendon P., 1871. 4v.

KAHLER, Erich.; Jas Reuter (trad.). La desintegración de la forma en las artes. 5a ed. México D.F.: Siglo Veintiuno, 1993. (artes).

KANDINSKY, Wassily.; Philippe Sers (ed.); Suzanne et Jean Leppien (trad.). et al. Écrits Complets, La Forme. Paris: Denöel-Gonthier, 1970. (Grand Format Médiations).

KANDINSKY, Wassily.; Elisabeth Palma (trad.). De lo espiritual en el arte. 4a ed. México D.F.: Premià, 1981.

KANDINSKY, Wassily. Punto y línea sobre el plano. Barcelona: Paidos, 1998. (Paidós Estética; 25).

KEEFER C. "Raumlichtmusik” Early 20th Century Abstract Cinema Immersive Environments. [en línea]. Massachusetts: Leonardo Electronic Almanac. Disponible en:

http://www.oskarfischinger.org

[Consulta: 31 Diciembre 2010].

KELKEL, Manfred. Alexander Scriabine. Une musicien á la recherche de l'absolute. Paris: Fayard, 1999. 
KEMP, M. La Ciencia del Arte, La Óptica en el Arte Occidental, de Brunelleschi a Seurat. Madrid: Akal, 2000. (Arte y Estética).

KIVY, P. Music, language, and cognition: and other essays in the aesthetics of music. Oxford: Clarendon P, 2007.

KLEE, Paul.; Pedro Tanagra R. (trad.). Bases para la estructuración del arte. México D.F.: Coyoacán, 2004. (Arte; 36).

KÜPPERS, Harald.; Yves Zimmermann (dir.); Michael Faber-Kaiser (trad.); Joaquim Romaguera i Ramió (rev.). Color, Fundamentos de la teoría de los colores. Barcelona: Gustavo Gili, 1989. (GG Diseño).

KÜPPERS, Harald: Teoría del color de Küppers. [en línea]. http://www.uni-bielefeld.de/lili/kumu/farbenlehre-kueppers/ [Consulta: 31 Diciembre 2010].

LAFUENTE, H.: Microtonalismo y afinaciones alternativas. [en línea]. Disponible en: http://www.apocatastasis.com/microtonalismo-afinacionesalternativas.php\#axzz0kdwIsEat

[Consulta: 31 Diciembre 2010].

LAMB, Horace. The Dynamical Theory of Sound. London: Edward Arnold, 1910.

LAPP, Ralph E.; et al. Materia. México D.F.: TIME-LIFE, 1976.

LAURES, Henry.; Raymond Meunier (dir.). Les Synésthesies. Paris: Librairie Bloud et C., 1908. (Bibliothéque de Psychologie Expérimentale et de Métapsychie; 6).

LAYDEN, T.B. Aportaciones Teóricas y Prácticas sobre la Sinestesia $y$ las Percepciones Sonoras en la Pintura Contemporánea. [Tesis Doctoral Inédita]. Departamento de Pintura, Facultad de Bellas Artes, Universidad de Barcelona, 2004. 
LOWENGARD, S. "La Creación de Color en la Europa del Siglo XVIII" Disponible en:

http://www.gutenberg-e.org/lowengard/A_Chap03.html

[Consulta: 31 Diciembre 2010].

LUYS, J. The Brain and its functions. New York: Appleton and Company, 1893. (The International Scientific Series; 39).

MACLAURIN, Richard C. Light. New York: Columbia University P., 1909.

McDONNELL, M. "Early Colour Organs” [en línea]. Disponible en: http://homepage.tinet.ie/ musima/visualmusic/visualmusic.htm

[Consulta: 31 Diciembre 2010].

MARQUÉS, M.L. "Desarrollo Musical y Desarrollo Neurológico." [en línea]. Disponible en:

http://www.waece.org/biblioteca/pdfs/d145.pdf

Congreso Mundial de Lecto-Escritura, Valencia 2000.

[Consulta: 30 Enero 2011].

MARTIN, Judy.; et al. Dynamic Color Drawing. London: Quarto, 1989.

Matemáticas. México D.F.: TIME-LIFE, 1976.

MATRAS, J. El Sonido. Buenos Aires: El Ateneo, 1979 .

MATTINGLEY, J.B.; et al. "Unconscious priming eliminates automatic binding of colour and alphanumeric form in synaesthesia." NATURE, Vol. 410, 2001.

MAUR, v. Karin. The sound of painting. Music in modern art. Munich: Prestel, 1999. (Pegasus Library).

MESSIAEN, Olivier. Quatuor pour la fin du temps. Paris: Durand S.A. Editions Musicales, 1942. 
M'KENDRIK, J.K.; y William Snodgrass. The Physiology of the Senses. New York : Charles Scribner's Sons, 1893.

MOLINA, Miguel. “¿Narciso enamorado de Eco?. Cuando la imagen visual móvil persigue a la música: del absolute film a los Vj's". $18^{\circ}$ Encontro da Associação Nacional de Pesquisadores em Artes Plásticas: Transversalidades nas Artes Visuais. Salvador de BahiaBrasil: ANPAP, 2009.

MUELLER, Conrad G.; Mae Rudolph; et al. Luz y Visión. México D.F.: TIME-LIFE, 1976.

MUNSELL, Albert Henry.; H.E. Clifford (intro.). A Color Notation. Boston: H. Ellis Co., 1905.

MUNSELL, Albert Henry. Color Balance Illustrated. Boston: H. Ellis Co., 1913.

NATHAN, M.M. Rimsky-Korsakof. New York : Duffield \& Co., 1917.

NAVE, C.R. Hyperphysics. [en línea]. Disponible en:

http://hyperphysics.phy-astr.gsu.edu/hbase/hframe.html

[Consulta: 31 Diciembre 2010].

NEWTON, Isaac.; Andrew Motte (trad.). Mathematical Principles of Natural Philosophy. New York: Daniel Adee, 1846.

NEWTON, Isaac. Opticks: Or a Treatise of the Reflexions, Refractions, Inflexions and Colours of Light. London: Royal Society, 1704.

NICOLESCU, Basarab. Manifesto of Transdisciplinarity. AlbanyNew York: State University of New York Press, 2002.

NIETZSCHE, F. El drama musical griego. [en línea]. Disponible en: www.adamar.org/ivepoca/node/1071

[Consulta: 31 Diciembre 2010]. 
ORTEGA y GASSET, José. Obras. Madrid: Espasa-Calpe, 1932.

Pantone/North America. [en línea].

http://www.pantone.com/pages/pantone/index.aspx

[Consulta: 31 Diciembre 2010].

PARKER, G.H. Smell, Taste, and Allied Senses in the Vertebrates. London: J.P. Lippincott Company, 1922. (Monographs on Experimental Biology).

PAUL, Christiane. Digital Art. 2a ed. Londres: Thames \& Hudson, 2008. (World of Art).

PAVEY, D.A.; Roy Osborne (ed.). Color and Humanism. 2a ed. rev. Florida: Universal Publishers, 2008.

PEACOCK, K. Instruments to perform color-music. Two centuries of technological experimentation. Leonardo, vol. 21, 1998, num. 4, pp. 397-406.

PEARSON, Karl. The Problem of Practical Eugenics. London: Dulau and Co., 1912.

PESCIO, S. Color. [lecturas]. Facultad de Arquitectura, Diseño y Urbanismo, Universidad de Buenos Aires, 1999.

PISTON, Walter.; Ramón Barce (prol.); et al (trad.). Orquestación. Madrid: Real Musical, 1984.

PRESTON, Thomas. The Theory of Light. New York: Ed.MacMillan and Co. Limited, 1901.

Psiquiatría. México D.F.: Organización Panamericana de la Salud, 2006.

RAMACHANDRAN, V.S.; and E.M. HUBBARD. "Synaesthesia-A Window into Perception, Thought and Language." Journal of Consciousness Studies, 8, 2001, núm. 12, pp. 3-34. 
RAMEAU, J.P. A Teatrife of Mufic. ed. trad. London: J. French, 1805.

RAMEAU, J.P. Démonstration du principe de l'Harmonie. París: Durand, 1749.

PUCKETTE, Miller.; Max Mathews (pról.). The Theory and Technique of Electronic Music. Singpore: World Scientific Publishing, 2007.

RAYMOND, George L. Proportion and Harmony of Line and Color. London: G.P. Putnam's Sons, 1899. (Comparative Aesthetics; 7).

RIMSKY-KORSAKOV, Nikolay.; Edward Agate (trad.); M. Steinberg (ed.). Principles of Orchestration. New York : E.F. Kalmus Orchestra Scores, 1912.

RIMSKY-KORSAKOV, Nikolay; Jacobo y Miguel Ficher (trad.). Tratado práctico de Armonía. Buenos Aires: Ricordi Americana, 1947.

ROBERTSON, L.C.; y Noam Sagiv. (eds.). Synesthesia: Perspectives from cognitive neuroscience. New York: Oxford University P., 2005.

SABBAGH, P. The development of Harmony in Scriabin's Works. U.S.A.: Universal Publishers, 2001.

ISBN 1-58112-595-X

SACKS, O.; Damián Alou (trad.). Musicofilia, Relatos de la música y el cerebro. Barcelona: Anagrama, 2009. (Argumentos).

S.A.C.M. Sociedad de Autores y Compositores de Música: "Biografías, Héctor Quintanar." [en línea]. http://www.sacm.org.mx/archivos/biografias.asp?txtSocio=00241 [Consulta: 31 Diciembre 2010].

SALA, Emilio; Adrián Espí Valdés (intro.). Gramática del Color. Valencia: Instituciò Alfons el Magnànim, 1999. (Fundamentos; 2). 
SALAZAR, Adolfo. La música orquestal en el siglo XX. 2a ed. México D.F.: Fondo de Cultura Económica, 1998. (Breviarios; 117).

SANDLOTSCIENCE. Arcimboldo [en línea]. Disponible en:

http://www.sandlotscience.com/EyeonIllusions/Arcimboldo.htm [Consulta: 31 Diciembre 2010].

SCANDINAVIAN COLOUR INSTITUTE. "The NCS System.” [en línea].

http://www.ncscolour.com

[Consulta: 31 Diciembre 2010].

SCHARA, Julio César (comp.). Diálogos Transdisciplinarios México D.F.: Fontamara, 2009. (Argumentos; 86).

ISBN 978-968-476-759-1

SCHOENBERG, A.; Wassily Kandinsky; et al. Cartas, cuadros y documentos de un encuentro extraordinario. Madrid: Alianza Editorial, 1993. (Alianza Música).

SCHOENBERG, A.; Leonard Stein (rev.); Juan Luis Milán Amat (trad.). Funciones estructurales de la armonía. Barcelona: Idea Books, 1999. (Idea Música).

SCHOENBERG, A.; A. Santos (trad.).; Leonard Stein (pról..). Fundamentos de la Composición Musical. Madrid : Real Musical, 1989. (Pedagogía Musical).

SCHOENBERG, A. Fünf Klavierstücke op. 23. Copenhagen: Wilhelm Hansen, 1923.

SCHOENBERG, A. Sechs Kleine Klavier Stücke op.19. Wien: Universal, 1913.

SCHOENBERG, A.; Roy E. Carter (trad.). Theory of Harmony. Berkeley: University of California P., 1990. (California Library Reprint Series). 
SCHUMANN, Robert. Papillons op.2. Leipzig: Breitkopf \& Härtel, 1912.

SCHWARTZ, Lilian F.; y Laurens R. Schwartz.; et al. The Computer Artist's Handbook. Concepts, Techniques, and Applications. New York: W.W. Norton \& Company. 1992.

SCRIABINE , A. Piano sonatas. New York: Ed. Dover, 1988.

SCRIABINE, A. "Poem of Ecstasy" and "Prometheus: Poem of Fire”. New York: Dover, 1995.

SEYFRIED, I. (rec. and bio.); Henry Hugh Pierson (trad. and ed.). Louis van Beethoven's Studies. New York: Schuberth and Comp., 1853.

SIMNER, J.; and Emma Holenstein. Ordinal Linguistic Personification as a Variant of Synesthesia.

Journal of Cognitive Neuroscience, Vol.19, 2007, núm. 4, pp. 694703.

SOCIEDAD SCRIABINE DE AMÉRICA. Biografía de Scriabine. [en línea]. http://www.scriabinsociety.com/biography.html [Consulta: 31 Diciembre 2010].

SOMMERVOGEL, P.C. Table Méthodique des Mémoires de Trévoux. Paris: Auguste Durand Libraire, 1864. 2v.

STARR, M.A. Brain Surgery. New York: William Wood and Company, 1898.

STUCKENSCHMIDT, H.H.; Maria Calonge (trad.). La música del siglo XX. Madrid: Guadarrama, 1960. (Biblioteca para el hombre actual; 39).

TADEO, L. J.; et al. Color, Reflexiones. Bogotá: Fundación Universidad de Bogotá, 1993. (Cuaderno temático de Bellas Artes; 4). 
TAGORE, A. Some notes on Indian Artistic Anatomy. Calcutta: Indian Society of Oriental Art, 1914.

TAGORE, G.N.; and C.W. Cotton. Rupam, an Illustrated Quarterly Journal of Oriental Art. Ordhendra Coomar Cangoly, Vol. 2-11, 1920-1922, Calcutta-India.

TAYLOR, E.J. Colour-sense training and color using. London: Blackie \& Son, 1908. (Library of Pedagogics).

TCHAIKOVSKY, P.I.; Emil Krall and James Liebling (trad.). Guide to the Practical Study of Harmony. New York: Dover Pub., 2005.

THOMSON, W.H. Brain and Personality. New York: Dodd, Mead \& Company, 1907.

TYNDALL, John. Sound. 3a ed. New York: Appleton and Company, 1884.

VALDÉS de MARTÍNEZ, S. Carmen. De la Estética y el Arte. Guadalajara: Universidad de Guadalajara, 1989. (Espejo de Obsidiana).

VALENCIA, E.; et al. Análisis Comparado de las diferencias de Color en muestras Munsell casi neutras medidas con una cámara 3CCD. [Ensayo]. Departamento de Óptica y Optometría, Departamento de Ingeniería Electrónica de la Universidad Politécnica de Cataluña, 2001.

VICENS, Francesc (text.). Arte abstracto y Arte figurativo. Barcelona: Salvat, 1973.

YOUNG, T.; y M. Tschering (trad.). Ouvres Ophtalmologiques. Copenhague: Andr. Fred. Höst \& Son, 1894.

WAGNER, Richard. La obra de arte del futuro. Valencia: Universitat de València, 2007. 
WAGNER, Richard. Tristan und Isolde. Leipzig: Breitkopf \& Härtel, 1911.

WARD, J.; et al. "A Comparison of Lexical-Gustatory and GraphemeColour Synaesthesia." Psychology Press, Cognitive Neurophsychology, Vol. 22, núm. 1, 2005.

WARD, J.; and Noam Sagiv. "Synaesthesia for Finger Counting and Dice Patterns: A Case of Higher Synaesthesia?" Psychology Press, Neurocase, Vol. 13, 2007.

ISSN 1355-4794

WATT, Henry J. The Psychology of sound. Cambridge: Cambridge U.P., 1917.

WESTLAND, S. "Qué es el espacio de color C.I.E.-L.A.B." [en línea]. Disponible en:

http://www.gusgsm.com/espacio_color_cie_lab

[Consulta: 31 Diciembre 2010].

WETZEL, D.L. Alexander Scriabin in Russian Musicology and it's background in Russian Intellectual History. [Dissertation]. University of Southern California, 2009.

WHELLER, R.H.; y Thomas D. Cutsforth. The Synaesthesia of a blind subject with comparative data from an Asynaesthetic blind subject. Oregon: University of Oregon, 1922.

WIERZBICKI, J. "Synaesthesia” [en línea]. Disponible en: http://pages.sbcglobal.net/jameswierzbicki/synaesthesia.htm [Consulta: 31 Diciembre 2010].

WILSON, Mitchell; et al. Energía. México D.F.: TIME-LIFE, 1976.

WILSON, J.R.; et al. La Mente. México D.F.: TIME-LIFE, 1976. 
WISE, H.H. The Relationship of Pitch Sets to Formal Structure in the last six Piano Sonatas of Scriabin. [Doctoral Document]. Department of Music Theory, Eastman School of Music, University of Rochester, New York, 1987.

WONG, Wucius; y Emili Olcina i Aya (trad.). Principios del diseño en color. Barcelona: Gustavo Gili, 1988.

WOODWARD, J.H.M. Brain Laterality and Emotional Processing in Children. [Doctoral Document]. University of Florida, 1984.

WRIGHT, Mark R. Sound, Light and Heat. London: Longmans, Green \& Co., 1888.

XENAKIS, Iannis. Musiques Formelles: Nouveaux Principes Formels De Composition Musicale. Paris: Richard-Masse, 1963. (Revue Musicale).

X-Rite. “About Munsell Color” [en línea].

http://www.xrite.com/top_munsell.aspx?action=products\&CategoryID $=44$ [Consulta: 31 Diciembre 2010].

ZAHM, J.A. Sound and Music. Chicago: McClurg and Company, 1892.

ZAKIA, R.D. Perception and Imaging. 2a ed. London: ButterworthHeinemann, 2002. 


\section{Fuente de las Imágenes.}

\section{Capítulo 1}

Figura 1. Pitágoras realizando sus experimentos sobre las relaciones interválicas que rigen el sonido.

Matemáticas. Colección Científica de TIME-LIFE,

Figura 2. El "Clavier à Lumières" de Scriabine, uno de los diseños, consistente en bulbos de colores para la proyección.

http://prometheus.kai.ru/IMAGES/Fig1b.jpg

[Consulta: 17 Octubre 2011]

Figuras 3 y 4. Arriba, tramoya de 1885 para el

Acto primero del "Oro del Rin". Izquierda, andamiaje y maquinaria de 1902 para el Acto segundo de "Siegfried". Para la Tetralogía, "El anillo de los Nibelungos", de R. Wagner.

Enciclopedia Salvat de los Grandes Compositores; Tomo 7.

Figura 5. El Teatro de Dionisos, en Atenas.

http://www.fotoaleph.com/Colecciones/GreciaClasica/GreciaClasicatexto.html

[Consulta: 17 Octubre 2011]

Figura 6. Página manuscrita del "Acte Préalable" de la obra inacabada "Mysterium" (1912-1915) de A.Scriabine, donde se incluye un acorde de 12 tonos. Museo Scriabine de Moscú

Figura 7. Representación del "Mesías" de Händel en la Catedral de Oviedo. www.fpa.es

[Consulta: 17 Octubre 2011] 
Figura 8. Cinematógrafo Lumiere http://www.institut-lumiere.org/ [Consulta: 17 Octubre 2011]

\section{Capítulo 2}

Figura 9. Esquema de la audición.

Dominio Público

Figura 10. Amplitud y Frecuencia, La línea punteada indica la posición de equilibrio (silencio). La Flecha vertical la Amplitud sonora y la flecha horizontal la frecuencia, las líneas curvas representan una onda sonora.

Imagen por Francisco Javier González Compeán.

Figuras 11 y 12. Izquierda, panorámica espectral de un trombón. Derecha, panorámica espectral de un violín.

Imágenes creadas con el software "Adobe Audition" por Francisco Javier González Compeán.

Figura 13. El experimento de Matrás. Una alarma sonora consistente en un martillo golpeando una campana, no producirá sonido cuando se encuentra en un ambiente "al vacio".

ZAHM, J.A.: Sound and Music. Chicago: Ed. McClurg and Company, 1892

Figura 14. Esquema de las tres secciones del oído humano http://www.ocw.espol.edu.ec/

[Consulta: 17 Octubre 2011]

Figura 15. Sonograma de un acorde, varias frecuencias simultáneas. http://www.fing.edu.uy/iie/ense/asign/sisdsp/proyectos/2006/analizad or_acordes/procedimiento.html

[Consulta: 17 Octubre 2011] 
Figura 16. Sonograma de los armónicos, frecuencias secundarias producidas por el ataque a una sola nota.

Imagen por Francisco Javier González Compeán.

Figura 17. Acorde "Dominante" teniendo como nota generadora el "Do" índice 4 a $131 \mathrm{~Hz}$. con su escala "mayor" resultante.

Imagen por Francisco Javier González Compeán.

Figura 18. Cadencias, el acorde "Dominante" indicado con la letra "D" y el acorde "Tónica" con la letra " $T$ " en el inicio de la Quinta Sinfonía de L.V. Beethoven.

Leipzig: Ed. Breitkopf \& Härtel. Ludwig van Beethoven's Werke, Serie I, Symphonien no. 5, 1862.

Figura 19. Primer movimiento de la "Sonatina en Do mayor" de Clementi. En círculos rojos las notas con función de "Tónica", enmarcados en rojo los pasajes cuya función tonal "gira" en torno a la tonalidad original; enmarcado en azul, el pasaje central cuya función "gira" en torno a la función de dominante.

New York: Ed. Schirmer, Inc. 1904.

Figura 20. Inicio de "Papillons op.2" De Robert Schumann. En círculos rojos las notas con función de "Tónica", nótese que son las primeras notas escuchadas en la obra, pero no vuelven a aparecer con una función cadencial sino hasta el final de la primera frase de la primera danza, y al final de la misma.

Leipzig: Ed. Breitkopf \& Härtel. Robert Schumanns Werke, 1912.

Figura 21. Inicio de la opera "Tristan und Isolde" de R. Wagner. Enmarcado en rojo, el pasaje con la primera cadencia de la obra, aproximadamente a los dos minutos con cuarenta segundos de la obra. Leipzig: Ed. Breitkopf \& Härtel. Tristan und Isolde, 1911. 
Figura 22. Inicio del "Walzer" op. 23 de A. Schoenberg. Al inicio en rojo y azul, numeradas las dos series dodecafónicas simultaneas; posteriormente, numeradas en rojo y separadas por líneas del mismo color, las notas presentadas en series de doce sonidos; nótese la ausencia de repetición de un centro tonal hasta no haber transcurrido todas las notas del sistema temperado occidental.

Copenhagen: Ed. Wilhelm Hansen, Fünf Klavierstücke op. 23, 1923.

Figura 23. Portada manuscrita de la primera recopilación de preludios y fugas realizada por Johann Sebastian Bach

Dominio Público.

Figura 24. El maestro Doreswamy Iyengar, tocando el "MysoreVeena" instrumento hindú.

Fotografía por la Dra. Kamat K.L.

www.kamat.com

[Consulta: 17 Octubre 2011]

Figura 25. Instrumentos de música javanesa para un ensamble "Gamelan" (metalófonos percutidos) instrumentos construidos para poder ser ejecutados juntos, con la misma afinación.

Museo Nacional de Etnologia "Minpaku” en Osaka.

www.minpaku.ac.jp

[Consulta: 17 Octubre 2011]

Figura 26. Ejecutante de Koto.

Dominio Público.

\section{Capítulo 3}

Figura 27. "Atlas" de color de Munsell.

MUNSELL, Albert Henry: Color Balance Illustrated. Boston: Ed. H. Ellis Co., 1913, s.p. 
Figura 28. Esquema de producción de la "sensación del color". (1) La luz cae sobre un objeto (2) Parte de la luz es absorbida por el objeto causando que su temperatura aumente, (3) la parte no absorbida de la luz es reflejada (4) El órgano receptor, el ojo humano, es impactado por la luz reflejada (5) y transmitida por medio de impulsos eléctricos a los nervios y de estos al cerebro; (6) Los datos proporcionados por medio de impulsos eléctricos son traducidos en imagen tridimensional y multicolor.

http://www.uni-bielefeld.de/lili/kumu/farbenlehre-

kueppers/es/sehen1.html

[Consulta: 17 Octubre 2011]

Figura 29. El espectro electromagnético.

http://astronomos.net23.net/teorias/espectroelectromagnetico.html

[Consulta: 17 Octubre 2011]

Figura 30. Contrastes Simultáneos.

WONG, Wucius: Principios del diseño en color, Ed. Gustavo Gili, Barcelona 1988, p. 53.

Figura 31. Esquema generalizado de la anatomía del ojo humano.

V.V.A.A.: Luz y Visión. Colección Científica de TIME-LIFE, Ciudad de México: Ed. Offset Larios, 1976.p. 54.

Figura 32. Esquema de la teoría Young-Helmholtz y Hering. Un receptor sensible al color capta una luz (a la izquierda) y envía un impulso a uno de los tres clasificadores de pares de colores que la absorben y descifran antes de transmitir la señal al centro visual del cerebro.

V.V.A.A.: Luz y Visión. Colección Científica de TIME-LIFE, Ciudad de México: Ed. Offset Larios, 1976.p. 133.

Figura 33. El "Espacio de color NCS". En los puntos cardinales los colores primarios de da Vinci, con un eje compuesto por los colores blanco y negro, también considerados como primarios, sistema de similitudes y diferencias entre colores primarios.

http://www.ncscolour.com/

[Consulta: 17 Octubre 2011] 
Figura 34. Circulo cromático de colores resultante del espacio de color NCS.

http://www.ncscolour.com/

[Consulta: 17 Octubre 2011]

Figura 35. Uno de los "Triángulos de Color" del sistema NCS. El "Triangulo de Color -Y90R"

http://www.ncscolour.com/

[Consulta: 17 Octubre 2011]

Figura 36. Espacio C.I.E.L.A.B. 1976. Establecido por la Comisión Internacional de Iluminación.

http://www.gusgsm.com/espacio_color_cie_lab

[Consulta: 17 Octubre 2011]

Figura 37. Diagrama de cromaticidad C.I.E. 1976. Insertado en ejes bidimensionales.

http://www.gusgsm.com/espacio_color_cie_lab

[Consulta: 17 Octubre 2011]

Figura 38. El círculo de Itten.

http://irtel.uni-mannheim.de/colsys.html

[Consulta: 17 Octubre 2011]

Figura 39. Un círculo de colores con mayor luminosidad al centro.

V.V.A.A.: Color Harmony. Massachusetts: Ed. Rockport, 2007.

Figura 40. Colores primarios.

Dominio Público.

Figura 41. Paleta monocromática.

Dominio Público.

Figura 42. Paleta acromática.

Dominio Público. 
Figura 43. Triadas terciarias.

Dominio Público.

Figura 44. Paleta de análogos. Verde, Verde-azul, Azul.

Dominio Público.

Figura 45. Paleta de complementarios divididos. Rojo, verde-amarillo, verde-azul.

Dominio Público.

Figura 46. Triada de colores neutros.

Dominio Público.

\section{Capítulo 4.}

Figura 47. Visión sinestésica. Ejemplo de un "test" para diagnosticar sinestesia. A la izquierda, visión normal, a la derecha visión sinestésica.

The journal of Consciousness Studies http://www.bbc.co.uk [Consulta: 17 Octubre 2011]

Figura 48. Ejemplos de sinestésica espacio-temporal, "Diagramas" realizados por el sujeto ejemplificando la espacialidad de lapsos temporales.

FLOURNOY, T.H.: Des phénomènes de synopsie (audition colorée). París: Ed. Félix Alcan, 1893, p. 169.

Figura 49. Comparativa de resultados entre un sujeto sinestésico (izquierda) y un no sinestésico (derecha) de control, al cual se le pidió que imitara una condición sinestésica. La barra a la derecha del grafema indica la diferencia en asociaciones, mientras la barra es más grande mayor es la diferencia en la correspondencia. http://www.synesthete.org/ [Consulta: 17 Octubre 2011] 
Figura 50. A la izquierda, radiografía mostrando la implantación de electrodos superficiales y profundos en el cráneo de un mono. A la derecha "Cuando por el electrodo pasa una corriente eléctrica al cerebro, el mono reacciona con un guiño". V.V.A.A.: La Mente. Colección Científica de TIME-LIFE, Ciudad de México: Ed. Offset Larios, 1976.p. 185.

Figura 51. "Mapa" de la división de los lóbulos en el cerebro. Centre for Neuro Skills. http://www.neuroskills.com/tbi/esptemporl.shtml [Consulta: 17 Octubre 2011]

Figura 52. Esquema de una tomografía por emisión de positrones (TEP). "El compuesto radiactivo se administra por vía intravenosa. Aproximadamente treinta segundos después llega al cerebro. Los positrones en descomposición se encuentran con los electrones del tejido cerebral y se aniquilan mutuamente en un choque del cual se desprenden rayos gamma... Estos rayos son detectados por las cámaras colocadas en círculo alrededor de la cabeza del sujeto... De esta manera se obtiene un mapa de los cambios en el flujo sanguíneo". HARRISON, John: El Extraño Fenómeno de la Sinestesia. Ciudad de México: Ed. Fondo de Cultura Económica, 2004, p. 136.

Figura 53. Diagrama de representación realizado por "T.M." sobre su sinestesia espacio-secuencia. "La representación que llevo en mi mente de las series numéricas es sumamente distintiva para mi, de tal forma que no puedo pensar en un número, sino que lo veo (como si estuviera) en un lugar determinado del diagrama... El diagrama está presente en mi mente desde la infancia temprana..." GALTON, Francis: Inquiries into Human Faculty and its Development. Londres: Ed. McMillan \& Co., 1883, p. 121.

Figura 54. Arcimboldo. Autorretrato.

Dominio Público. 
Figura 55. Tabla de correspondencias interválicas del sonido afinado y color de Arcimboldo.

http://home.comcast.net/ sean.day/html/history.html

[Consulta: 17 Octubre 2011]

Figura 56. Graduación de doce pasos entre el blanco y el negro. Cureau de la Chambre.

DE LA CHAMBRE, Marin C.: Nouvelles Observations et Coniectures sur l'iris. París: Ed. P. Blaise, 1650, p. 64.

Figuras 57 y 58. Esquemas de correspondencia interválica entre color y sonido de Cureau de la Chambre.

DE LA CHAMBRE, Marin C.: Nouvelles Observations et Coniectures sur l'iris. París: Ed. P. Blaise, 1650, p. 215.

Figuras 59 y 60. Arriba, ilustración de Newton sobre sus experimentos de descomposición de la luz blanca con prismas. Abajo, colores resultantes, por el investigador.

NEWTON, Isaac: Opticks: Or a Treatise of the Reflexions, Refractions, Inflexions and Colours of Light. Londres: Ed. Royal Society, 1704, p. 385.

Figura 61. Clavecin Ocular diseñado por Krüger J.G., sobre laidea de Castel.

FRANSSEN M.: The Ocular Harpsichord of Louis-Bertrand Castel. Amsterdam: Ed. Univesiteit van Amsterdam. Tractrix: Yearbook for the History of Science, Medicine, Technology and Mathematics 3, , 1991, p. 34.

Figura 62. Esquema técnico del órgano de colores de Bainbridge Bishop.

BISHOP, B.: A souvenir of the color organ, with some suggestions in regard to the soul of the rainbow and the Harmony of light. New York: Ed. The De Vinne Press., 1893, p. 4. 
Figura 63. Correspondencia establecida por Bainbridge Bishop, entre los armónicos del sonido y los colores del arcoíris.

BISHOP, B.: A souvenir of the color organ, with some suggestions in regard to the soul of the rainbow and the Harmony of light. New York: Ed. The De Vinne Press., 1893, p. 8.

Figura 64. Rossiné, Autorretrato.

Fundación Rossiné.

http://www.baranoffrossine.com

[Consulta: 17 Octubre 2011]

Figura 65. Piano Optofónico de Rossiné.

Fundación Rossiné.

http://www.baranoffrossine.com

[Consulta: 17 Octubre 2011]

Figura 66. Retrato de Scriabine.

Dominio Público.

Figura 67. Correspondencia de Color-Tonalidad de Scriabine.

STUCKENSCHMIDT, H.H.: La música del siglo XX. Biblioteca para el hombre actual. Madrid: Ediciones Guadarrama, S. A. 1960, p.19.

Figura 68. Correspondencia de Color-Tonalidad-Estado del alma. De Scriabine, como es indicado en la primera página de su obra "Prometeo".

SCRIABIN A.: Poem of Ecstasy and -Prometheus: Poem of Fire. New York: Ed. Dover, 1995, p. 2.

Figura 69. Inicio de la obra "Prometeo" de Scriabine. Fragmento.

SCRIABIN A.: Poem of Ecstasy and -Prometheus: Poem of Fire. New York: Ed. Dover, 1995.

Figura 70. Final de la obra "Prometeo" de Scriabine. Fragmento.

SCRIABIN A.: Poem of Ecstasy and -Prometheus: Poem of Fire. New York: Ed. Dover, 1995. 
Figura 71. Retrato de Kandinsky.

Dominio Público.

Figura 72. Esquema de Kandinsky sobre el "movimiento" y carácter de los colores.

KANDINSKY W.W.: The art of spiritual Harmony. New York: Ed. Houghton Mifflin Company, 1914, p. 73.

Figura 73. Traducción de Kandinsky de sucesos musicales a símbolos pictóricos a partir de un pasaje de la Quinta Sinfonía de Beethoven.

KANDINSKY, Wassily: Punto y línea sobre el plano. Barcelona: Ed. Paidos, 1998, p.39.

Figura 74. Improvisación no. 85. Kandinsky.

Museo de Bellas Artes de Basilea.

www.kunstmuseumbasel.ch

[Consulta: 17 Octubre 2011]

Figura 75. Acordes de Alban Berg a los que hace referencia Schoenberg en su libro de Armonía.

Alban Berg. Vier Lieder op. 2 no. 4. Cuatro compases antes del final. SCHOENBERG A.: Theory of Harmony. Ed. University of California Press, Traducción al inglés de la tercera edición alemana de 1922, p.420.

Figura 76. Esquema de correspondencias color-sonido elaborado por Hauer.

DUPLAIX , Sophie: Sons \& Lumières. París: Ediciones del Centre Pompidou, 2004, p. 163.

Figuras 77, 78 y 79. Imágenes del video “Allegretto" de Oscar

Fischinger.

Fischinger Trust. www.oscarfischinger.org

[Consulta: 17 Octubre 2011] 


\section{Capitulo 5.}

Figura 80. J.S. Bach, "Minueto en Sol” para instrumento de teclado. Tipografiada por Francisco Javier González Compeán..

Figura 81. Traducción a colores del "Minueto en Sol” de J.S. Bach. Imagen por Francisco Javier González Compeán.

Figura 82. C.A. Debussy, "Syrinx" para flauta sola.

Tipografiada a mano por Francisco Javier González Compeán.

Figura 83. Traducción a colores de "Syrinx" de C.A. Debussy. Imagen por Francisco Javier González Compeán.

Figura 84. A. Schoenberg, “op. 19 no. 6" para piano solo.

Schoenberg, Arnold: Sechs Kleine Klavier Stücke op.19. Viena: Ed. Universal, 1913.

Figura 85. Traducción a colores del “op. 19 no. 6" de A. Schoenberg. Imagen por Francisco Javier González Compeán.

Figura 86. F. Javier G. Compeán "En gris azul” para piano solo. Manuscrito por el compositor.

Figura 87. Traducción a colores de "En gris azul" de F. Javier G. Compeán.

Imagen por Francisco Javier González Compeán.

Figuras 88, 89, 90. Presentación en vivo del "Trío" música de colores de F. Javier G. Compeán, Festival Internacional Cervantino 2010, "Ensamble Tumkul", "Colores en vivo" por el autor. Ciudad de Guanajuato-México 


\section{Anexo I Data-DVD Correspondencias Sinestésicas.}

Se anexa a manera de muestra práctica de este trabajo de investigación, un "Data DVD" (Digital Video Disc) titulado "Correspondencias Sinestésicas".

El contenido de este DVD son archivos ".dir" (archivos de plataforma "Macromedia Director"), ".mp3" (archivos de audio), ".jpg" (archivos de imagen), ".exe" (aplicaciones, "Macromedia Projector"), y un archivo ".pdf" (archivos de "Adobe Reader"); las animaciones realizadas para ilustrar las traducciones de música a color son los archivos ".exe" o "aplicación". El archivo ".pdf”, contiene la partitura del "Trío para marimba y dos vibráfonos" realizada por medio del concepto de "Tonalidad Sinestésica", partitura escrita con una comisión del "Festival Internacional Cervantino 2010" para ser estrenada por ocasión del Bicentenario de la Independencia de México, en el marco del festival.

Los archivos se encuentran ordenados en cuatro carpetas numeradas y tituladas de la siguiente manera:

1 bach
2 debussy
3 schoenberg
4 música de colores

En el interior de las carpetas 1 a 4, el usuario podrá encontrar las animaciones que ilustran la "Correspondencia Sinestésica" en los archivos de "aplicación" (".exe"), los cuales, pueden ser visualizados en cualquier PC con plataforma "Windows".

Añadido a las carpetas, el usuario encontrará archivos sueltos, de imagen ("jpg") y el archivo "pdf". Los archivos de imagen ilustran la correspondencia a colores, establecida por medio de la herramienta de la "Tonalidad Sinestésica", para las piezas indicadas; el usuario tendrá además, acceso por medio de la partitura a la obra de música 
de cámara realizada para ilustrar la utilidad de la "Tonalidad Sinestésica" en obras de gran formato para público.

El usuario no necesita tener ningún software especial para visualizar las animaciones, solo debe abrir las carpetas, y ejecutar alguno de los archivos ".exe" o "aplicación". Una vez hecho esto, la pantalla del ordenador se pondrá en blanco, y le otorgara las siguientes opciones al usuario:

"iniciar animación": al elegir esta opción, el usuario podrá visualizar la animación elegida.

"salir": para terminar la aplicación.

Cada una de las carpetas contiene cuatro diferentes configuraciones de las animaciones, siempre con la misma pieza y traducción. Por ejemplo:

La carpeta "1 bach", contiene cuatro archivos de aplicación:

1 bach.exe

2 bach.exe

3 bach.exe

4 bach.exe

En la primera configuración de cada autor, el punto de color que ilustra la "Correspondencia Sinestésica" solo es colocado en la nota correspondiente, manteniendo como fondo de la animación la partitura o documento musical escrito, mientras el usuario escucha la obra musical.

La segunda configuración, ilustra mediante el movimiento del "punto de color" la duración de la nota musical, el punto de color se mueve en el plano horizontal hasta llegar al momento en que, el documento musical indica que esa nota debe dejar de ser escuchada.

En la tercera configuración, el punto de color, se mueve hasta el sitio geográfico indicado por la partitura, pero a diferencia de la segunda configuración, el color permanece, lo cual permite al usuario ver de una mejor manera los colores de la pieza en un contexto global. 
En la cuarta y última configuración, se abandona la "plantilla" o partitura para dejar en blanco el fondo de la animación, de esta manera, el usuario podrá contemplar la imagen final de colores sin la partitura.

Las siguientes obras fueron las utilizadas para la elaboración del DVD “Correspondencias Sinestésicas":

1 bach: "Minueto en Sol Mayor" (1725) de Bach J.S., para clavecín, interpretada en el piano por el investigador, partitura tipografiada a mano, y grabación de audio realizada por él mismo.

2 debussy: "Syrinx" (1913) Debussy, Claude A. para flauta sola, interpretada por: Doriot Anthony Dwyer, partitura tipografiada por el investigador, grabación de "Deutsche Gramophone".

3 schoenberg: "Kleine Klavier Stücke op.19 no.6" (1911) de Schoenberg, A. para piano solo, interpretada por el investigador, partitura tipografiada, y grabación por él mismo.

4 música de colores “ 1 en gris azul” (2008) de González Compeán, F.J., para piano solo, interpretada por el investigador, partitura manuscrita y grabación por él mismo.

5 música de colores "Trío para marimba y dos vibráfonos" (2010) de González Compeán, F.J., para ensamble de percusiones, interpretada por el ensamble "TUMKUL" y el compositor realizando la proyección de colores en vivo durante los ensayos y el concierto realizado durante el "Festival Internacional Cervantino 2010" en la ciudad de Guanajuato-México. 


\section{Anexo II Video-DVD “TUMKUL"}

Se anexa a manera de segunda muestra práctica de este trabajo de investigación, un "Video DVD" (Digital Video Disc) titulado "TUMKUL", el cual, está contemplado para ser visualizado por medio de un reproductor de Video DVD en el televisor, lo cual permitirá observar la presentación en vivo del "Trío para marimba y dos vibráfonos" del autor, denominado en el menú del DVD como "Trío, México Bicentenario"; muestra final de la experimentación realizada con el concepto de "Tonalidad Sinestésica".

El Video-DVD, contiene el concierto presentado en Octubre de 2010 durante el "Festival Internacional Cervantino" en su totalidad; por medio del "menú" del DVD, se puede visualizar tanto el concierto completo, como el "Trío México Bicentenario", muestra de una pieza para percusiones en gran formato de duración temporal, realizada por medio de la "Tonalidad Sinestésica". 